\title{
An Assessment of the Risk of Transporting Propane by Truck and Train
}

\author{
C. A. Geffen
}

Project Coordinator

March 1980

Prepared for the U.S. Department of Energy under Contract DE-AC06-76RLO 1830

Pacific Northwest Laboratory Operated for the U.S. Department of Energy by Battelle Memorial Institute 
NOTICE

This report was prepared as an account of work sponsored by the United States Government. Neither the United States nor the Department of Energy, nor any of their employees, nor any of their contractors, subcontractors, or their employees, makes any warranty, express or implied, or assumes any legal liability or responsibility for the accuracy, completeness or usefulness of any information, apparatus, product or process disclosed, or represents that its use would not infringe privately owned rights.

The views, opinions and conclusions contained in this report are those of the contractor and do not necessarily represent those of the United States Government or the United States Department of Energy.

\author{
PACIFIC NORTHWEST LABORATORY \\ operated by \\ BATTELLE \\ for the
}

UNITED STATES DEPARTMENT OF ENERGY

Under Contract EY-76-C-06-1830

\begin{tabular}{|c|c|c|}
\hline \multicolumn{3}{|c|}{$\begin{array}{c}\text { Printed in the United States of America } \\
\text { Available from } \\
\text { National Technical Information Service } \\
\text { United States Department of Commerce } \\
5285 \text { Port Royal Road } \\
\text { Springfield, Virginia } 22151\end{array}$} \\
\hline Price: & Printed Copy S & $\therefore$ Microfiche $\$ 3.00$ \\
\hline & - Pages & $\begin{array}{c}\text { NTIS } \\
\text { Selling Price }\end{array}$ \\
\hline & $001-025$ & $\$ 4.00$ \\
\hline & $026-050$ & $\$ 4.50$ \\
\hline & $051-075$ & $\$ 5.25$ \\
\hline & $076-100$ & $\$ 6.00$ \\
\hline & $101-125$ & $\$ 6.50$ \\
\hline & $126-150$ & 57.25 \\
\hline & $151-175$ & $\$ 8.00$ \\
\hline & 176.200 & $\$ 9.00$ \\
\hline & $201-225$ & $\$ 9.25$ \\
\hline & $226-250$ & $\$ 9.50$ \\
\hline & $251-275$ & $\$ 10.75$ \\
\hline & $276-300$ & $\$ 11.00$ \\
\hline
\end{tabular}


PNL -3308

TTC-0115

UC-71

\section{2}

AN ASSESSMENT OF THE RISK OF TRANSPORTING PROPANE BY TRUCK AND TRAIN

C. A. Geffen

Project Coordinator

Technical Contributors

W. B. Andrews

T. M. Buckingham

A. L. Franklin

J. Friley

C. A. Geffen

D. J. McNaughton

B. A. Ross

March 1980

Prepared for

the U.S. Department of Energy

under Contract DE-ACO6-76RLO 1830

Pacific Northwest Laboratory

Richland, Washington 99352 
-

$\leadsto$

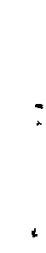
- 


\section{PREFACE}

This study was initiated in FY79 in the Transportation Safety Studies Project performed at Pacific Northwest Laboratory for DOE's Division of Environmental Control Technology. In FY80, responsibility for this work was transferred to the Division of Transportation and Fuel Storage and overview of the work was assigned to the Transportation Technology Center (TTC) at Sandia Laboratories, DOE's lead laboratory for Nuclear Materials Transportation Technology. This work was substantially complete when assigned to TTC overview and TTC funds were

used only for incorporation of review comments and for publication. Funds for completion and publication of this study have been provided to PNL through TTC. 
$-$

;

-

• 


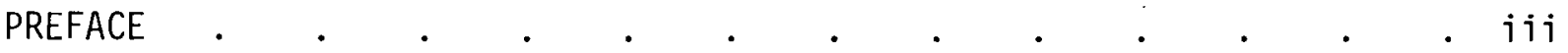

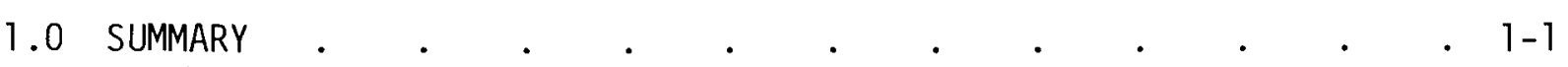

$\angle .0$ INTRODUCTION

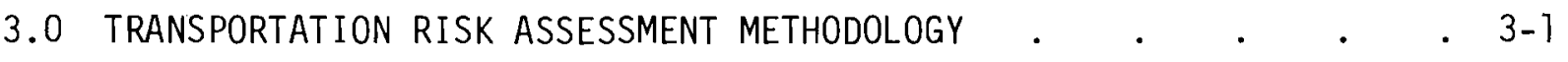

3.1 HISTORY .

3.2 RISK ASSESSMENT MODEL . . . . . . . . . . . . . $3-2$

3.2.1 System Description . . . . . . . . . 3-4

3.2.2 Release Sequence Identification . . . . . 3-4

3.2.3 Release Sequence Evaluation . . . . . . . 3-6

3.2.4 Risk Calculation and Assessment . . . . . . 3-7

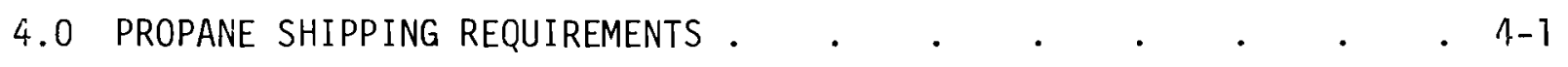

4.1 PROPANE DISTRIBUTION PATTERNS . . . . . . . . . . 4-3

4.2 TRANSPORTATION MODES . . . . . . . . . . . 4-3

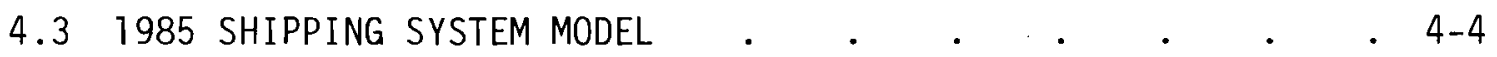

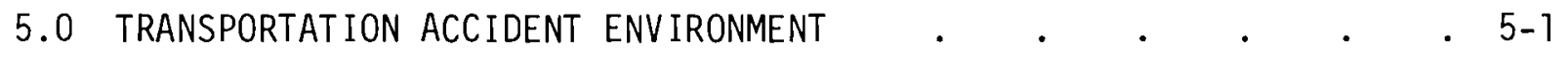

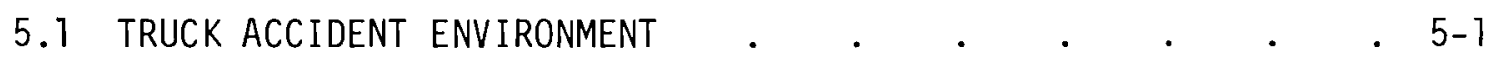

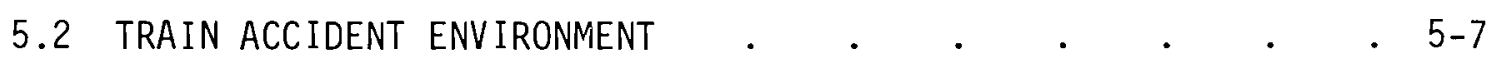

5.3 HISTORICAL RELEASES FROM PROPANE TANKS . . . . . . 5-12

6.0 PROPANE TANK FAILURE THRESHOLDS $\quad . \quad$. . . . . . . . . . . $6-1$

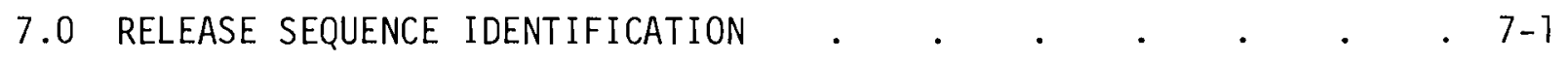

7.1 FAULT TREE CONSTRUCTION . . . . . . . . . . .

7.2 FAULT TREES FOR SHIPMENT OF PROPANE BY TRUCK AND TRAIN . . 7-3

7.3 RELEASE SEQUENCES . . . . . . . . . . . . . . 7-14

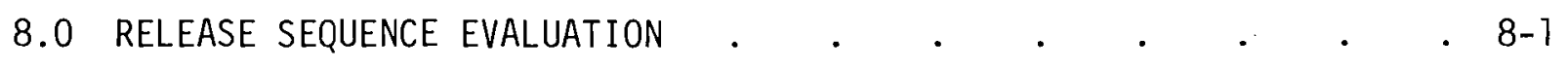

8.1 BASIC EVENT PROBABILITIES: TRUCK . 
8.1.1 Tank Truck Transport . . . . . . . . . 8-3

8.1 .2 Bobtail. . . . . . . . . . . . . 8-12

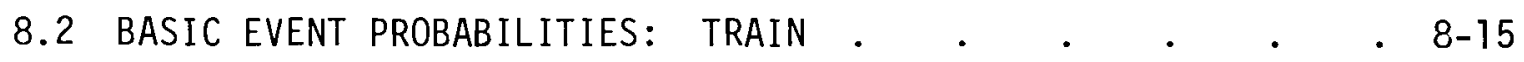

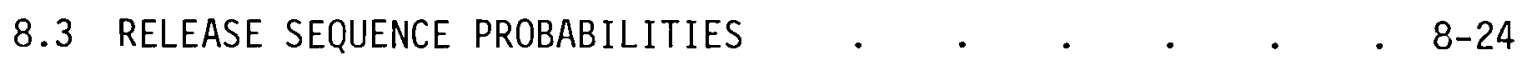

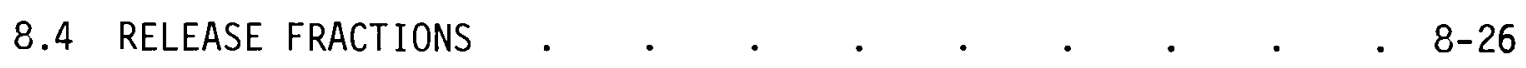

9.0 EVALUATION OF THE CONSEQUENCES OF PROPANE RELEASES . . . . 9 9-1

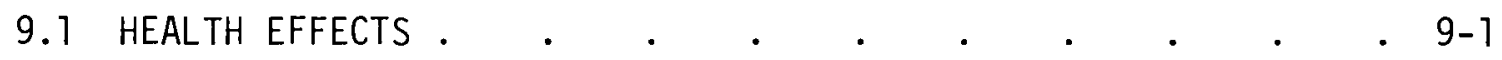

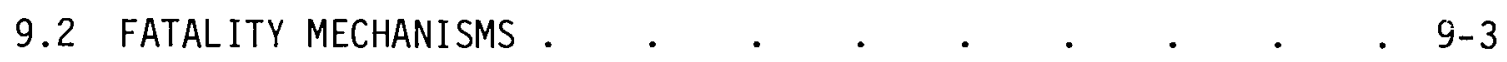

9.1.1 Direct Flame Exposure . . . . . . . . . 9-4

9.1 .2 Explosion Effects . . . . . . . . . . . 9-7

9.1.3 Radiant Heat Flux. . . . . . . . . 9-11

9.1 .4 Secondary Fires . . . . . . . . . . . 9-15

9.3 DEMOGRAPHY . . . . . . . . . . . . 9-17

9.4 METEOROLOGY . . . . . . . . . . . . . . . $9-20$

9.5 ATMOSPHERIC DISPERSION OF PROPANE VAPORS . . . . . 9-23

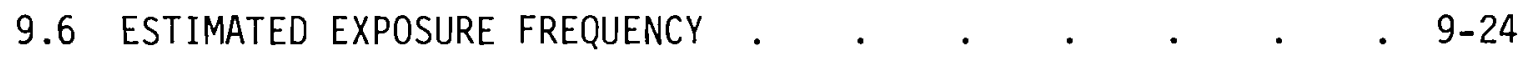

10.0 THE RISK OF SHIPPING PROPANE BY TRUCK AND TRAIN . • . . . 10-1

10.1 RISK EVALUATION OF PROPANE SHIPMENTS . $\quad . \quad$. $10-1$

10.2 MAJOR CONTRIBUTORS TO OVERALL RISK . . . . . . 10-6

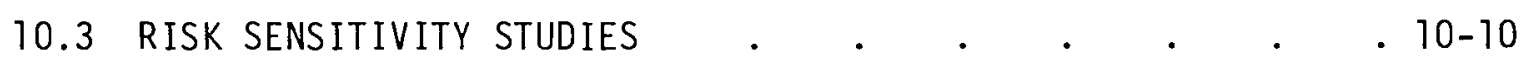

APPENDIX A - PROPERTIES OF PROPANE . . . . . . . . . . . . A-1

APPENDIX B - PROPANE TANK TRUCK, BOBTAIL TRUCK AND RAIL TANK CAR
DESCRIPTIONS $. . \quad . \quad . \quad . \quad . \quad . \quad . \quad . \quad .1$

APPENDIX C - FAILURE THRESHOLD DETERMINATION FOR PROPANE TANKS • $\quad$ - C-1

APPENDIX D - PROPANE DISPERSION MODELS . . . . . . . . . . . D-1 


\section{FIGURES}

1.1 Risk Spectra for Propane Shipments in 1985 . . . . . . . 1-4

3.1 Model to Calculate the Risk of Shipping Energy Materials . . 3-5

4.1 General Patterns of LPG Transport and Distribution . . . . 4-2

4.2 Crossover Routes of Propane Rail Shipments Between Geographic Regions . . . . . . . . . . . . . . 4-7

5.1 Cumulative Distribution of Fire Durations for Truck Transport Accidents . . . . . . . . . . 5-2

5.2 Impact Velocity Change as a Function of Cumulative Frequency of Occurrence for Highway Transportation . . . . . 5-5

5.3 Duration Probability of Train-Fire Accidents Involving Large Packages . . . . . . . . . . . . . . 5-9

5.4 Cumulative Distribution of the Expected Severity of Impact Forces in Rail Accidents . . . . . . . . . 5-10

5.5 Cumulative Distribution of Total Crush Load . . . . . . 5-11

5.6 DOT Hazardous Materials Incident Report . . . . . . 5-13

7.1 Fault Tree for the Shipment of Propane by Truck . . . . 7-4

7.2 Fault Tree for the Transportation of Propane by Rail Tank Car . 7-9

8.1 Remaining Steps in the Risk Evaluation . . . . . . . 8-1

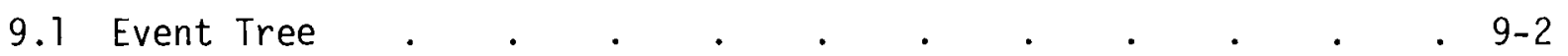

9.2 General Public Exclusion Zone . . . . . . . . . . . $\quad$. $9-3$

9.3 Damage Limits versus Scaled Range $\quad$. . . . . . . . 9-8

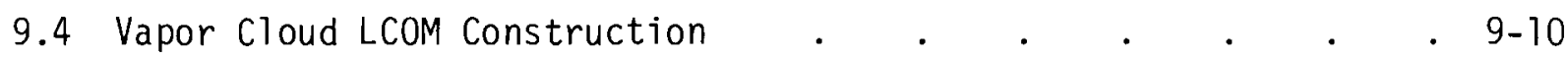

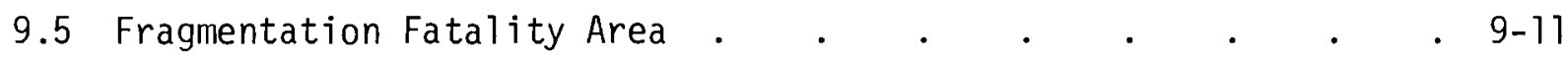

9.6 Fatality Probability versus 2nd Degree Burns . . . . 9-12

9.7 Radiant Exposures to Ignite Various Materials . . . . 9-16

9.8 Map of the U.S., Showing Census Divisions and Regions . . . 9-18 
10.1 Risk Spectra for Propane Shipments in 1985 . . . . . 10-4

10.2 Estimated Total Number of Vehicle Occupants Involved in Heavy Truck Accidents Plotted as a Function of Accident Frequency 10-8

A.1 Vapor Pressures of Typical Butane-Propane Mixtures . . . . A-3

B. 1 Propane Tank Truck . . . . . . . . . . . . . . B-2

B.2 Schematic of Safety Relief Valve . . . . . . . . . B-4

B.3 Propane Bobtail . . . . . . . . . . . . . . . . B-7

B.4 Propane Bobtail Piping Details . . . . . . . . . . . . . B-9

B.5 Propane Rail Tank Car . . . . . . . . . . . . . B-11

B.6 Propane Rail Tank Car Manway Bonnet . . . . . . . B-13

B.7 Loading and Unloading Arrangement for Liquefied Petroleum Gases
and Anhydrous Arimonia Cars . . . . . . . . . . $\quad$ B-14

C.1 Graphical Location of Equivalent Static Head Required to Produce a Localized $5 \%$ Diametrical Change. . . . . . . C-3

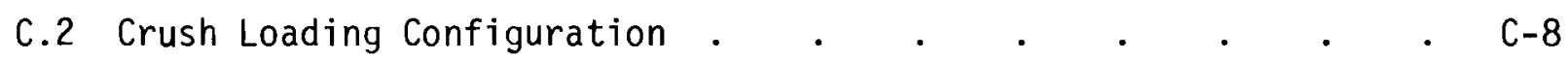

C.3 Crush Load versus Percent Void (tank trucks) . . . . . C-11

C.4 Crush Load versus Percent Void (rail car) . . . . . . C-11

\begin{tabular}{l} 
C. 5 Heat Flux as Influenced by Amount of Insulation Removed at a \\
Fire Temperature of $1010^{\circ} \mathrm{C}$. \\
\hline
\end{tabular}

C.6 Maximum Flow of Liquid Propane Through an Orifice . . . . C-16 
$\underline{\text { TABLES }}$

1.1 Simplified Propane Shipping System Mode1 . . . . . . . 1-2

1.2 Average Total and Individual Risk from Various Accidents and

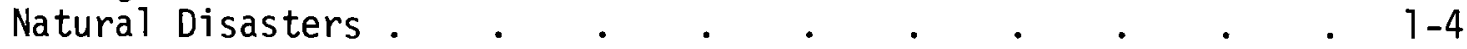

4.1 1985 Shipping System: Number of Shipments and Average Trip Length . $\quad . \quad . \quad . \quad . \quad . \quad . \quad . \quad . \quad . \quad 4-5$

4.2 Percent Travel of Each Transport Mode in Each Population Region . . . . . . . . . . . . . . . . 4-6

5.1 Distribution of BMCS Accident Data . . . . . . . . 5-3

5.2 Collision Accident Distribution by Direction of Acceleration Vector on Shipment Truck . . . . . . . . . . 5-4

5.3 Velocity Change Due to Impact in a Highway Transportation Collision Accident . . . . . . . . . . . .

5.4 Probability of Occurrence of a Puncture Situation Given a Truck Transport Collision Accident . . . . . . . 5-7

5.5 Composition of Average Train Used in Sandia Studies . . . 5-8

5.6 Probability of Puncture Situation . . . . . . . . 5-12

5.7 Summary of DOT Hazardous Material Incident Reports for Propane
Tank Trucks and Raj1 Tank Cars $(1971$ to 1976).$\quad$.

5.8 Sales and Actual Movement of Propane Supplies in the U.S. (1971
to 1976)
.

5.9 Amount of Propane Moved by Reference Tank Truck and Rai1 Tank Car Systems and Number of Shipments (1971 to 1976) . . . . 5-16

5.10 Summary of Release Frequencies for Tank Truck and Rail Tank Car

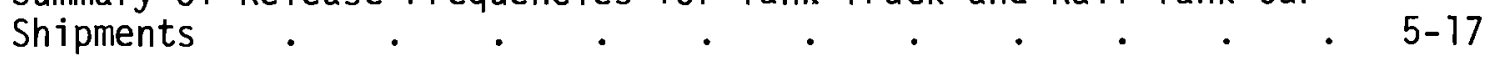

6.1 Summary of Minimum Forces Required to Produce Tank Failure 6-3

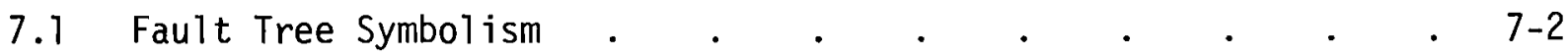

7.2 Listing of Basic Events for Propane Tank Truck Transportation Fault Tree . . . . . . . . . . . . . . . . . .

7.3 Listing of Gate Logic Rectangle Labels for Propane Tank Truck Transportation Fault Tree . . . . . . . . 7-16 
7.4 Listing of Basic Events for Propane Rail Tank Car Transportation

Fault Tree . . . . . . . . . . . 7-17

7.5 Listing of Gate Logic Rectangle Labels for Propane Rail Tank

Car Transportation Fault Tree . . . . . . . 7-18

7.6 Listing of Selected Propane Tank Truck Fault Tree Release

Sequences $\cdot$. $\cdot$. . . . . . . 7-19

7.7 Listing of Selected Propane Rail Tank Car Fault Tree Release

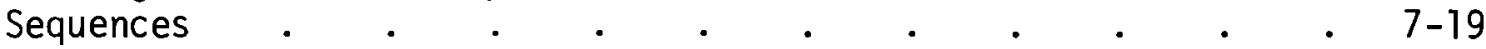

8.1 Release Sequences and Probabilities for Propane Tank Truck Shipments . . . . . . . . . . . 8-25

8.2 Release Sequences and Probabilities for Propane Rail Tank Car

Shipments . . . . . . . . . . . . 8 8-26

8.3 Release Sequences for Propane Tank Truck Shipments Grouped

According to Release Category . . . . . . . 8-27

8.4 Release Sequences for Propane Rai1 Tank Car Shipments Grouped

According to Release Category . . . . . . . 8-28

9.1 Vapor Flash Percentages . . . . . . . . . . 94

9.2 Plume Ignition Probability . . . . . . . . 9-6

9.3 TNT Equivalent Masses for Tank Rupture . . . . . 9-11

9.4 Factors for Radiant Heat Exposures . . . . . . 9-15

9.5 Building Densities . . . . . . . . . . 9-17

9.6 Estimated Probability of $n$ Deaths from $j$ Secondary Building

Fires • . . . . . . . . . . . . . 9-17

9.71974 Census Data . . . . . . . . . . . . . . . 9-19

9.8 Projected 1985 Census Data . . . . . . . . . . 9-21

9.9 Average Wind Speed/Stability Characteristics . . . . 9-22

10.1 Simplified Propane Shipping System Model . . . . . 10-1

10.2 Summary of Propane Shipping System Risks . . . . . 10-2

10.3 Probability Values Used to Obtain Risk . . . . . 10-3

10.4 Average Total and Individual Risk from Various Accidents and
Natural Disasters. . . . . . . 
10.5 Estimated Fatalities of Vehicle 0ccupants in an Accident with a Significant Release . . . . . . . . 10-8

10.6 Approximate Percentage Contributions to Total Risk to the General Public of Various Fatality liechanisms . . . . 10-9

10.7 Total Public Risk Sensitivity Cases for Propane Shipments . . 10-13

A.1 Approximate Properties of Propane . . . . . . A-2

A.2 GPA Liquefied Petroleum Gas Specifications . . . . . . A-4

B.1 Tank Truck Dimensions and Material Properties . . . . B-3

B.2 Bobtail Truck Dimensions and Material Properties . . . B-8

B.3 Rail Tank Car Dimensions and Material Properties . . . B-12

C.1 Time to Shellfull and to Venting Conditions for Propane Tanks . C-2l

C.2 Time to Failure for Propane Tanks . . . . . . C C-22

C.3 Time to Failure for Propane Tanks by Overpressurization . . C-23

D.1 Dispersion Equation for an Instantaneous Propane Release . . D-4

D.2 Dispersion Equation for a Continuous Propane Release . . . D-5 


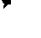




\subsection{SUMMARY}

This report is the seventh in a series of assessments of the risk of transporting potentially hazardous energy materials. (a) The report presents the risk of shipping propane by truck and train. The risk assessment methodology used in this study was developed in the first report of this series. (1) This methodology is summarized in Section 3. The risk assessment model has been constructed as a series of separate analysis steps to allow the risk to be readily reevaluated as additional data becomes available or as postulated system characteristics change.

The report is sectioned to correspond to specific analysis steps identified in the model. The transportation system and accident environment are described in Sections 4 and 5. The responses of the shipping system to forces in transportation accidents are presented in Section 6 . Release sequences are postulated in Section 7 and evaluated in Sections 8 through 10 to determine both the likelihood and possible consequences of a release. Supportive data and analyses are given in the appendices.

The risk assessment results are related to the year 1985 to allow a comparison with other reports in this series. Certain assumptions about the propane shipping industry were made for the purposes of this assessment. These assumptions included the following:

- Shipping systems and basic distribution patterns are the same as in the mid-1970s.

- All tank truck shipments are made in tank trucks or trailers designed to meet Department of Transportation specification MC-331 or MC-330.

- All rail tank car shipments are made in an insulated rail tank car designed to meet the new Department of Transportation specification $112 \mathrm{~J} 340 \mathrm{~W}$.

- The total amount of propane shipped corresponds to the projected U.S. requirements for 1985 .

(a)The others are 1 isted as References $1,2,3,4,5$ and 6 . 
- About two-thirds of the total propane movements are by tank truck, while roughly three percent of total movements are by rail tank car. The remainder of the shipments are made primarily by pipelines.

The shipping system description developed from these assumptions is summarized in Table 1.1.

Based on the information presented in Table 1.1, accidents involving tank truck shipments of propane will be expected to occur at a rate of 320 every year; accidents involving bobtails would be expected at a rate of 250 every year. Train accidents involving propane shipments (in the assumed rail tank car) would be expected to occur at a rate of about 60 every year.

A release of any amount of material from propane trucks, under both normal transportation and transport accident conditions, is to be expected at a rate of about 110 per year. Releases from propane rail tank cars would occur about 40 times a year. However, only those releases that occur during a transportation accident or involve a major tank defect will include sufficient propane to present the potential for danger to the public. These significant releases can be expected at the lower rate of about fourteen events per year for truck transport and about one event every two years for rail tank car transport. The estimated number of public fatalities resulting from these significant releases in 1985 is fifteen. About eleven fatalities per year result from tank truck operation, and approximately half a death per year stems from the movement of propane in rail tank cars.

\section{TABLE 1.1. Simplified Propane Shipping System Model}

\begin{tabular}{|c|c|c|c|c|c|c|}
\hline $\begin{array}{c}\text { Propane } \\
\text { Tank Type }\end{array}$ & $\begin{array}{c}\text { Transport } \\
\text { Mode }\end{array}$ & $\begin{array}{c}\text { Amount/ } \\
\text { Container }\left(\mathrm{m}^{3}\right) \\
\end{array}$ & $\begin{array}{c}\text { Material } \\
\text { Shipped/year } \\
\text { (million } \mathrm{m}^{3} \text { ) } \\
\end{array}$ & $\begin{array}{c}\text { Number of } \\
\text { Shipments/ } \\
\text { year. }\end{array}$ & $\begin{array}{c}\text { Average } \\
\text { Shipment } \\
\text { Distance }(\mathrm{km}) \\
\end{array}$ & $\begin{array}{c}\text { Accident/ } \\
\quad \mathrm{km}\end{array}$ \\
\hline $\begin{array}{l}\text { MC-331 } \\
\text { Tank Truck }\end{array}$ & Truck & 43.0 & 42 & 980,000 & 210 & $1.55 \times 10^{-6}$ \\
\hline $\begin{array}{l}\text { MC-331 } \\
\text { Bobtail }\end{array}$ & Truck & 10.6 & 21 & $1,980,000$ & 80 & $1.55 \times 10^{-6}$ \\
\hline $\begin{array}{l}\text { DOT-112J340W } \\
\text { Rail Tank Car }\end{array}$ & Rail & 127.2 & 3 & 25,000 & 400 & $6.21 \times 10^{-6}$ \\
\hline
\end{tabular}


Additional fatalities involve the population in the immediate area of a propane accident. These fatalities include truck drivers, emergency response teams and occupants of other vehicles involved in the accident (for highway accidents). An additional six deaths per year from propane truck accidents may be expected to account for drivers and other people in the immediate vicinity of the accident. For rail tank car accidents, an expected one to two deaths per year account for firefighters and other personnel in the immediate area. Causes of death varied with population distributions, largely because of shielding effects. In urban areas, direct flame contact and explosion effects caused the majority of deaths. In suburban and rural areas, explosion effects and radiant heat caused most of the fatalities.

The public risk spectrum for the shipment of propane by truck and train is presented in Figure 1.1. The risk spectrum is a plot of the expected frequency (in events per year) of events versus the number of fatalities that are predicted from those events. For example, the curve shows that for the 1985 shipping levels used in the analysis, about two accidents resulting in one or more fatalities to the general public are predicted to occur each year from the release of propane during transport. Accidents that produce ten or more public fatalities are estimated to occur at a rate of 0.17 per year, or one every six years. The propane shipping risks are compared to other risks in society in Table 1.2 .

Sensitivity studies were performed to determine the most important contributors to the risk. It was found that tank wall failures from impact or puncture contributed most of the risk. The failure of the tank in an impact or puncture accident situation was conservatively assumed to result in a release of the entire tank contents to the atmosphere, forming a large vapor cloud. The flammable area of the cloud was large enough to affect many of the general public, and this resulted in the most severe consequences once the cloud was ignited. It was found that in an accident where the propane is immediately ignited, or a fire is involved in the accident, consequences were more localized, and less likely to result in fatalities to the general public. However, these explosions and inmediate fire sequences did result in fatalities to the population immediately surrounding the propane tank. 


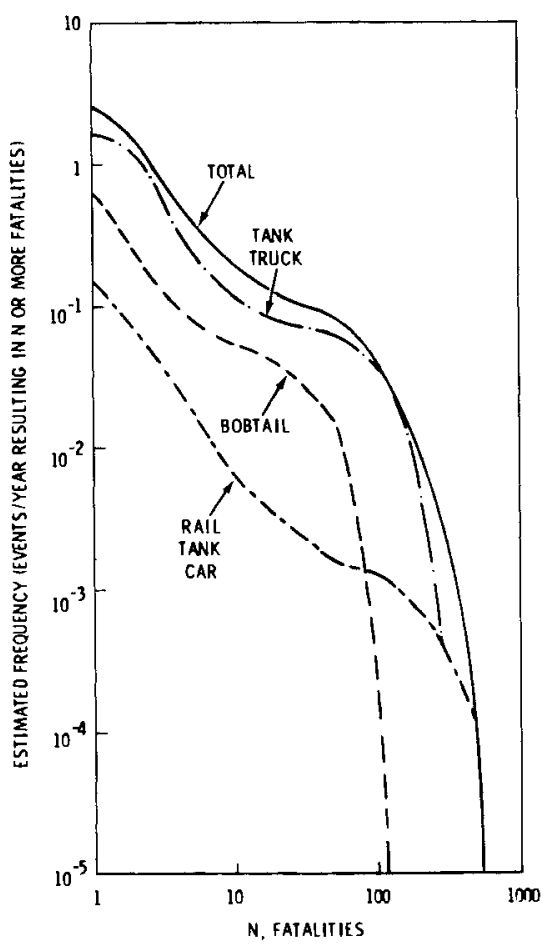

FIGURE 1.1. Risk Spectra for Propane Shipments in 1985

TABLE 1.2. Average Total and Individual Risk from Various Accidents and Natural Disasters

\begin{tabular}{|c|c|c|}
\hline Event & $\begin{array}{c}\text { Total Risk } \\
\text { (fatalities/year) }\end{array}$ & $\begin{array}{l}\text { Indivjdyal } \\
\text { Risk(a) }\end{array}$ \\
\hline Al1 Accidents & $103,030^{(b)}$ & 1 in 2,000 \\
\hline $\begin{array}{l}\text { Motor Vehicle } \\
\text { Accidents }\end{array}$ & $46,700^{(b)}$ & 1 in 5,000 \\
\hline Air Crashes & $1,552^{(b)}$ & 1 in 140,000 \\
\hline Dam Failures & $35^{(c)}$ & 1 in $6,300,000$ \\
\hline Gasoline & $28^{(d)}$ & 1 in $7,900,000$ \\
\hline Propane Shipments & 15 & 1 in $15,000,000$ \\
\hline $\begin{array}{l}\text { Air Crashes } \\
\text { (persons on ground) }\end{array}$ & $6^{(\mathrm{e})}$ & 1 in $33,000,000^{(f)}$ \\
\hline Meteorites & $1.0 \times 10^{-3^{(9)}}$ & 1 in $2 \times 10^{11}$ \\
\hline
\end{tabular}

(a)Based on total U.S. population $(220,000,000)$.

(b) Based on 1975 statistics.

(c) Average for dam failures 1889-1972. (7)

(d) From Reference 4.

(e) Average for years 1960-1973. (7)

(f) Based on population at risk.

(g)From Reference 7 . 
Judgments about the acceptability of the risks from shipping propane by tank truck and rail tank car are beyond the scope of this analysis, but the information presented here can provide input to such decisions. The analysis has shown that the risk from propane shipments is less than many other commoniy accepted risks in society. Further perspective on the total risk to the public from transporting propane may be gained by examining some of the benefits provided by this material. Propane and other liquefied petroleum gases are a significant source of clean-burning fuel in the United States, supplying about 3 percent of total U.S. energy demand in 1976. About one and a half million farms depend on propane as their sole fuel for a variety of uses.

It should be noted that any analysis of this type is generally conservative; the calculated risk is usually somewhat higher than the actual risk might be if it could be measured. This is because many assumptions and simplifications must be made to make the analysis tractable. Every attempt has been made to make these assumptions as realistic as possible, but when lacking information, a generally conservative assumption was made. Sensitivity studies were used to test the effect of key assumptions on the analysis results. It is believed that the results presented are the most realistic possible using existing information. 


\section{REFERENCES}

1. T. I. Sweeney, R. J. Hall et al., An Assessment of the Risk of Transporting Plutonium Oxide and Liquid Plutonium Nitrate by Truck. BNWL-1846, Pacific Northwest Laboratory, Richland, Washington, 1975.

2. R. J. Hall et al., An Assessment of the Risk of Transporting Plutonium Dioxide and Liquid Plutonium Nitrate by Train. BNWL-1996, Pacific Northwest Laboratory, Richland, Washington, February 1977.

3. T. I. McSweeney and J. F. Johnson, An Assessment of the Risk of Transporting Plutonium Dioxide by Cargo Aircraft. BNWL-2030, Pacific Northwest Laboratory, Richland, Washington, June 1977.

4. R. E. Rhoads et al., An Assessment of the Risk of Transporting Gasoline by Truck. PNL-2133, Pacific Northwest Laboratory, Rich1and, Washington, November 1978.

5. C. A. Geffen et a1., An Assessment of the Risk of Transporting Uranium Hexafluoride by Truck and Train. PNL-2211, Pacific Northwest Laboratory, Richland, Washington, August 1978.

6. H. K. Elder et al., An Assessment of the Risk of Transporting Spent Nuclear Fuel by Truck. PNL-2588, Pacific Northwest Laboratory, Richland, Washington, November 1978.

7. Reactor Safety Study - An Assessment of Accident Risks in U.S. Commercial Nuclear Power Plant. WASH-1400 (NUREG-75/014), U.S. Nuclear Regulatory Commission Washington, D.C., October 1975. 


\subsection{INTRODUCTION}

Liquefied petroleum gases have been routinely transported within the United States for over 50 years. The primary use of propane and other LP-gases is as a fuel in rural areas not served by main natural gas lines. LP-gas products are also used as feedstock for petrochemical plants.

Most of the long distance transportation of propane is by pipeline. However, local distribution and final delivery of propane usually requires shipment by tank truck or rail tank car. Recent truck and train accidents involving propane shipments have focused public attention on the safety of shipping propane by truck and train.

This report presents an assessment of the safety of propane truck and train shipping systems. This study is part of a program on transportation safety conducted by Pacific Northwest Laboratory (PNL) for the Department of Energy's Division of Environmental Control Technology. The objective of the program was to develop a methodology for quantitatively assessing the safety of transporting energy materials and to apply this methodology to current and future shipping systems. Risk analysis is the technique selected for this assessment. Through analysis of risk, consequences of postulated releases of energy materials during transport can be put into perspective by viewing the events relative to their expected frequency of occurrence.

Risk assessments can be based on statistical analyses of accident case histories. However, accident data for propane carriers have not been collected in a way that permits accurate risk assessments. Furthermore, the use of historical data tends to identify only the most probable kinds of accidental releases, while accidents with lower probabilities but potentially larger consequences may not be identified. This risk analysis thus uses a predictive risk assessment technique developed by PNL instead of the historical analysis method. The predictive risk assessment methodology is more fully defined in Section 3 of this report.

Risk, as used in the context of this report, is the product of the probability of a release of propane to the environment and the consequences 
resulting from the release. There are two measures of risk that are important in a risk assessment. The first is the total risk, a numerical value that is the sum of the risk associated with each loss for a particular time period (e.g., one year).

Although the total risk is an important measure, it gives only the loss that would be expected on the average during the reference time interval. The range of losses that could be experienced is not discernable. For example, the risk associated with an accident that occurs once a year and results in one fatality is the same (i.e., one fatality/year) as that from an accident that occurs once in ten years but results in ten fatalities. In a plot of the expected frequency of $N$ or more fatalities as a function of $N$, these two accidents would appear as discrete points. The second measure of risk is a curve called a risk spectrum, which is generated by connecting discrete accident points. The risks associated with two activities are similar only if they have the same total risk (risk magnitude) and the same risk spectrum. Both risk measures are used in this report.

This risk methodology was initially applied to the shipment of plutonium by truck $(1)$ and has subsequently been applied to the shipment of plutonium by rail ${ }^{(2)}$ and air, (3) the shipment of uranium hexafluoride by truck and train, (4) the shipment of gasoline by truck ${ }^{(5)}$ and the shipment of spent fuel by truck. (6) This report presents the results of an assessment of the risk of transporting propane by tank truck and rail tank car. The general risk methodology used in this assessment, as well as in the previous risk studies, is reviewed in Section 3. The report is sectioned to correspond to specific analysis steps identified in the model. The transportation system and accident environments are described in Sections 4 and 5. Results of calculations of the response of the shipping system to forces produced in transportation accidents are presented in Section 6. Release sequences are postulated in Section 7 and evaluated in Sections 8 through 10 to determine both the likelihood and possible consequences of a release. Supportive data and analyses are given in the appendices. 


\section{REFERENCES}

1. T. I. McSweeney, R. J. Hall et a1., An Assessment of the Risk of Transporting Plutonium Oxide and Liquid Plutonium Nitrate by Truck. BNWL-1846, Pacific Northwest Laboratory, Richland, Washington, August 1975.

2. R. J. Hall et a1., An Assessment of the Risk of Transporting Plutonium Dioxide and Liquid Plutonium Nitrate by Train. BNWL-1996, Pacific Northwest Laboratory, Richland, Washington, February 1977.

3. T. I. McSweeney and J. F. Johnson, An Assessment of the Risk of Transporting Plutonium Dioxide by Cargo Aircraft. BNWL-2030, Pacific Northwest Laboratory, Richland, Washington, June 1977.

4. C. A. Geffen and J. F. Johnson et a1., An Assessment of the Risk of Transporting Uranium Hexafluoride by Truck and Train. PNL-2211, Pacific Northwest Laboratory, Richland, Washington, August 1978.

5. R. E. Rhoads et al., An Assessment of the Risk of Transporting Gasoline by Truck. PNL-2133, Pacific Northwest Laboratory, Richland, Washington, November 1978.

6. H. K. Elder et a1., An Assessment of the Risk of Transporting Spent Nuclear Fuel by Truck. PNL-2588, Pacific Northwest Laboratory, Richland, Washington, July 1978. 
I. 


\subsection{TRANSPORTATION RISK ASSESSMENT METHODOLOGY}

This risk assessment represents the seventh in a series of analyses of the transportation of hazardous energy materials. The history of the methodology and a brief summary of the risk assessment model used in all studies to date is presented below.

\subsection{HISTORY}

The risk methodology used in this and earlier transportation risk studies evolved from a number of risk analysis models originally developed for use in the nuclear industry. The risk methodology was initially suggested as a method of selecting an acceptable site for nuclear power facilities. (1) The product of the probability of a radioactive material release, expressed in terms of reactor years between releases, and the consequences of that release, in curies, was used as the measure of risk.

Developments in the area of health effects of radiation exposure allowed the use of individual mortality as the measure of release consequences in later studies. $(2,3,4)$ The units of risk became the probability of an individual mortality in any operation year. Analyses $(5,6)$ were further expanded to show that the risk level individuals are willing to accept is related to the benefits received by the individual. For small benefits, it was determined that an individual will accept low-risk activities, where the probability of the activity producing a fatality is lower than $10^{-7}$ per year. (5) For activities with higher benefits, the individual is willing to accept higher levels of risk. The use of health effects in expressing risk generates more meaningful comparisons among risk assessments. In the Reactor Safety Study, ${ }^{(7)}$ for example, the risk of operating a nuclear power plant was compared to the risks from natural disasters and man-caused events such as automobile accidents.

The risk assessment methodologies discussed above have been limited to analyses of fixed facilities with a well-defined population distribution. The population in the immediate vicinity of the plant (the exclusion area) 
is controlled by the facility operator. The population distribution in the vicinity of a transportation accident, however, is highly variable. Transportation accidents may occur in rural areas (with very low population densities), in suburban areas, or in urban areas (with relatively high population densities). A variety of geographic and meteorological conditions are also encountered, since transportation accidents can occur at virtually any location along the shipping route. The variability in population distribution, geography and meteorology in transportation accidents adds a degree of complexity not found in risk assessments of activities at fixed sites.

A number of methodologies have been developed to analyze the transport of hazardous materials. A method based on accident case histories was used by the University of Southern California ${ }^{(8)}$ in a study for the Department of Transportation. However, this technique cannot be applied to all energy material shipments since the accident experience may be extremely limited or the accident data may not have been collected in a way that permits accurate assessment.

Another technique, developed by Holmes and Narver, was used to determine the risk of transporting bioweapons ${ }^{(9)}$ and radioactive material. (10) These analyses were performed for shipments of material along a selected route. A limitation of the Holmes and Narver technique is that only an average number for the risk is obtained. It would be more useful to know how the risk varies with route, weather, population, material form and accident severity. The variability of risk with different transport conditions could then be considered.

\subsection{RISK ASSESSMENT MODEL}

The risk assessment model used in this analysis of the transport of energy materials was developed in conjunction with a method developed at PNL ${ }^{(11)}$ to analyze the risks associated with nuclear fuel cycle operations. The methodology provides a flexibility not available in previous transportation risk studies, since it permits the risk to be analyzed for a spectrum of population densities and weather conditions that can be encountered along shipping routes. The model uses one fundamental equation: 


$$
R=\sum_{\mathbf{i}} R_{\mathbf{i}}
$$

The total system risk $R$ is the sum of the risks of all accidental releases of material as denoted by the subscript $i$. The risk of an individual release is the product of the consequences of the release and the probability of its occurrence. In the current formulation of the model, each term in Equation 3-1 is expanded into two expressions that have more physical significance. The expanded equation for $R_{i}$ is:

$$
R_{i}=\left(Q_{i} \times P_{i}\right) \times \underset{q}{\Sigma}\left(C_{Q_{i, q}} \times P_{q}\right)
$$

The first expression, $Q_{i} \times P_{i}$, can be thought of as a probabilistic source term for each identified release sequence. The first factor in this term, $Q_{i}$, represents the amount of material released in the $i^{\text {th }}$ release sequence. The second factor, $P_{i}$, is the probability that the release sequence will occur during transport.

The second expression in Equation $3-2 \sum_{\mathrm{q}}\left(\mathrm{C}_{\mathrm{Q}_{j}, \mathrm{q}} \times \mathrm{P}_{\mathrm{q}}\right)$ represents the consequences of a release of material under probabilistically weighted weather conditions and population distributions. The consequences of a release of material are evaluated in the expression $C_{Q_{i}, q}$. The subscript $q$ is added to show that this factor is a function of the specific weather conditions existing at the time of the release and the population exposed to the release. The consequences are expressed as health effects. The final factor in this expression, $P_{q}$, is the joint probability of encountering a particular set of weather conditions within a specific population zone.

The methodology used to provide input data for solution of the above equations involves four components:

- System Description

- Release Sequence Identification

- Release Sequence Evaluation

- Risk Calculation and Assessment 
These four components, shown graphically in Figure 3.1, are described in detail below. Step numbers correspond to the number shown in the figure.

\subsubsection{System Description}

In this portion of the analysis, the basic information on the shipping system to be analyzed is collected. Most of the information is already available or easily derived. A complete description of the transportation system generally consists of seven steps, which are shown in Figure 3.1.

The industry being studied is characterized in steps 1 and 2 by gathering data on facility locations, industry shipping requirements and shipping destinations. Information on the physical and chemical properties of the material being transported is gathered in step 3. The shipping packages used and the number of packages per shipment are determined in steps 4,5 and 6 for each transport mode of interest. In step 7, the population distributions and weather characteristics along the shipping routes are characterized.

\subsubsection{Release Sequence Identification}

The next component in the risk assessment process is the identification of the sequences of events that could lead to a release of material from the transport vehicle. This study uses a deductive reasoning process to identify release sequences. Event sequences are identified by assuming that the undesired event has occurred and working backward to identify the sequences of events that must occur to cause this system failure. Fault tree analysis is a formalized way of performing these deductive reasoning processes. Computer codes, such as the MFAULT ${ }^{(12)}$ code used at PNL, can be used to quickly and accurately perform the Boolean algebra that reduces the fault tree to a series of release sequences or "cut sets" required for subsequent steps in the analysis.

Before the possible release sequences are identified (step 9), the scope of the analysis must be delineated (step 8). Completed studies using this risk assessment model have considered releases from two general causes. In addition to releases caused by forces produced in transportation accidents, releases resulting from package closure errors, substandard packaging construction or deterioration in packaging condition in the normal transportation 


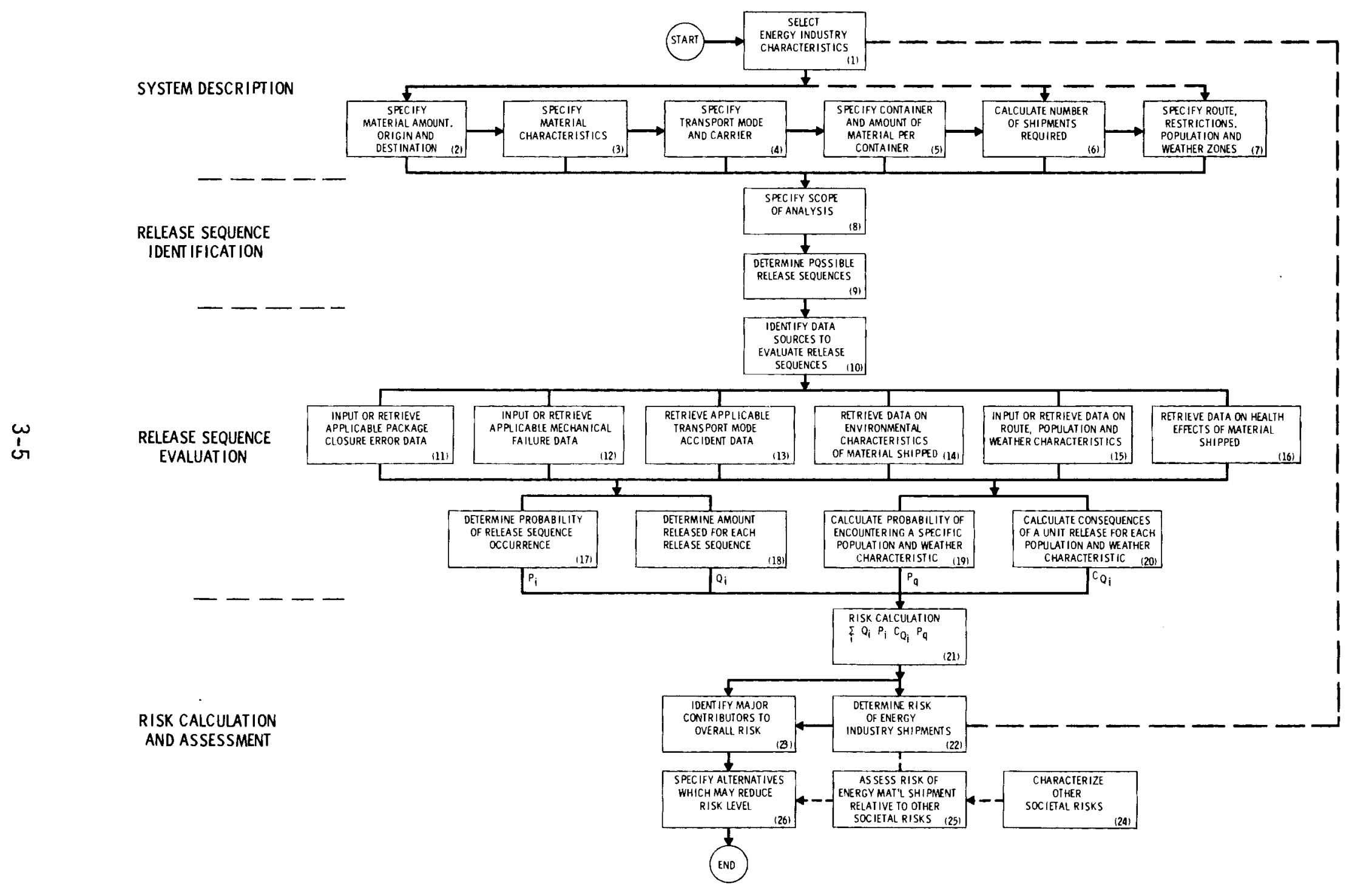

FIGURE 3.1. Model to Calculate the Risk of Shipping Energy Materials 
environment have been considered. Failure associated with deliberate sabotage or diversion attempts has not been considered, but the techniques used in the model are sufficiently general to permit consideration of these events if failure rate (probability) data were available.

\subsubsection{Release Sequence Evaluation}

This step consists of two basic parts: 1) estimation of release sequence probabilities and 2) evaluation of the potential consequences of each release sequence.

Release sequence probabilities are obtained by estimating the probability of each of the events that must occur to produce a system failure. This requires either historical data or development of information on the response of the shipping system to normal and transportation accident forces (to determine the level of forces required to produce a system failure). A knowledge of the forces present in transportation accidents is also required.

Package closure data (step 11) have been obtained from general 1iterature and accident reports. Mathematical analysis or data available from testing programs is generally used to determine system failure thresholds (step 12). This can be combined with accident environment data, such as that developed at Sandia Laboratories, $(13,14)$ or statistical analysis of other accident data to determine failure probabilities (step 13).

The consequences of a system failure depend on the type of failure that has occurred, the location of the failure along the shipping route and the weather and population conditions at the time of failure. The consequences of the failure sequences may be determined by mathematical modeling, from historical accident data and/or from information on tests that have been conducted with the material being shipped. In genera1, consequences must be evaluated for each type of failure that can occur for each combination of weather condition and population distribution that can be encountered along the route. The probability of encountering the various population distributions and weather conditions along the route must also be determined.

The environmental behavior characteristics and health effects of the material (steps 14 and 16) depend on the material itself and must be developed 
individually for each study. Data for population and weather characteristics (step 15) are available from U.S. Census data (15) and summaries of regional weather data compiled by the U.S. Weather Bureau. (16) Information from steps 14 to 16 is used to evaluate the probability of experiencing a given set of weather conditions and population characteristics.

\subsubsection{Risk Calculation and Assessment}

The final component in the risk assessment is to sum and evaluate the risks associated with the applicable release sequences. The steps involved in this component are shown graphically in Figure 3.1 .

The overall risk calculation for each release sequence is described by Equations $3-1$ and 3-2. These release sequence risks are added to determine the risk associated with individual shipping routes, which are weighted according to the amounts being shipped along each route. The overall transportation risk (total risk) is the sum of risks from these weighted routes. The risk is also expressed in terms of a risk spectrum (plot of magnitude of consequence versus frequency of events resulting in that magnitude consequence or a more severe consequence).

The results are then analyzed to determine the primary contributors to the risk (step 23) and to specify and evaluate alternatives that could reduce the system risk, if the current risk is judged by society to be unacceptable. Since the information to perform the risk assessment has been developed in discrete data blocks, sensitivity studies can also be carried out to test the effect on the system risk of assumptions and approximations that were made to develop key pieces of information. This may identify areas where further analysis is required or delineate the limitations of the assessment. 


\section{REFERENCES}

1. F. R. Farmer, "Reactor Safety and Siting: A Proposed Risk Criterion." Nuclear Safety, 8:539, 1967.

2. H. J. Otway and R. C. Erdmann, "Reactor Siting and Design From a Risk Viewpoint." Nuclear Engineering and Design, 13:365, 1970.

3. M. Meleis and R. C. Erdmann, "The Development of Reactor Siting Criteria Based Upon Risk Probability." Nuclear Safety, 13:22, 1972.

4. G. D. Be11, "Safety Criteria, "Quantitative Safety Analysis." Nuclear Engineering and Design, 13:183-244, 1970.

5. C. Starr, "Benefit-Cost Studies in Socio-Technical Systems." Proceedings of Conference on Hazard Evaluation and Risk Analysis, Houston, Texas, 18-19 August, 1971, National Academy of Sciences, Washington, D.C.

6. C. Starr, M. A. Greenfield and D. F. Hausknecht, "A Comparison of Public Health Risks: Nuclear versus $0 i 1$ Fired Power Plants." Nuclear News, 15(10):37, 1972 .

7. Reactor Safety Study. WASH-1400, U.S. Nuclear Regulatory Commission, Washington, D.C., October 1975.

8. G. P. Jones and R. W. Barrow, Risk Analysis in Hazardous Materials Transportation. RAP0-72-106, U.S. Department of Transportation, Office of Hazardous Materials, Washington, D.C., November 1972.

9. B. J. Garrick, W. C. Gekler, 0. C. Baldonado, H. K. Elder and J. E. Shapley, A Risk Model for the Transport of Hazardous Materials. $\mathrm{HN}-204$, Holmes and Narver, Inc., Los Angeles, California, August 1969.

10. C. V. Hodge and 0. C. Baldonado, "Risk Analysis of Shipments in the Nuclear Power Industry." Proceedings of the 4th International Symposium on Packaging and Transportation of Radioactive Materials, CONF-740901, September 22-27, 1974.

11. T. I. Smith, A Risk-Based Fault Tree Analysis Method for Identification, Prel iminary Evaluation, and Screening of Potential Accidental Release Sequences in Nuclear Fuel Cycle Operations. BNWL-1959, Pacific Northwest Laboratory, Richland, Washington, January 1976.

12. P. J. Pelto, W. L. Purce11, MFAULT: A Computer Program For Analyzing Fault Trees. BNWL-2145, Pacific Northwest Laboratory, Richland, Washington, November 1977.

13. R. K. Clarke et a1., Severities of Transport Accidents. SLA-74-0001, Sandia Laboratories, ATbuquerque, New Mexico, July 1976. 
14. A. W. Dennis, J. T. Foley, W. F. Hartman and D. W. Larson, Severities of Transportation Accidents Involving Large Packages. SAND77-0001, Sandia Laboratories, Albuquerque, New Mexico, May 1978.

15. U.S. Bureau of the Census, County and City Data Book, 1967, (A Statistical Abstract Supplement). U.S. Department of Commerce, Washington, D.C., 1967.

16. U.S. Weather Bureau, Climatological Data Summaries. U.S. Department of Commerce National Climatic Center, Asheville, North Carolina. 
' 


\subsection{PROPANE SHIPPING REQUIREMENTS}

Propane is a member of a family of petroleum products called liquefied petroleum gases (LPG). Other LP-gases include butane, ethane, propylene, butylene, and mixtures of these hydrocarbons. The material characteristics of propane and other LP-gases are presented in Appendix A.

The primary use of propane is for fuel, although it is also used as a feedstock for petrochemical plants. (1) Propane and other LP-gases supplied about 3\% of total U.S. energy demand in 1976. Propane is produced in two ways: 1) about $70 \%$ of domestic supplies are stripped at natural gas processing plants from the natural gas stream produced at gas wells; and 2) about $30 \%$ of domestic propane is produced from crude oil at refineries by the cracking process used to produce most petroleum products. (2) The propane industry is thus closely tied to the oil and natural gas industries.

An entire market for propane and other LP-gases has evolved in the U.S. during the last 65 years, utilizing the "bottled gas" for multiple purposes in the residential, commercial and industrial sectors, particularly in areas that natural gas pipelines and distribution lines do not serve. (2) The LP-gas industry serves about 13 million customers. Most of these customers are in rural areas, including approximately one and one-half million farms. Many factories also rely on propane as a back-up fuel in case their natural gas supplies are curtailed. (1)

Propane is typically shipped as a component of crude oil to the oil refinery or in the natural gas stream to the natural gas processing plant by pipeline. From the refinery or the processing plant, it is transported by a combination of modes (barge, tankship, truck, rail and pipeline) to distribution terminals and underground storage facilities. Some propane travels directly from the refinery or the processing plant to dealer plants and consumers. Most propane, however, is shipped in two stages: first, from the refinery or processing plant to an intermediate terminal and then on to the consumer (see Figure 4.1). 


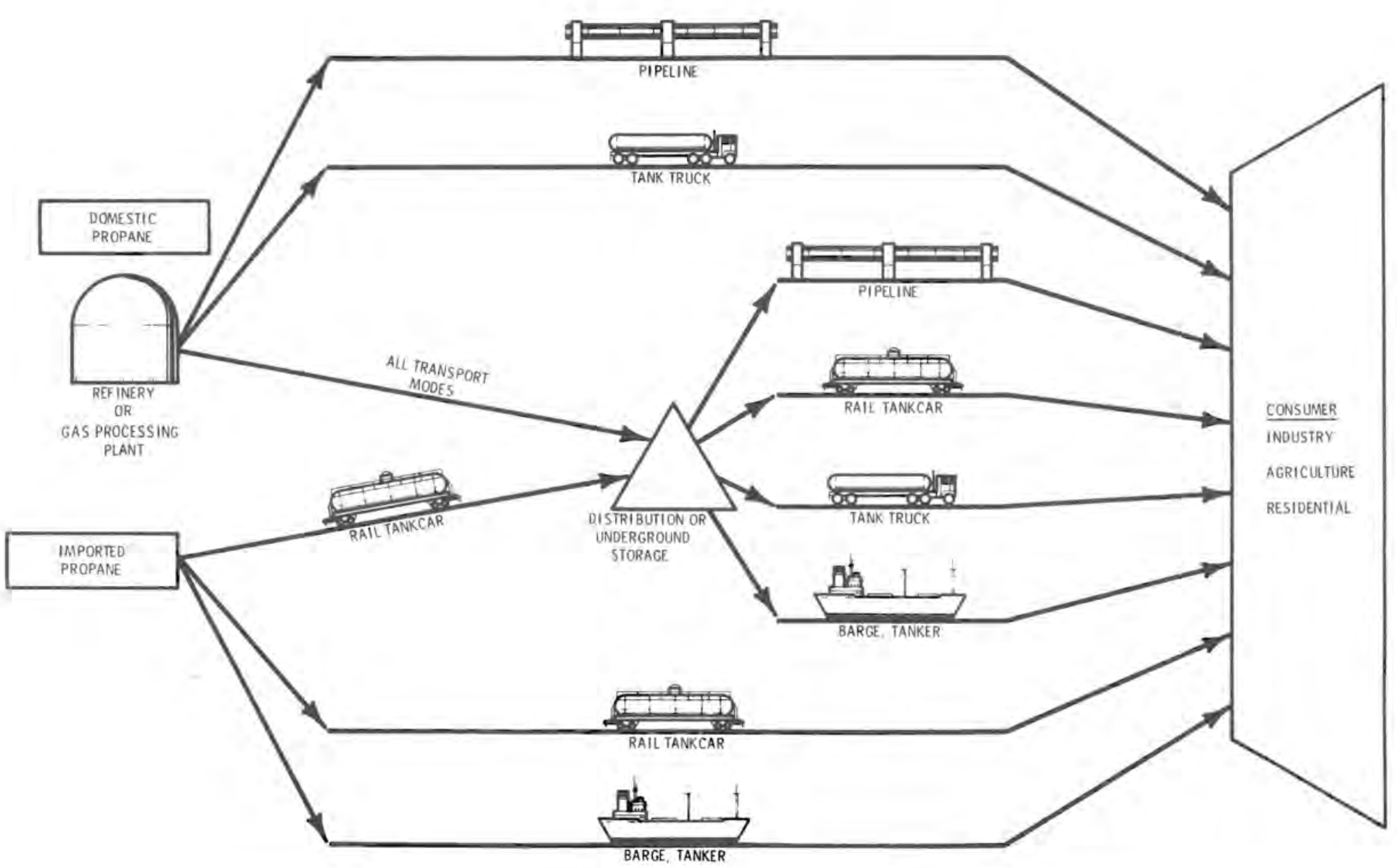

FIGURE 4.1. General Patterns of LPG Transport and Distribution 
As discussed in Section 3, this propane risk assessment is based on a specific set of propane shipping requirements. The reference year for the assumed shipping system is 1985 . This report addresses the transport of propane by rail tank car and tank truck only. Shipments from the refinery, the processing plant, or import terminal to distribution or storage terminals, transfer from storage to dealers and consumers, and direct shipments of propane from the point of origin to the consumer will be analyzed.

\subsection{PROPANE DISTRIBUTION PATTERNS}

Domestic supplies of propane in 1976 were about $45 \mathrm{mi} 11$ ion cubic meters $\left(\mathrm{m}^{3}\right)$ (11,770 million gallons); imports supplied another 4 million $\mathrm{m}^{3}$ (960 million gallons) of propane. Most of the propane (90.6\%) shipped in the United States in 1976 was by pipeline to storage or distribution terminals and then to trucks for final delivery; $4.6 \%$ was shipped by pipeline to intermediate terminals to rail tank cars. Only $3.4 \%$ of the total propane moved in 1976 was transported by truck from the point of origin directly to the consumer; $0.9 \%$ solely by rail. Less than $1 \%$ of the propane moved in the U.S. traveled by tanker or barge. (a) Most imported propane is moved by rail tank cars, while most local distribution of propane is by truck. (1)

\subsection{TRANSPORTATION MODES}

This study considers the shipment of propane by both truck and rail transport modes. Two types of truck transport vehicles and one rail tank car type were chosen as reference systems. A larger tank truck size was chosen to represent the trailers and semitrailers that carry between 25 and $44 \mathrm{~m}^{3}$ of propane per shipment. A smaller tank truck, called a bobtail, was chosen to represent the local delivery units that commonly haul between 6 and $12 \mathrm{~m}^{3}$ of propane. The reference rail tank car is a modification of the currently used DOT-112A340W non-insulated tank car, with a 129-m ${ }^{3}$ capacity. New safety regulations require that by 1985 this car (reclassified as a 112J340W) must be fitted with head shields, full thermal insulation and a new type of

(a) These figures reflect the movement of LPG from points of production or import to distribution or storage facilities. 
safety coupler. (3) The 112J tank car, which will be required by 1985, is the one used in this shipping system model. A detailed description of the reference tank trucks and the rail tank car is included in Appendix $B$.

Current hardware for the LPG distribution system includes 25,000 transport and local delivery trucks and 22,000 railroad tank cars. (1) It is assumed that current infrastructure will either be adequate to handle future propane shipments or that industry will develop the increased capacity necessary to handle these shipments.

\subsection{SHIPPING SYSTEM MODEL}

The 1985 shipping system model assumes the same transportation patterns as existed in the mid-1970s. Projections $(2,4)$ indicate that the U.S. will require about $53 \mathrm{million} \mathrm{m}^{3}$ of propane in 1985. Domestic production should supply about $80 \%$ ( $43 \mathrm{million} \mathrm{m}^{3}$ ) of these requirements, leaving $20 \%$ (10 million $\mathrm{m}^{3}$ ) as imports. Since most of the propane is shipped in two or more stages, the final volume of propane being moved in 1985 is estimated to be 95 million $\mathrm{m}^{3}$. (a)

Current (1974) distribution patterns of propane, obtained from industry literature $(1,5)$ and Interstate Commerce Commission (ICC) statistics $^{(6)}$ were used to determine the portion of 1985 propane supplies that would move by each transport mode. In 1974, 39\% of all propane moved from the point of origin to intermediate terminals was by tank truck; $55 \%$ was shipped by pipeline; $6 \%$ of propane movements were by rail tank cars; and less than $1 \%$ of propane supplies were moved by water modes. All propane imports are shipped either by rail, barge or pipeline modes. (5) From dealer plants, most of the propane is moved by truck. It is assumed that 1985 propane distribution patterns will be essentially the same as in 1974. Thus, of the initial propane supply in 1985 ( 53 million $\mathrm{m}^{3}$ ), it is postulated that $39 \%$ will be moved by tank truck; $55 \%$ will be shipped by pipeline; $6 \%$ by rail; and less than $1 \%$ by water. 0 f the 42 million $\mathrm{m}^{3}$ of propane shipped in two or more stages, approximately equal amounts are shipped by tank trucks and bobtails. All final deliveries

(a) This figure was obtained by scaling up the 1985 propane supply by the ratio of 1974 supply versus actual shipments. 
are assumed to be made by truck. The amount of propane transported by each mode and the number of shipments required in 1985 are outlined in Table 4.1.

ICC statistics ${ }^{(6)}$ also record the amount of propane moved in tons for each vehicle weight category and the number of ton-miles traveled. The average shipping distance for each reference vehicle was thus determined by dividing the total ton-miles traveled by the total number of tons transported within each weight class. This average shipping distance compared well with those presented in Reference 5, and was thus used in this report. The average shipping distance for bobtails was obtained from figures given in Reference 2 for local truck delivery of petroleum products, since the ICC does not record statistics for bobtails.

Propane shipments were also categorized geographically. The United States was divided into 9 sections, corresponding to the divisions used by the U.S. Bureau of Census. These divisions and the amount of propane moving within each region are presented in Table 4.2. A11 truck travel was found to be intraregional. Rail movements, however, crossed various geographic regions. The crossover routes between regions for propane rail shipments are shown in Figure 4.2 .

TABLE 4.1. 1985 Shipping System: Number of Shipments and Average Trip Length

\begin{tabular}{|c|c|c|c|}
\hline & $\begin{array}{c}\text { MC-331 Tank } \\
\text { Truck Transport } \\
\end{array}$ & $\begin{array}{c}\text { MC-331 } \\
\text { Bobtail Transport }\end{array}$ & $\begin{array}{l}\text { DOT-112J340W } \\
\text { Rail Tank Car }\end{array}$ \\
\hline $\begin{array}{l}\text { Total Propane Transported } \\
\text { Million } \mathrm{m}^{3} \text { (million gal) }\end{array}$ & $42(12,000)$ & $21(6,000)$ & $3(860)$ \\
\hline Container Size ${ }^{(a)} m^{3}$ (gal) & $43.0(11,600)$ & $10.6(2,800)$ & $127.2(33,600)$ \\
\hline $\begin{array}{l}\text { Number of Shipments } \\
\text { Required (thousands) }\end{array}$ & 980 & 1980 & 25 \\
\hline $\begin{array}{l}\text { Average Trip Length (loaded) } \\
\text { km (mi les) }\end{array}$ & $210(130)$ & $80(50)$ & $400(250)$ \\
\hline $\begin{array}{l}\text { Total Distance Traveled } \\
\text { (loaded) million km } \\
\text { (million miles) }\end{array}$ & $205(130)$ & $160(100)$ & $10(6)$ \\
\hline
\end{tabular}

(a) The legal filling limits for these tanks require them to carry less than the actual water capacity of the tank. Allowable loads for the tank truck, bobtail and rail tank car tanks are $38.8 \mathrm{~m}^{3}(10,250 \mathrm{ga} 7) ; 9.4 \mathrm{~m}^{3}$ (2475 gal); and $124.9 \mathrm{~m}^{3}(33,000 \mathrm{gal})$, respectively. 
TABLE 4.2. Percent Travel of Each Transport Mode in Each Population Region

$\underline{\text { Tank Truck }}{ }^{(a)} \quad \underline{\text { Bobtail }}{ }^{(a)}$ Rail Tank Car ${ }^{(b)}$

New England (NE)

Middle Atlantic (MA)

East North Central (ENC)

West North Central (WNC)

South Atlantic (SA)

East South Central (ESC)

West South Central (WSC)

Mountain (MT)

Pacific (PAC)

\section{3}

5

21

18

13

10

19

5

6
3

5

21

18

13

10

19

5

6
2.0

7.3

6.2

33.5

11.1

21.3

15.2

2.7

0.6

(a) Since all truck movements are intraregional, these numbers refer to the fraction of total propane moved by that size truck.

(b) Rail movements are interregional; these numbers refer to the percent of miles traveled by rail tank cars in each region. 


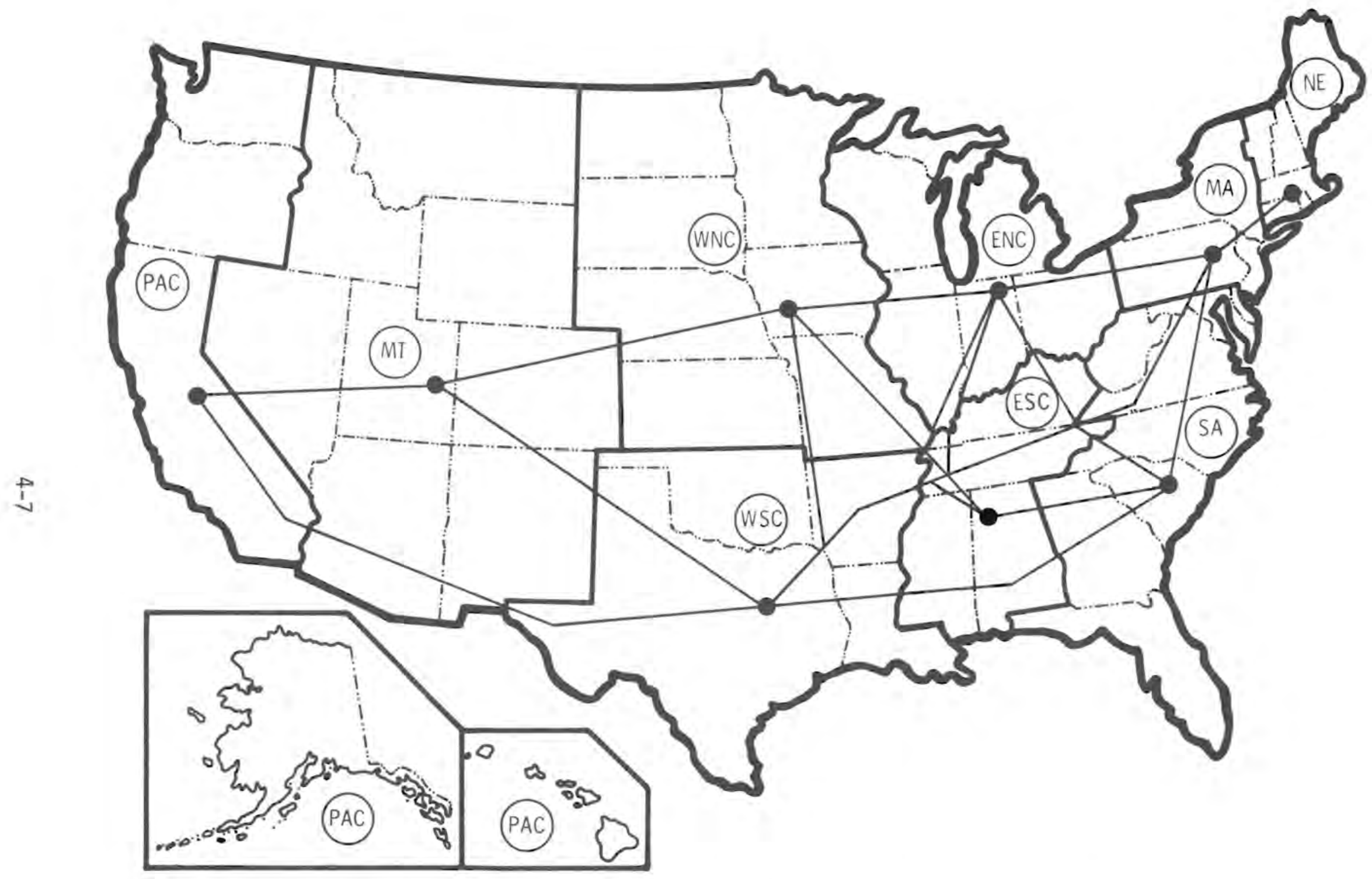

FIGURE 4.2. Crossover Routes of Propane Rail Shipments Between Geographic Regions 
1. 1976 LP-Gas Market Facts. National LP-Gas Association, Oak Brook, Illinois, 1978.

2. National Energy Transportation. Volume III - Issues and Problems. John W. Jimison, ed. Congressional Research Service. Publication No. 95-15. March 1978.

3. Federal Register. 42(179), September 15, 1977.

4. Annual Report to Congress, Volume II, 1977. DOE/EIA-0036/2, Energy Information Administration, Washington, D.C., Apri 1978.

5. D. N. McClanahan and K. 0. Stowe11, Propane Transportation 1974. Houston, Texas, June 1976.

6. 1972 Census of Transportation Volumes I-IV. U.S. Government Printing Office, Washington, D.C., 1974. 


\subsection{TRANSPORTATION ACCIDENT ENVIRONMENT}

Failure of a propane tank truck or rail tank car during an accident occurs when the forces generated in the accident exceed the mechanical strength of the container affected. This section discusses the forces or stresses which may be generated in truck and rail accident environments. Section 5.1 presents the truck accident environment data. The train accident environment data is presented in Section 5.2. Section 5.3 presents the data for releases from tank valves and fittings. Section 6 discusses the mechanical strength of the propane tanks. The use of information from Sections 5 and 6 to estimate the likelihood of container failure in an accident is demonstrated in Section 8 .

The accident environment data summarized here were developed by Sandia Laboratories. (1) These data represent the most comprehensive accident environment information currently available. Although other data sources for accident rates do exist, none of these address the forces generated in accidents. Because this information is necessary for the risk assessment, the Sandia data will be used. In Sandia's analysis the accident environment is categorized by five accident stresses: impact, crush, puncture, fire and immersion. The following paragraphs briefly summarize the Sandia results.

\subsection{TRUCK ACCIDENT ENVIRONMENT}

Truck accidents as defined by Sandia ${ }^{(1)}$ include all accidents that result in fatalities, injuries or property damage of $\$ 250$ or more. The accident rate selected by Sandia which will be used for this study is $1.55 \times 10^{-6}$ accidents per truck kilometer. This rate is the basis for the accident environment data and was based on accident frequency data prepared by the Bureau of Motor Carrier Safety of the U.S. Department of Transportation.

For this analysis, the stresses present in a truck accident have been divided into four categories: fire, impact, puncture and crush. 0ther stresses, such as abrasion and immersion, were assumed to contribute insignificantly to the likelihood of propane tank failures and were not included. The four accident stresses of interest are discussed below. 
Fire

Fire accident environment data used in this study were developed by Sandia Laboratories (1) from accident reports compiled by the Bureau of Motor Carrier Safety (BMCS). These data were used in a Monte Carlo program to model the probability distribution of fire durations. Only fires that did not involve the cargo initially were considered, since the intent is to establish the likelihood of tank failure.

Based on the Sandia compilation of the truck accident environment, fire can be expected to occur in $1.6 \%$ of all truck accidents. The mean temperature of the fire is $1010^{\circ} \mathrm{C}\left(1850^{\circ} \mathrm{F}\right)$ and the duration of the fire can range from a few minutes to several hours. The expected duration of fires in truck accidents as a function of frequency is shown in Figure 5.1.

Because of the fire pool sizes and the general nature of the truck accidents used in the Sandia analysis, it was conservatively assumed that the entire tank was exposed to fire in all truck accidents with fire.

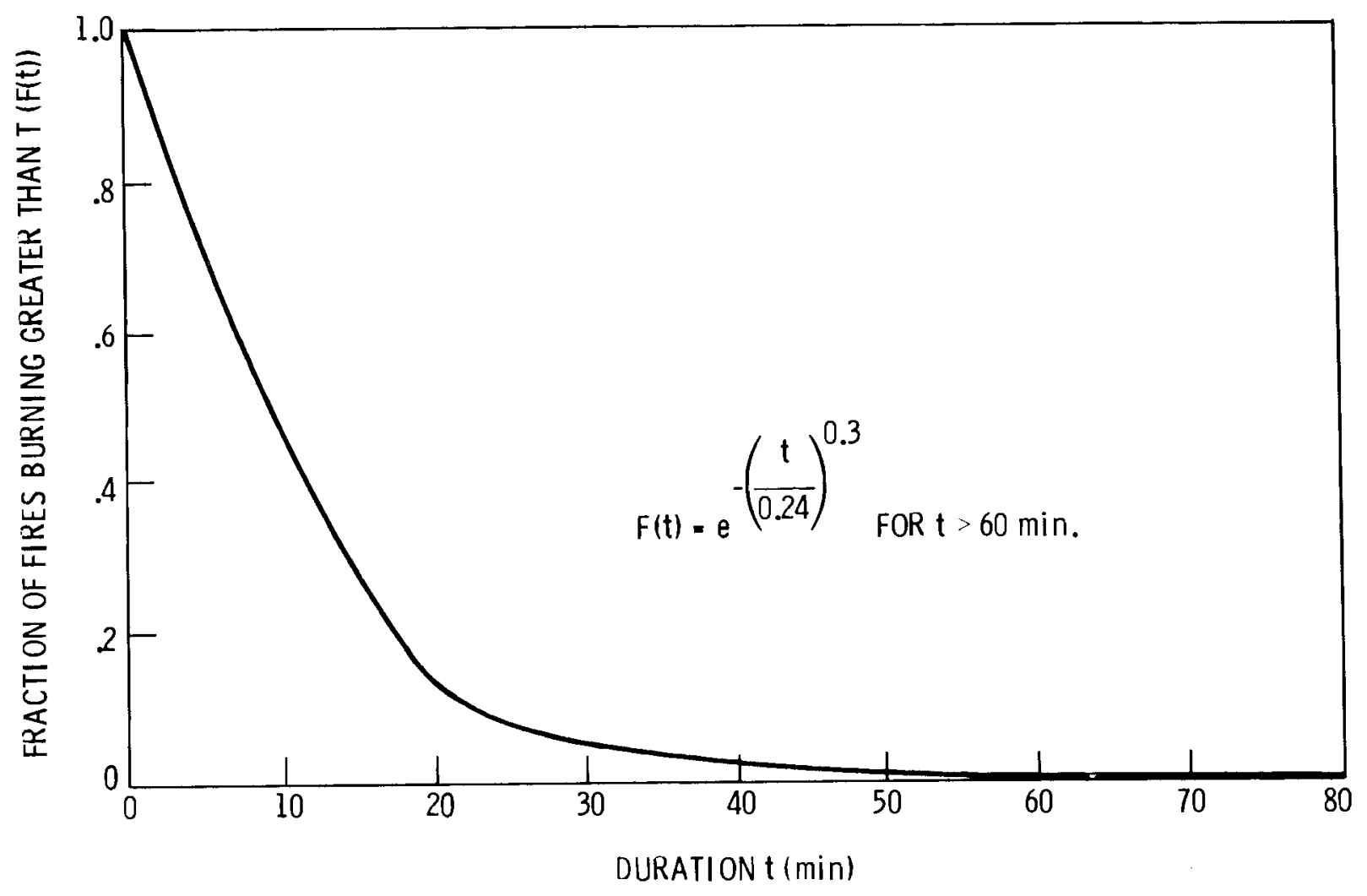

FIGURE 5.1. Cumulative Distribution of Fire Durations for Truck 


\section{Impact}

The impact environment for an accident involving a propane tank truck is also taken from information developed at Sandia Laboratories. (1) The statistical information provided by Sandia was developed from Bureau of Motor Carrier Safety (BMCS) data. The BMCS data were used by Sandia in a Monte Carlo computer simulation to estimate the impact environment experienced by a large truck in an accident.

The impact environment is assumed to be present in every truck collision accident other than rollover incidents. Collision with other vehicles, trains or stationary objects produces an impact environment in 80.2 percent of expected truck accidents. As shown in Table 5.1, the overturn and runningoff-the-road accident represents the remaining 19.8 percent of the expected accidents.

TABLE 5.1. Distribution of BMCS Accident Data (1)

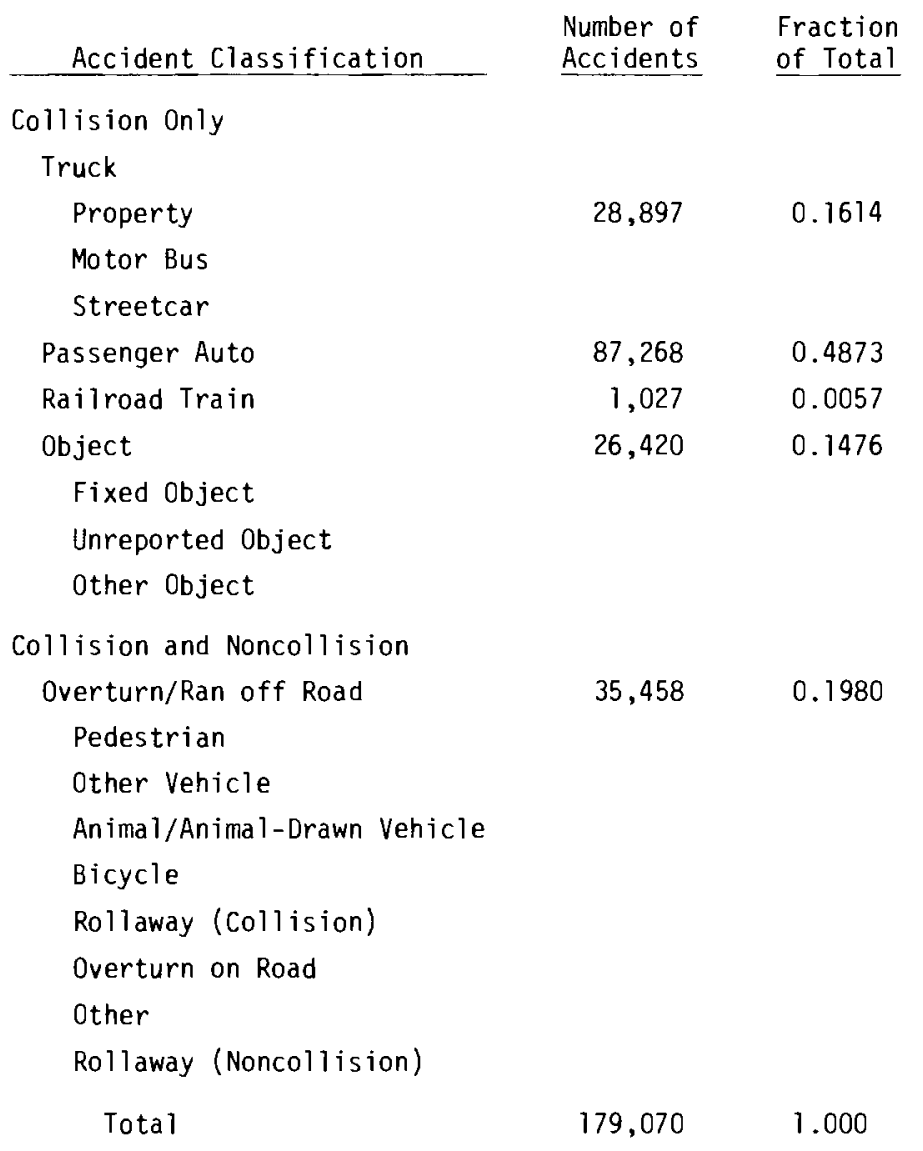


Overturn accidents were not included in the analysis of the impact environment. These accidents tend to involve a series of low-level impacts and ground friction that slow the vehicle rather than one primary impact. The collision or impact effects on the truck cargo in these overturn accidents is considered to be slight; the primary damage to the truck and cargo in these accidents is from the overturning or running-off-the-road of the truck. (1) The distribution of collision accidents by the direction of impact (i.e., a rear-end or head-on collision) is represented in Table 5.2 .

TABLE 5.2. Collision Accident Distrjpution by Direction of Acceleration
Vector on Shipment Truck

\begin{tabular}{|c|c|c|}
\hline $\begin{array}{l}\text { Direction of Acceleration } \\
\text { Vector on Package }\end{array}$ & $\begin{array}{l}\text { Distribution } \\
\text { Factors } \\
\end{array}$ & $\begin{array}{l}\text { Normalized Sets of } \\
\text { Distribution Factors }\end{array}$ \\
\hline \multicolumn{3}{|l|}{ Truck Decelerated Along Its Axis } \\
\hline Head-on, truck & 0.0081 & 0.0137 \\
\hline End-on $\# 1^{(a)}$ into $\# 2,{ }^{(b)}$ truck & 0.0856 & 0.1450 \\
\hline Side-on \#1 into \#2, truck & 0.0086 & 0.0146 \\
\hline Head-on, auto & 0.0327 & 0.0554 \\
\hline End-on \#1 into \#2, auto & 0.2245 & 0.3803 \\
\hline Side-on \#1 into \#2, auto & 0.0451 & 0.0764 \\
\hline Ran into Train & 0.0018 & 0.0030 \\
\hline \multirow[t]{2}{*}{ Object } & $\underline{0.1840}$ & $\underline{0.3116}$ \\
\hline & 0.5904 & 1.0000 \\
\hline \multicolumn{3}{|l|}{ Truck Accelerated Along Its Axis } \\
\hline End-on \#2 into \#1, truck & 0.0806 & 0.3044 \\
\hline \multirow[t]{2}{*}{ End-on \#2 into \#1, auto } & $\underline{0.1842}$ & $\underline{0.6956}$ \\
\hline & 0.2648 & 1.0000 \\
\hline \multicolumn{3}{|l|}{$\begin{array}{l}\text { Truck Accelerated Perpendicular } \\
\text { to Its Axis }\end{array}$} \\
\hline Side-on \#2 into \#1, truck & 0.0183 & 0.1264 \\
\hline Side-on \#2 into \#1, auto & 0.1211 & 0.8363 \\
\hline \multirow[t]{2}{*}{ Struck by train } & 0.0054 & 0.0373 \\
\hline & 0.1448 & 1.0000 \\
\hline
\end{tabular}


The results of the Sandia analysis for a truck weighing about $36,000 \mathrm{~kg}$ (40 tons) loaded, which represents the tank truck transport, and a 13,600-kg (15-ton) truck, which represents the bobtail, are shown in Figure 5.2, which presents the magnitude of the expected velocity change of the truck versus the expected frequency of occurrence of that change in a collision accident. Table 5.3 contains the basic information plotted in Figure 5.2 for the two vehicle sizes.

\section{Crush}

Information on the crush environment experienced by a large package in an accident situation is obtained from studies done by Sandia Laboratories. The load considered in this case is the truck trailer coming to rest on the tank, or the truck overturning and pinning the tank underneath the truck trailer. The probability of crush, given a collision or overturn, is given by Sandia as $5 \times 10^{-2}$. This value is conservative, according to the Sandia analysis, as available accident data seem to indicate a lower occurrence rate. The maximum expected crush value for the tank truck is about 66,700 Newtons $(\mathrm{N})$.

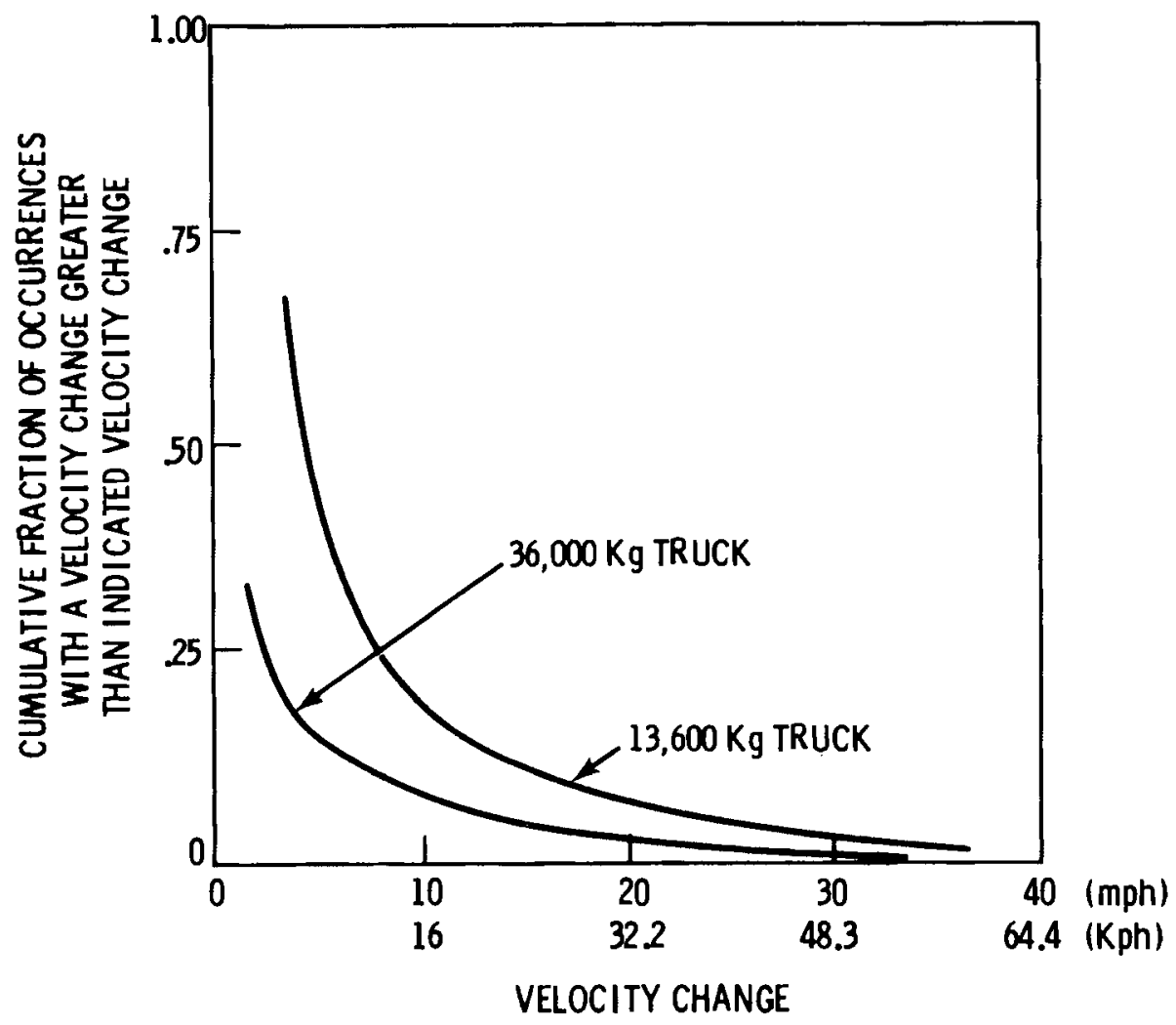
FIGURE 5.2. Impact Velocity Change as a Function of Cumulative Frequency
of Occurrence for Highway Transportation $(1)$ 
TABLE 5.3. Velocity Change Due to Impact in a Highway

Transportation Collision Accident

\begin{tabular}{|c|c|c|c|c|c|c|c|}
\hline \multirow{2}{*}{$\begin{array}{c}\text { Velocity Change } \\
\text { Due to Impact } \\
\text { (mph) }\left(\begin{array}{l}\mathrm{a} \\
\text { ) }\end{array}\right.\end{array}$} & \multicolumn{7}{|c|}{$\begin{array}{l}\text { Cumulative Fraction of Sample With a Velocity Change Less } \\
\text { Than or Equal to Indicated Velocity Change for Each Over- } \\
\text { the-Road Transport Vehicle Weight (in tons) (b) }\end{array}$} \\
\hline & 10 & 15 & 20 & 25 & 30 & 40 & 50 \\
\hline 5 & 0.5038 & 0.6220 & 0.7146 & 0.7813 & 0.8248 & 0.8711 & 0.8962 \\
\hline 10 & 0.7541 & 0.8489 & 0.8881 & 0.9104 & 0.9256 & 0.9454 & 0.9579 \\
\hline 15 & 0.8759 & 0.9173 & 0.9386 & 0.9520 & 0.9610 & 0.9721 & 0.9782 \\
\hline 20 & 0.9244 & 0.9508 & 0.9642 & 0.9723 & 0.9775 & 0.9834 & 0.9872 \\
\hline 25 & 0.9528 & 0.9997 & 0.9782 & 0.9828 & 0.9859 & 0.9899 & 0.9923 \\
\hline 30 & 0.9701 & 0.9810 & 0.9859 & 0.9890 & 0.9911 & 0.9936 & 0.9949 \\
\hline 35 & 0.9809 & 0.9876 & 0.9910 & 0.9931 & 0.9945 & 0.9959 & 0.9966 \\
\hline 40 & 0.9878 & 0.9921 & 0.9945 & 0.9950 & 0.9965 & 0.9973 & 0.9978 \\
\hline 45 & 0.9922 & 0.9951 & 0.9966 & 0.9973 & 0.9977 & 0.9983 & 0.9987 \\
\hline 50 & 0.9951 & 0.9970 & 0.9978 & 0.9983 & 0.9986 & 0.9990 & 0.9994 \\
\hline 55 & 0.9970 & 0.9982 & 0.9987 & 0.9990 & 0.9996 & 0.9996 & 0.9998 \\
\hline 60 & 0.9981 & 0.9989 & 0.9992 & 0.9995 & 0.9998 & 0.9998 & 0.9999 \\
\hline 65 & 0.9989 & 0.9994 & 0.9996 & 0.9997 & 0.9999 & 0.9999 & \\
\hline 70 & 0.9993 & 0.9996 & 0.9998 & 0.9999 & & & \\
\hline 75 & 0.9996 & 0.9998 & 0.9999 & & & & \\
\hline 80 & 0.9997 & 0.9999 & & & & & \\
\hline 85 & 0.9998 & & & & & & \\
\hline 90 & 0.9999 & & & & & & \\
\hline
\end{tabular}

(a) $\mathrm{mph} \times 1.609=\mathrm{kph}$.

(b) tons $\times 907.2=\mathrm{kg}$.

\section{Puncture}

An analysis of the puncture situation present in truck accidents is obtained from Sandia Laboratories. (1) The Sandia analysis was based on the assumption that no puncture would occur in collision accidents involving passenger autos, light stationary objects, or terrain features. The 
probability of a puncture situation given a truck accident is presented in Table 5.4 for selected package wall thicknesses. The probability of puncture given a puncture situation is 1 out of 100 . Note that the probability of collision given a truck accident is 0.802 .

\subsection{TRAIN ACCIDENT ENVIRONMENT}

Train accidents as defined by Sandia (1) include all accidents associated with the operation or movement of trains, locomotives or cars that result in railroad equipment, track or roadbed damage in excess of $\$ 750$. The accident rate selected by Sandia that will be used for this study is $6.21 \times 10^{-6}$ train accidents per train kilometer. This rate is the basis for the accident environment data and will therefore be used in this report.

As in the truck accident environment, four categories of accident stresses were considered in the train accident environment: fire, impact, crush and puncture. Other stresses, such as immersion, were not considered because of their assumed insignificant contribution to the likelihood of propane tank car failure.

TABLE 5.4. Probability of Occurrence of a Puncture Situation Given a Truck Transport Collision Accident $(T)$

Package Wall Thickness (mild steel) $(\mathrm{cm})$

$1.00(0.44$ in.)

1.27 (0.50 in.)

1.91 (0.75 in.)

2.54 ( 1.00 in.)

3.18 ( 1.25 in.)

3.81 ( 1.50 in.)

4.45 ( 1.75 in.)

5.08 (2.00 in.)
Probability of Puncture Situation Given a Collison Accident

$2.21 \times 10^{-1}$

$2.18 \times 10^{-1}$

$2.04 \times 10^{-1}$

$1.64 \times 10^{-1}$

$9.38 \times 10^{-2}$

$2.88 \times 10^{-2}$

$3.97 \times 10^{-3}$

$2.31 \times 10^{-3}$ 
Fire

Sandia's accident environment study (1) estimates the frequency of rail accidents with fire to be $2.8 \times 10^{-8}$ car fire accidents/car mile. The basic accident numbers used here however, are based on train-miles. To convert this into meaningful figures per train, we use a model train developed by Sandia, which is assumed to be made up of 66 cars (see Table 5.5). Sandia data also suggests that the average number of cars involved in any rail fire is 10 . For any train accident, then, the probability of a fire occurring is 0.0185 car-fires per train accident.

Sandia further determined that the average fire temperature is $1010^{\circ} \mathrm{C}$ $\left(1850^{\circ} \mathrm{F}\right)$. Fire durations, shown in Figure 5.3, range from minutes to hours. As in the truck accident environment, only fires that do not initially involve the cargo are considered here, since the intent is to establish the likelihood of tank failure.

Because of the fire pool sizes and the general nature of the train data used in the Sandia analysis, it was conservatively assumed that any railcar exposed to fire was totally engulfed. TABLE 5.5. Composition of Ayerage Train Used in
Sandia Studies $(1)$

\begin{tabular}{lcccc}
\multicolumn{1}{c}{$\begin{array}{c}\text { Type of } \\
\text { Car }\end{array}$} & $\begin{array}{c}\text { Number } \\
\text { Full }\end{array}$ & Other & $\begin{array}{c}\text { Number } \\
\text { Empty }\end{array}$ \\
Locomotive & & 3 & \\
Plain Boxcar & 7 & & 6 \\
Equipped Boxcar & 4 & & 3 \\
Gondola & 4 & & 3 \\
Open Hopper & 8 & & 6 \\
Covered Hopper & 4 & & 3 \\
Flat Car & 3 & & 2 \\
Refrigerator Car & 2 & & 2 \\
Tank Car & 4 & & 1 \\
Other Car & 1 & &
\end{tabular}




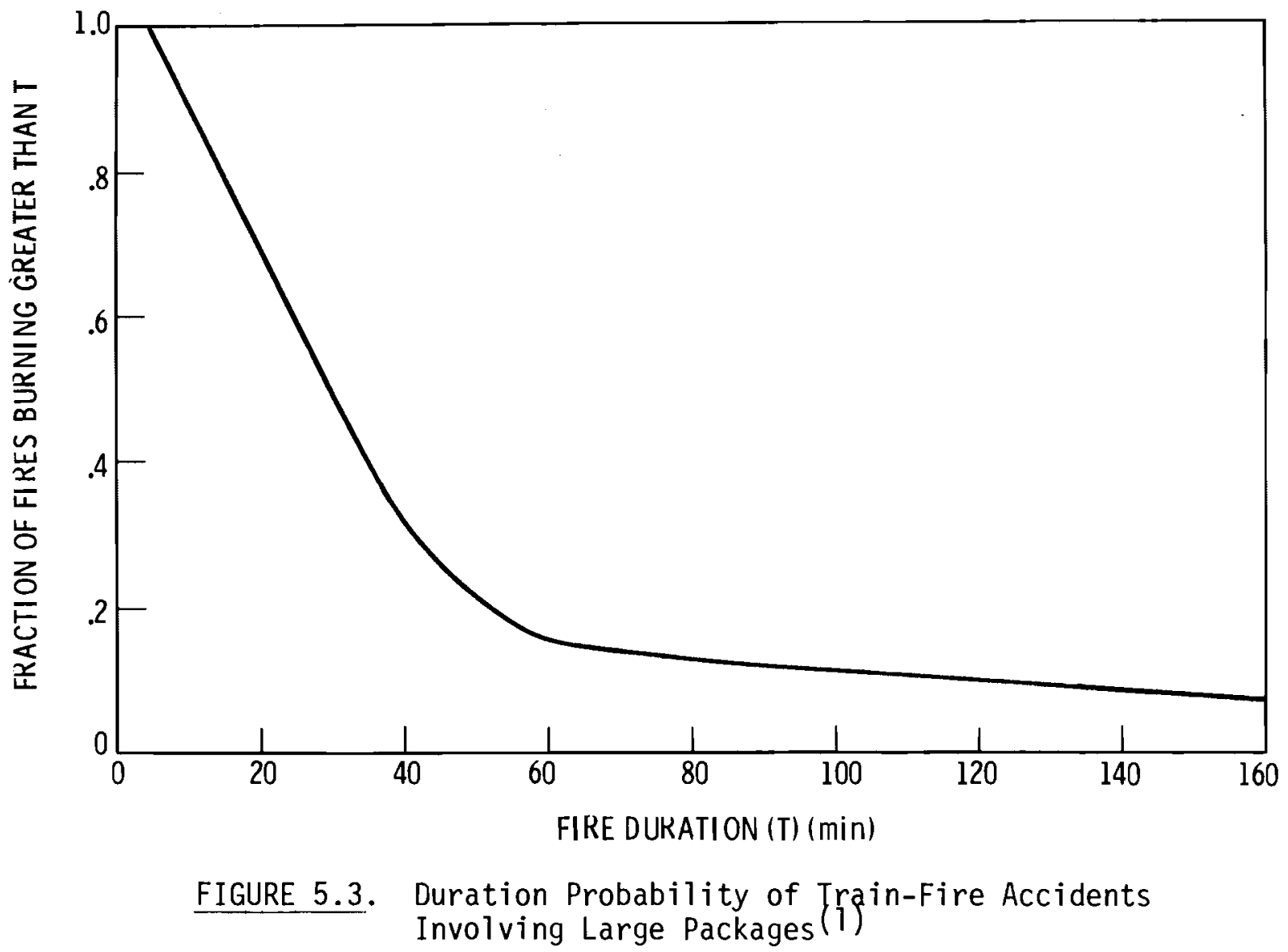

Impact

A description of the impact environment for accidents involving rail cars was obtained from information supplied by Sandia Laboratories. (1) As for the truck impact environment, existing accident data were analyzed and a cumulative distribution for the expected severity of impact forces in rail accidents was determined.

Rail cars undergo impact forces, expressed as net velocity changes, only in the event of a collision or derailment, which represent 90 percent of a11 rail accidents. Other accidents are not considered to be important in impact analysis. Impact forces on a particular tank car are produced in $15 \%$ of all collision and derailment accidents. The distribution of the expected severity of impact forces in rail accidents is shown in Figure 5.4 . 


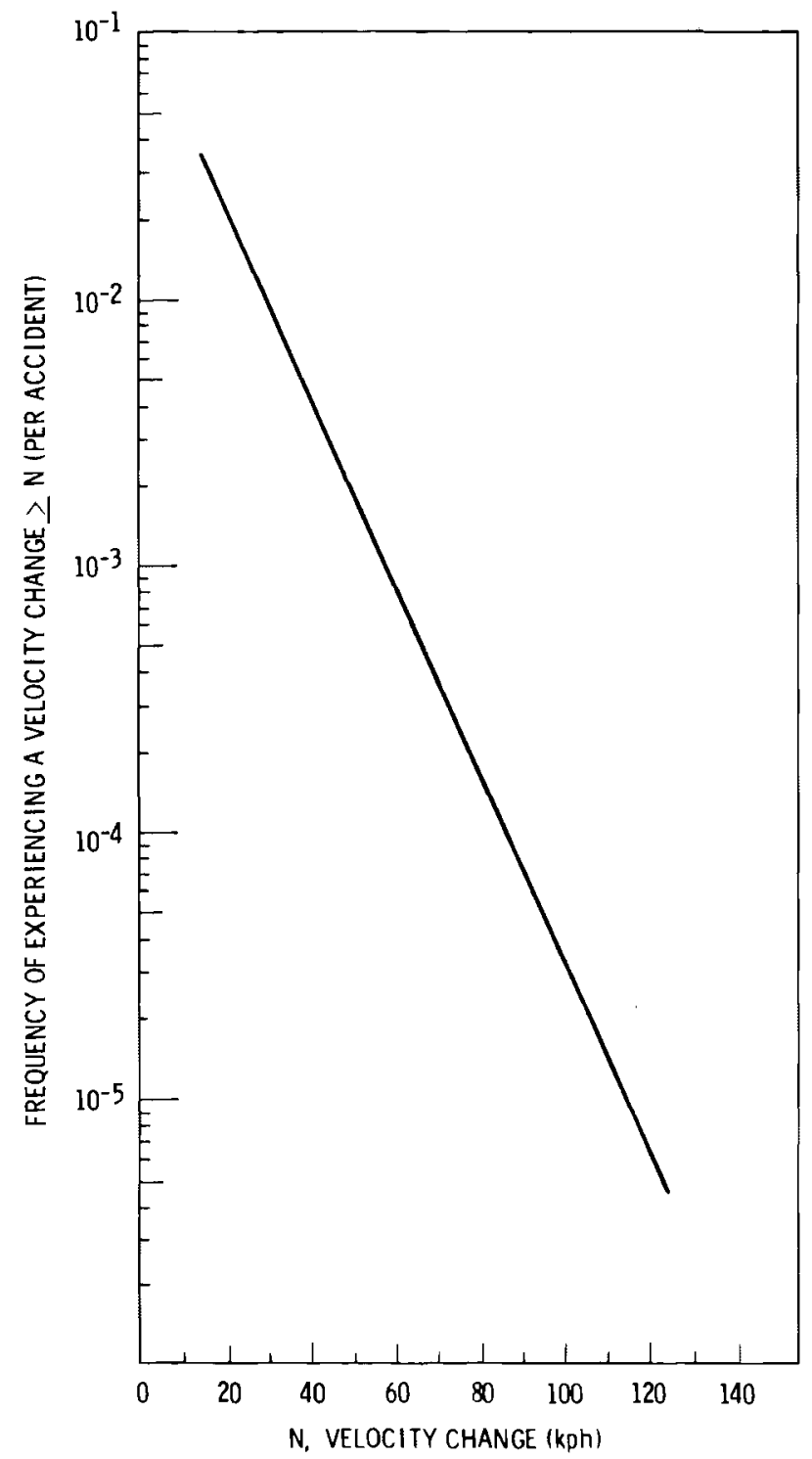

FIGURE 5.4. Cumulative Distribution of the Expected Severity of Impact Forces in Rail Accidents

\section{Crush}

Information on the crush environment in rail car accidents has been obtained from studies by Sandia Laboratories. (1) Crush is defined as the result of a package (the tank car) resting between the ground and a derailed car or locomotive. The probability of crush, given a derailment or collision accident, is about $2.0 \times 10^{-3}$ per car accident. The cumulative distribution of the expected total crush load is given in Figure 5.5. It is estimated 


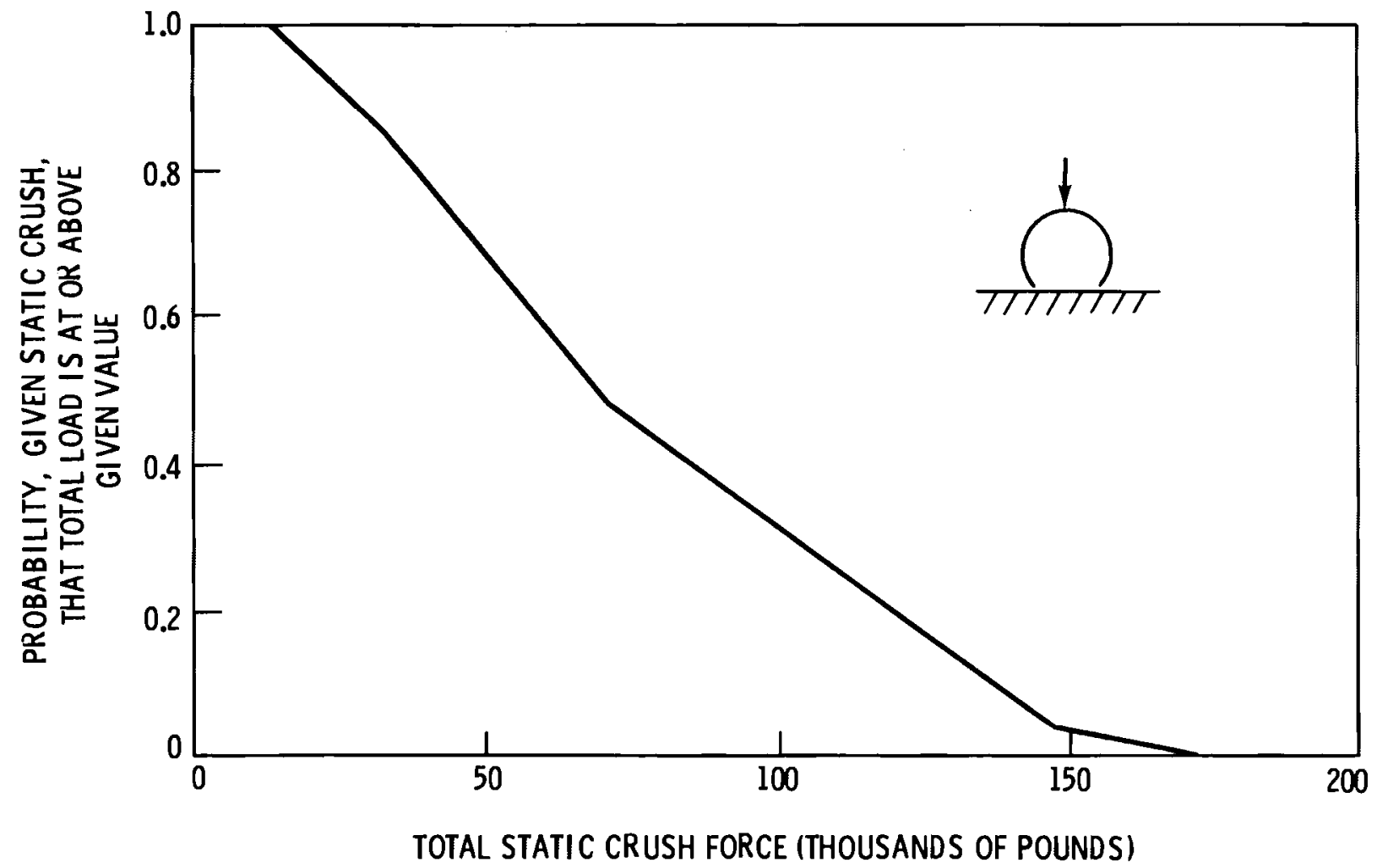

1 pound $=4.45$ Newtons

FIGURE 5.5. Cumulative Distribution of Total Crush Load $(1)$

that $25 \%$ of derailed cars overturn, subjecting themselves to crush; $75 \%$ remain upright.

\section{Puncture}

A description of the puncture environment associated with railroad tank cars was obtained from information developed by Sandia. (1) Existing accident data on tank car punctures were used to estimate the expected frequency of a puncture situation, given a train accident. Puncture probes, represented by train couplers, are assumed present in all accident situations. The rate of puncture given a puncture situation is obtained from studies done on tank cars by the American Association of Railroads. (2) That rate is estimated to be 18 percent for tank walls and 82 percent for rail tank car heads. Estimated probabilities of puncture situations are represented in Table 5.6. 
TABLE 5.6. Probability of Puncture Situation (1)

Package Wall Thickness (in.) ${ }^{(a)}$ Probability per Reportable Accident

$\begin{array}{ll}0.4375 & 7.41 \times 10^{-4} \\ 0.50 & 6.90 \times 10^{-4} \\ 0.75 & 5.85 \times 10^{-4} \\ 1.00 & 4.90 \times 10^{-4} \\ 1.25 & 4.18 \times 10^{-4} \\ 1.50 & 3.37 \times 10^{-4} \\ 1.75 & 2.43 \times 10^{-4} \\ 2.00 & 1.52 \times 10^{-4} \\ 2.50 & 3.15 \times 10^{-5} \\ 3.00 & 4.70 \times 10^{-6} \\ 4.00 & 5.54 \times 10^{-8} \\ 5.00 & 9.41 \times 10^{-12} \\ 6.00 & ---\end{array}$

(a) 1 inch $=2.54$ centimeters

\subsection{HISTORICAL RELEASES FROM PROPANE TANKS}

The data presented in this section is obtained from the Office of Hazardous Materials of the U.S. Department of Transportation (DOT). The Office of Hazardous Materials collects data on releases of hazardous materials during transportation. The data are collected on the incident report form shown in Figure 5.6. An incident report is required from interstate commerce hazardous material carriers whenever a release of material occurs from the package or transport vehicle. The reported release need not be the result of a transportation accident.

The data obtained from DOT cover a 5-year period from 1971 to 1976. The reports include releases from MC-330 and MC-331 specification tank trucks and several types of rail tank car specifications. A summary of the various causes of release for tank trucks and rail tank cars is presented in Table 5.7. 


\section{HAZARDOUS MATERIALS INCIDENT REPORT}

INSTRUCTIONS: Submit this report in duplicate to the Secretary, Hazardous Materials Regulations Board, Department of Transportation, Washington, D.C. 20590. (ATTN: Op. Div.). If space provided for any item is inadequate, complete that item under Section H, "Remarks", keying to the entry number being completed. Copies of this form, in limited quantities, may be obtained from the Secretaty. Hazardous Materials Regulations Board Additional copies in this prescribed format may be reproduced and used, if on the same size and kind of paper.

A INCIDENT

1. TYPE OF OPERATION
1 aIR 2 D HIGHWAY $3 \square$ RAIL 4 W WATER $5 \square$ FREIGHT

\begin{tabular}{l|l} 
2. DATE AND TIME OF INCIDENT (MONTh-Day-Yoar) & 3. LOCATION OF INCIDENT
\end{tabular} p.m.

B REPORTING CARRIER, COMPANY OR INDIVIDUAL

\begin{tabular}{l|l} 
4. FULL NAME & 5. ADDRESS (Number, Street, City, Stale and Zip Codo)
\end{tabular}

6. TYPE OF VEHICLE OR FACILITY

C SHIPMENT INFORMATION

\begin{tabular}{|l|l}
\hline 7. NAME AND AODRESS OF SMIPPER (Origin address) & 8. NAME AND ADDRESS OF CONSIGNEE (Deatination address)
\end{tabular}

10. SHIPPING PAPERS ISSUED BY

[] CARRIER $\square$ SHIPPER

[.] OTHER

(ldentily)

D DEATHS, INJURIES, LOSS AND DAMAGE

DUE TO HAZARDOUS MATERIALS INVOLVED

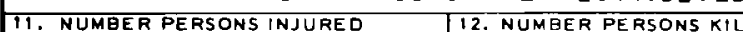

3. ESTIMATED AMOUNT OF LOSS ANDIOR PROPERTY DAMAGE INCLUDING COST

OF DECONTAMINATION (ROund Olt in

14. ESTIMATED TOTAL QUANTITY OF HAZARDOUS MA TERIALS RELEASED

dollars)

E HAZARDOUS MATERIALS INVOLVED

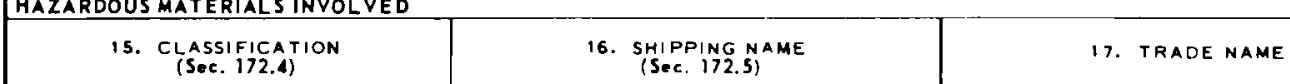

\section{F NATURE OF PACKAGING FAILURE}

18. (Check all applicable bores)

18. (Chech all applicable boxes)

\begin{tabular}{|c|c|c|}
\hline (1) DROPPED IN HANDLING & (2) EXTERNAL PUNCTURE & (3) DAMAGE BY OTHER FREIGHT \\
\hline (4) WATER DAMAGE & (5) DAMAGE FROM OTHER LIQUID & (6) FREEZING \\
\hline (7) EXTERNAL HEAT & (8) INTERNAL PRESSURE & (9) CORROSION OR RUST \\
\hline $\begin{array}{l}\text { (10) DEFECTIVE FITTINGS, } \\
\text { VALVES, OR CLOSURES }\end{array}$ & $\begin{array}{l}\text { (11) LOOSE FITTINGS, VALVES OR } \\
\text { CLOSURES }\end{array}$ & $\begin{array}{l}\text { (12) FAILURE OF INNER } \\
\text { RECEPTACLES }\end{array}$ \\
\hline (13) SOTTOM FAILURE & $(14)$ BODY OR SIDE FAILURE & (15) WELD FAILURE \\
\hline (16) CHIME FAILURE & (17) OTHER CONDITIONS (Identily) & SPACE FOR DOT USE ONLY \\
\hline
\end{tabular}

FIGURE 5.6. DOT Hazardous Materials Incident Report 


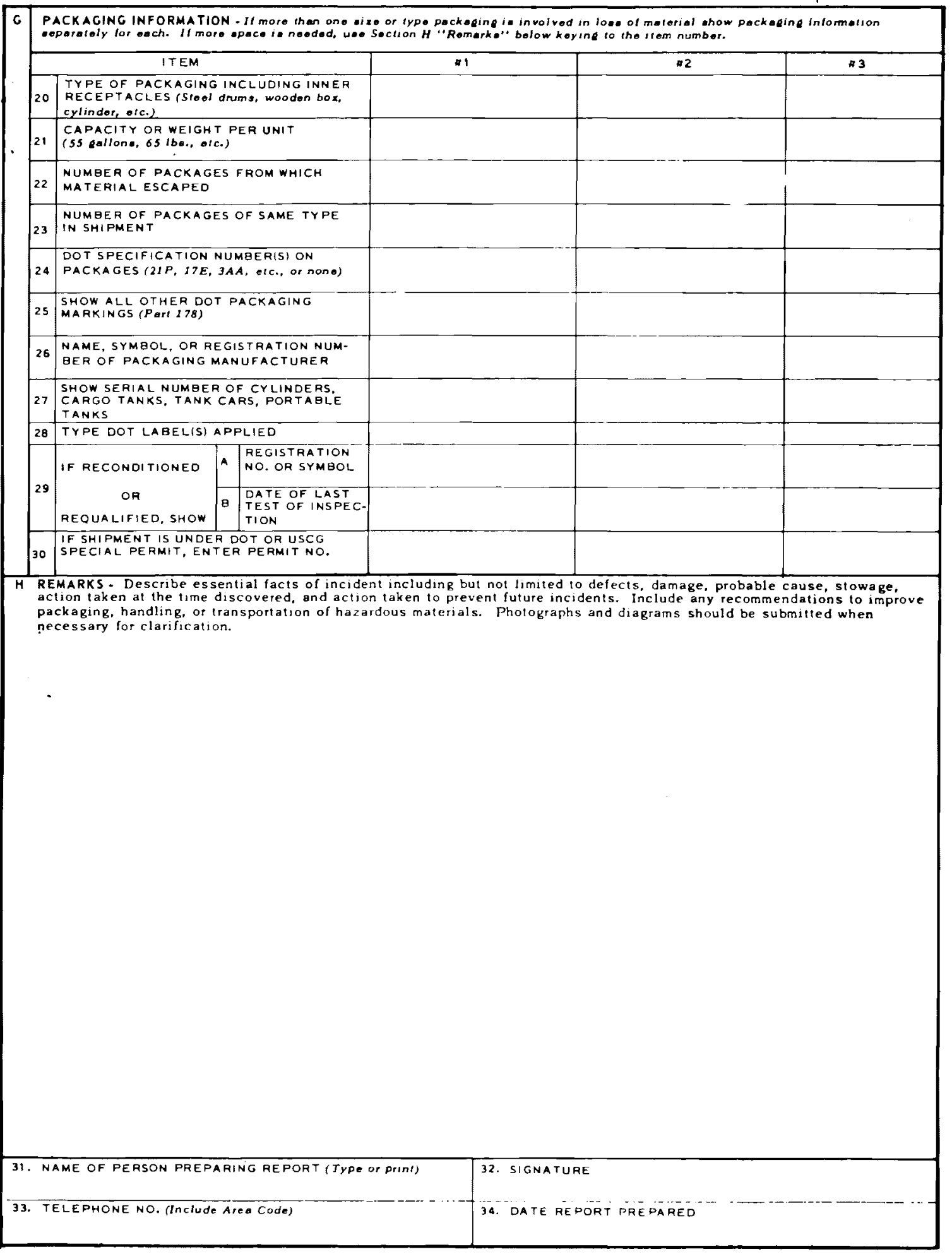

FIGURE 5.6. (contd) 
TABLE 5.7. Summary of DOT Hazardous Material Incident Reports for Propane Tank Trucks and Rail Tank Cars (1971 to 1976)

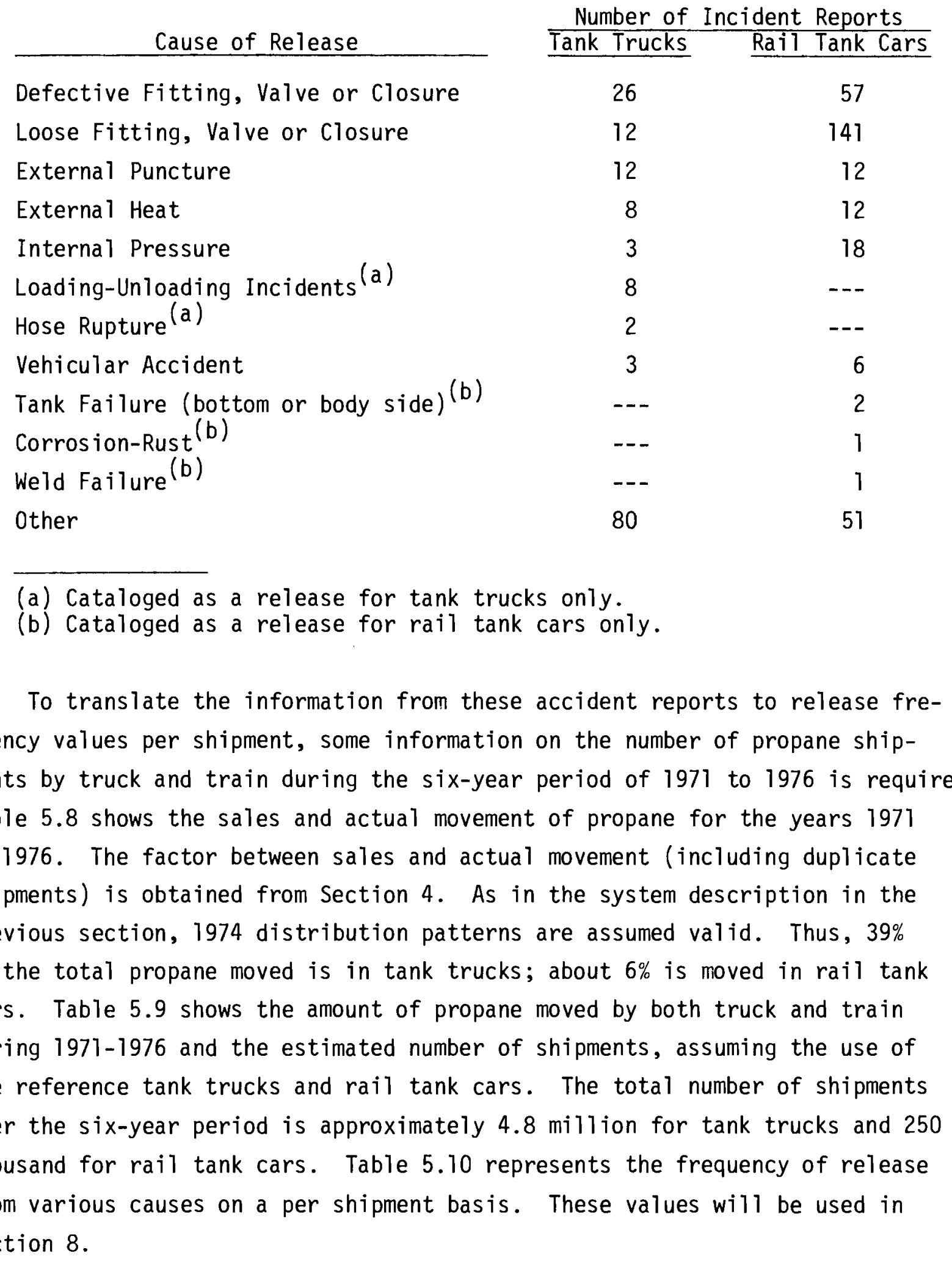


TABLE 5.8. Sales and Actual Movement of Propane Supplies in the U.S. (1971 to 1976)

Year Sales (million $\mathrm{m}^{3}$ ) Actual Movements (million $\mathrm{m}^{3}$ )

$\begin{array}{lll}1971 & 46.6 & 83.9 \\ 1972 & 52.4 & 94.3 \\ 1973 & 51.0 & 91.8 \\ 1974 & 49.8 & 89.6 \\ 1975 & 46.8 & 84.2 \\ 1976 & 50.8 & 91.4\end{array}$

SOURCE: Reference 3.

TABLE 5.9. Amount of Propane Moved by Reference Tank Truck and Rai1 Tank Car Systems and Number of Shipments (1971 to 1976)

\begin{tabular}{|c|c|c|c|c|}
\hline \multirow[b]{2}{*}{ Year } & \multicolumn{2}{|c|}{ Tank Truck } & \multicolumn{2}{|c|}{ Rail Tank Car } \\
\hline & $\begin{array}{l}\text { Propane Moved } \\
\left(\mathrm{million} \mathrm{m}^{3}\right) \\
\end{array}$ & $\begin{array}{c}\text { Number of } \\
\text { Shipments }\left(x \quad 10^{3}\right)\end{array}$ & $\begin{array}{l}\text { Propane Moved } \\
\left(\text { million } \mathrm{m}^{3}\right) \\
\end{array}$ & $\begin{array}{c}\text { Number of } \\
\text { Shipments }\left(x \quad 10^{3}\right)\end{array}$ \\
\hline 1971 & 32.7 & 745 & 5.0 & 40 \\
\hline 1972 & 36.8 & 840 & 5.7 & 45 \\
\hline 1973 & 36.0 & 820 & 5.5 & 43 \\
\hline 1974 & 35.0 & 800 & 5.4 & 42 \\
\hline 1975 & 33.0 & 750 & 5.0 & 40 \\
\hline 1976 & 35.6 & 810 & 5.5 & 43 \\
\hline Total & 210 & 4,765 & 32.0 & 250 \\
\hline
\end{tabular}


TABLE 5.10. Summary of Release Frequencies for Tank Truck and Rai1 Tank Car Shipments

Cause of Release
Defective Fitting, Valve or Closure
Loose Fitting, Valve or Closure
External Puncture
External Heat
Internal Pressure
Loading-Unloading Incidents (a)
Hose Rupture (a)
Vehicular Accident
Tank Failure (bottom or body side)
Corrosion-Rust
(b)
Weld Failure
Other

\begin{tabular}{|c|c|}
\hline Tank Truck & $\begin{array}{l}\text { Release per Shipmer } \\
\text { Rail Tank Car }\end{array}$ \\
\hline $5.46 \times 10^{-6}$ & $2.28 \times 10^{-4}$ \\
\hline $2.57 \times 10^{-6}$ & $5.64 \times 10^{-4}$ \\
\hline $2.57 \times 10^{-6}$ & $4.80 \times 10^{-5}$ \\
\hline $1.61 \times 10^{-6}$ & $4.80 \times 10^{-5}$ \\
\hline $6.43 \times 10^{-7}$ & $7.20 \times 10^{-5}$ \\
\hline $1.61 \times 10^{-6}$ & $\ldots$ \\
\hline $3.21 \times 10^{-7}$ & -- \\
\hline $6.43 \times 10^{-7}$ & $2.40 \times 10^{-5}$ \\
\hline-- & $8.40 \times 10^{-6}$ \\
\hline-- & $3.60 \times 10^{-6}$ \\
\hline-- & $3.60 \times 10^{-6}$ \\
\hline $1.67 \times 10^{-5}$ & $2.04 \times 10^{-4}$ \\
\hline
\end{tabular}

(a) Cataloged as a release for tank trucks only.

(b) Cataloged as a release for rail tank cars only.

\section{$\underline{\text { REFERENCES }}$}

1. A. W. Dennis, J. T. Foley, W. F. Hartman and D. W. Larson, Severities of Transportation Accidents Involving Large Packages. SAND 77-0001, Sandia Laboratories, ATbuquerque, New Mexico, May 1978.

2. Phase 05 Report on June 9, 1974 Accident Involving Head Shields. RA05-2-29, August 28, 1974.

3. 1976 LP-Gas Market Facts. National LP-Gas Association, Oak Brook, Illinois, 1978. 


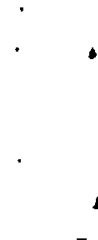




\subsection{PROPANE TANK FAILURE THRESHOLDS}

The previous section described the accident environment associated with highway and rail transport of propane in tank trucks and rail tank cars. The reference tank trucks used in this study are built to the DOT specification MC-330 or MC-331 and are described in Appendix B. A description of the DOT specification 112J340W rail car is also included in Appendix $B$. Estimates of failure thresholds for the tanks are presented in this section.

A failure threshold is the level of applied thermal or mechanical stress that results in a breach of the container and subsequent lading release in an accident. Thresholds are related to the minimum energy or vehicle velocity required to produce failure. These results must be used in conjunction with other information on the stresses to which propane tanks may be exposed to assess whether the tank will fail in the accident environment. These assessments are made in Section 8.

The package failure threshold estimates presented here were obtained using mathematical analysis and engineering estimates. Only thresholds relating to the accident environment and posing a threat to the propane tank (impact, puncture, crush and fire) were evaluated. Conservative assumptions were made as necessary to carry out the analysis. The analysis that was performed provides results that are within the overall accuracy range of the risk assessment and it is believed that they provide a conservative estimate of the system risk. The results represent estimates of failure thresholds obtained in using elastic and energy absorption theories of structure behavior. The failure estimates obtained using these methods are believed to be less than the actual strength of the container if tests to failure had been performed. The degree of conservatism is unknown. Analysis can be performed to show the sensitivity of the overall system risk to various assumptions and calculational techniques. Based on the sensitivity studies discussed in Section 10, the techniques used to estimate failure thresholds do not appear to introduce significant error into the risk assessment. The failure threshold should not, however, be used in assessing propane tank integrity for purposes other than those for which they are used in this analysis. 
Both side and end impact failure thresholds were calculated for the tank trucks and the rail tank car. Impact, as used in this analysis, is defined as a collision between the LPG tank and a rigid vertical surface. In a collision with this rigid surface, the energy of impact is absorbed by the tank structure. An energy solution method, described in detail in Appendix C, was used to find the impact failure threshold. The failure thresholds are in terms of accident velocity changes required to produce tank rupture. Defective tanks are assumed to fail at $3 / 4$ of the velocity required to fail a normal tank. Although the assumption of impact with an unyielding surface is conservative, the failure threshold results seem consistent with tank car test results.

Puncture failure thresholds are in terms of equivalent material thicknesses for the tank trucks and the rail tank cars. Crush failure thresholds are calculated as allowable stresses. The crush environment was assumed to result from an overturn, where the flat bed of the tank trailer or rail car is resting on the propane tank. The load is uniformly distributed along the length of the tank since the bed is structurally attached to the tank itself.

Fire failure thresholds are calculated in terms of fire durations required to fail a tank. There are two basic fire failure modes considered in this report for a propane tank engulfed in a fire. First, the tank car can fail because of overheating of the unwetted shell, which is the part of the tank in contact with vapor space. In this failure sequence, safety valves operate normally, opening once internal tank pressure reaches the relief valve setpoint. The valves are sufficient, in this case, to vent the tank, preventing excessive pressure buildup. However, the unwetted portion of the tank, heated by fire, becomes too weak even to sustain a normal working pressure and fails.

The second failure mode considered, although it actually occurs very rarely in accident situations, is that of overpressurization of the tank. When engulfed in a fire, the temperature of the liquid inside the tank begins to rise, increasing internal pressure. If the safety relief valves are blocked from venting the tank, are defective in a way that prevents release of lading, or are insufficiently sized to handle the required discharge of propane, the internal pressure will continue to increase until the tank fails. To determine 
the time to failure, information on the heat flux present in a $1010^{\circ} \mathrm{C}\left(1850^{\circ} \mathrm{F}\right)$ fire was required. The heat flux to an insulated tank surface was calculated to be $3.2 \mathrm{~kW} / \mathrm{m}^{2}\left(1020 \mathrm{Btu} / \mathrm{h}-\mathrm{ft}^{2}\right)$; the heat flux to an uninsulated tank is $110 \mathrm{~kW} / \mathrm{m}^{2}\left(35,700 \mathrm{Btu} / \mathrm{h}-\mathrm{ft}^{2}\right)$. The time to failure for tanks exposed to fire was calculated by using the heat input to the tank and the change in temperature of the propane that is required to reach the failure point.

Detai1s for the above analyses are presented in Appendix C. A summary of failure thresholds is presented in Table 6.1.

TABLE 6.1. Summary of Minimum Forces Required to Produce Tank Failure

Tank Truck Bobtail Transport

Rail Tank Car

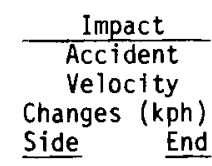

56

56

40

32

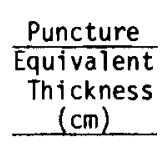

0.96

1.1

1.6 (side)

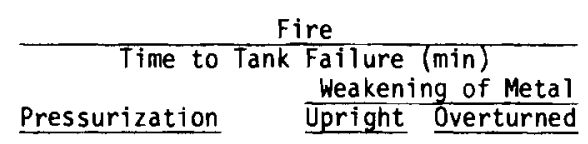

$\frac{\text { Weakening of Metal }}{\text { Upright Overturned }}$

$\begin{array}{rr}16 & 10 \\ 7 & 4 \\ 200 & 190\end{array}$

270

120

480

\begin{tabular}{c}
$\begin{array}{c}\text { Crush } \\
\text { Stress } \\
\text { Values } \\
\text { KN }\end{array}$ \\
\hline 270 \\
120 \\
480
\end{tabular}

Press 


\subsection{RELEASE SEQUENCE IDENTIFICATION}

Propane releases occur every year from tank truck or rail tank car accidents. However, the statistical information available from state and federal agencies does not provide a sufficient basis to identify the mechanisms by which these tanks failed. Possible ways that releases could occur (release sequences) must thus be identified by a reasoning process. The information presented in Sections 5 and 6 gives a basis for identifying events or combinations of events that could result in the release of propane.

This section describes a formalized procedure for identifying combinations of conditions that could result in a release. The first step in the procedure is to develop a fault tree for each transport system using the techniques described in Section 7.1. Fault trees developed for truck and train shipment of propane are presented in Section 7.2. A list of release sequences is then developed from the fault tree. The development of these sequences is discussed in Section 7.3.

\subsection{FAULT TREE CONSTRUCTION}

The fault tree analysis technique was developed in the 1960s in the aerospace industry to identify equipment design deficiencies before actual space flight. The procedure basically assumes a failure and works backwards to identify basic component failures that could cause or contribute to that failure. These failure sequences are also called cut sets. The fault tree should be related to individual components for which failure data are available. In practice, fault trees are seldom developed to that degree. Instead, the fault trees are constructed in terms of basic system modules. Such a fault tree is called a Top Level Fault Tree since it usually identifies only large systems which could result in a failure. Table 7.1 gives the various fault tree symbols and their meanings.

The methodology applied to transportation of propane involves the postulation of a release of propane during transport and the examination of the series of events that must have occurred to cause the release. This form of 


\section{TABLE 7.1. Fault Tree Symbolism}

"And" logic gate. The simultaneous occurrence of inputs

inputs

"OR" logic gate. The occurrence of any one of the inputs will result in an output.

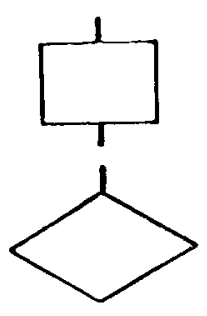

inputs

Fault event that results from the logical operation of two or more fault events. It is aliays the output from a logic gate.

Inferred fault event. Any failure except a primary failure which is not developed further due to lack of information, tire or roney or due to the low probability of occurrence. It can diso be used inere other dnalyses give sufficient inforation to indicote that further andlysis would be recuntini.

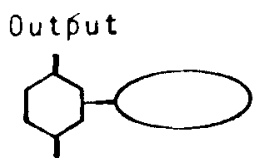

Input
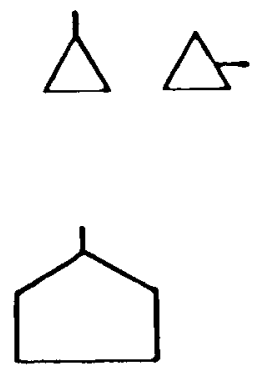

"Inhibit" gate. The condition specitied in the oval is required for an input fault cuent to result in an outiut event. This condition is frequently a design limit ...ich will not transmit a failure until the design linits tave been exceeded.

Transfer symbol denoting that failure also impacts or. other branches of fault tree. A line at the apex of the triangle represents a "transfer in." A line in the side represents a "transfer out." A number is placed in the triangle to identify transfer locations.

"House" defines an event that must occur. or is expected to occur, due to design and normal ocerating conditicns. 
reasoning is thought to be more inclusive than beginning with an initiating event and working toward a release (i.e., constructing accident scenarios or decision trees). The tree that is developed is then broken down into all the possible release sequences. In effect, all the accident scenarios will be obtained from the fault tree. When properly applied, the accident scenarios obtained from using the fault tree methodology are likely to be more complete than the alternative method of trying to list all accident scenarios without the aid of any formalized reasoning process. The tree constructed using the fault tree methodology is used as the basis for estimating the total release probability.

\subsection{FAULT TREES FOR SHIPMENT OF PROPANE BY TRUCK AND TRAIN}

The fault trees for shipment of propane by truck and train were developed for normal truck and train transport on primary highways and railways in the United States. The effects of sabotage or natural disasters on propane shipments were not included in this analysis. The analysis does not address loading and unloading accidents. It does, however, consider the combined effects of the accident environment and packaging condition.

It is assumed for this analysis that all propane shipped by truck moves in DOT specification MC-331 trucks. All rail shipments of propane are assumed to be moved in DOT specification 112J340W rail tank cars. The rationale for selecting these vehicle types and a description of the particular vehicle models used in this study are outlined in Appendix B.

The fault tree developed for shipment of propane in an MC-331 tank truck is shown in Figure 7.1 , sheets 1 through 5 . The fault tree developed for shipment of propane in a 112J340W rail tank car is shown in Figure 7.2, sheets 1 through 5 . The fault trees were drawn using the fault tree computer graphics code ACORN. ${ }^{(1)}$ The top event of each tree is the postulated release of propane to the environment during transportation. The fault trees were constructed by drawing a separate branch to analyze the failure of each type of tank component--tank walls, outlet valve and piping, safety relief valve, liquid level vent valves, and manway cover--that could release propane during 


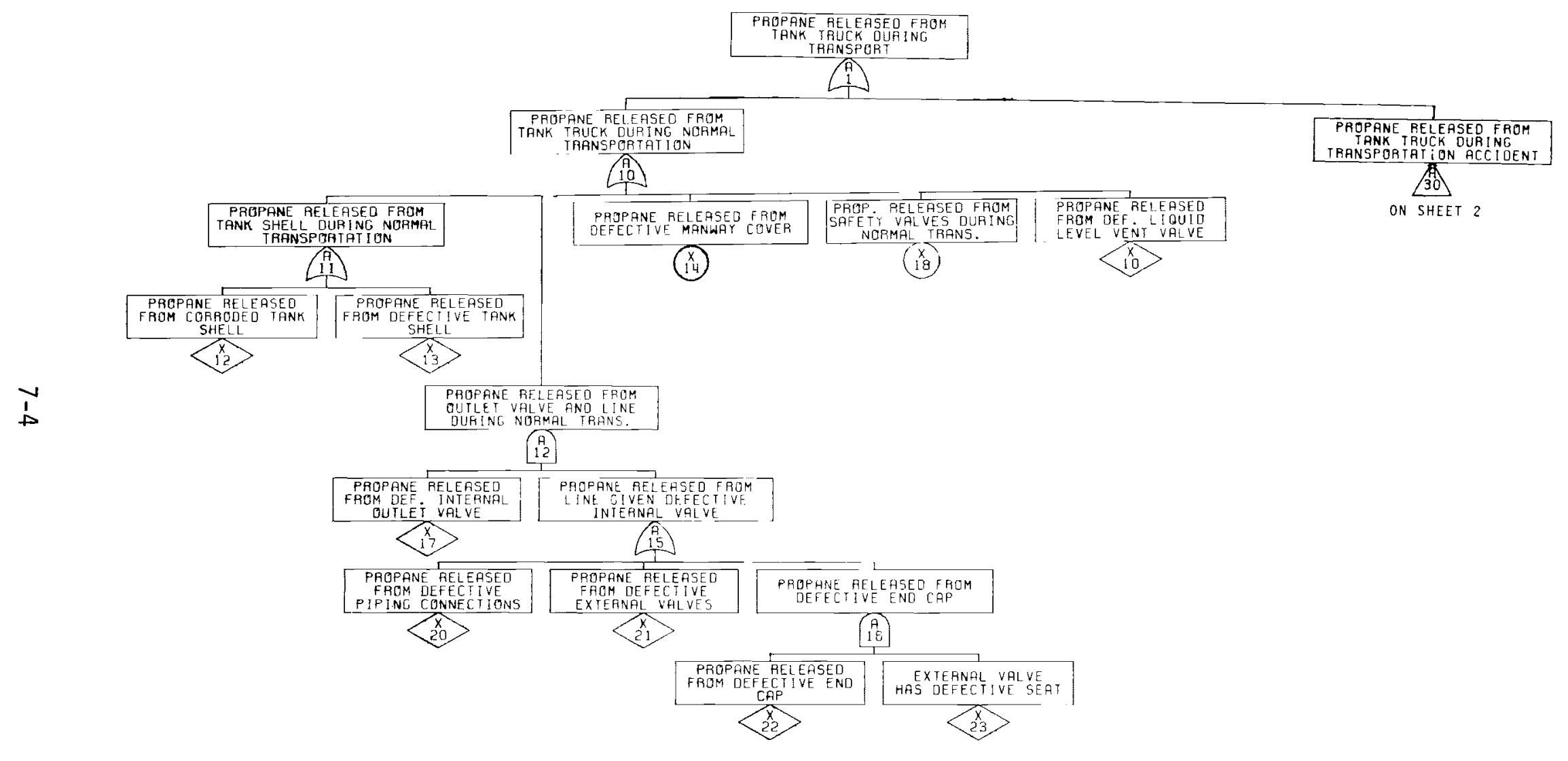

Sheet 1

FIGURE 7.1. Fault Tree for the Shipment of Propane by Truck 


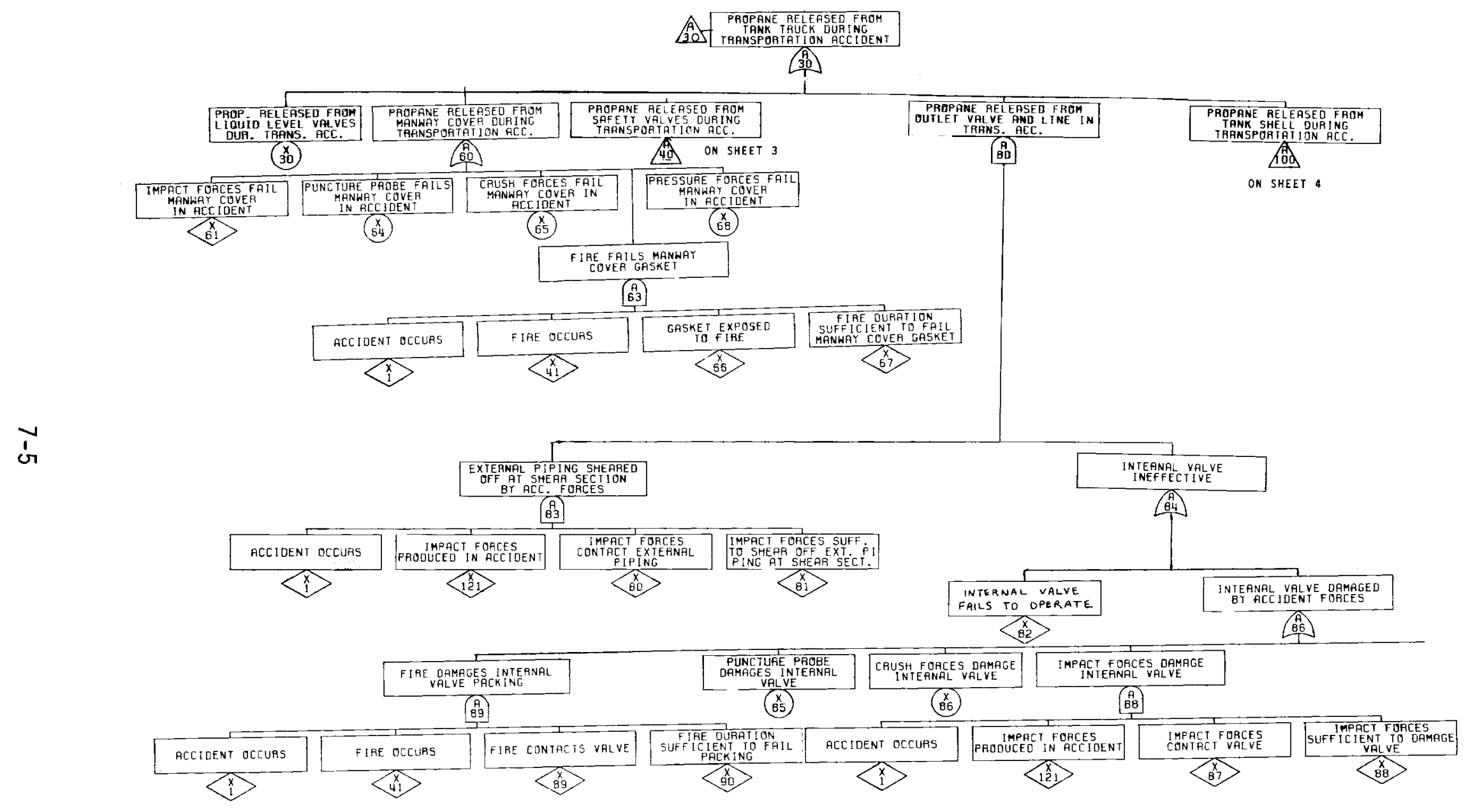

Sheet 2

FIGURE 7.1. (contd) 


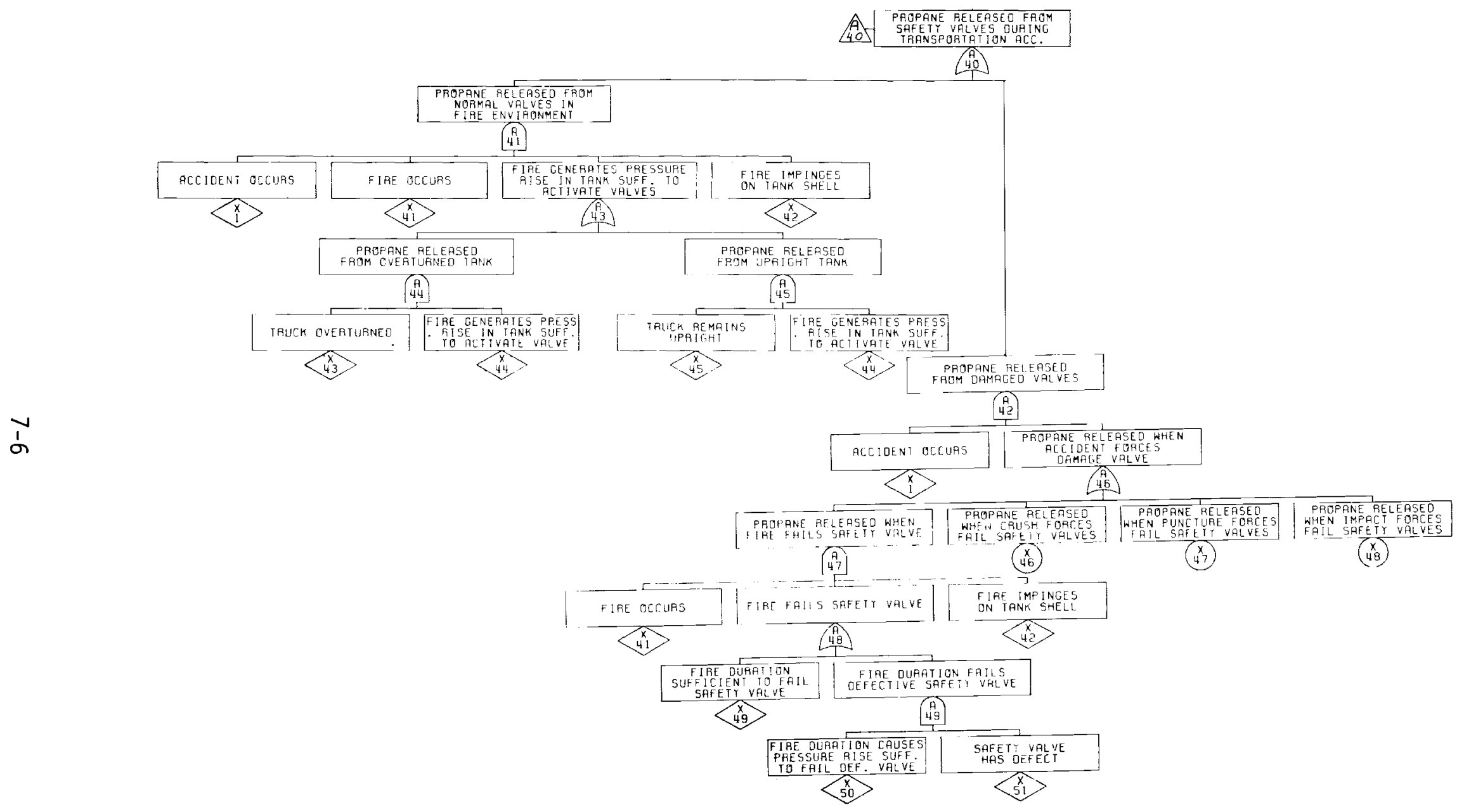

Sheet 3

FIGURE 7.1. (contd) 


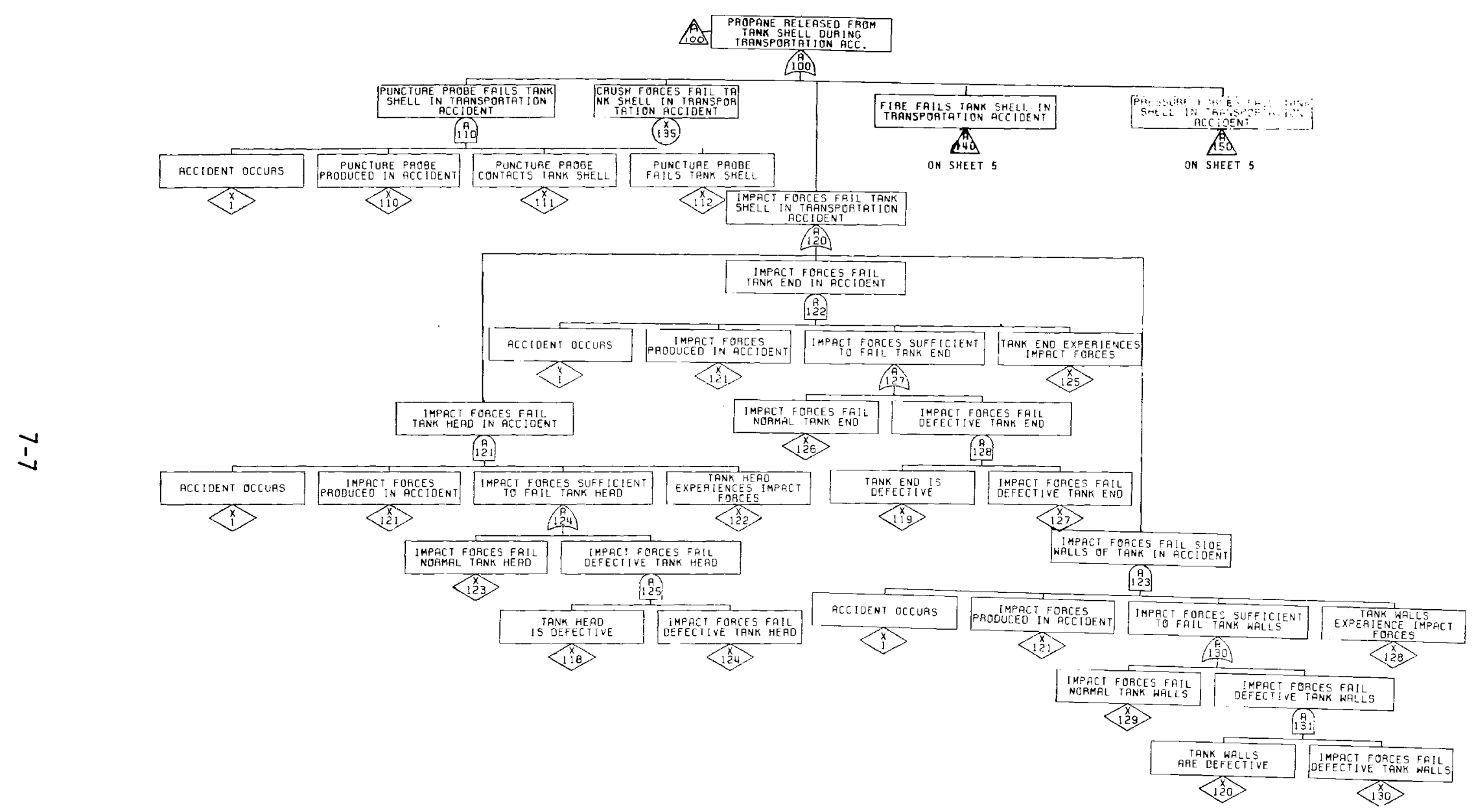

Sheet 4

FIGURE 7.1. (contd) 


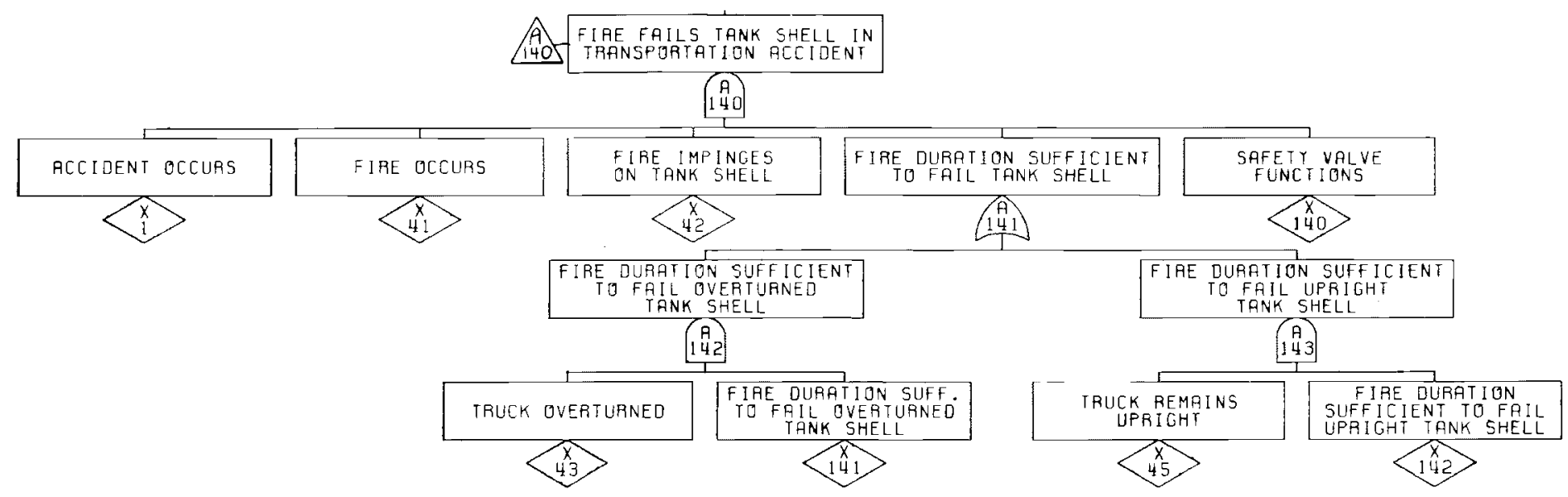

có

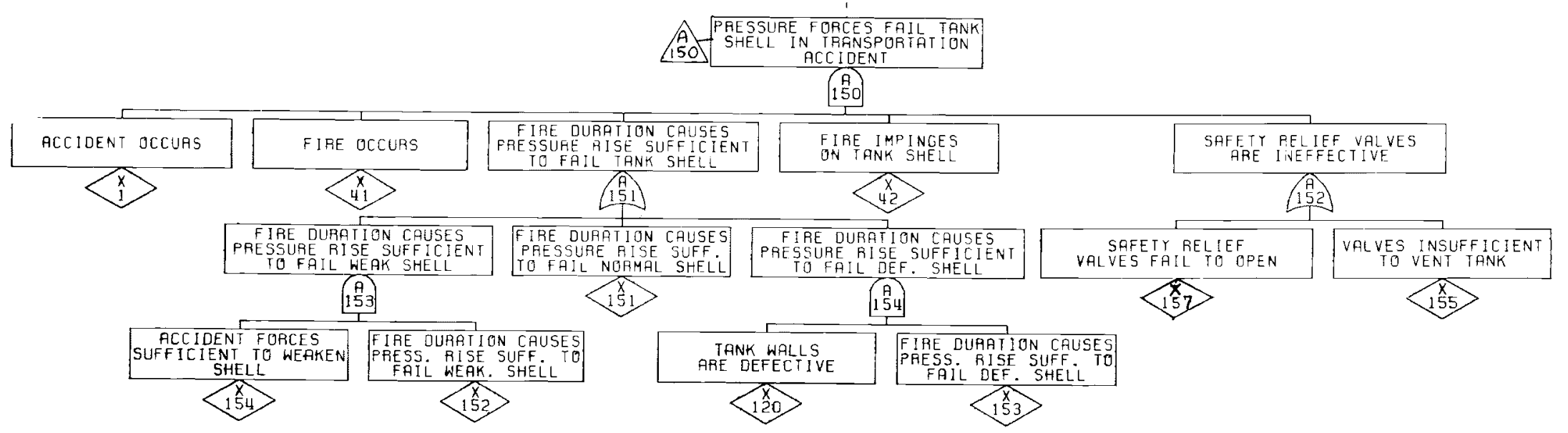

Sheet 5

FIGURE 7.1. (contd) 


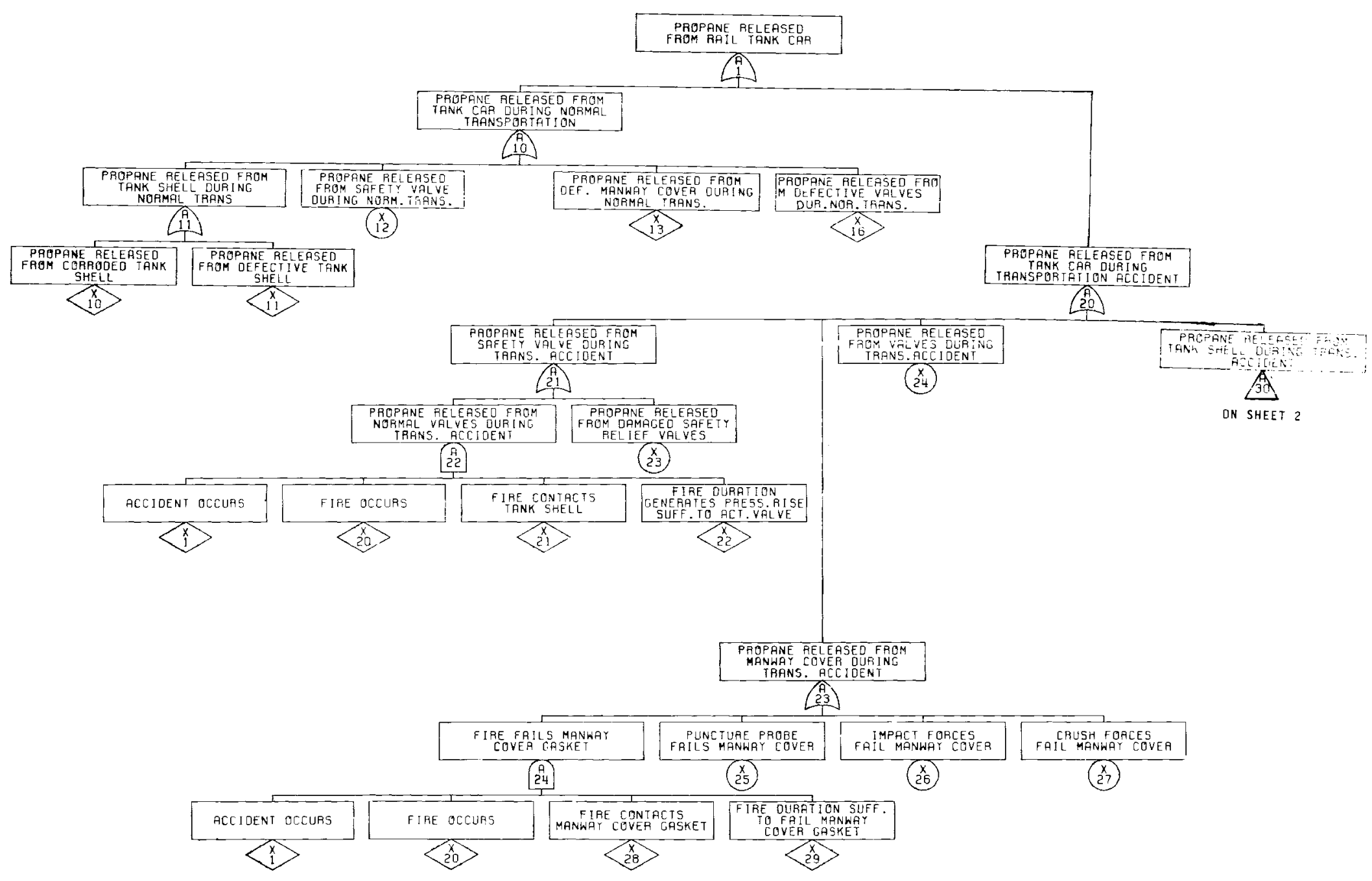

FIGURE 7.2. Fault Tree for the Transportation of Propane by Rajl Tank Car 


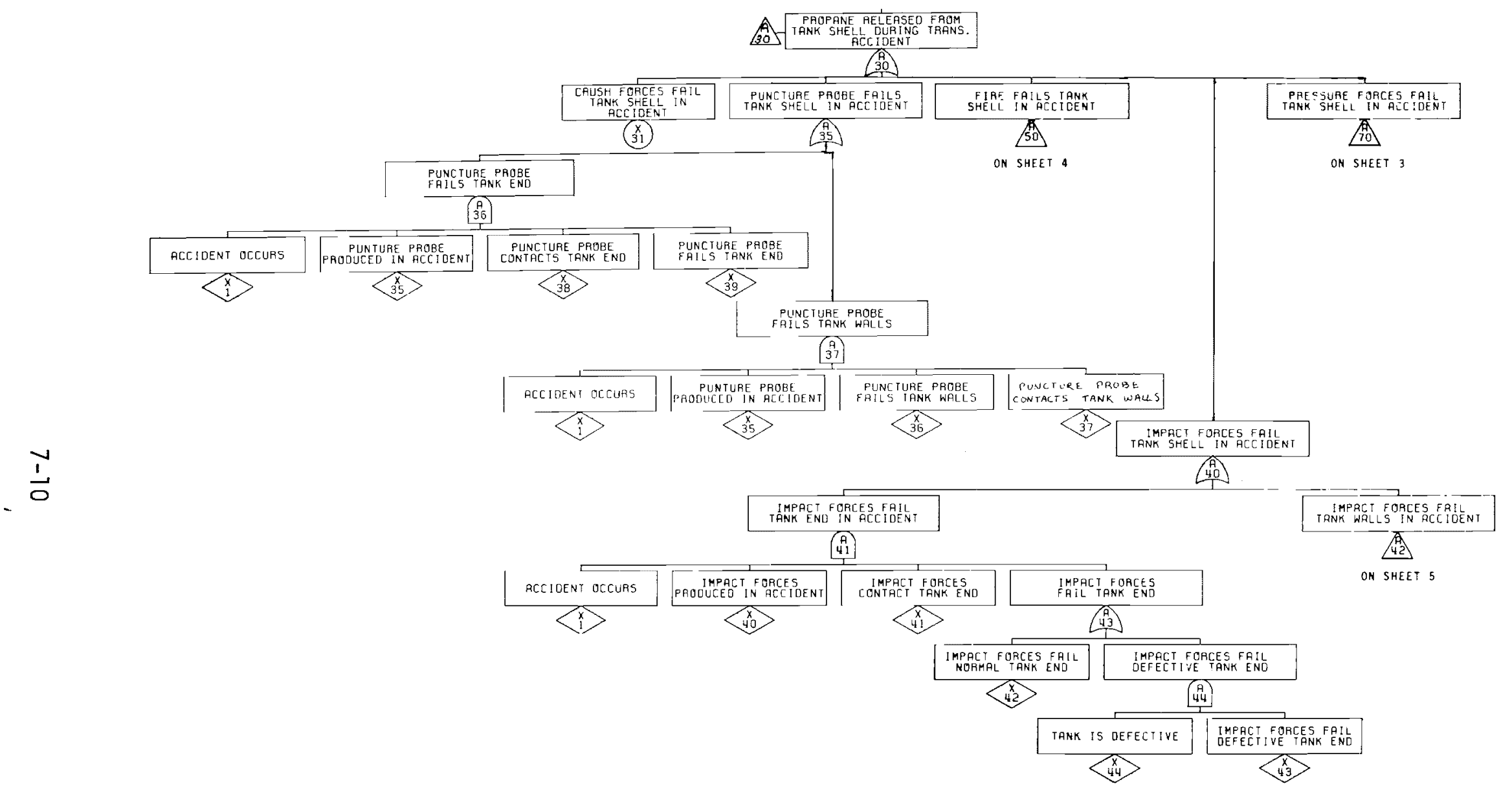

Sheet 2

FIGURE 7.2. (contd) 


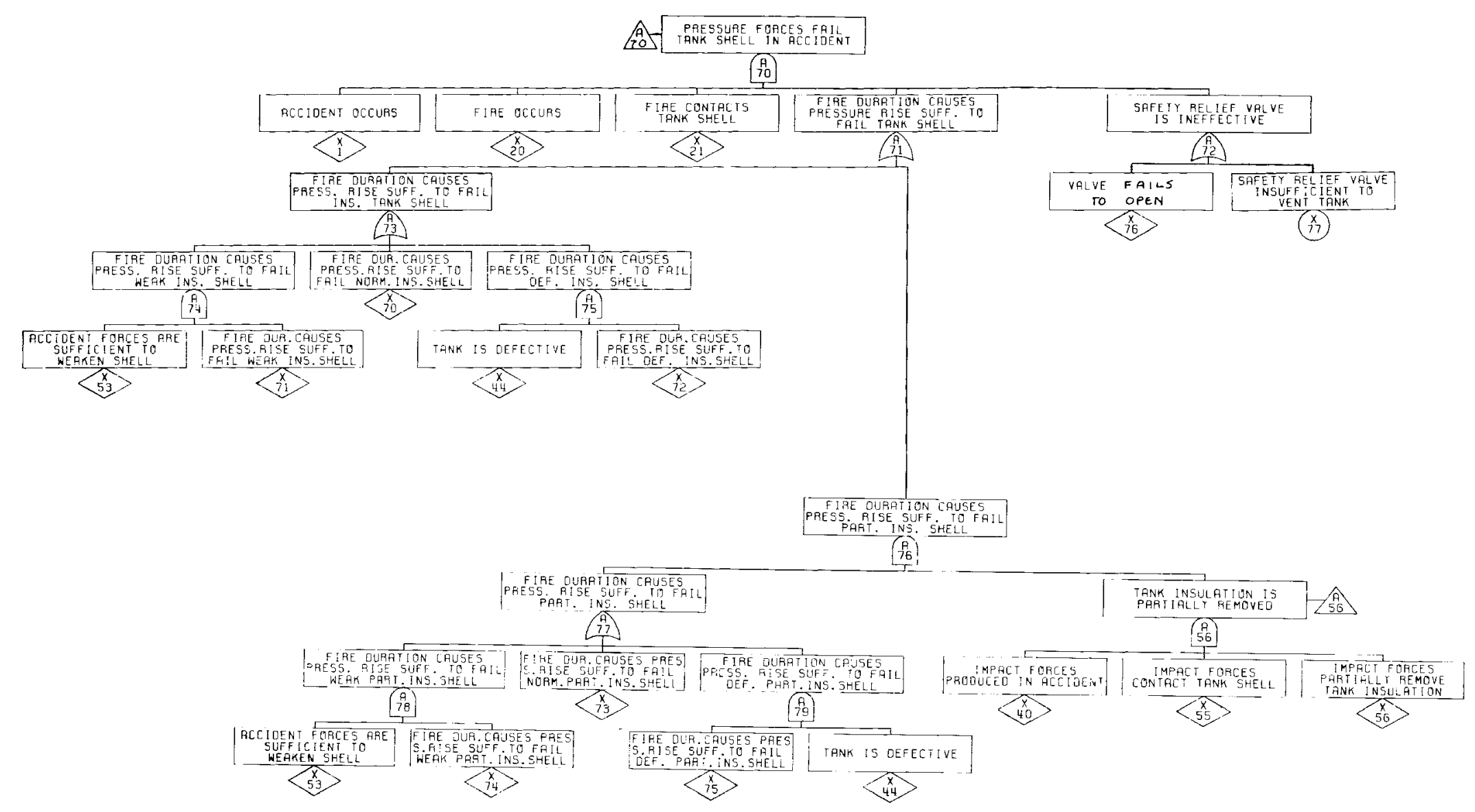

Sheet 3

FIGURE 7.2. (contd) 


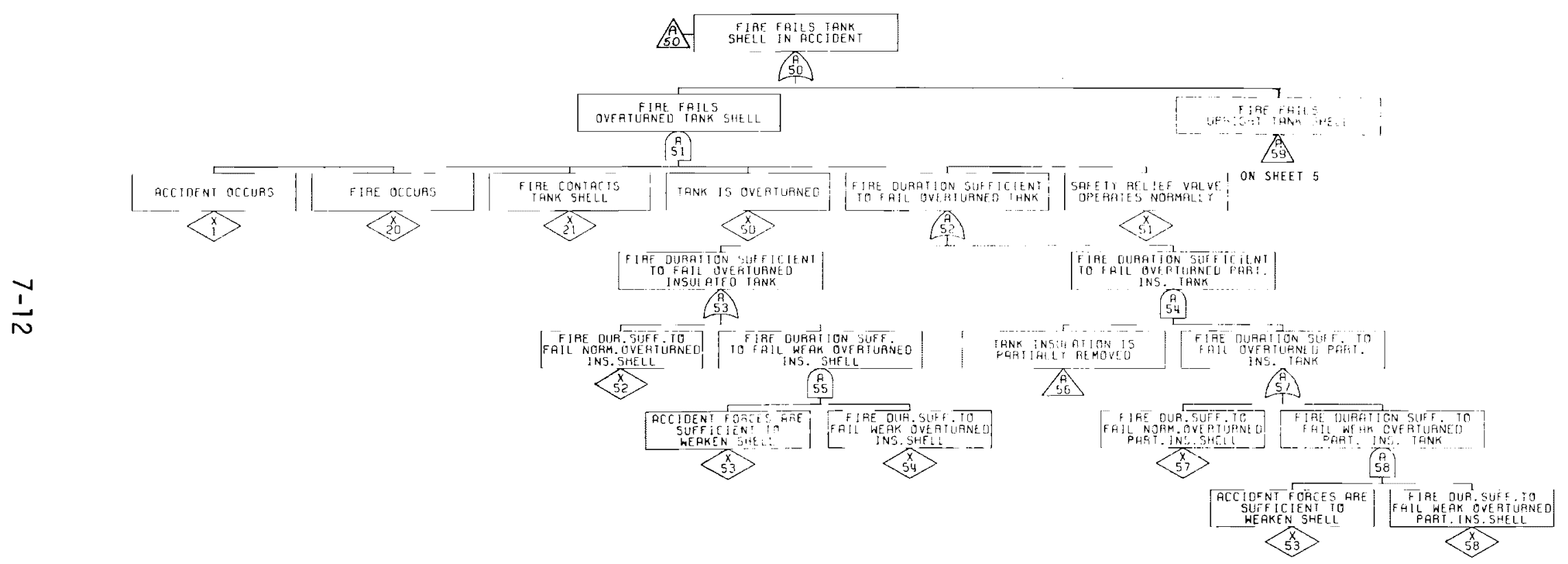

Sheet 4

FIGURE 7.2. (contd) 


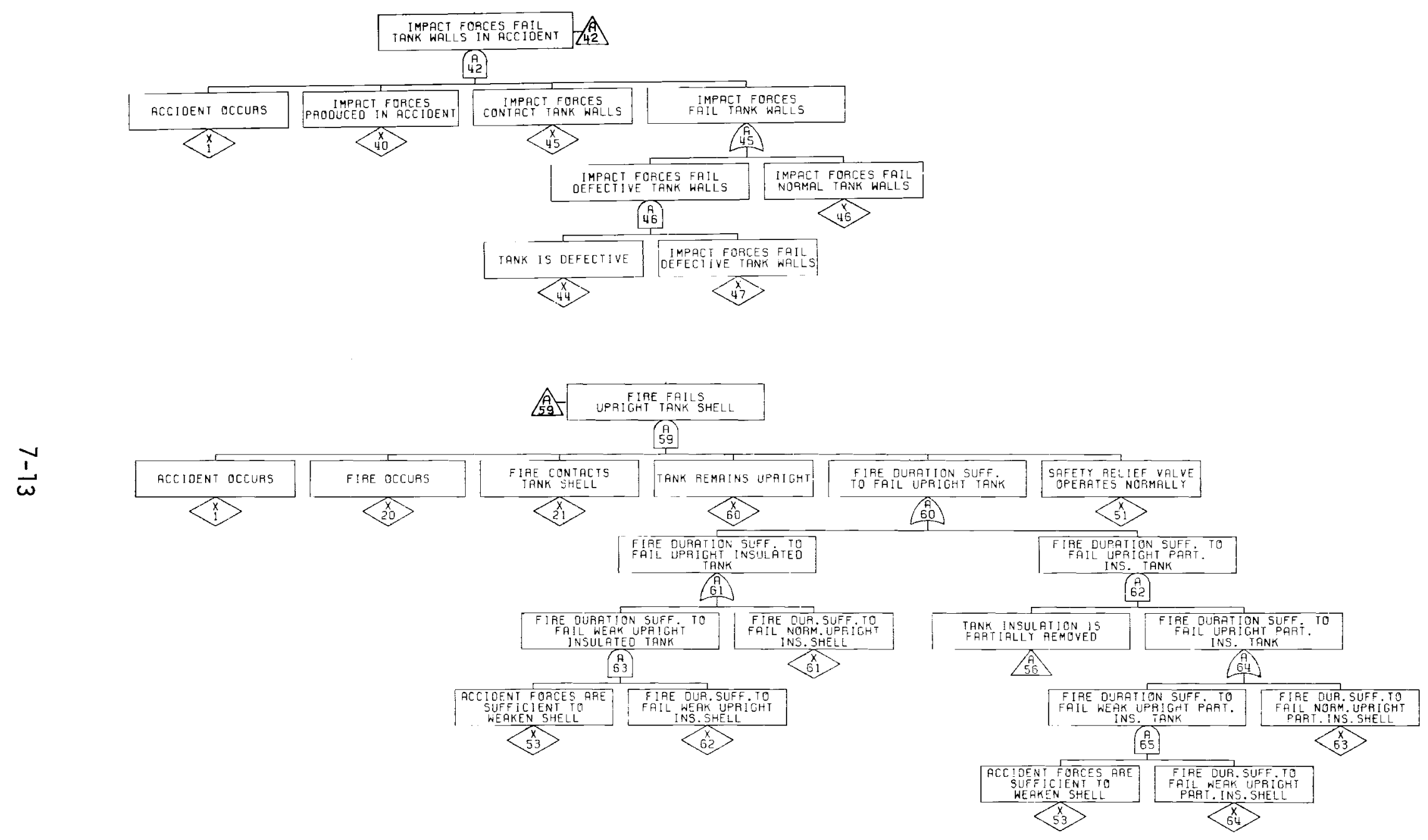

Sheet 5

FIGURE 7.2. (contd) 
normal transportation or in a transportation accident. Failure of each of these components by impact, puncture, fire (both metal weakening and pressure failures) and crush was examined. The contribution to failure of substandard component manufacture or human error in installing the components was also considered. Each of the fault tree branches for the different tank components are then further broken down to basic events that can be assigned failure probabilities. Identified events or failure elements used in the fault tree that could contribute to a release are designated in the fault tree as " $X$ " with associated numerical designations and descriptive titles. Elements that have been further developed in the fault tree are designated by "A". The list of basic " $X$ " events for the tank truck fault tree is shown in Table 7.2. The labels for the truck gate logic rectangles, or "A" elements, are presented in Table 7.3. The list of basic " $X$ " events for the rail tank car fault tree is shown in Table 7.4. The labels for the rail "A" events are shown in Table 7.5. The basic fault events in the tree designated by the circle symbol were not analyzed individually because they were found to be highly improbable occurrences or because they were included in other events. They are included in the fault tree only for completeness.

\subsection{RELEASE SEQUENCES}

The fault tree can be thought of as a compact notation for identifying and displaying large numbers of release sequences. For larger trees, it is convenient to utilize computer programs to perform the Boolean algebra that reduces the fault tree to a series of release sequences or "cut sets." The computer code MFAULT ${ }^{(2)}$ was used for this analysis.

Partial listings of the release sequences identified from the propane transportation fault trees are presented in Tables 7.6 and 7.7. Table 7.6 lists representative release sequences for tank truck transport. Table 7.7 lists the release sequences for the transport of propane by rail tank car. There are a total of over 50 possible release sequences in the fault trees. These have been screened for presentation here to eliminate those sequences that have a probability of occurrence of less than once in $10^{12}$ shipments. All of the release sequences were retained in the actual analysis. 


\section{TABLE 7.2. Listing of Basic Events for Propane Tank Truck Transportation Fault Tree}

$X \quad 1$ ACCIDENT OCCURS

$X 10$ PROPANE RELEASED FROM DEFECTIVE LIQUID LEVEL VENT VALVE

$X 12$ PROPANE RELEASED FROM CORRODED TANK SHELL

$X 13$ PROPANE RELEASED FROM DEFECTIVE TANK SHELL

$x$ i4 PROPANE RELEASED FROM DEFECTIVE MANWAY COVER

$x \quad 17$ PROPANE RELEASED FROM DEFECTIVE INTERNAL OUTLET VALVE

$X 18$ PROPANE RELEASED FROM SAFETY VALVES DURING NORMAL TRANSPORT

$X 20$ PROPANE RELEASED FROM DEFECTIVE PIPING CONNECTIONS

$X 21$ PROPANE RELEASED FROM DEFECTIVE EXTERNAL VALVES

$X 22$ PROPANE RELEASED FROM DEFECTIVE END CAP

$X 23$ EXTERNAL VALVE HAS DEFECTIVE SEAT

$X 30$ PROPANE RELEASED FROM LIQUID LEVEL VALVES DURING TRANSPORT ACCIDENT

$X 41$ FIRE OCCURS

$X 42$ FIRE IMPINGES ON TANK SHELL

$X 43$ TRUCK OVERTURNED

$X 44$ FIRE GENERATES PRESSURE RISE IN TANK SUFFICIENT TO ACTIVATE VALVES

$X 45$ TRUCK REMAINS UPRIGHT

$X 46$ PROPANE RELEASED WHEN CRUSH FORCES FAIL SAFETY VALVES

$X 47$ PROPANE RELEASED WHEN PUNCTURE FORCES FAIL SAFETY VALVES

$X 48$ PROPANE RELEASED WHEN IMPACT FORCES FAIL SAFETY VALVES

$X 49$ FIRE DURATION SUFFICIENT TO FAIL SAFETY VALVE

$X 50$ FIRE DURATION CAUSES PRESSURE RISE SUFFICIENT TO FAIL DEFECTIVE VALVES

$X 51$ SAFETY VALVE HAS DEFECT

$X 61$ IMPACT FORCES FAIL MANWAY COVER IN ACCIDENT

$X 64$ PUNCTURE PROBE FAILS MANWAY COVER IN ACCIDENT

$X 65$ CRUSH FORCES FAIL MANWAY COVER IN ACCIDENT

$X 66$ GASKET EXPOSED TO FIRE

$X 67$ FIRE DURATION SUFFICIENT TO FAIL MANWAY COVER GASKET

$X 68$ PRESSURE FORCES FAIL MANWAY COVER IN ACCIDENT

$X 80$ IMPACT FORCES CONTACT EXTERNAL PIPING

$X 81$ IMPACT FORCES SUFFICIENT TO SHEAR OFF EXTERNAL PIPING AT SHEAR SECTION

$X 82$ INTERNAL VALVE FAILS TO OPERATE

$X 85$ PUNCTURE PROBE DAMAGES INTERNAL VALVE

$X 86$ CRUSH FORCES DANAGE INTERNAL VALVE

$X 87$ IMPACT FORCES CONTACT VALVE

$X 88$ IMPACT FORCES SUFFICIENT TO DAMAGE VALVE

$X 89$ FIRE CONTACTS VALVE

$X 90$ FIRE DURATION SUFFICIENT TO FAIL PACKING

$X 110$ PUNCTURE PROBE PRODUCED IN ACCIDENT

$X 111$ PUNCTURE PROBE CONTACTS TANK SHELL

$X 112$ PUNCTURE PROBE FAILS TANK SHELL

$X 118$ TANK HEAD IS DEFECTIVE

$X 119$ TANK END IS DEFECTIVE

X120 TANK WALLS ARE DEFECTIVE

$X 121$ IMPACT FORCES PRODUCED IN ACCIDENT

$\times 122$ TANK HEAD EXPERIENCES IMPACT FORCES

$X 123$ IMPACT FORCES FAIL NORMAL TANK HEAD

$X 124$ IMPACT FORCES FAIL DEFECTIVE TANK HEAD

$X 125$ TANK END EXPERIENCES IMPACT FORCES

$X 126$ IMPACT FORCES FAIL NORMAL TANK END

$X 127$ IMPACT FORCES FAIL DEFECTIVE TANK END

$X 128$ TANK WALLS EXPERIENCE IMPACT FORCES

X129 IMPACT FORCES FAIL NORMAL TANK WALLS

$X 130$ IMPACT FORCES FAIL DEFECTIVE TANK WALLS

X135 CRUSH FORCES FAIL TANK SHELL IN TRANSPORTATION ACCIDENT

XI40 SAFETY VALVE FUNCT IONS NORMALLY

X141 FIRE DURATION SUFFICIENT TO FAIL OVERTURNED TANK SHELL

X142 FIRE DURATION SUFFICIENT TO FAIL UPRIGHT TANK SHELL

$x 151$ FIRE DURATION CAUSES PRESSURE RISE SUFFICIENT TO FAIL NORMAL SHELL

X152 FIRE DURATION CAUSES PRESSURE RISE SUFFICIENT TO FAIL WEAKENED SHELL

X153 FIRE DURATION CAUSES PRESSURE RISE SUFFICIENT TO FAIL DEFECTIVE SHELL

X154 ACCIDENT FORCES SUFFICIENT TO WEAKEN SHELL

X155 VALVES INSUFFICIENT TO VENT TANK

X157 VALVES FAIL TO OPEN 
TABLE 7.3. Listing of Gate Logic Rectangle Labels for Propane Tank Truck Transportation Fault Tree

A 1 PROPANE RELEASED FROM TANK TRUCK DURING TRANSPORT

A 10 PROPANE RELEASED FROM TANK TRUCK DURING NORMAL TRANSPORTATION

A 11 PROPANE RELEASED FROM TANK SHELL DURING NORMAL TRANSPORTATION

A 12 PROPANE RELEASED FROM OUTLET VALVE AND LINE DURING NORMAL TRANSPORT

A 13 PROPANE RELEASED FROM DEFECTIVE MANWAY COVER

A 15 PROPANE RELEASED FROM LINE GIVEN DEFECTIVE INTERNAL VALVE

A 16 PROPANE RELEASED FROM DEFECTIVE END CAP

A 30 PROPANE RELEASED FROM TANK TRUCK DURING TRANSPORTATION ACCIDENT

A 40 PROPANE RELEASED FROM SAFETY VALVES DURING TRANSPORTATION ACCIDENT

A 41 PROPANE RELEASED FROM NORMAL VALVES IN FIRE ENVIRONMENT

A 42 PROPANE RELEASED FROM DAMAGED VALVES

A 43 FIRE GENERATES PRESSURE RISE IN TANK SUFFICIENT TO ACTIVATE VALVES

A 44 PROPANE RELEASED FROM OVERTURNED TANK

A 45 PROPANE RELEASED FROM UPRIGHT TANK

A 46 PROPANE RELEASED WHEN ACCIDENT FORCES DAMAGE VALVE

A 47 PROPANE RELEASED WHEN FIRE FAILS SAFETY VALVE

A 48 FIRE FAILS SAFETY VALVE

A 49 FIRE DURATION FAILS DEFECTIVE SAFETY VALVE

A 60 PROPANE RELEASED FROM MANWAY COVER DURING TRANSPORTATION ACCIDENT

A 63 FIRE FAILS MANWAY COVER GASKET

A 80 PROPANE RELEASED FROM OUTLET VALVE AND LINE IN TRANSPORTATION ACCIDENT

A 83 EXTERNAL PIPING SHEARED OFF AT SHEAR SECTION BY ACCIDENT FORCES

A 84 INTERNAL VALVE INEFFECTIVE

A 86 INTERNAL VALVE DAMAGED BY ACCIDENT FORCES

A 88 IMPACT FORCES DAMAGE INTERNAL VALVE

A 89 FIRE DAMAGES INTERNAL VALVE PACKING

A100 PROPANE RELEASED FROM TANK SHELL DURING TRANSPORTAITON ACCIDENT

A110 PUNCTURE PROBE FAILS TANK SHELL IN TRANSPORTATION ACCIDENT

A120 IMPACT FORCES FAIL TANK SHELL IN TRANSPORTATION ACCIDENT

A121 IMPACT FORCES FAIL TANK HEAD IN ACCIDENT

A122 IMPACT FORCES FAIL TANK END IN ACCIDENT

A123 IMPACT FORCES FAIL SIDE WALLS OF TANK IN ACCIDENT

A124 IMPACT FORCES SUFFICIENT TO FAIL TANK HEAD

A125 IMPACT FORCES FAIL DEFECTIVE TANK HEAD

A127 IMPACT FORCES SUFFICIENT TO FAIL TANK END

A128 IMPACT FORCES FAIL DEFECTIVE TANK END

A130 IMPACT FORCES SUFFICIENT TO FAIL TANK WALLS

A131 IMPACT FORCES FAIL DEFECTIVE TANK WALLS

A140 FIRE FAILS TANK SHELL IN TRANSPORTATION ACCIDENT

A141. FIRE DURATION SUFFICIENT TO FAIL TANK SHELL

A142 FIRE DURATION SUFFICIENT TO FAIL OVERTURNED TANK SHELL

A143 FIRE DURATION SUFFICIENT TO FAIL UPRIGHT TANK SHELL

A150 PRESSURE FORCES FAIL TANK SHELL IN TRANSPORTATION ACCIDENT

A151 FIRE DURATION CAUSES PRESSURE RISE SUFFICIENT TO FAIL TANK SHELL

A152 SAFETY RELIEF VALVES ARE INEFFECTIVE

A153 FIRE DURATION CAUSES PRESSURE RISE SUFFICIENT TO FAIL WEAK SHELL

A154 FIRE DURATION CAUSES PRESSURE RISE SUFFICIENT TO FAIL DEFECTIVE SHELL

A155 SAFETY RELIEF VALVES FAIL TO OPEN

A156 SAFETY VALVE IS DEFECTIVE 


\section{TABLE 7.4. Listing of Basic Events for Propane Rail Tank Car Transportation Fault Tree}

$X 1$ ACCIDENT OCCURS

X10 PROPANE RELEASED FROM CORRODED TANK SHELL

$X 11$ PROPANE RELEASED FROM DEFECTIVE TANK SHELL

X12 PROPANE RELEASED FROM SAFETY VALVES DURING NORMAL TRANSPORT

X13 PROPANE RELEASED FROM DEFECTIVE MANWAY COVER DURING NORMAL TRANSPORT PROPANE RELEASED FROM DEFECTIVE VALVES DURING NORMAL TRANSPORT

X20 FIRE OCCURS

X21 FIRE CONTACTS TANK SHELL FIRE DURATION GENERATES PRESSURE RISE SUFFICIENT TO ACTIVATE VALVE PROPANE RELEASED FROM DAMAGED SAFETY RELIEF VALVES PROPANE RELEASED FROM VALVES DURING TRANSPORTATION ACCIDENT PUNCTURE PROBE FAILS MANWAY COVER IMPACT FORCES FAIL MANWAY COVER CRUSH FORCES FAIL MANWAY COVER FIRE CONTACTS MANWAY COVER GASKET FIRE DURATION SUFFICIENT TO FAIL MANWAY COVER GASKET CRUSH FORCES FAIL TANK SHELL IN ACCIDENT PUNCTURE PROBE PRODUCED IN ACCIDENT PUNCTURE PROBE FAILS TANK WALLS PUNCTURE PROBE CONTACTS TANK WALLS PUNCTURE PROBE CONTACTS TANK END PUNCTURE PROBE FAILS TANK END IMPACT FORCES PRODUCED IN ACCIDENT IMPACT FORCES CONTACT TANK END IMPACT FORCES FAIL NORMAL TANK END IMPACT FORCES FAIL DEFECTIVE TANK END TANK IS DEFECTIVE IMPACT FORCES CONTACT TANK WALLS IMPACT FORCES FAIL NORMAL TANK WALLS IMPACT FORCES FAIL DEFECTIVE TANK WALLS TANK IS OVERTURNED SAFETY REL IEF VALVE OPERATES NORMALLY

X52 FIRE DURATION SUFFICIENT TO FAIL NORMAL OVERTURNED INSULATED SHELL ACCIDENT FORCES ARE SUFFICIENT TO WEAKEN SHELL FIRE DURATION SUFFICIENT TO FAIL WEAK OVERTURNED INSULATED SHELL IMPACT FORCES CONTACT TANK SHELL IMPACT FORCES PART IALLY REMOVE TANK INSULATION FIRE DURATION SUFFICIENT TO FAIL NORMAL OVERTURNED PARTIALLY INSULATED SHELL FIRE DURATION SUFFICIENT TO FAIL WEAK OVERTURNED PARTIALLY INSULATED SHELL TANK REMAINS UPRIGHT FIRE DURATION SUFFICIENT TO FAIL NORMAL UPRIGHT INSULATED SHELL FIRE DURATION SUFFICIENT TO FAIL WEAK UPRIGHT INSULATED SHELL FIRE DURATION SUFFICIENT TO FAIL NORMAL UPRIGHT PARTIALLY INSULATED SHELL FIRE DURATION SUFFICIENT TO FAIL WEAK UPRIGHT PART IALLY INSULATED SHELL FIRE DURATION CAUSES PRESSURE RISE SUFFICIENT TO FAIL NORMAL INSULATED SHELL FIRE DURATION CAUSES PRESSURE RISE SUFFICIENT TO FAIL WEAK INSSULATED SHELL FIRE DURATION CAUSES PRESSURE RISE SUFFICIENT TO FAIL DEFECTIVE INSULATED SHELL FIRE DURATION CAUSES PRESSURE RISE SUFFICIENT TO FAIL NORMAL PARTIALLY INSULATED SHELL FIRE DURATION CAUSES PRESSURE RISE SUFFICIENT TO FAIL WEAK PARTIALLY INSULATED SHELL FIRE DURATION CAUSES PRESSURE RISE SUFFICIENT TO FAIL DEFECTIVE PARTIALLY INSULATED SHELL VALVE FAILS TO OPEN

X77 SAFETY RELIEF VALVE INSUFFICIENT TO VENT TANK 


\section{TABLE 7.5. Listing of Gate Logic Rectangle Labels for Propane}

Rail Tank Car Transportation Fault Tree

A 1 PROPANE RELEASED FROM RAIL TANK CAR

A10 PROPANE RELEASED FROM TANK CAR DURING NORMAL TRANSPORTATION

A11 PROPANE RELEASED FROM TANK SHELL DURING NORMAL TRANSPORTION

A12 PROPANE RELEASED FROM DEFECTIVE MANWAY COVER DURING NORMAL TRANSPORTATION

A20 PROPANE RELEASED FROM TANK CAR DURING TRANSPORTATION ACCIDENT

A21 PROPANE RELEASED FROM SAFETY VALVE DURING TRANSPORTATION ACCIDENT

A22 PROPANE RELEASED FROM NORMAL VALVES DURING TRANSPORTATION ACCIDENT

A23 PROPANE RELEASED FROM MANWAY COVER DURING TRANSPORTATION ACCIDENT

A24 FIRE FAILS MANWAY COVER GASKET

A30 PROPANE RELEASED FROM TANK SHELL DURING TRANSPORTATION ACCIDENT

A35 PUNCTURE PROBE FAILS TANK SHELL IN ACCIDENT

A36 PUNCTURE PROBE FAILS TANK END

A37 PUNCTURE PROBE FAILS TANK WALLS

A40 IMPACT FORCES FAIL TANK SHELL IN ACCIDENT

A41 IMPACT FORCES FAIL TANK END IN ACCIDENT

A42 IMAPCT FORCES FAIL TANK WALLS IN ACCIDENT

A43 IMPACT FORCES FAIL TANK END

A44 IMPACT FORCES FAIL DEFECTIVE TANK END

A45 IMPACT FORCES FAIL TANK WALLS

A46 IMPACT FORCES FAIL DEFECT IVE TANK WALLS

A50 FIRE FAILS TANK SHELL IN ACCIDENT

A51 FIRE FAILS OVERTURNED TANK SHELL

A52 FIRE DURATION SUFFICIENT TO FAIL OVERTURNED TANK

A53 FIRE DURATION SUFFICIENT TO FAIL OVERTURNED INSULATED TANK

A54 FIRE DURATION SUFFICIENT TO FAIL OVERTURNED PARTIALLY INSULATED TANK

A55 FIRE DURATION SUFFICIENT TO FAIL WEAK OVERTURNED INSULATED SHELL

A56 TANK INSULATION IS PARTIALLY REMOVED

A57 FIRE DURATION SUFFICIENT TO FAIL OVERTURNED PARTIALLY INSULATED TANK

A58 FIRE DURATION SUFFICIENT TO FAIL WEAK OVERTURNED PARTIALLY INSULATED TANK

A59 FIRE. FAILS UPRIGHT TANK SHELL

A60 FIRE DURATION SUFFICIENT TO FAIL UPRIGHT TANK

A61 FIRE DURATION SUFFICIENT TO FAIL UPRIGHT INSULATED TANK

A62 FIRE DURATION SUFFICIENT TO FAIL UPRIGHT PARTIALLY INSULATED TANK

A63 FIRE DURATION SUFFICIENT TO FAIL WEAK UPRIGHT INSULATED TANK

A64 FIRE DURATION SUFFICIENT TO FAIL UPRIGHT PARTIALI.Y INSLLLATED TINHK

A65 FIRE DURATION SUFFICIENT TO FAIL WEAK UPRIGHT PARTIALLY INSULATED TANK

A70 PRESSURE FORCES FAIL TANK SHELL IN ACCIDENT

A71 FIRE DURATION CAUSES PRESSURE RISE SUFFICIENT TO FAIL TANK SHELL

A72 SAFETY RELIEF VALVE IS INEFFECTIVE

A73 FIRE DURATION CAUSES PRESSURE RISE SUFFICIENT TO FAIL INSULATED TANK SHELL

A74 FIRE DURATION CAUSES PRESSURE RISE SUFFICIENT TO FAIL WEAK INSULATED TANK SHELL

A75 FIRE DURATION CAUSES PRESSURE RISE SUFFICIENT TO FAIL DEFECTIVE INSULATED SHELL

A76 FIRE DURATION CAUSES PRESSURE RISE SUFFICIENT TO FAIL PARTIALLY INSULATED SHELL

A77 FIRE DURATION CAUSES PRESSURE RISE SUFFICIENT TO FAIL PARTIALLY INSULATED SHELL

A78 FIRE DURATION CAUSES PRESSURE RISE SUFFICIENT TO FAIL WEAK PARTIALLY INSULATED SHELL

A79 FIRE DURATION CAUSES PRESSURE RISE SUFFICIENT TO FAIL DEFECTIVE PARTIALLY INSULATED SHELL 
TABLE 7.6. Listing of Selected Propane Tank Truck Fault Tree Release Sequences

Cut Set Components

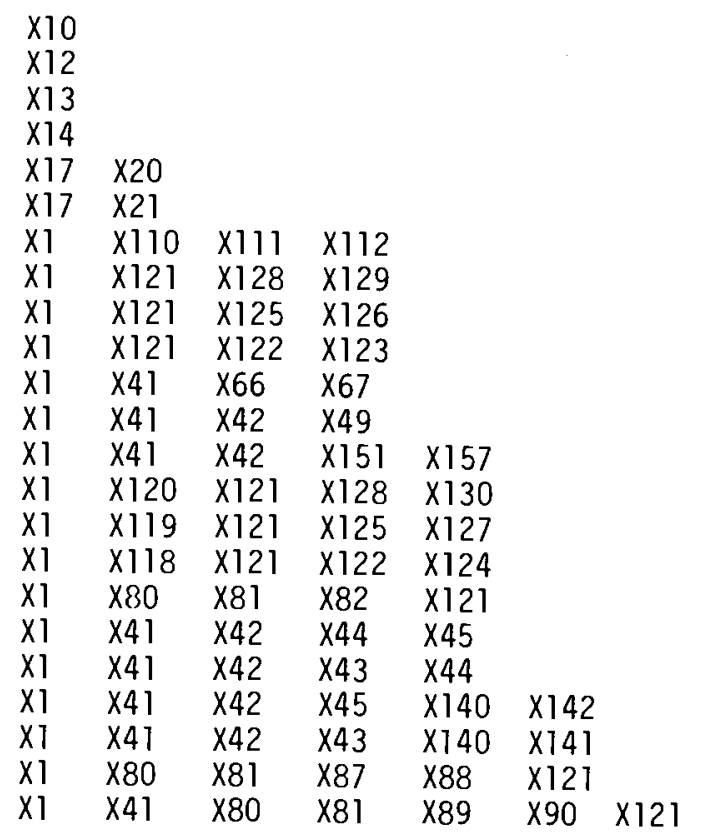

TABLE 7.7. Listing of Selected Propane Rail Tank Car Fault Tree Release Sequences

Cut Set Components

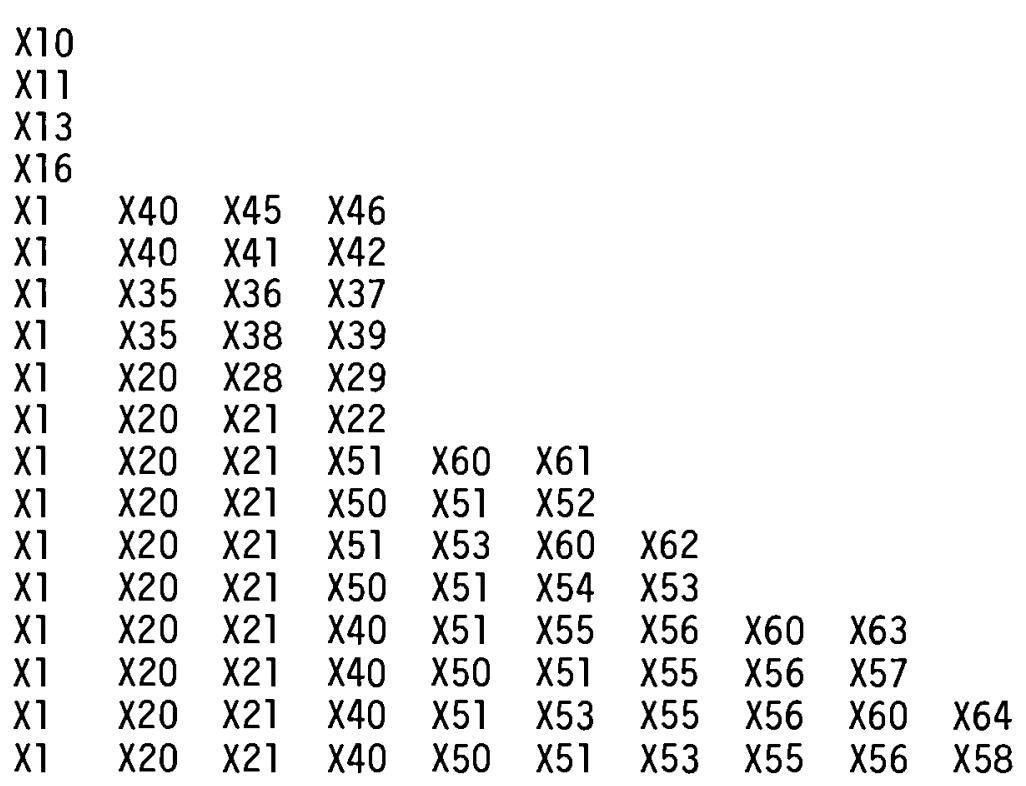




\section{REFERENCES}

1. J. L. Carter, ACORN, A Program for Plotting Fault Trees. BNWL-2144, Pacific Northwest Laboratory, Richland, Washington, October 1977.

2. P. J. Pelto, W. L. Purce11, MFAULT: A Computer Program for Analyzing Fault Trees. BNWL-2145, Pacific Northwest Laboratory, Richland, Washington, November 1977. 


\subsection{RELEASE SEQUENCE EVALUATION}

The fault tree can be thought of as a compact notation for summarizing several thousand release sequences. The previous section presented the fault trees for the shipment of propane by tank truck and rail tank car. As shown in Figure 8.1, based on the release sequences determined in Section 7 , both the frequency of occurrence and the amount of material released (release fraction) must now be determined for each release sequence. The release fraction is required as input to the environmental consequence model in Section 9. The consequence of each release sequence is multiplied by its probability and this product is summed for all release sequences to determine the total risk.

The fault trees in Section 7 were developed to a point where data on basic events could be obtained through analysis or from historical data. Probability values are obtained primarily from the information presented in Sections 5 and 6 of this report. Other values and general failure data are obtained as necessary from the best available source. In many instances, only rough estimates were available for certain inputs. Conservative estimates are used for inputs with uncertain values. Risk sensitivity analyses

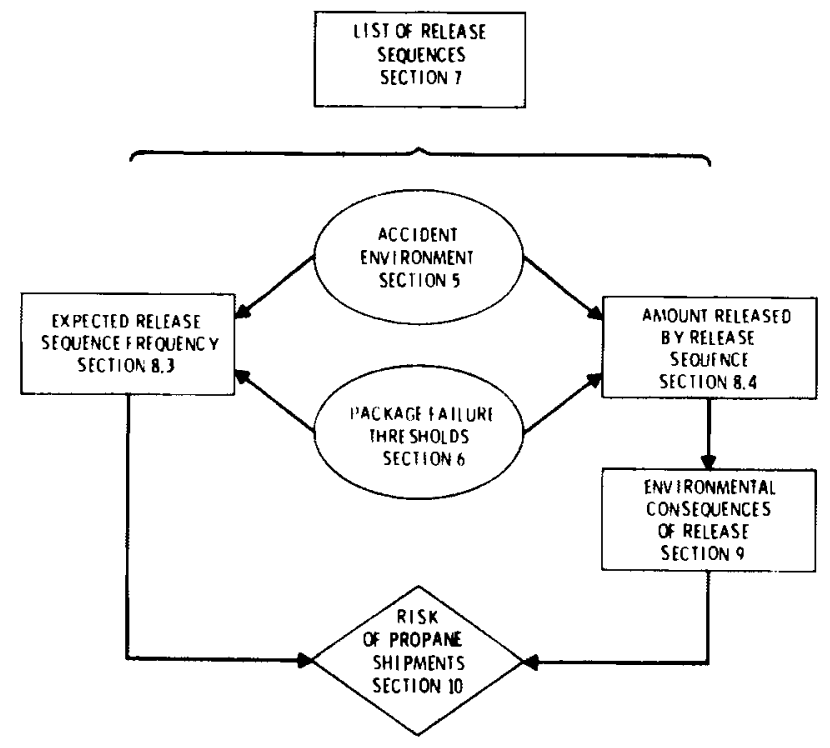

FIGURE 8.1. Remaining Steps in the Risk Evaluation 
were performed to yield insight to the contributions of these events. The estimated basic event probabilities are presented in Section 8.1 for truck transport and Section 8.2 for rail transport. The individual event probabilities are then used to develop the information on release sequence probabilities, which are summarized in Section 8.3. Release fractions are evaluated in Section 8.4.

\subsection{BASIC EVENT PROBABILITIES: TRUCK}

The following paragraphs provide a sequential description of failure probability estimates for events that could contribute to a release during the shipment of propane in tank truck and bobtail transports. Since the fault tree is made up of several branches, a numbering system was used to help identify the different branches of the tree. The numbering system, while consecutive, is not necessarily continuous. Events numbered $x 10$ through $\times 23$ refer to tank and fitting failures during normal transportation. A11 other events refer to events leading to a release in a transportation accident. Events numbered $\times 41$ through $\times 51$ refer to failure of, or release from, the safety relief valves. Events numbered $\times 61$ through $\times 68$ refer to failure of the tank manway cover. Events numbered $\times 80$ through $\times 90$ lead to failure of the tank outlet valve and connecting 1 ines. Events numbered $\times 110$ through $\times 157$ refer to failure of the tank itself by various accident forces. Since the basic events for the bobtail truck are identical to those used in the tank truck fault tree (because of design similarities) many of the basic events will have identical probabilities. These events will be noted in the text. Several basic events were determined to be impossible occurrences, or were found to be included in other events. Although these events were given a value of zero in the analysis, they are presented here for completeness.

The expected frequency of each release sequence is obtained by taking the product of the probability of each event in the sequence. The estimates of the basic event probabilities are presented below. 


\subsubsection{Tank Truck Transport}

The following basic event probabilities are the values used in this risk assessment for the transport of propane in large tank trucks.

Accident Occurs (X1)

The accident rate for truck transport is $1.55 \times 10^{-6}$ truck accidents per kilometer. (1) For an average shipping distance of $210 \mathrm{~km}$, the expected accident frequency is $3.25 \times 10^{-4}$ accidents per shipment. This value is used in the analysis.

Propane Released from Defective Liquid Level Vent Valve (X10)

Historical accident data obtained from the Office of Hazardous Materials (OHM) in the Department of Transportation (DOT) shows a frequency of $8.0 \times 10^{-6}$ releases per shipment from loose or defective fittings. This information is presented in Section 5. The value of $8.0 \times 10^{-6}$ is thus used for this event.

\section{Propane Released from Corroded Tank Shell (X12)}

DOT data presented in Section 5 show a rail tank car failure rate of $3.6 \times 10^{-6}$ releases per shipment due to tank corrosion. This value is assumed valid for truck transportation also. The value used for this event is thus $3.6 \times 10^{-6}$.

\section{Propane Released from Defective Tank Shell (x13)}

DOT data presented in Section 5 show a rail tank car failure rate of $3.6 \times 10^{-6}$ releases per shipment due to defective welds. This value is assumed valid for truck transportation also and is used for this event.

Propane Released from Defective Manway Cover (X14)

Releases from a defective manway cover are included in releases from a defective or corroded tank shell. The value used for this event is thus zero.

Propane Released from Defective Internal Outlet Valve (X17)

The value used for this event is $8.0 \times 10^{-6}$, the same as for event $\times 10$. 
Propane Released from Defective Piping Connections (x20)

The value used for this event is $8.0 \times 10^{-6}$, the same as for event $\times 10$.

Propane Released from Defective External Valves (X21)

The value used for this event is $8.0 \times 10^{-6}$, the same as for event $\times 10$.

Propane Released from Defective End Cap (X22)

The value used for this event is $8.0 \times 10^{-6}$, the same as for event $\times 10$.

External Valve Is Defective (X23)

The failure rate of a manual valve (gate, globe or ball valve) is given in Reference 2 as about $5 \times 10^{-5}$ failures per hour. An average trip speed of $48 \mathrm{kph}$ is assumed for the tank truck. For an average trip length of $210 \mathrm{~km}$, one trip takes about 4.3 hours. This leads to an expected valve failure rate per shipment of about $2 \times 10^{-4}$ failures per shipment. This is the value used for this event.

Propane Released from Liquid Level Valves During Transportation

Accident $(\times 30)$

The liquid level vent valves are located in the side walls of the tank. These valves were thus included in the tank wall failure events for this analysis. A value of zero was used for this event.

Fire Occurs $(X 41)$

Information from Sandia ${ }^{(1)}$ presented in Section 5.1 shows that fire can be expected to occur in 1.6 percent of all truck accidents. The value used for this event is thus .016 fires per accident.

Fire Impinges on Tank Shell (X42)

It is assumed that all tanks are exposed to fire if a fire occurs. The value used for this event is one.

Truck Overturned $(x 43)$

The probability of overturn in a truck accident is given in Section 5 as .198. This value is used for this event. 
Fire Generates Pressure Rise in Tank Sufficient to Activate Valve (X44)

Calculations in Appendix $C$ show that a 2.8 minute fire is sufficient to generate a pressure rise in the tank that will activate the safety relief valves. Figure 5.1 shows the probability of this fire duration to be .88 . This value is used for this event.

Truck Remains Upright (X45)

The probability of this event is one minus the probability of overturn, or .802 .

\section{Propane Released When Crush Forces Fail Safety Valves (X46)}

The safety relief valves are set inside the top of the tank. They are thus considered a part of the tank shell for crush analysis and were not analyzed separately here. The value used for this event is thus zero.

Propane Released When Puncture Forces Fail Safety Valves (X47)

The safety relief valves are set inside the tank itself, and are considered a part of the tank shell for puncture analysis. The value used for this event is thus zero.

Propane Released When Impact Forces Fail Safety Valves (X48)

The safety relief valves are set inside the tank itself, and are considered a part of the tank shell for impact analysis. The value used for this event is thus zero.

Fire Duration Sufficient to Fail Safety Valve (X49)

The valve packing is made of tetrafluoroethylene (TFE), which is assumed to be equivalent to tefion in thermal properties. Reference 3 shows that teflon fails if the temperature exceeds $280^{\circ} \mathrm{C}$. It is conservatively assumed that a fire duration of thirty minutes would be required to fail a TFE packing. However, the valve would have been activated long before this time (see

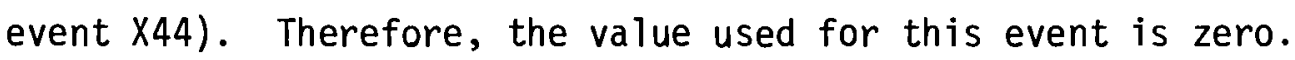


Fire Causes Pressure Rise Sufficient to Fail Defective Valves (X50)

The safety relief valves are set inside the tank walls. It is assumed that the tank shell will fail before the valves do. The value used for this event is thus zero.

Safety Valve Fails to Open (X51)

The failure rate for safety relief valves is given in Reference 4 as $1 \times 10^{-5}$ failures per demand. This value is used for this event.

Impact Forces Fail Manway Cover in Accident (X61)

The manway cover is thicker than the tank shell and is firmly reinforced. It is assumed that the governing failure mode will be buckling and splitting of the tank shell rather than failure of the manway cover. Thus, the value used for this event is zero.

Puncture Probe Fails Manway Cover in Accident (X64)

Following the reasoning used in event $\times 61$, the value used for this event is zero.

Crush Forces Fail Manway Cover in Accident (X65)

Following the reasoning used in event $\times 61$, the value used for this event is zero.

Gasket Exposed to Fire (X66)

Overturn of the tank is required to directly expose the manway cover gasket to fire. It is conservatively assumed that all overturn incidents will expose the gasket to a fire situation, if fire occurs. The value used for this event is .198 .

Fire Duration Sufficient to Fail Manway Cover Gasket (X67)

It is assumed that the manway cover gasket is composed of stainless steel and asbestos. Although no failure data was immediately available on this material, it is conservatively assumed that it will fail, as does the TFE packing, in event $\times 49$ after exposure to a 30-minute fire. From Figure 5.1, the probability of a fire lasting at least 30 minutes is .04 . This value is used for this event. 
Pressure Forces Fail Manway Cover in Accident (X68)

Following the reasoning used in event $\times 61$, the value used for this event is zero.

Impact Forces Contact External Piping (X80)

The value used for this event is the product of the fraction of side-on impacts. (.1448) and a length factor of piping length divided by the length of the tank (about one-third). The resultant value, .048, is used for this event.

Impact Forces Sufficient to Shear Off External Piping at Shear

Section (x81)

It is assumed that all impacts that contact the external piping are sufficient to shear it off. The value used for this event is one.

Internal Valve Fails to Operate (X82)

The failure rate for air-operated valves is given in Reference 4 as $3 \times 10^{-4}$ failures per demand. This value is used for this event.

Puncture Probe Damages Internal Valve (X85)

The internal valve is set inside the tank, and is considered a part of the tank shell for puncture analysis. The value used for this event is thus zero.

Crush Forces Damage Internal Valve $(X 86)$. The internal valve is set inside the tank, and is considered a part of the tank shell for puncture analysis. The value used for this event is thus zero.

Impact Forces Contact Internal Valve (X87)

It is assumed that any impact forces contacting external piping will also affect the internal valve. The value used for this event is one.

Impact Forces Sufficient to Damage Valve (X88)

It is assumed that all impact forces contacting the valve and shearing off external piping will be sufficient to damage the valve. The value used for this event is one. 


\section{Fire Contacts Valve (X89)}

It is assumed that truck accident fires engulf the entire tank, and thus also contact the outlet valve. The value used here is one.

Fire Duration Sufficient to Fail Packing ( $\times 90)$

The valve packing is made of tetrafluoroethylene (TFE), which is assumed to be equivalent to teflon in thermal properties. Reference 3 shows that teflon fails if the temperature exceeds $280^{\circ} \mathrm{C}$. Since the internal valve is somewhat protected from direct thermal stress, it is conservatively assumed that a fire duration of 30 minutes would be required to fail a TFE packing. From Figure 5.1, the probability of a fire lasting at least 30 minutes is .04 . However, if the tank shell is backed by liquid, to absorb the heat from the fire, it may not reach these high temperatures. Thus, the tank must be overturned for this failure mode to occur. The value used for this event is the product of the probability of overturn (.193) and the probability of sufficient fire duration $(.04)$, or $7.9 \times 10^{-3}$.

Puncture Probe Produced in Accident $(x 110)$

Data developed by Sandia $(1)$ show that puncture probes are only produced in truck collisions. This event is used to denote a collision occurring, since specific puncture situation frequencies are outlined in event $\times 111$. From Sandia data, the probability of a collision, given an accident, is .802 . This is the value used for this event.

\section{Puncture Probe Contacts Tank Shel1 (x111)}

From the Sandia report, (1) a probability of a puncture situation given a truck transport collision accident can be obtained. An extrapolation of the Sandia data presented in Table 5.3 for the tank truck wall thickness of $1 \mathrm{~cm}$ yields a probability for a puncture situation of .224 .

\section{Puncture Probe Fails Tank She11 (x112)}

From Section 5 of this report, the probability of puncture in a puncture situation is .01 . This is the value used for this event. 
Tank Head Is Defective (X118)

Reference 2 gives a pressure vessel failure rate of about $5 \times 10^{-7}$ failures per hour for stationary vessels in continuous use. This rate will be increased by a factor of 100 for use in this assessment because of the more severe environment of a transport vessel and the cycle fatigue experiences as a result of loading and unloading operations. Using the average trip time of 4.3 hours, the failure rate for a propane tank is estimated to be $2 \times 10^{-4}$ failures per shipment. This is the value used for this event.

Tank End Is Defective (X119)

The value used here is $2 \times 10^{-4}$ failures per shipment, the same as for event $X 118$.

Tank Walls Are Defective (X120)

The value used here is $2 \times 10^{-4}$ failures per shipment, the same as for event $\times 118$.

Impact Forces Produced in Accident (X121)

Impact forces are assumed present in all tank truck collisions. The probability of a collision accident occurring, .802, is the value used for this event. (1)

Tank Head Experiences Impact Forces (X122)

From Table 5.2, the fraction of collisions that are head-on collisions is $\mathbf{. 5 9 0 4 . ~ T h i s ~ i s ~ t h e ~ v a l u e ~ u s e d ~ f o r ~ t h i s ~ e v e n t . ~}$

Impact Forces Fail Normal Tank Head (X123)

Failure threshold analysis indicated that a velocity change of at least 40 kilometers per hour (kph) is necessary to fail a tank end. Figure 5.2 shows that the fraction of $36,000-\mathrm{kg}$ truck impact accidents with a velocity change greater than or equal to $40 \mathrm{kph}$ is about $1.0 \times 10^{-2}$. This is the value used for this event.

Impact Forces Fail Defective Tank Head (X124)

It is assumed that defective tanks will fail at $3 / 4$ of the failure threshold of normal tanks. From Figure 5.2, the fraction of accidents with a velocity 
city change of $38 \mathrm{kph}$ or greater is $1.2 \times 10^{-2}$. This value is used for this event.

Tank End Experiences Impact Forces (X125)

From Table 5.2, the fraction of collisions that are rear-end collisions is .2648. This is the value used for this event.

Impact Forces Fail Normal Tank End (X126)

Failure threshold analysis indicated that a velocity change of at least $40 \mathrm{kph}$ is necessary to fail a tank end. Figure 5.2 shows that the fraction of $36,000-\mathrm{kg}$ truck impact accidents with a velocity change greater than or equal to $40 \mathrm{kph}$ is $1.0 \times 10^{-2}$. This is the value used for this event.

Impact Forces Fail Defective Tank End (X127)

It is assumed that the defective tanks will fail at $3 / 4$ of the failure threshold of normal tanks. From Figure 5.2, the fraction of accidents with a velocity change of $30 \mathrm{kph}$ or greater is $1.9 \times 10^{-2}$. This value is used for this event.

Tank Walls Experience Impact Forces (X128)

From Table 5.2, the fraction of collisions that are side-on collisions is .1448. This is the value used for this event.

Impact Forces Fail Normal Tank Walls (X129)

Failure threshold analysis indicated that a velocity change of at least $56 \mathrm{kph}$ is required to fail tank walls in a collision accident. From Figure 5.2, the fraction of accidents with a velocity change of $56 \mathrm{kph}$ or greater is $4.1 \times 10^{-3}$. This is the value used for this event.

Impact Forces Fail Defective Tank Walls (X130)

It is assumed that defective tanks will fail at $3 / 4$ of the failure threshold of normal tanks. From Figure 5.2, the fraction of truck accidents with a velocity change of $42 \mathrm{kph}$ or greater is $8.2 \times 10^{-3}$. This is the value used for this event. 


\section{Crush Forces Fail Tank Shell in Transportation Accident (X135)}

Analys is of crush is modeled by an overturned truck trailer under which the tank is lodged. Sandia $(1)$ accident environment information (Section 5) gives $66,700 \mathrm{~N}$ as the maximum static crush loading expected in a truck accident. Because the weight is distributed over the total length of the tank, this results in a distributed crush loading of about $6,600 \mathrm{~N} / \mathrm{m}$. The failure threshold of the tank is substantially higher than this (about $27,000 \mathrm{~N} / \mathrm{m}$ ). It is thus expected that the probability of the tank being failed by crush forces is zero. This is the value used for this event.

Safety Valve Functions Normally (X140)

In the fire failure sequence, the valve must function normally. Thus, the value used for this event is one.

Fire Duration Sufficient to Fail Overturned Tank Shell (X141)

From Section 6, a propane tank truck shell has a fire failure threshold of about 10 minutes. From Figure 5.1, the probability of a fire lasting this long in a truck accident is .48. This is the value used for this event.

Fire Duration Sufficient to Fail Upright Tank Shell (X142)

The fire failure threshold of a normal upright tank shell was shown in Section 6 to be about 15.8 minutes. From Figure 5.1, the probability of a fire lasting this long in a truck accident is .25 . This is the value used for this event.

Fire Duration Causes Pressure Rise Sufficient to Fail Normal Shell (X151)

The tanks used for transporting propane by tank truck are designed to withstand pressures of $6.9 \mathrm{MPa}$. They are tested to $3.4 \mathrm{MPa}$ and working pressure is $1.7 \mathrm{MPa}$. A pressure failure point for a normal tank she 11 is assumed to be $6.9 \mathrm{MPa}$. Assuming that all valves and relief outlets remain closed, it would take a fire of 5.9 minutes to raise the internal pressure of the tank to $6.9 \mathrm{MPa}$. These calculations are outlined in Appendix C. From Figure 5.1, about 68 percent of the truck accident fires can be expected to last this long. Thus, the value used for this event is .68. 
Fire Duration Causes Pressure Rise Sufficient to Fail Weakened She11 (X152)

A tank shell that has been weakened by accident forces is assumed to fail at 3.6 MPa, normal tank test pressure. The fire duration required for tank failure (calculations are shown in Appendix C) is about 3.6 minutes. From Figure 5.1, about 82 percent of truck accident fires will last at least this long. The value used for this event is .82 .

Fire Duration Causes Pressure Rise Sufficient to Fail Defective She11 (X153)

A defective tank shell is also assumed to fail at $3.4 \mathrm{MPa}$. The fire duration required for tank failure is about 3.6 minutes. From Figure 5.1 , the probability of a fire lasting this long is .82 . This is the value used for this event.

\section{Accident Forces Sufficient to Weaken Shell (X154)}

It is assumed that a velocity change of at least $16 \mathrm{kph}$ is required to significantly weaken the tank in an accident. The probability of an accident with this velocity change or greater, from Figure 5.2 , is .0546 . This value is used for this event.

Valves Insufficient to Vent Tank (X155)

Calculations in Appendix $C$ show that the valves are sufficient to vent either an overturned or an upright tank. The value used for this event is thus zero.

Valves Fail to Open (X157)

The failure rate for safety relief valves is given in Reference 4 as $1.0 \times 10^{-5}$ failures per demand. This value is used for this event.

\subsubsection{Bobtail}

The bobtail is similar in many respects to the tank truck, although it does not have a manway cover and has a smaller capacity. Many of the basic event probabilities for bobtail transport are thus the same as those for the tank truck transport. Since the same numbering system is used in both fault trees, the following paragraphs describe only the events whose probabilities are different from those used in the tank truck analysis, Section 8.1.1. 


\section{Accident Occurs (XI)}

The accident rate for truck transport is $1.55 \times 10^{-6}$ truck accidents per kilometer. (1) The bobtail truck travels an average $80 \mathrm{~km}$ per shipment. The expected accident frequency for the bobtail truck is thus $1.24 \times 10^{-4}$ accidents per shipment.

Fire Generates Pressure Rise in Tank Sufficient to Activate Valves (X44)

Calculations in Appendix $C$ show that a two-minute fire is sufficient to generate a pressure rise in the bobtail tank that will activate safety relief valves. Figure 5.1 shows the probability of this fire duration to be .91 . This value is used for this event.

\section{Events $\times 61$ Through $\times 68$}

Because the bobtail transport does not have a manway cover, the values for all of these events are zero.

\section{Impact Forces Contact External Piping (X80)}

The external piping on the bobtail truck is located at the rear end of the truck. It is assumed that any rear-end collision will result in impact forces contacting the external piping. The value used for this event is the probability of a rear-end impact, or .2648 .

Puncture Probe Contacts Tank Shell ( $x 111)$

Information presented in Table 5.3 indicates that the probability of a puncture situation for the bobtail truck transport wall thickness of $1 \mathrm{~cm}$ is .221 . This is the value used for this event.

Impact Forces Fail Normal Tank Head (X123)

Failure threshold analysis indicated that a velocity change of at least $61 \mathrm{kph}$ is necessary to fail the tank head. From Figure 5.2, the fraction of accidents for $13,600 \mathrm{~kg}$ trucks with a velocity change of $61 \mathrm{kph}$ or greater is $9.7 \times 10^{-3}$. This value is used for this event. 
Impact Forces Fai1 Defective Tank Head (X124)

It is assumed that defective tanks will fail at $3 / 4$ of the failure threshold of normal tanks. From Figure 5.2, the fraction of truck accidents with a velocity change of $46 \mathrm{kph}$ or greater is $1.94 \times 10^{-2}$. This value is used for this event.

Impact Forces Fail Normal Tank End (X126)

Failure threshold analysis indicated that a velocity change of at least $61 \mathrm{kph}$ is required to fail a tánk end. Figure 5.2 shows that the fraction of $13,600 \mathrm{~kg}$ truck impact accidents with a velocity change greater than or equal to $61 \mathrm{kph}$ is $9.7 \times 10^{-3}$. This value is used for this event.

Impact Forces Fail Defective Tank End (X127)

It is assumed that defective tanks will fail at $3 / 4$ of the failure threshold of normal tanks. From Figure 5.2, the fraction of accidents with a velocity change of $46 \mathrm{kph}$ or greater is $1.94 \times 10^{-2}$ for a $13,600 \mathrm{~kg}$ truck. This value is used for this event.

Impact Forces Fail Normal Tank Walls (X129)

Failure threshold analysis indicated that a velocity change of at least $40 \mathrm{kph}$ is required to fail tank walls in a collision accident. From Figure 5.2 , the fraction of accidents for a $13,600 \mathrm{~kg}$ truck with a velocity change of $40 \mathrm{kph}$ or more is .0203 . This value is used for this event.

Impact Forces Fail Defective Tank Walls (X130)

It is assumed that defective tanks fail at $3 / 4$ of the failure threshold of normal tanks. From Figure 5.2, the fraction of accidents with a velocity change of $30 \mathrm{kph}$ or greater is .0576 . This value is used for this event.

Fire Duration Sufficient to Fail Overturned Tank She11 (X141)

From Section 6, a normal bobtail tank she11 has a fire failure threshold of about 4.5 minutes. Figure 5.1 shows the probability for this fire duration as about .87. This is the value used for this event. 
Fire Duration Sufficient to Fail Upright Tank She11 (X142)

The fire failure threshold of a normal upright bobtail tank shell was shown in Section 6 to be about 6.6 minutes. From Figure 5.1 , the probability of a fire of this duration is .70 . This is the value used for this event.

Fire Duration Causes Pressure Rise Sufficient to Fail Normal Shell (X151)

The pressure failure thresholds for the bobtail tank are the same as described in event $\times 151$ for the tank truck. A fire duration of 4.1 minutes is required to overpressurize the bobtail tank. From Figure 5.1, the probability of this fire duration is .78. This value is used for this event.

Fire Duration Causes Pressure Rise Sufficient to Fail Weakened Shell (X152)

A tank shell that has been weakened by accident forces is assumed to fail at $3.4 \mathrm{MPa}$. The fire duration required for tank failure (calculations are shown in Appendix $C$ ) is 2.5 minutes. From Figure 5.1 , the probability of a fire lasting at least this long is .88. This is the value used for this event.

Fire Duration Causes Pressure Rise Sufficient to Fail Defective Shell (X153)

A defective tank shell is assumed to fail at $3.4 \mathrm{MPa}$. A fire duration of 2.5 minutes is required to generate this internal pressure in the bobtail tank. The fraction of fires lasting at least this long is shown in Figure 5.1 to be .88. This value is used for this event.

Accident Forces Sufficient to Weaken Shell (X154)

It is assumed that a velocity change of at least $16 \mathrm{kph}$ is required to significantly weaken the tank in an accident. The probability of an accident for a $13,600-\mathrm{kg}$ truck with a $16-\mathrm{kph}$ or greater velocity change is given in Figure 5.2 as .1511 . This value is used for this event.

\subsection{BASIC EVENT PROBABILITIES: TRAIN}

The following paragraphs provide a sequential description of failure probability estimates for events that could contribute to a release during the shipment of propane in rail tank cars. Since the fault tree is made up of several branches, a numbering system was used to help identify the different 
branches of the tree. The numbering system, while consecutive, is not necessarily continuous. Events numbered $X 10$ through $X 16$ refer to failures of the tank and fittings during normal transportation. All other events refer to events leading to a release in a transportation accident. Events numbered $X 20$ through $\times 24$ refer to failure of, or releases from, the safety relief or other valves. Events numbered $X 25$ through $X 29$ refer to failure of the manway cover. Events numbered $X 31$ through $X 77$ lead to failure of the tank itself as a result of various accident forces.

Several basic events were determined to be impossible occurrences, or were found to be included in other events. Although these events were given a value of zero in the analysis, they are presented here for completeness.

The expected frequency of each release sequence is obtained by taking the product of the probability of each event in the sequence. The following basic event probabilities are the values used in this risk assessment for the transport of propane in rail tank cars.

\section{Accident Occurs $(X 1)$}

The accident rate for rail car transport is $6.21 \times 10^{-6}$ train accidents per train-kilometer. (1) For an average shipping distance of $400 \mathrm{~km}$, the expected accident frequency is $2.50 \times 10^{-3}$ accidents per shipment. This value is used in the analysis.

\section{Propane Released from Corroded Tank (X10)}

Historical accident data obtained from the Office of Hazardous Materials (OHM) in the Department of Transportation (DOT) shows a tank failure rate of $3.6 \times 10^{-6}$ releases per shipment because of tank corrosion. This information is presented in Section 5. The value used for this event is thus $3.6 \times 10^{-6}$. Propane Released from Defective Tank (x11)

DOT data presented in Section 5 shows a rail tank car failure rate of $3.6 \times 10^{-6}$ releases per shipment due to defective welds. This value is used for this event. 
Propane Released from Safety Valves During Normal Transportation (X12)

Calculations in Appendix $C$ show that it is impossible to get a release of propane through the safety relief valves as a result of heat input from solar insulation. A larger heat source is required to generate the internal tank pressure necessary to activate the valves. This event was thus given a value of zero for this analysis.

Propane Released from Defective Manway Cover (X13)

Releases from a defective manway cover are included in releases from a defective or corroded tank shell. The value used for this event is thus zero.

Propane Released from Defective Valves During Normal Transportation (X16)

DOT data presented in Section 5 shows a release frequency of $8.0 \times 10^{-4}$ releases per shipment from loose or defective fittings. This value is used for this event.

Fire Occurs $(\times 20)$

Information from Sandia ${ }^{(1)}$ presented in Section 5 shows that fire can be expected to occur in 18.5 percent of all train accidents. This value is the probability of a fire occurring for a 66-car train. The value used for this event is .185 fires per accident.

Fire Contacts Tank Shel1 (X21)

The probability of any train fire contacting the car of interest is given in Section 5 as .1. This value is used for this event.

Fire Duration Generates Pressure Rise Sufficient to Activate Valve (x22)

Calculations in Appendix $C$ show that a 42.6 minute fire is required to generate an internal pressure rise in the insulated tank car sufficient to activate the safety relief valves. Figure 5.3 shows the probability of a fire lasting at least this long to be .265 . This value is used for this event.

Propane Released from Damaged Safety Relief Valves (X23)

The safety valve is set inside the tank wall. Failure of the valve by accident forces is included in the analys is of the tank shell. A value of zero is thus used for this event. 
Propane Released from Valves During Transportation Accidents (X24)

The valves are located at the top of the tank, within the manway cover, and are considered a part of the tank itself for accident analysis. The value used for this event is thus zero.

Puncture Probe Fails Manway Cover (X25)

The manway cover is thicker than the tank shell, and firmly reinforced. It is assumed that the governing failure mode will be buckling and splitting of the tank shell rather than failure of the manway cover itself. Thus, the value used for this event is zero.

Impact Forces Fail Manway Cover (X26)

Following the reasoning used in event $\times 25$, the value used here is zero. Crush Forces Fail Manway Cover (X27)

Following the reasoning used in event $\times 25$, the value used for this event is zero.

\section{Fire Contacts Manway Cover Gasket (X28)}

Overturn of the tank is required to expose the gasket to fire. It is assumed that all overturn accidents will expose the gasket to fire, if fire is present. The value used for this event is .25 , the fraction of accidents that are overturn accidents.

\section{Fire Duration Sufficient to Fail Manway Cover Gasket (X29)}

The gasket used on the rail tank car manway cover is made of asbestos. Following the reasoning used for the tank truck manway cover gasket in tank truck event $\times 67$, the value used for this event is .04 .

\section{Crush Forces Fail Tank Shel1 in Accident (X31)}

Analysis of crush is modeled by an overturned flatbed railcar under which the propane tank is lodged. However, this situation cannot occur for rail tank cars, since the tank itself is the structural member, and is not attached to any substructure such as a flatbed trailer. The value used for this event is thus zero. 
Puncture Probe Produced in Accident (X35)

The coupler on rail tank cars is used in the Sandia model as the example of a puncture probe. ${ }^{(1)}$ Since the coupler will be present in all rail tank car accidents, the value used for this event is one.

Puncture Probe Fails Tank Walls (x36)

From Section 5.2 of this report, the probability of puncture in a puncture situation is .18. This is the value used for this event.

Puncture Probe Contacts Tank Walls (X37)

From Table 5.6, the probability of a puncture situation for a wall thickness of $1.6 \mathrm{~cm}$ is $6.375 \times 10^{-4}$. This value is used for this event.

Puncture Probe Contacts Tank End (X38)

The probability of a puncture situation can be obtained from Table 5.6 as $3.6 \times 10^{-4}$ for the tank end equivalent wall thickness of $3.64 \mathrm{~cm}$. This value is used here.

Puncture Probe Fails Tank End (X39)

The value used for this event is .82 , as described in Section 5.2 .

Impact Forces Produced in Accident (X40)

Impact forces are produced in 15 percent of all rail car collisions and derailments. The probability of a collision or derailment given a train accident is .90. (1) The value used for this event is thus the product of these two numbers, or .135 .

Impact Forces Contact Tank End (X41)

The probability of particular car orientation in a derailment accident is not readily available. However, historical data collected by the American Association of Railroads shows that the probability of rear-end and head-on collisions, given an accident, is .82. All other accident orientations are assumed to impact tank walls. The value of .82 is used for this event. 
Impact Forces Fail Normal Tank End (X42)

Failure threshold analysis indicated that a velocity change of at least 51-kph is required to fail tank ends. Figure 5.4 shows that the fraction of rail car accidents with a velocity change greater than or equal to $51-\mathrm{kph}$ is $1.8 \times 10^{-3}$. This value is used for this event.

Impact Forces Fail Defective Tank Head (X43)

Defective rail tanks are assumed to fail at $3 / 4$ of the failure threshold of normal tanks, or $38.6 \mathrm{kph}$. Figure 5.4 shows this velocity change to have a frequency of occurrence of $5.0 \times 10^{-3}$. This is the value used for this event.

\section{Tank Is Defective (X44)}

Reference 2 gives a pressure vessel failure rate of about $5 \times 10^{-7}$ failures per hour for stationary vessels in continuous use. This rate will be increased by a factor of 100 for use in this assessment because of the more severe environment of a transport vessel and the cycle fatigue experienced as a result of loading and unloading operations. An average trip speed of $56 \mathrm{kph}$ is assumed for the rail tank car. For an average trip length of $400 \mathrm{~km}$, one trip takes about 7 hours. Using the average trip time of 7 hours, the failure rate for a propane tank is estimated to be $3.5 \times 10^{-4}$ failures per shipment. This is the value used for this event.

Impact Forces Contact Tank Walls (X45)

All impacts that do not affect tank ends are assumed to affect tank walls. The value used for this event is thus .18.

Impact Forces Fail Normal Tank Walls (X46)

Failure threshold analysis indicated that a velocity change of at least $32 \mathrm{kph}$ is required to fail tank walls. Figure 5.4 shows this velocity change or greater occurring with a frequency of $8.0 \times 10^{-3}$. This value is used for this event. 
Impact Forces Fail Defective Tank Walls (X47)

Defective walls are assumed to fail at $3 / 4$ the velocity change required for normal wall failure, or $24 \mathrm{kph}$. This velocity change occurs with a frequency of $1.6 \times 10^{-2}$. This value is used for this event.

Tank Is Overturned $(\times 50)$

The probability of overturn in a train accident is given in Section 5.0 as .25. This value is used for this event.

Safety Relief Valve Operates Normally (X51)

In the fire failure sequence, the valve must function normally. Thus, the value used for this event is one.

Fire Duration Sufficient to Fail Normal Overturned Insulated Shell (X52)

Calculations in Appendix $C$ show that a normal insulated tank car requires a fire duration of almost 190 minutes before failure occurs. Figure 5.3 shows the probability of a fire lasting this long to be .02 . This value is used for this event.

Accident Forces Are Sufficient to Weaken Shell (x53)

It is assumed that any impact with a velocity change of at least $16 \mathrm{kph}$ is sufficient to weaken the tank car she11. From Figure 5.4, this event has an expected frequency of occurrence of $2.6 \times 10^{-2}$.

Fire Duration Sufficient to Fail Weak, Overturned, Insulated Shell (X54)

A weak tank car shell is assumed to fail at $3 / 4$ the failure time of a normal she11, or 140 minutes. From Figure 5.3, the probability of a fire lasting at least this long is .08. This value is used for this event.

Impact Forces Contact Tank She11 (X55)

It is assumed that any impact forces generated in a train accident will contact the tank car shell. The value used for this event is one.

Impact Forces Partially Remove Tank Insulation (X56)

It is assumed that all side and/or raking collisions will partially remove tank insulation. The amount removed is calculated in Appendix $C$. The 
probability of a side/raking collision given an accident is given as .315. (1) This value is used for this event.

Fire Duration Sufficient to Fail Normal, Overturned, Partially Insulated She11 (X57)

Calculations in Appendix $C$ show that a normal partially insulated tank will fail after exposure to a 50 -minute fire of $1010^{\circ} \mathrm{C}$. The probability of this fire duration is given in Figure 5.3 as .22 . This value is used for this event.

Fire Duration Sufficient to Fail Weak, Overturned, Partially Insulated She11 (X58)

A weak tank car she 11 is assumed to fail at $3 / 4$ the failure time of a normal she11, or 38 minutes. The probability of a fire lasting at least this long is given in Figure 5.3 as .34 . This value is used for this event.

Tank Remains Upright (X60)

The probability of this event is one minus the probability of overturn, or .750 .

Fire Duration Sufficient to Fail Normal Upright Insulated Tank (X61)

Calculations in Appendix $C$ show that a normal upright insulated tank will fail in about 200 minutes if exposed to a $1010^{\circ} \mathrm{C}$ fire. Information in Figure 5.3 shows the probability of a fire lasting this long as less than .01. The value used for this event is .01.

Fire Duration Sufficient to Fail Weak Upright Insulated Shell (X62)

A weak tank car shell is assumed to fail at $3 / 4$ the failure time of a normal she11, or 150 minutes. The probability of a fire lasting about this long is given in Figure 5.3 as .07 . This value is used for this event.

Fire Duration Sufficient to Fail Normal Upright Partially Insulated Shell $\underline{(x 63)}$

Calculations in Appendix $C$ show that an upright tank car that is partially insulated will fail after a 60 -minute exposure to a $1010^{\circ} \mathrm{C}$ fire. The probability of this fire duration is given in Figure 5.3 as .17 . This value is used for this event. 
Fire Duration Sufficient to Fail Weak Upright Partially Insulated Shell (X64)

A weak tank car shell is assumed to fail at $3 / 4$ the failure time of a normal shell, or 45 minutes. Figure 5.3 shows the probability of a fire lasting at least this long as .33. This value is used for this event.

Fire Duration Causes Pressure Rise Sufficient to Fail Normal Insulated Shell (x70)

The tanks used for transporting propane by rail tank car are designed to withstand internal pressures of up to $5.9 \mathrm{MPa}$ (bursting pressure) and are tested to $2.3 \mathrm{MPa}$. It is assumed that if a normal rail tank car reaches its design pressure of $5.9 \mathrm{MPa}$, it will fail. Assuming that the relief valve and all other tank outlets remain closed, it would take a fire duration of 280 minutes to raise the internal pressure of the insulated tank to $5.9 \mathrm{MPa}$. The probability of this fire duration is given in Figure 5.3 as .001 . This value is used for this event.

Fire Duration Causes Pressure Rise Sufficient to Fail Weak Insulated Shell (x71)

A weak tank shell is assumed to fail at the tank pressure of $2.3 \mathrm{MPa}$. Assuming that all tank outlets remain closed, it would take a fire duration of 130 minutes to raise the internal pressure of the insulated tank to $2.3 \mathrm{MPa}$. The probability of this fire duration is given in Figure 5.3 as .10 . This value is used for this event.

Fire Duration Causes Pressure Rise Sufficient to Fail Defective Insulated She11 (X72)

A defective shell is assumed to have the same pressure failure threshold as a weakened shell. The value used for this event is .10 , the same as for event $x 71$.

Fire Duration Causes Pressure Rise Sufficient to Fail Normal Partially Insulated Shell (X73)

A normal shell is assumed to fail at a pressure of $5.9 \mathrm{MPa}$. The partially insulated shell will reach this internal pressure more quickly than a fully insulated shell because of a greater heat flux. The time required to raise 
the internal pressure of this tank to $5.9 \mathrm{MPa}$ when exposed to a $1010^{\circ} \mathrm{C}$ fire is about 60 minutes (see Appendix $C$ ). Figure 5.3 shows the frequency of occurrence of a fire of this duration to be about .15. This value is used for this event.

Fire Duration Causes Pressure Rise Sufficient to Fail Weak Partially Insulated She $11(\times 74)$

A weak tank shell is assumed to fail at the tank test pressure of $2.3 \mathrm{MPa}$. A partially insulated tank exposed to a fire of $1010^{\circ} \mathrm{C}$ will reach this internal pressure after about 30 minutes. The probability of this fire duration is given in Figure 5.3 as .50. This is the value used for this event.

Fire Duration Causes Pressure Rise Sufficient to Fail Defective Partially Insulated She $11(\times 75)$

A defective shell is assumed to have the same pressure failure threshold as a weakened she11. The value used for this event is .50 , the same as for event $\times 74$.

Valve Fails to Open $(X 76)$

The failure rate for safety relief valves is given in Reference 4 as $1.0 \times 10^{-5}$ failures per demand. This value is used for this event.

Safety Relief Valve Insufficient to Vent Tank (X77)

Calculations in Appendix $C$ show that the valve is sufficient to vent either an overturned or an upright tank. The value used for this event is thus zero.

\subsection{RELEASE SEQUENCE PROBABILITIES}

The basic event probabilities presented in Sections 8.1 and 8.2 provide the basis for evaluating the probability of each release sequence identified in the fault trees. The probabilities of some of the release sequences for propane tank truck shipments are shown as an example in Table 8.1. A 1ist of release sequence probabilities for rail tank car propane shipments is shown in Table 8.2. Only the release sequences with a frequency of occurrence greater than $10^{12}$ per shipment are listed in the table. All release sequences were retained in the actual risk calculation. 
IABLE 8.1. Release Sequences and Probabilities for Propane Tank Truck Shipments

Rei ease Sequence Probability

$8.000 \mathrm{E}-06$ ReTease Sequence

$3.600 \mathrm{E}-06$

$\times 10$

3.600E-06

$\times 12$

$6.400 \mathrm{E}-11$

$x 13$

$6.400 \mathrm{E}-11$

$\times 17 \times 20$

$5.839 \mathrm{E}-07$

$\times 17 \times 21$

$1.550 \mathrm{E}-07$

$\begin{array}{llll}X 1 & X 110 \quad X 111 \quad X 112\end{array}$

6.976E-07

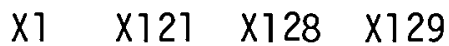

$1.540 \mathrm{E}-06$

$X 1 \quad X 121 \quad X 125 \quad X 126$

$4.118 \mathrm{E}-08$

$\begin{array}{llll}X 1 & X 121 \quad X 122 \quad X 123\end{array}$

$3.536 \mathrm{E}-11$

$\begin{array}{llll}x 1 & \times 41 \quad x 66 \quad x 67\end{array}$

9.610E-11

$\begin{array}{lllll}X 1 & X 41 & X 42 & X 151 & X 157\end{array}$

3. $180 \mathrm{E}-10$

$\begin{array}{lllll}X 1 & X 120 & X 121 & X 128 & X 130\end{array}$

7.070E-10

$\begin{array}{lllll}X 1 & X 119 & X 121 & X 125 & X 127\end{array}$

$3.753 \mathrm{E}-09$

$\begin{array}{lllll}X 1 & X 118 & X 121 & X 122 & X 124\end{array}$

3.670E-06

$\begin{array}{lllll}x 1 & \times 80 & x 81 & x 82 & x 121\end{array}$

9.050E-07

$\begin{array}{lllll}X 1 & X 41 \quad X 42 & X 44 & X 45\end{array}$

$1.042 \mathrm{E}-06$

$\begin{array}{lllll}X 1 & X 41 \quad X 42 \quad X 43 \quad X 44\end{array}$

$\begin{array}{llllll}X 1 & X 41 & X 42 & X 45 & X 140 & X 142\end{array}$

4. $942 \mathrm{E}-07$

$x 1 \quad x 41$

$\begin{array}{llllll}X 1 & X 80 & X 81 & X 87 & X 88 & X 121\end{array}$

$1.251 \mathrm{E}-05$

$\mathrm{x} 1 \mathrm{x}$

$\times 41 \quad \times 80$

$\times 81 \quad \times 89 \quad \times 90 \quad \times 121$ 
TABLE 8.2. Release Sequences and Probabilities for Propane Rail Tank Car Shipments

Release Sequence

Probability

Release Sequence

8.000E-04 $\quad \times 16$

3.600E-06 $\times 10$

3.600E-06 $\quad \times 11$

2.003E-06 $\quad \times 1 \quad \times 40 \times 45 \times 46$

$1.569 \mathrm{E}-07 \quad \times 1 \quad \times 40 \quad \times 41 \quad \times 42$

$1.596 \mathrm{E}-08 \quad \times 1 \quad \times 35 \times 36 \quad \times 37$

$1.226 \mathrm{E}-08 \quad \times 1 \quad \times 35 \times 38 \quad \times 39$

4.630E-07 $\times 1 \quad \times 20 \times 28 \times 29$

$1.227 \mathrm{E}-05 \quad \times 1 \quad \times 20 \quad \times 21 \quad \times 22$

$\begin{array}{lllllll}3.472 \mathrm{E}-07 & \times 1 & \times 20 & \times 21 & \times 51 \quad \times 60 & \times 61\end{array}$

$2.315 \mathrm{E}-07 \quad \times 1 \quad \times 20 \quad \times 21 \quad \times 50 \quad \times 51 \quad \times 52$

8.124E-08 $\quad \times 1 \quad \times 20 \quad \times 21 \quad \times 51 \quad \times 53 \quad \times 60 \quad \times 62$

2.917E-07 $\quad \times 1 \quad \times 20 \quad \times 21 \quad \times 50 \quad \times 51 \quad \times 54 \quad \times 53$

2.510E-07 $\quad \times 1 \quad \times 20 \quad \times 21 \quad \times 40 \quad \times 51 \quad \times 55 \quad \times 56 \quad \times 60 \quad \times 63$

$\begin{array}{llllllllll}1.083 \mathrm{E}-07 & \times 1 & \times 20 & \times 21 & \times 40 & \times 50 & \times 51 & \times 55 & \times 56 & \times 57\end{array}$

$\begin{array}{lllllllllll}1.267 \mathrm{E}-07 & \times 1 & \times 20 & \times 21 & \times 40 & \times 51 & \times 53 & \times 55 & \times 56 & \times 60 & \times 64\end{array}$

$\begin{array}{lllllllllll}4.352 E-07 & \times 1 & \times 20 & \times 21 & \times 40 & \times 50 & \times 51 & \times 53 & \times 55 & \times 56 & \times 58\end{array}$

\subsection{RELEASE FRACTIONS}

The final step in the evaluation of release sequences is the determination of release fractions. For the purposes of this risk analysis, the lists of release sequences were divided into six categories and release characteristics were assigned to each. The total probability of any one release category is the sum of the individual release sequence probabilities leading to that category of release. Tables 8.3 and 8.4 show the release sequences from Tables 8.1 and 8.2, respectively, divided into the various release categories, along with assigned release characteristics. The six release rate categories are described in the following paragraphs: 
TABLE 8.3. Release Sequences for Propane Tank Truck Shipments Grouped According to Release Category

Release

Sequence

Probability

Release Sequence

Group 1 - Continuous Slow Leak $\left(2.20 \times 10^{-3} \mathrm{~m}^{3} / \mathrm{sec}\right)$

8.000E-06 $\times 10$

3.600E-06 $\quad X 12$

$3.600 \mathrm{E}-06 \quad \times 13$

$6.400 \mathrm{E}-11 \quad \times 17 \quad \times 2.0$

$6.400 \mathrm{E}-11 \quad \cdot \times 17 \quad \times 21$

$\begin{array}{llllll}3.753 E-09 & X 1 & \times 80 & \times 81 & \times 82 & X 121\end{array}$

Group 2 - Continuous Leak $\left(1.9 \times 10^{-2} \mathrm{~m}^{3} / \mathrm{sec}\right)$

$\begin{array}{lllllll}1.251 E-05 & X 1 & \times 80 & \times 81 & \times 87 & \times 88 & X 121\end{array}$

Group 3 - Release from Safety Relief Valves

$\begin{array}{llllll}3.670 \mathrm{E}-06 & X 1 & X 41 & X 42 & X 44 & X 45 \\ 9.061 \mathrm{E}-07 & X 1 & X 41 & X 42 & X 43 & X 44\end{array}$

Group 4 - Continuous Slow Leak, Fire Present $\left(9.16 \times 10^{-3} \mathrm{~m}^{3} / \mathrm{sec}\right)$
4.118E-08
$\begin{array}{llll}X 1 & X 41 & X 66 & X 67\end{array}$
$1.581 E-09$
$X 1 \quad \times 41 \quad \times 80 \quad \times 81$
$\times 89 \quad \times 90 \quad \times 121$

Group 5 - Immediate Release of Total Tank Contents

\begin{tabular}{|c|c|c|c|c|}
\hline $5.838 \mathrm{E}-07$ & $X_{1}$ & $x 110$ & $x 111$ & X112 \\
\hline $1.550 \mathrm{E}-07$ & $x 1$ & $\mathrm{X} 121$ & $\times 128$ & $\times 129$ \\
\hline $6.976 \mathrm{E}-07$ & $x_{1}$ & $\times 121$ & $\times 125$ & $X 126$ \\
\hline $1.540 \mathrm{E}-06$ & $x_{1}$ & $\times 121$ & $\mathrm{X} 122$ & $\mathrm{X} 123$ \\
\hline $9.610 \mathrm{E}-11$ & $x 1$ & $\times 120$ & $\mathrm{X} 121$ & $\mathrm{X} 128$ \\
\hline $3.180 \mathrm{E}-10$ & $x_{1}$ & $\times 119$ & $\times 121$ & $\times 125$ \\
\hline $7.070 \mathrm{E}-10$ & $X 1$ & $x 118$ & $\times 121$ & X122 \\
\hline
\end{tabular}

Group 6 - Immediate Release of Total Tank Contents, Fire Present

$\begin{array}{lllllll}3.536 \mathrm{E}-11 & X 1 & X 41 & X 42 & X 151 & X 157 & \\ 1.043 \mathrm{E}-06 & X 1 & X 41 & X 42 & X 45 & X 140 & X 142 \\ 4.942 \mathrm{E}-07 & X 1 & X 41 & X 42 & X 43 & X 140 & X 141\end{array}$


TABLE 8.4. Release Sequences for Propane Rail Tank Car Shipments Grouped According to Release Category

Release

Sequence

Probability

Release Sequence

Group 1 - Continuous Slow Leak $\left(2.20 \times 10^{-3} \mathrm{~m}^{3} / \mathrm{sec}\right)$

8.000E-04 X16

$3.600 \mathrm{E}-06 \quad \times 10$

3.600E-06 X11

Group 2 - Continuous Leak $\left(1.96 \times 10^{-2} \mathrm{~m}^{3} / \mathrm{sec}\right)$

Group 3 - Release from Safety Relief Valves

$1.227 \mathrm{E}-05 \quad \mathrm{X} 1 \quad \times 20 \quad \times 21 \quad \times 22$

Group 4 - Continuous Slow Leak, Fire Present $\left(9.16 \times 10^{-3} \mathrm{~m}^{3} / \mathrm{sec}\right)$

4.630E-07 X1 X20 X28 $\times 29$

Group 5 - Immediate Release of Total Tank Contents

2.003E-06 $\quad \times 1 \quad \times 40 \quad \times 45 \quad \times 46$

$1.596 \mathrm{E}-07 \quad \times 1 \quad \times 40 \quad \times 41 \quad \times 42$

$\begin{array}{lllll}1.596 \mathrm{E}-08 & \times 1 & \times 35 & \times 36 & \times 37\end{array}$

$1.226 \mathrm{E}-08 \quad \times 1 \quad \times 35 \quad \times 38 \quad \times 39$

Group 6 - Immediate Release of Total Tank Contents, Fire Present

$\begin{array}{lllllll}3.472 E-07 & \times 1 & \times 20 & \times 21 & \times 51 & \times 60 & \times 61\end{array}$

$2.315 E-07 \quad \times 1 \quad \times 20 \quad \times 21 \quad \times 50 \quad \times 51 \quad \times 52$

$\begin{array}{llllllll}8.124 \mathrm{E}-08 & \times 1 & \times 20 & \times 21 & \times 51 & \times 53 & \times 60 & \times 62\end{array}$

2.917E-07 $\quad \times 1 \quad \times 20 \quad \times 21 \quad \times 50 \quad \times 51 \quad \times 54 \quad \times 53$

2.510E-07 $\quad \times 1 \quad \times 20 \quad \times 21 \quad \times 40 \quad \times 51 \quad \times 55 \quad \times 56 \quad \times 60 \quad \times 63$

$\begin{array}{llllllllll}1.083 \mathrm{E}-07 & \times 1 & \times 20 & \times 21 & \times 40 & \times 50 & \times 51 & \times 55 & \times 56 & \times 57\end{array}$

$\begin{array}{lllllllllll}1.267 E-07 & \times 1 & \times 20 & \times 21 & \times 40 & \times 51 & \times 53 & \times 55 & \times 56 & \times 60 & \times 64\end{array}$

$\begin{array}{lllllllllll}4.352 \mathrm{E}-07 & \times 1 & \times 20 & \times 21 & \times 40 & \times 50 & \times 51 & \times 53 & \times 55 & \times 56 & \times 58\end{array}$ 
- The first release category represents a continuous slow leak from an equivalent $2.5-\mathrm{cm}$ diameter opening. These release sequences do not generally occur as a result of transportation accidents. The release rate for this category is $2.20 \times 10^{-3} \mathrm{~m}^{3} / \mathrm{sec}$ of propane. (a) This release is postulated to occur either as a result of a defective weld or corrosion in the tank itself, or from a release through a defective internal valve that travels on through defective or missing external hardware.

- The second release category represents a continuous outflow from an opened or damaged valve. These release sequences occurred as a result of mechanical forces (impact or puncture). Accidents with fire present are not included here. The rate of release of propane is assumed to be the equivalent of that emanating from the area of a $7.6-\mathrm{cm}$ diameter opening. The release rate for this category of release sequences is $1.96 \times 10^{-2} \mathrm{~m}^{3} / \mathrm{sec}$ of propane. There were no releases of this class from the rail tank car.

- A third release category is the outflow of propane from activated safety relief valves in an accident where fire is present. This release is modeled as a continuous leak. The release from the valves of the overturned tank is greater than that for the upright tank. The larger release rate is used in this case. This corresponds to a release rate of $5.23 \times 10^{-2} \mathrm{~m}^{3} / \mathrm{sec}$ for the large tank truck; a rate of $3.62 \times 10^{-2} \mathrm{~m}^{3} / \mathrm{sec}$ for the bobtail; and a rate of propane release of $1.04 \times 10^{-1} \mathrm{~m}^{3} / \mathrm{sec}$ for the rail tank car.

- The fourth release category is that of a smal1, continuous leak of propane in an accident situation with a fire present. The propane is released, as in release category \#2, from a $2.5-\mathrm{cm}$ diameter opening. The elevated temperature results in a larger release rate of $9.16 \times 10^{-3} \mathrm{~m}^{3} / \mathrm{sec}$.

- A fifth release category is a release of propane from a major mechanical failure (impact or puncture) of the propane tank. These represent major accident sequences where a fire is not initially present, although the

(a)This rate is calculated from equations given in Reference 5 for determining the maximum flow or propane through an orifice. 
released propane may later be ignited. It is assumed that the total contents of the tank are released almost immediately.

- The last category of release corresponds to an explosive rupture of the propane tank, caused by an overpressurization of the tank or a weakening of the tank walls by fire. These represent major accident sequences where a fire (not caused by the propane cargo) is the cause of tank failure. It is assumed that the total contents of the tank are released almost immediately.

\section{REFERENCES}

1. A. W. Dennis, J. T. Foley, W. F. Hartman and D. W. Larson, Severities of Transportation Accidents Involving Large Packages. SAND 77-0001, Sandia Laboratories, Albuquerque, New Mexico, May 1978.

2. J. G. Melvin and R. B. Maxwell, Reliability and Maintainability Manual, Process Systems. AECL-4607, January 1974.

3. H. K. Elder et al., An Assessment of the Risk of Transporting Spent Nuclear Fuel by Truck. PNL-2588, Pacific Northwest Laboratory, Richland, Washington, July 1978.

4. Reactor Safety Study - An Assessment of the Accident Risks in U.S. Commercial Nuclear Power Plants. WASH-1400 (NUREG-75/014), U.S. Nuclear Regulatory Commission, Washington, D.C., October 1975.

5. W. A. Bullerdick et al., A Study to Reduce the Hazards of Tank Car Transportation. Department of Transportation, DOT-FR-00028, Washington, D.C., November 1970. 


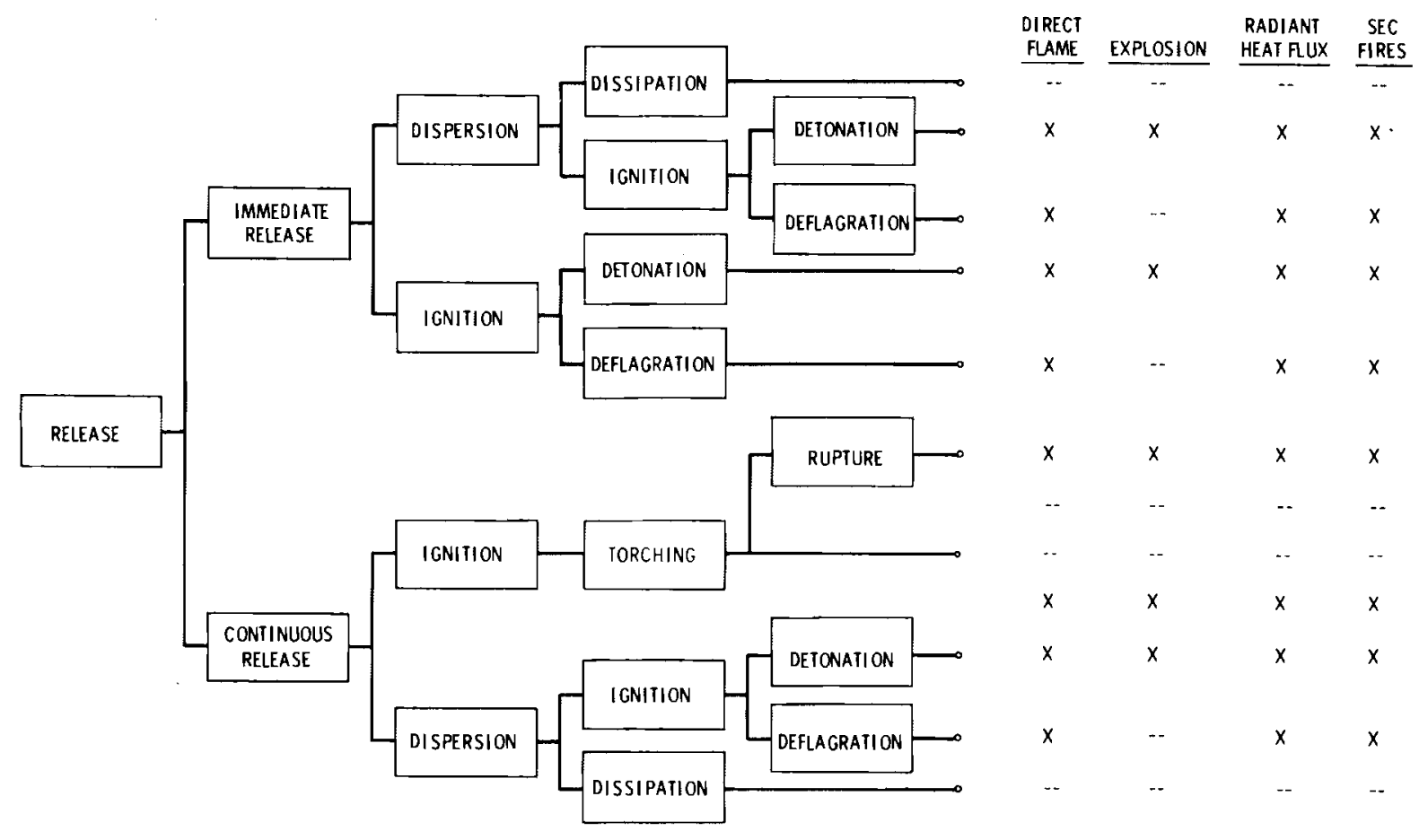

FIGURE 9.1. Event Tree

A continuous release of propane with immediate ignition corresponds to release categories three and four. These releases normally result in a torching effect, where the propane flame burns until the fuel is exhausted. These flames do not usually contact the tank itself. However, there is a possibility that the torch may be directed so that it impinges on the tank walls. In this case, tank rupture may eventually occur as a result of a weakening of tank walls that are not backed by liquid propane.

A continuous release with dispersion represents the first and second release categories described in Section 8.4. The vapor cloud formed by these release sequences could either harmlessly disperse, or ignite, creating a detonation or deflagration.

The major health effects of the release scenarios considered in this report are direct flame exposure, explosion effects (overpressure and fragmentation), radiant heat flux, and secondary fires. Consequences to the public are measured in terms of expected fatalities. The number of fatalities from each major health effect is estimated by determining a size and shape 


\subsection{EVALUATION OF THE CONSEQUENCES OF PROPANE RELEASES}

In Section 8, individual release sequences were identified and evaluated by determining their expected frequency of occurrence and the corresponding release fraction. At this point, a risk number could be obtained by multiplying the individual release sequence probabilities and release fractions together, and summing over a 11 release sequences. The resulting risk number, however, would not be in a suitable form for comparison with other societal risks, which is one of the objectives of the risk assessment.

To express the risk in a more useful form, conversion factors must be developed to allow modification of the consequence portion of the risk number (in this case, to fatalities). The purpose of this section is to develop these conversion factors. Areas that must be evaluated include: health effects of a propane release, demography, meteorology, and quantity of the release dispersed. The final portion of this section will show how these factors are applied to obtain the risk number.

\subsection{HEALTH EFFECTS}

The release sequences developed in Sections 7 and 8 represent major pathways for the release of propane during transportation. The potential sequences of events following a release are depicted in Figure 9.1. This section describes these events, their physical characteristics, and resultant consequences. In this analysis, the consequences are generally restricted to risks to the general public. The treatment of the risks to vehicle drivers and emergency response personnel will be discussed in Section 10.

The release categories determined in Section 8.4 are represented by various branches of the event tree shown in Figure 9.1. An immediate release with dispersion corresponds to the fifth category of release, a release from a major mechanical failure of the propane tank. This release, as shown, could dissipate into the atmosphere, resulting in no significant consequences, or could ignite at some point, causing damages related to a detonation or deflagration. An immediate release could also be ignited instantaneously, as in release category six, an explosive rupture of the propane tank. 
(range and geometry) for each effect and applying this information to a uniform population density. The fatality mechanisms used to estimate the consequences of a propane release are described in Section 9.2. The U.S. population model used here is described in Section 9.3. Required meteorology and vapor dispersion models are described in Sections 9.4 and 9.5, respectively.

\subsection{FATALITY MECHANISMS}

The fatality mechanisms described in the following subsections are used to estimate the consequences of a propane release. Each mechanism is assigned a priority in the consequence calculations based on the fatality percentage attributed to it. Those mechanisms with higher fatality percentages are calculated first; all other consequence calculations exclude those areas affected by the higher priority mechanisms, to avoid double-counting fatalities.

Typically, the general public does not reside immediately adjacent to major transportation pathways. General public fatalities attributable to propane releases will thus occur at moderate distances from a release occurring on this pathway. To model this, a 15-meter exclusion zone on either side of the transportation pathway centerline will be assumed for all releases. The uniform population density assigned to the remaining areas will not be applied to this exclusion zone. Instead, the exclusion zone is assigned a population density of zero. The risk to the population that would normally be inside this exclusion zone, such as the tank truck and other drivers and emergency response personne1, wi11 be discussed in Section 10. Figure 9.2 depicts this

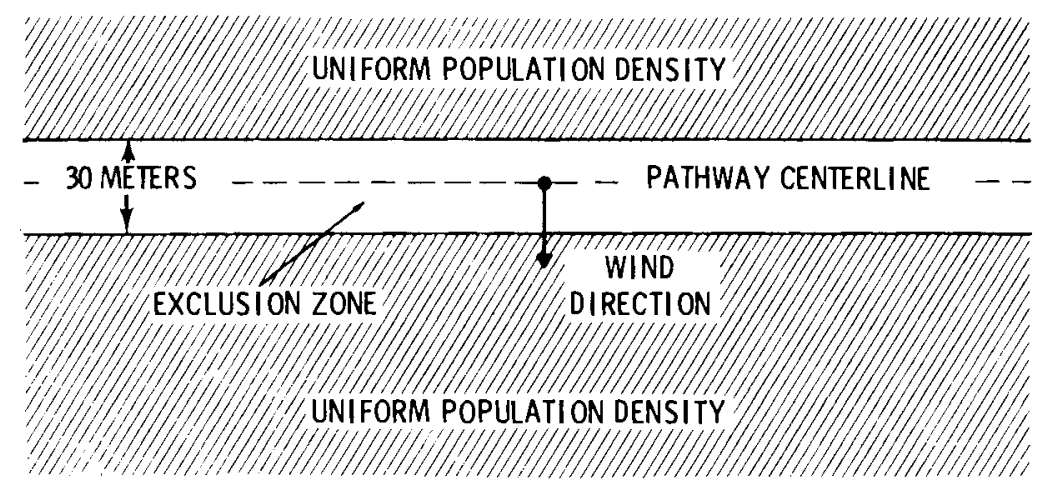

FIGURE 9.2. General Public Exclusion Zone 
30-meter exclusion zone. The wind direction for all dispersed releases will be assumed to be normal to the transportation pathway.

\subsubsection{Direct Flame Exposure}

It is assumed that any person coming into direct contact with flames from a propane fire will not survive. However, portions of the general public will be shielded from the flames at the time of ignition by building structures or automobiles. Others will be able to evacuate the immediate area. It is thus assumed that, because of shielding from the flames or evacuation only $10 \%$ of the available population will be directly exposed to the fireball.

The term "fireball" implies a spherical shape for the flame geometry. In the case of an immediate release, the actual flame geometry may vary somewhere between a sphere and a hemisphere. A hemispherical fireball will expose more ground area to direct flame contact than will a spherical firebal1. To ensure a conservative fatality estimate, a hemispherical fireball will be used, with a radius given by Equation $(9-1)$.

$$
r=1.93 \mathrm{~m}^{0 \cdot 32}
$$

In this equation, the mass of the propane vapor available for immediate combustion is represented by " $m$ ", given in kilograms. The amount of vapor immediately generated at the time of release is a function of the temperature of the liquid propane. Table 9.1 lists the percentage of liquid that instantaneously flashes to vapor for several temperatures. These temperatures reflect expected propane temperatures for several of the release scenarios.

TABLE 9.1. Vapor Flash Percentages (2)

\begin{tabular}{cc} 
Temperature & Percent Flash \\
\hline $21.1^{\circ} \mathrm{C}$ & 35 \\
$86.4^{\circ} \mathrm{C}$ & 41 \\
$51.3^{\circ} \mathrm{C}$ & 55 \\
$55.3^{\circ} \mathrm{C}$ & 57 \\
$57.8^{\circ} \mathrm{C}$ & 59
\end{tabular}


The area encompassed by the flame is given by:

$$
A=\pi r^{2}
$$

where $r$ is the fireball radius, in meters. Again, because of shielding effects and potential evacuation, only about $10 \%$ of the available population is exposed to this fireball. All those within the fireball area are assumed fatalities.

Equation (9-1) is only valid for those releases where ignition immediately follows the release itself. If ignition is delayed for a short period of time, the fireball geometry is controlled by the dispersion of the vapor cloud. In the case of a dispersed vapor cloud, the fireball (or more appropriately, the flame area) is assumed to be defined by the flammable region of the cloud. Determination of the flammable region is based on dispersion models, discussed in Section 9.5. When dispersion occurs, the probability of ignition decreases from one to some value which is dependent upon the area of the flammable region. The probability of finding an ignition source $(P)$ for several ranges of flammable cloud area is given in Table 9.2. (3) To facilitate computation by a computer, Table 9.2 has been approximated by Equation (9-3):

$$
p=0.525 \exp \left(-\frac{A}{100}\right)+\left[1-\exp \left(-\frac{A}{80}\right)\right]\left[1-\exp \left(-\frac{3(\log A-0.4)}{4}\right)\right]
$$

where $A$ is the area of the flammable region in $\mathrm{m}^{2}$. It should be noted that the terms in Equation (9-3) have no physical interpretation. Propane is easily ignited. Thus, the probability of ignition decreases as the area of the cloud increases, since ignition will most likely occur before the larger areas can be achieved.

Direct flame hazards also exist for continuous releases. When an ignition source is immediately available, a continuous release will typically result in a torching effect. In this case, the propane is consumed immediately upon release and the flames are normally confined to a small local area. Direct flame contact presents little hazard under these circumstances. However, torching can lead to a more significant hazard as the 
TABLE 9.2. Plume Ignition Probability

\begin{tabular}{cc} 
Area Range $\left(\mathrm{m}^{2}\right)$ & Probability of Ignition in That Range \\
\cline { 2 - 2 }$<30$ & 0.5223 \\
$30-100$ & 0.1173 \\
$100-300$ & 0.0969 \\
$300-1,000$ & 0.0884 \\
$1,000-3,000$ & 0.0615 \\
$3,000-10,000$ & 0.0479 \\
$10,000-30,000$ & 0.0287 \\
$30,000-100,000$ & 0.0183 \\
$100,000-300,000$ & 0.0094 \\
$300,000-1,000,000$ & 0.0052 \\
$1,000,000-3,000,000$ & 0.0022 \\
$3,000,000-10,000,000$ & 0.0011
\end{tabular}

flame impinges on the propane tank. The heat from the direct flame contact may weaken the tank and allow it to rupture, releasing major amounts of propane and creating fireballs similar to those created by an immediate release. Vapor flash percentages will be higher than those for ambient temperature releases (see Table 9.1). For this analysis, it has been assumed that $50 \%$ of the tank contents are depleted by torching prior to tank rupture. Fireball geometry is calculated by Equation (9-1), the same method as was used for immediate releases with no dispersion. Differences in fireball size for the immediate and continuous releases are the result of different values of mass, $m$, remaining at the time of release.

A more significant flame hazard results when a continuous release is allowed to disperse and delayed ignition occurs. As in the case of an immediate release with dispersion, the flame geometry is controlled by the establishment of a flammable region of vapor. Again, models describing the dispersion of propane and the establishment of flammable areas are discussed in Section 9.5 of this report. The probability of a dispersed continuous release reaching an ignition source follows the same prediction formula as an immediate release (see Equation 9-3). 
Dispersion models for continuous releases generally provide geometry parameters for steady-state isopleths only. Isopleths are lines of constant concentration and are used to identify the boundaries of the upper and lower flammability limits. The flammability limits define the fireball geometry and probability of ignition. Steady-state isopleths are established within minutes following a release. It is assumed here that sufficient amounts of propane exist to allow the attainment of steady-state conditions.

However, the calculation of consequences based on these steady-state isopleths is misleading because the probability of reaching steady-state conditions (even for the short periods of time involved here) is quite low. It is much more likely that the dispersed cloud will find an ignition source before reaching the maximum or steady-state size. This phenomena relates back to information given in Table 9.2. To more closely approximate reality, the steady-state isopleth area for continuous releases with dispersion is divided into 15 increments. Each increment represents a flammable cloud size that must be passed through to reach maximum or steady-state isopleth area. Calculating the risk from each increment and then adding these risks together arrives at a release risk more closely approximating what might be expected of an actual release. As in the case of an immediate release, fatality of those exposed to direct flame contact is $100 \%$ of the population in the fireball area. However, only $10 \%$ of the available population is exposed to the fireball, because of shielding effects and evacuation efforts.

\subsubsection{Explosion Effects}

Explosion effects can be divided into two categories. These are overpressure and fragmentation. Overpressure effects are those deleterious effects caused by a radially expanding blast wave or pressure wave centered about the point of initiating energy release. The initiating energy release may be the result of a chemical reaction or a mechanical reaction, hereafter referred to as a detonation or an explosive rupture, respectively. In this report, a chemical reaction, or detonation, refers to an explosion occurring after a vapor cloud has been formed. The flame front moves at supersonic speeds, creating pressure or shock waves. A mechanical reaction, on the other hand, refers to the explosion forces associated with tank rupture. The flame front 
moves at subsonic speeds (deflagration) and does not create pressure waves. Any shock wave or blast effects are a result of tank rupture. Fragmentation accounts for those effects caused by flying objects set in motion by the blast wave. The objects may be pieces of the propane tank or secondary objects in the neighborhood of the explosion.

Overpressure effects are estimated by assigning fatality percentages based on lines of constant overpressure magnitude (LCOM). It is assumed that 100\% of the population within the $6.9 \times 10^{4} \mathrm{~Pa}$ LCOM will die. The $6.9 \times 10^{4} \mathrm{~Pa}$ limit was chosen from Figure 9.3, where it defines the limit of probable total destruction. (4) Areas inside the $1.7 \times 10^{4} \mathrm{~Pa}$ LCOM are assigned a fatality percentage of $10 \%$. The $1.7 \times 10^{4} \mathrm{~Pa}$ limit was chosen from Figure 9.3, where it represents the limit of serious structural damage. Distances to the $6.9 \times 10^{4} \mathrm{PA}$ and $1.7 \times 10^{4} \mathrm{PA}$ LCOM are found by calculating an equivalent TNT magnitude of the blast and using a scaled range approach. (5) The distance to any LCOM can be found by multiplying the scaled range value by the TNT equivalent of the blast raised to the one-third power. For example, if the TNT equivalent is $2.7 \mathrm{~kg}$ the distance to the $6.9 \times 10^{4}$ PA LCOM is $6.1 \mathrm{~m}$. Figure 9.3 has been approximated by Equation (9-4) to ease the implementation of later calculations by computer.

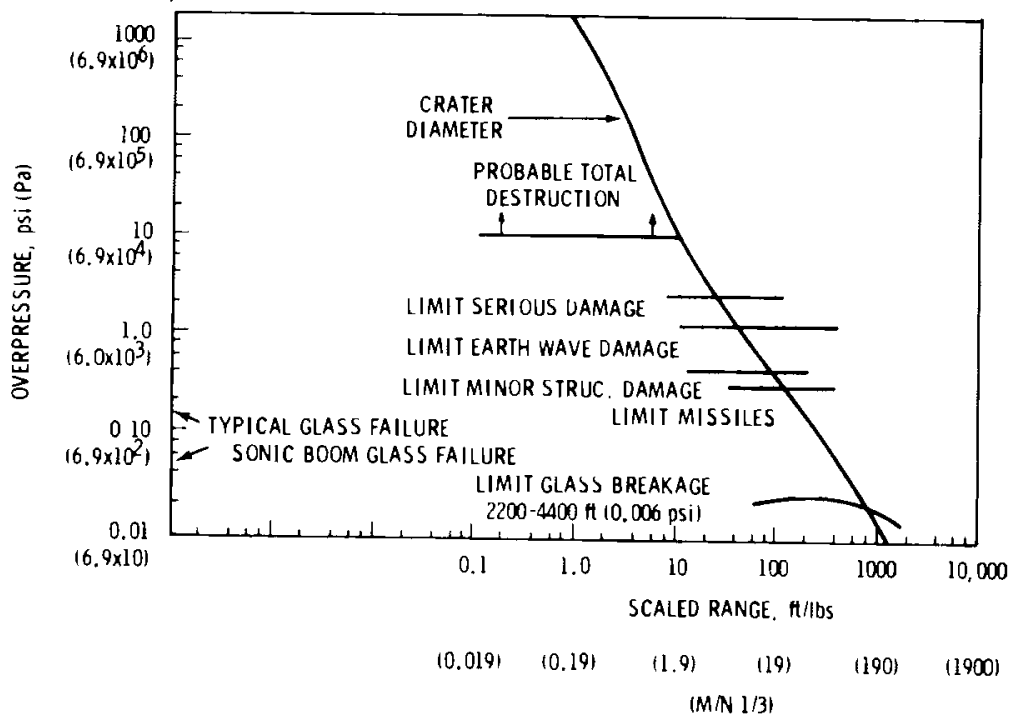

FIGURE 9.3. Damage Limits versus Scaled Range ${ }^{(4)}$ 


$$
\mathrm{p}=82.88{\frac{\mathrm{x}}{\mathrm{m}^{0.33}}}^{-1.4362}
$$

The key to defining blast effects on the basis of peak overpressure now lies in calculating the TNT equivalent of the blast. For chemical reactions, Equation $(9-5)^{(a)}$ is used to predict the TNT equivalent mass. (5)

$$
\text { TNT Eq. }=m=\varepsilon \frac{\Delta{ }_{C_{p}} m_{p}}{\Delta H_{C_{T N T}}}
$$

$$
\begin{aligned}
m_{p} & =\text { mass of the propane; } \mathrm{kg} \\
\Delta \mathrm{H}_{\mathrm{CP}} & =\text { propane heat of combustion; } 1.196 \times 10^{7} \frac{\mathrm{cal}}{\mathrm{kg}} \\
\Delta \mathrm{H}_{\mathrm{C}_{\mathrm{TNT}}} & =\text { TNT heat of combustion; } 1.109 \times 10^{6} \frac{\mathrm{cal}}{\mathrm{kg}}
\end{aligned}
$$

Partial combustion and physical differences between TNT and gaseous explosions are accounted for by the unitless term, $\varepsilon$. The value of $\varepsilon$ has been empirically derived to be 0.1 for explosions of the type expected from propane releases. (5) The point of detonation is difficult to define for vapor clouds, such as those resulting from propane dispersion. Vapor cloud detonations are simulated in this report by dividing the overall TNT equivalent mass into eleven discrete charges. The LCOM establishment results from the simultaneous detonation of all eleven point charges when they are placed on the downwind centerline of the vapor cloud, as shown in Figure 9.4 .

Tank rupture, or mechanical reaction, can also cause overpressure effects. The same methods are used here to define the affected area and fatality percentages as were used in the chemical explosions. However, the TNT equivalency of a rupture is substantially different, being based upon the rupture pressure

(a) adapted from TNT Eq. $=\frac{\varepsilon \cdot V_{F} \cdot \Delta H_{C}}{2.17 \times 10^{6}}$ 


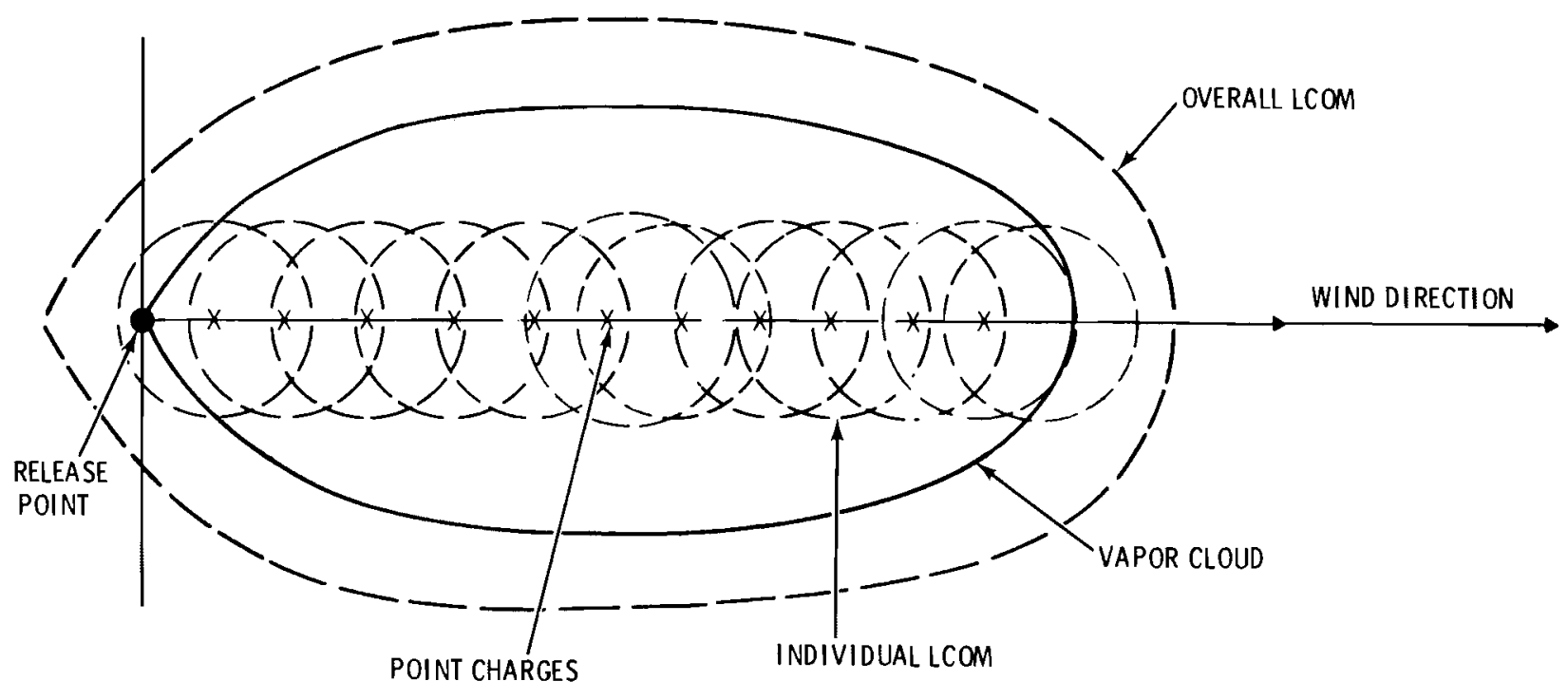

FIGURE 9.4. Vapor Cloud LCOM Construction

and physical dimensions of the tank. In all cases, rupture is assumed to be caused by a weakening of the tank wall by thermal stresses. (a) Safety valves are assumed to be functioning properly, thus limiting the tank pressure to the rating of the valves. Safety valve ratings, tank diameters, and TNT equivalent masses are listed in Table 9.3.

Fragmentation can also represent a significant explosion hazard. Fragments created during the rupture of a tank will most likely be portions of the tank itself and will be confined to a region of impact of 610 meters radially from the explosion. (1) Although the direction of fragment flight is unknown, there are a limited number of tank pieces that will act as missiles. To account for the fact that few people within a $610 \mathrm{~m}$ radius can actually be affected by tank fragments the fatalities due to rupture fragments are estimated to be all of those persons within an area equal to 610 meters times the length of the tank, as shown in Figure 9.5. In the case of a detonation the

(a)Failure of the tank by overpressurization has not occurred historically and will not be analyzed for consequences here. It is assumed that the consequences of tank overpressurization, if it should occur, are sufficiently similar to other consequences presented here to forego additional analysis. 
TABLE 9.3. TNT Equivalent Masses for Tank Rupture

\begin{tabular}{|c|c|c|c|}
\hline Mode & Valve Rating & Diameter & TNT Equivalent \\
\hline Bobtail Transport & $1.86 \mathrm{MPa}$ & $1.84 \mathrm{~m}$ & $10.0 \mathrm{~kg}$ \\
\hline Tank Truck & $1.86 \mathrm{MPa}$ & $2.18 \mathrm{~m}$ & $17.0 \mathrm{~kg}$ \\
\hline Rail Car & $1.93 \mathrm{MPa}$ & $3.02 \mathrm{~m}$ & $48.9 \mathrm{~kg}$ \\
\hline
\end{tabular}

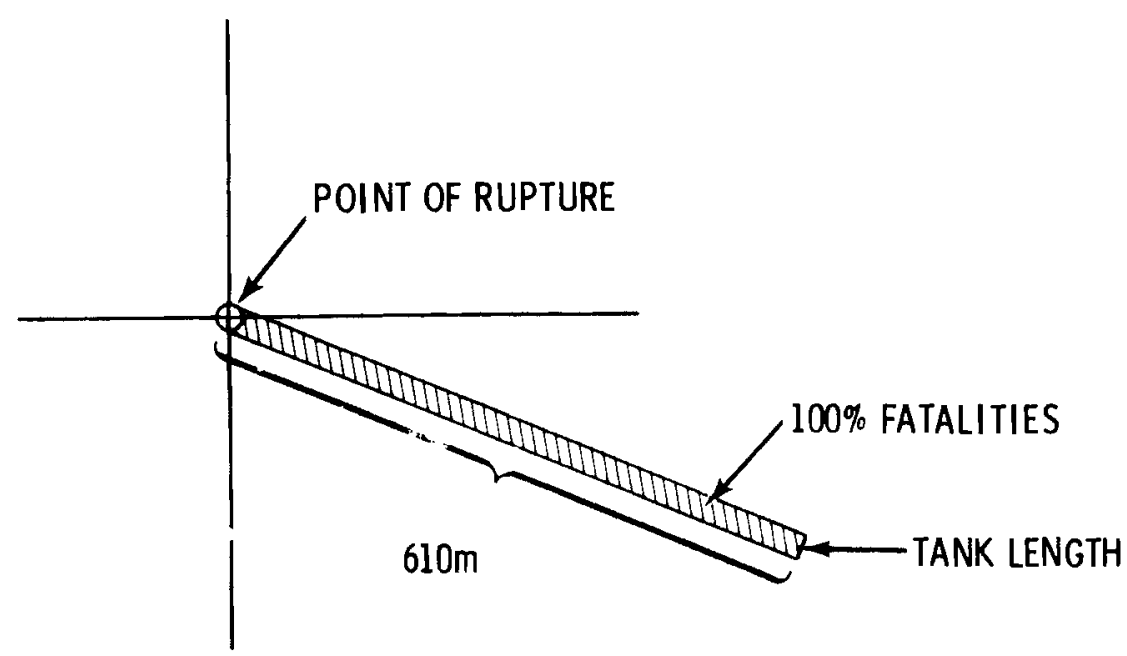

FIGURE 9.5. Fragmentation Fatality Area

fragments will be composed of secondary fragments from nearby objects. Since the dimensions and number of nearby objects cannot be predicted, the fatalities attributed to secondary objects will be estimated by the same methods used for overpressure fatalities. The defining LCOM for secondary fragments is $0.3 \mathrm{psi}$, which from Figure 9.2 is seen to be the limit of missle generation. A 0.1 fatality percentage is assigned to persons inside this LCOM.

\subsubsection{Radiant Heat Flux}

Fatalities from radiant heat are estimated by determining a distance from the fireball at which the threshold of 2nd degree burns exists. The threshold for 2 nd degree burns has been estimated at $5 \mathrm{cal} / \mathrm{cm}^{2}{ }^{(6)}$ It is assumed that anyone within the area described by this distance will experience 2nd degree burns on all exposed surfaces. The amount of exposure varies from person to person and from season to season. An average of $27 \%$ exposed skin has been 
chosen, corresponding roughly to both arms and the face. Figure 9.6, estimated from data presented in Reference 6 , shows the probability of fatality versus the amount of 2 nd degree burns. (6) From this figure it can be seen that 2 nd degree burns over about $27 \%$ of the body should result in a $10 \%$ chance of death.

Methods for predicting the distance to the burn threshold depend upon the type of release and the fireball geometry. For tank ruptures or immediate releases without dispersion, the fireball is assumed to be hemispherical. This simplifies heat flux calculations since hemispherical geometry can be assumed throughout. To calculate heat flux magnitude, a flame temperature of $2200^{\circ} \mathrm{K}$ is assumed ${ }^{(5)}$. This is the approximate combustion temperature of propane. The surface area of the firebal1 is given by Equation (9-6):

$$
A_{S}=2 \pi r^{2}
$$

The value of $r$ can be found by applying Equation (9-1). Total time integrated heat flux for the fireball is now given by Equation (9-7): (7)

$$
Q=\varepsilon \sigma A_{S} T^{4} t
$$

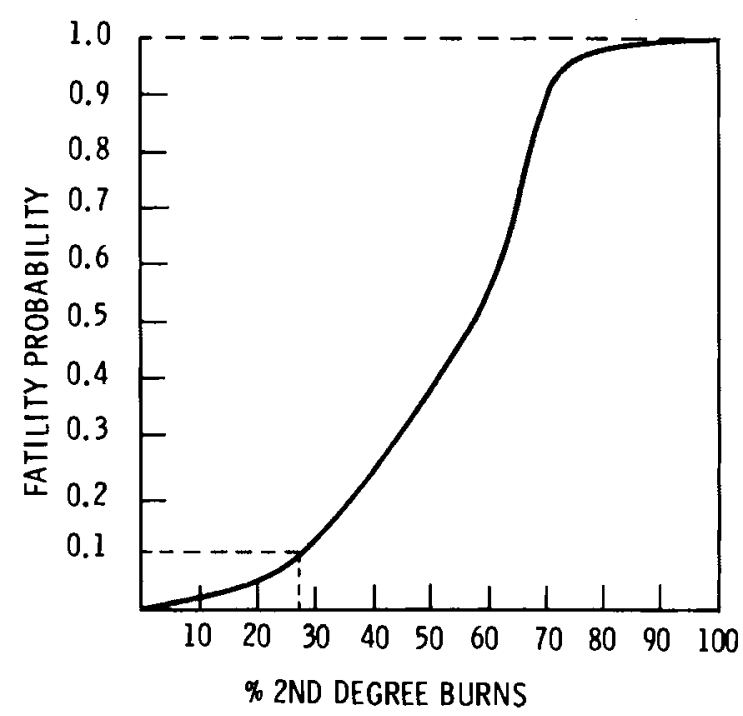

FIGURE 9.6. Fatality Probability versus 2nd Degree Burns 
where

$$
\begin{aligned}
A_{S} & =\text { flame surface area in } \mathrm{m}^{2} \\
T & =\text { flame temperature in }{ }^{\circ} \mathrm{K} \\
\sigma & =\text { Stephan-Boltzman constant }-1.3537 \times 10^{-10} \frac{\mathrm{cal}}{\mathrm{cm}^{2}}-\mathrm{S}-{ }^{\circ} \mathrm{K}^{4} \\
\varepsilon & =\text { gas emissivity } \\
\mathrm{t} & =\text { fireball duration in seconds }
\end{aligned}
$$

The value of $\varepsilon$ is dependent upon the geometry of the fireball and generally ranges between 0.3 and 0.1 . To maintain the conservatism of this study it has been assigned a constant value of 0.3 . The expected duration $(t)$ of the fireball is given by Equation (9-8) where as in Equation (9-1), $\mathrm{m}$ is the mass of the flammable propane in kilograms. (1)

$$
t=0.299 \mathrm{~m}^{0 \cdot 32}
$$

The distance to the 2nd degree burn threshold $\left(r^{2}\right)$ can now be determined using Equation $(9-9)$ :

$$
r_{2}=r_{1} \sqrt{Q_{1} / Q_{2}}
$$

where

$$
\begin{aligned}
& r_{1}=\text { fireball radius in meters } \\
& Q_{1}=\text { total heat flux given in Equation }(9-7) \\
& Q_{2}=\text { heat flux required to cause } 2 \text { nd degree burns. }
\end{aligned}
$$

The previous analysis will apply to releases with a hemispherical configuration. This excludes any releases involving dispersion. In these, a slightly different approach must be taken. Flame surface area must now be estimated by assuming the fireball to have the same shape as the flammable region just prior to ignition. To greatly simplify the calculations the region area will be approximated by an ellipsoid. The major and minor axes of the volume will be defined by the downwind and crosswind distances found by the applicable dispersion models. The height of the cloud is estimated by assuming a constant ratio between it and the crosswind width. This ratio 
was generated by the dispersion model used in this study. The average ratio was determined to be 0.133 . Therefore, the height of the cloud $(z)$ is given by Equation $9-10$ as follows:

$$
z=0.133 y
$$

where $z$ is the cloud height and $y$ is the crosswind width at the widest point. With these parameters identified, the surface area of the flame (A) can now be calculated using Equation (9-11). (8)

$$
A \approx \frac{\pi(x+y) z\left(64-3\left[\frac{x-y}{x+y}\right]^{4}\right)}{64-16\left[\frac{x-y}{x+y}\right]^{2}}+\pi x y
$$

Total heat flux from the fireball is found using Equation (9-7).

Finding the distance to the 2nd degree burn threshold also becomes more difficult. It is assumed that the distance to the burn threshold from the fireball perimeter will be constant at all points. In addition, the surface described by the burn threshold will have the same shape as the fireball. Using these two assumptions, the burn threshold surface area $\left(A_{2}\right)$ can be found by:

$$
A_{2}=A_{1} Q_{1} / Q_{2}
$$

where

$$
\begin{aligned}
& A_{1}=\text { flame surface area } \\
& Q_{1}=\text { total heat flux } \\
& Q_{2}=\text { 2nd degree burn threshold }
\end{aligned}
$$

Using the same ellipse eccentricity and height-width relationship as for the fireball, the distance to the 2nd degree burn threshold can be calculated by applying iteration techniques to Equation (9-11). Dimensions determined by this method are then applied to a standard ellipse area formula to arrive at the total land area subjected to 2 nd degree burn radiation. As in the case of 
direct flame contact, much of the general public will be shielded from the effects of radiant heat flux. Taking into account such factors as the number of persons indoors and shielding by exterior objects, the exposure factors given in Table 9.4 have been assigned to persons inside the 2nd degree burn area. The definitions of the population zones are discussed in Section 9.3.

TABLE 9.4. Factors for Radiant Heat Exposures

$\begin{array}{ll}\text { Population Zone } & \text { Exposure Factor } \\ \text { Urban } & 1.564 \times 10^{-3} \\ \text { Other Urban } & 0.1233 \\ \text { Rural } & 0.1875\end{array}$

\subsubsection{Secondary Fires}

In this report, secondary fires are considered to be an additional effect of radiant heat flux. As such, the techniques for calculating the number of secondary fires are essentially the same as calculating radiant heat fatalities. The major difference is the magnitude of radiant heat intensity necessary to cause damage. For exposed skin, a threshold value of $5 \mathrm{cal} / \mathrm{cm}^{2}$ caused 2nd degree burns. For secondary fires, the threshold intensities are defined in a different manner. Figure 9.7 depicts the intensities necessary to initiate spontaneous combustion for various materials versus exposure time. For this study, all structures will be assumed to be constructed of whitewood. Threshold intensities will then be based on the dashed line in Figure 9.7. To facilitate computer application, this curve has been approximated by the following equation:

$$
I=-\frac{\ln (t / 4000)}{5.5\left(1-e^{-0.1995} t\right)}
$$

The units for intensity (I) are $\mathrm{cal} / \mathrm{cm}^{2}-\mathrm{s}$ and $\mathrm{t}$ is given in seconds. The value of $t$ can be found using Equation (9-8). The secondary fire threshold is now defined as:

$$
Q=I t
$$




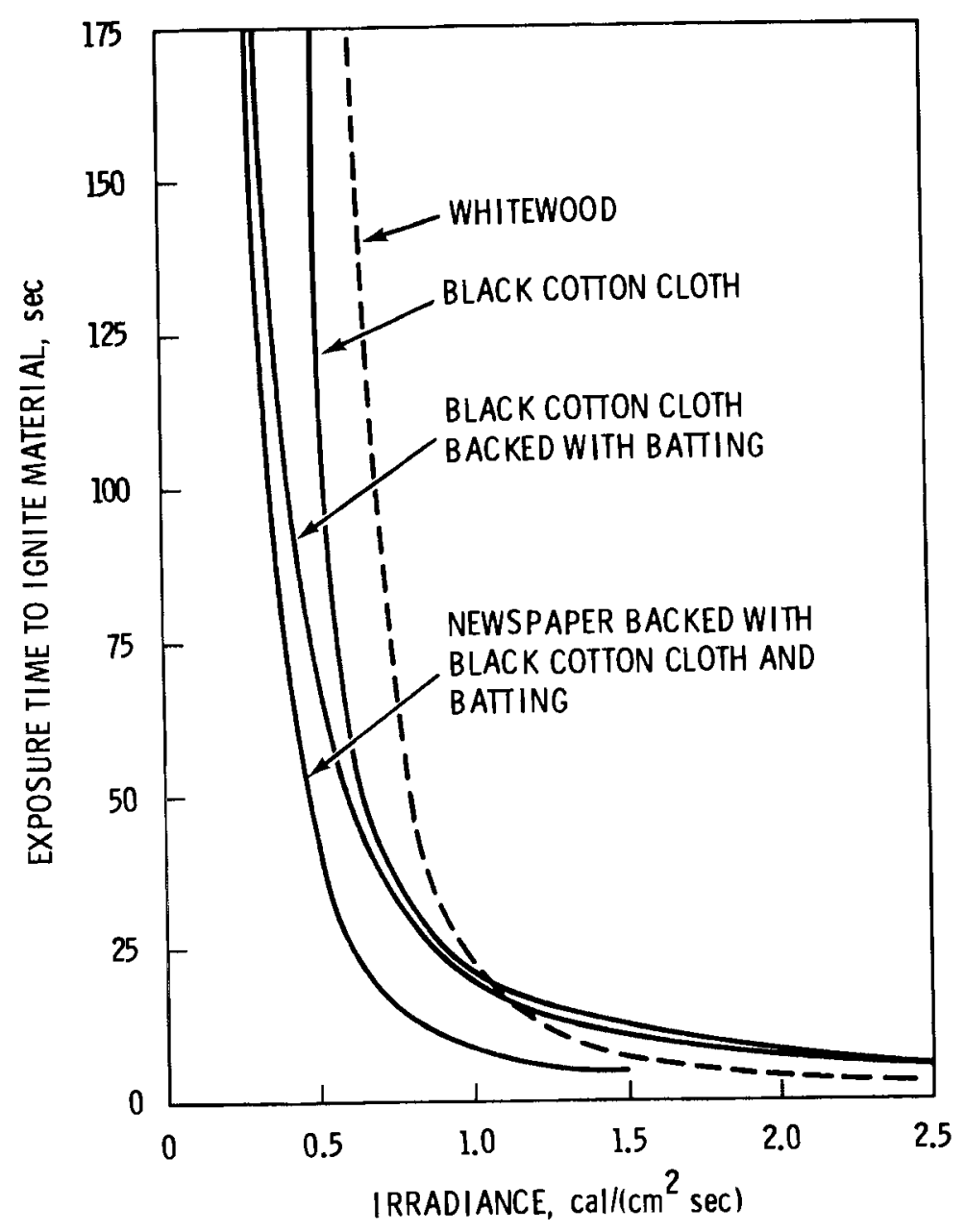

FIGURE 9.7. Radiant Exposures to Ignite Variou's Materials

and this term is used in Equations (9-9) and (9-12), in the same manner as described earlier, to define the areas exposed to secondary fire hazard.

The number of secondary fires started in the exposed area is estimated by multiplying the distance to the fire threshold times a building density factor. The building densities used in this study are presented in Table 9.5.

To compensate for building materials other than whitewood and the effect of low angles of incidence, the building densities listed in Table 9.5 have been reduced to $0.35,0.9$, and 0.2 buildings $/ \mathrm{km}$. Table 9.6 presents the probability of various fatality levels versus the number of building fires started. (10) 
TABLE 9.5. Building Densities

$\begin{array}{lr}\text { Population Zone } & \text { Building Density } \\ \text { Urban } & 35 \text { Buildings } / \mathrm{km} \\ \text { Other Urban } & 9 \text { Buildings } / \mathrm{km} \\ \text { Rural } & 2 \text { Buildings } / \mathrm{km}\end{array}$

TABLE 9.6. Estimated Probability of $n$ Deaths from $j$ Secondary Building Fires

\begin{tabular}{|c|c|c|c|c|c|c|c|c|}
\hline \multicolumn{9}{|c|}{ Probability of $n$ Deaths from $j$ Fires } \\
\hline n & $j=0$ & 1 & 2 & 3 & 4 & 5 & 6 & 7 \\
\hline 0 & 1.0 & 0.99 & 0.98 & 0.97 & 0.96 & 0.95 & 0.94 & 0.93 \\
\hline 1 & 0.0 & 0.01 & 0.02 & 0.03 & 0.04 & 0.05 & 0.06 & 0.07 \\
\hline 2 & 0.0 & 0.0035 & 0.007 & 0.01 & 0.014 & 0.018 & 0.021 & 0.025 \\
\hline 3 & 0.0 & $3.0 E-4(a)$ & $6.0 \mathrm{E}-4$ & $9.0 \mathrm{E}-4$ & $1.2 \mathrm{E}-3$ & $1.5 \mathrm{E}-3$ & $1.8 \mathrm{E}-3$ & $2.1 E-3$ \\
\hline 4 & 0.0 & $1.5 \mathrm{E}-4$ & $3.0 \mathrm{E}-4$ & $4.5 \mathrm{E}-4$ & $6.0 \mathrm{E}-4$ & $7.5 \mathrm{E}-4$ & $9.0 \mathrm{E}-4$ & $1.1 \mathrm{E}-3$ \\
\hline 5 & 0.0 & $1.0 \mathrm{E}-4$ & $2.0 \mathrm{E}-4$ & 3.0E-4 & $4.0 \mathrm{E}-4$ & $5.0 \mathrm{E}-4$ & $6.0 \mathrm{E}-4$ & $7.0 \mathrm{E}-4$ \\
\hline 10 & 0.0 & $2.5 \mathrm{E}-5$ & $5.0 \mathrm{E}-5$ & $7.5 \mathrm{E}-5$ & $1.0 \mathrm{E}-4$ & $1.3 \mathrm{E}-4$ & $1.5 \mathrm{E}-4$ & $1.8 \mathrm{E}-4$ \\
\hline 15 & 0.0 & $8.0 \mathrm{E}-6$ & $1.6 \mathrm{E}-5$ & $2.4 \mathrm{E}-5$ & $3.2 E-5$ & $4.0 \mathrm{E}-5$ & $4.8 E-5$ & $5.6 \mathrm{E}-5$ \\
\hline
\end{tabular}

(a) Read $3.0 \times 10^{-4}$

\subsection{DEMOGRAPHY}

To determine the number of people affected by a release of propane during a transportation accident, the U.S. population distribution must be characterized. The United States (excluding Alaska and Hawaii) was divided into the nine Census Bureau regions shown in Figure 9.8. The population densities were grouped into three classes: urban areas, "other urban" areas and rural areas. An urban area is a city or connecting cities with a total population of 50,000 and contingent areas of population of 2,500. Other urban areas are classified as areas that are not included in urban areas and have populations equal to or greater than 2,500 persons. Rural areas are assumed to be all those areas not included in the previous two categories. 


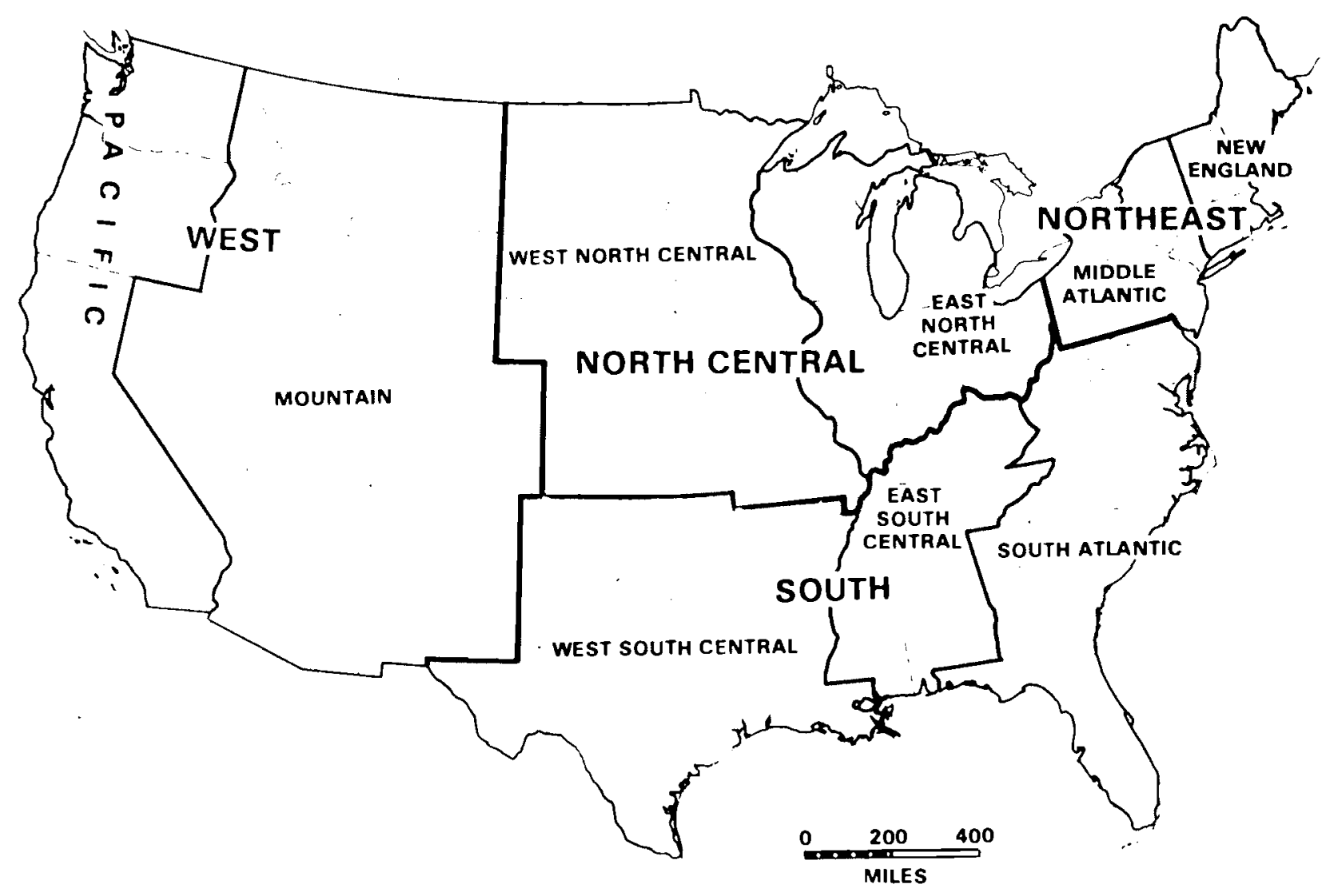

FIGURE 9.8. Map of the U.S., Showing Census Divisions and Regions

The total population and land area of each region in 1974 was obtained from Bureau of the Census information. (11) Land areas for urban areas (both urban and other urban) in 1970 and urban population data for 1974 were obtained from other Census Bureau reports. $(12,13)$ Rural population and land area figures were obtained by subtracting numbers for the urban areas from the total figures for any one region. The population densities and land areas for each region are shown in Table 9.7.

This risk assessment, however, is based on a 1985 shipping model. It was thus necessary to extrapolate population and land areas to 1985. A report by J. P. Pickard ${ }^{(14)}$ predicts that between 1975 and $2000,77 \%$ of the population growth in the U.S. will occur in urban regions. Using the 1985 population projections given in Reference $10,77 \%$ of the total growth was distributed 
TABLE 9.7. 1974 Census Data

\section{Population}

New Engiand

Total

Urbanized Areas

Other Urban

Rura 1

Middle Atlantic

Total

Urbanized Areas

Other Urban

Rural

East North Central

Total

Urbanized Areas

Other Urban

Rural

West North Central

Total

Urbanized Areas

Other Urban

Rural

South Atlantic

Total

Urbanized Areas

Other Urban

Rural

East South Central

Total

Urbanized Areas

Other Urban

Rural

West South Central

Tota $i$

Urbanized Areas

Other Urban

Rural

Mountain

Total

Urbanized Areas

Other Urban

Rural

Pacific

Total

Urbanized Areas

Other Urban

Rural
$12,150,000$

$7,666,000$

$1,409,000$

$3,075,000$

$37,401,000$

$27,510,000$

$2,928,000$

$6,963,000$

$40,824,000$

$24,818,000$

$5,309,000$

$10,697,000$

$16,682,000$

$6,876,000$

$3,517,000$

$6,289,000$

$33,206,000$

$15,196,000$

$4,454,000$

$13,556,000$

$13,387,000$

$4,457,000$

$2,550,000$

$6,380,000$

$20,584,000$

$10,199,000$

$3,846,000$

$6,539,000$

$9,411,000$

$4,176,000$

$1,879,000$

$3,356,000$

$26,649,000$

$19,282,000$

$2,767,000$

$4,600,000$
Land Area $\left(\mathrm{km}^{2}\right)$

172,515

6,843

4,281

161,391

266,110

13,996

3,386

248,728

643,053

18,443

6,355

618,255

$1,339,670$

6,716

5,344

$1,327,610$

722,030

13,773

8,224

700,033

471,287

5,281

5,924

460.082

$1,136,710$

11,305

7,469

$1,117,936$

$2,237,467$

4,098

3,190

$2,230,179$

838,813

13,067

4,527

821,219
Density (People $/ \mathrm{km}^{2}$ ) Land Area (\%)

$\begin{array}{rr}70.4 & 100.0 \% \\ 1,120.0 & 4.0 \% \\ 329.0 & 2.5 \% \\ 17.3 & 93.5 \% \\ & \\ 140 & 100.0 \% \\ 1,970 & 5.3 \% \\ 865 & 1.3 \% \\ 28 & 93.4 \%\end{array}$

$\begin{array}{rr}62.7 & 100.0 \% \\ 1.350 .0 & 2.9 \% \\ 835.0 & 1.0 \% \\ 17.3 & 96.1 \%\end{array}$

12.5

$100.0 \%$

$1,020.0$

$0.5 \%$

658.0

$0.4 \%$

$4.7 \quad 99.1 \%$

$\begin{array}{ll}46.0 & 100.0 \%\end{array}$

1,100

542

19.4

$1.9 \%$

$1.1 \%$

$97.0 \%$

$\begin{array}{cr}28.4 & 100.0 \% \\ 844 & 1.1 \% \\ 430 & 1.3 \% \\ 13.9 & 97.6 \%\end{array}$

$18.1 \quad 100.0^{\%}$

$902-1.0 \%$

$515 \quad 0.7 \%$

$5.8 \quad 98.3 \%$

$\begin{array}{rr}4.2 & 100.0 \% \\ .019 & 0.2 \% \\ 589 & 0.1 \% \\ 1.5 & 99.7 \%\end{array}$

$\begin{array}{cr}30.4 & 100.0 \% \\ 1,476 & 1.6 \% \\ 611 & 0.5 \% \\ 5.6 & 97.9 \%\end{array}$


between urban and other urban areas by the ratio of their 1974 populations. The remainder was added to the rural population. Figure 3.4 in Population and the American Future ${ }^{(15)}$ predicts that urban land area will grow approximately 25\% between 1974 and 1985. This enabled the calculation of 19851 and area values. As before, rural land area was found by subtraction. Projected 1985 data are given in Table 9.8.

\subsection{METEOROLOGY}

The diffusion climatology along the transport route must be incorporated into any risk analysis where the atmosphere is an important pathway for exposures to nearby populations. The important atmospheric variables are: 1) wind direction, which indicates the initial direction of travel; 2) wind speed, which indicates the rate of transport; and 3) atmospheric stability, which indicates the rate of dilution and plume rise potential. Certain characteristics of release (e.g., height and temperature) are also important in the evaluation of the atmospheric pathway.

Assuming a postulated accident with a surface release and little or no release-related plume rise, the immediate and greatest impact will be in the region surrounding the location of the event. Transport and diffusion are often determined by local influences. Wind speeds and directions show considerable variation that cannot always be summarized by large geographic regions. Local influences include topography (surface roughness, channeling), heat island effects, and proximity to large bodies of water. The inclusion of such influences in the present analysis is not feasible, principaliy because the information is not available either from a data base or from current modeling capabilities.

For estimates of long-term diffusion averages, the average persistence of winds by sectors are used. Considering wind direction persistences alone, the actual sector annual-average air concentrations can be considerably higher or lower than an average. Based on reported values from 129 weather bureau surface stations in the continental U.S., the concentrations range on the order of from half to 5 times the average. The air concentrations near a particular population center can be expected to vary by the same factor depending on the 


\section{TABLE 9.8. Projected 1985 Census Data}

\begin{tabular}{|c|c|c|c|c|}
\hline & Population & Land Area $\left(\mathrm{km}^{2}\right)$ & Density (people $/ \mathrm{km}^{2}$ ) & Land Area $(\%)$ \\
\hline \multicolumn{5}{|l|}{ New England } \\
\hline Total & $13,997,000$ & 172,510 & 81.1 & $100.0 \%$ \\
\hline Urbanized Areas & $8,867,000$ & 8,525 & 1,040 & $4.9 \%$ \\
\hline Other Urban & $1,630,000$ & 5,333 & 306 & $3.1 \%$ \\
\hline Rural & $3,500,000$ & 158,652 & 22.1 & $92.0 \%$ \\
\hline \multicolumn{5}{|l|}{ Middle Atlantic } \\
\hline Total & $41,930,000$ & 266,110 & 158 & $100.0 \%$ \\
\hline Urbantzed Areas & $30,662,000$ & 17,436 & 1,760 & $6.6 \%$ \\
\hline Other Urban & $3,263,000$ & 4,218 & 774 & $1.6 \%$ \\
\hline Rural & $8,005,000$ & 244,456 & 32.7 & $91.8 \%$ \\
\hline \multicolumn{5}{|l|}{ East North Central } \\
\hline Total & $47,042,000$ & 643,053 & 73.2 & $100.0 \%$ \\
\hline Urbanized Areas & $28,762,000$ & 22,976 & 1,260 & $3.6 \%$ \\
\hline Other Urban & $6.153,000$ & 7,917 & 177 & $1.2 \%$ \\
\hline Rural & $12,127,000$ & 612,160 & 19.8 & $95.2 \%$ \\
\hline \multicolumn{5}{|l|}{ West North Central } \\
\hline Total & $17,995,000$ & $1,339,670$ & 13.4 & $100.0 \%$ \\
\hline Urbanized Areas & $7,545,000$ & 8,367 & 902 & $0.6 \%$ \\
\hline Other Urban & $3,859,000$ & 6,657 & 580 & $0.5 \%$ \\
\hline Rural & $6,591,000$ & $1,324,646$ & 5.0 & $98.9 \%$ \\
\hline \multicolumn{5}{|l|}{ South Atlantic } \\
\hline Total & $36,942,000$ & 722,030 & 51.2 & $100.0 \%$ \\
\hline Urbanized Areas & $17,421,000$ & 17,157 & 1,020 & $2.4 \%$ \\
\hline Other Urban & $5,106,000$ & 10,245 & 498 & $1.4 \%$ \\
\hline Rural & $14,415,000$ & 694,628 & 20.8 & $96.2 \%$ \\
\hline \multicolumn{5}{|l|}{ East South Central } \\
\hline Total & $13,793,000$ & 471,287 & 29.3 & $100.0 \%$ \\
\hline Urbanized Areas & $4,656,000$ & 6,579 & 708 & $1.4 \%$ \\
\hline Other Urban & $2,664,000$ & 7,380 & 361 & $1.6 \%$ \\
\hline Rural & $6,473,328$ & 457,328 & 14.2 & $97.0 \%$ \\
\hline \multicolumn{5}{|l|}{ West South Central } \\
\hline Total & $22,804,000$ & $1,136,710$ & 20.1 & $100.0 \%$ \\
\hline Urbanized Areas & $11,440,000$ & 74,083 & 812 & $1.2 \%$ \\
\hline Other Urban & $4,314,000$ & 9,305 & 464 & $0.8 \%$ \\
\hline Rural & $7,050,000$ & $1,113,322$ & 6.3 & $98.0 \%$ \\
\hline \multicolumn{5}{|l|}{ Mountain } \\
\hline Total & $10,286,000$ & $2,237,467$ & 4.6 & $100.0 \%$ \\
\hline Urbanized Areas & $4,641,000$ & 5,105 & 909 & $0.2 \%$ \\
\hline Other Urban & $2,088,000$ & 3,974 & 524 & $0.2 \%$ \\
\hline Rural & $3,557,000$ & $2,228,388$ & 1.6 & $99.6 \%$ \\
\hline \multicolumn{5}{|l|}{ Pacific } \\
\hline Total & $33,257,000$ & 838,813 & 39.6 & $100.0 \%$ \\
\hline Urbanized Areas & $23,732,000$ & 16,278 & 1,460 & $1.9 \%$ \\
\hline Other Urban & $3,406,000$ & 5,640 & 604 & $0.7 \%$ \\
\hline Rural & $6,120,000$ & 816,895 & 7.5 & $97.4 \%$ \\
\hline
\end{tabular}


direction of the population center from the selected route. Such a factor could be quite important in determining the effects of releases near large population centers. Over a sufficiently long route, the effects of different wind direction persistences may tend to cancel if there is a random relationship between the prevailing wind directions and population centers. The alternative of picking a route based on known diffusion climatologies to minimize risk could be beneficial; however, at the present time it is not included in the model.

The meteorological data used in this analysis are shown in Table 9.9. The values were developed from micrometeorological data collected for diffusion calculations for reactor sites. Seven sets of micrometeorological data were selected from about 26 compilations from reactor sites to account for the range of conditions that could reasonably occur along the route. The use of a single averaged distribution allows for the typical range of wind speeds wi thout undue weighting to any particular site. Although this result cannot be expected to necessarily represent any particular portion of the route, it does represent the type of conditions that may be encountered on the average.

TABLE 9.9. Average Wind Speed/Stability Characteristics

\begin{tabular}{|c|c|c|c|c|c|c|}
\hline \multicolumn{3}{|c|}{ Wind Speed } & \multicolumn{4}{|c|}{ Pasquill Stability Classification } \\
\hline $\begin{array}{c}U_{k} \\
\mathrm{~m} / \mathrm{sec}\end{array}$ & $\mathrm{k}$ & $\mathrm{P}_{\mathrm{k}}$ & $\mathrm{B}(\mathrm{J}=1)$ & $D(j=2)$ & $E(j=3)$ & $F(j=4)$ \\
\hline 1 & 1 & 0.255 & 0.136 & 0.202 & 0.299 & 0.363 \\
\hline 3.5 & 2 & 0.508 & 0.243 & 0.274 & 0.272 & 0.211 \\
\hline 7 & 3 & 0.161 & 0.190 & 0.290 & 0.339 & 0.181 \\
\hline 10 & 4 & 0.052 & 0.240 & 0.312 & 0.358 & 0.090 \\
\hline 18 & 5 & 0.024 & 0.276 & 0.348 & 0.356 & 0.020 \\
\hline
\end{tabular}




\subsection{ATMOSPHERIC DISPERSION OF PROPANE VAPORS}

Atmospheric dispersion and vaporization models are required to determine the extent of a propane vapor cloud from a release without immediate ignition. Both immediate and gradual releases with dispersion are considered here.

There are two components of propane vaporization in any LPG spill. One is flash vaporization, an almost instantaneous vaporization of propane due to the drop from tank to atmospheric pressure. The other component is vaporization of gas from pools formed by the spilling, liquid propane.

In an immediate release of propane from a tank car failure, an initial vapor cloud is formed by flash vaporization. At ambient temperatures $\left(20^{\circ} \mathrm{C}\right)$, this cloud would contain about $35 \%$ of the tank contents. The propane that is not flash-vaporized forms a liquid pool. Additional vapor is formed by continuous evaporation from this liquid pool. In modeling the vapor cloud dispersion from an immediate propane release, it was assumed that the initial vapor cloud formed by flash vaporization presents the greatest hazard since the cloud from pool evaporation would cover a smaller area than the initial cloud. Thus, in an immediate propane release, only the cloud resulting from flash vaporization was considered in the dispersion calculations. The dispersion of this cloud can be simulated using a Gaussian puff equation.

For continuous liquid releases, both flash vaporization and evaporation from a pool must be considered. The amount of propane instantaneously vaporized due to a reduction in pressure (at ambient temperature) is $35 \%$. The remaining propane contributes to pool formation, and subsequently evaporates due to heat input from the ground surface. The total contribution to the vapor cloud is the sum of the emission rates from flash vaporization and pool evaporation.

However, surface vaporization has been studied by Shaw and Briscoe, Reid and Smith $(17)$ and others. Their work indicates that the liquid propane will spread until the total evaporation of the pool is equal to the input rate to the pool. Shaw and Briscoe ${ }^{(15)}$ present models representing heat transfer and subsequent vaporization from a semi-infinite slab, taking into account the 
initial soil and LPG boiling temperatures $\left(T_{s}, T_{b}\right)$, soil conductivity $\left(k_{s}\right)$ soil diffusivity $\left(\alpha_{S}\right)$ and the LPG latent heat $(L)$ :

$$
\frac{\dot{M}}{a}=\frac{k_{s}\left(T_{s}-T_{B}\right)}{\sqrt{L} \pi_{s} t}
$$

where $\dot{M}$ is the emission rate per unit area as a function of time, $t$. They also express the spil1 radius $(r)$ independent of vaporization rate as:

$$
r=\sqrt{\frac{2}{3}}\left(\frac{8 g B}{\pi}\right)^{1 / 4}\left(t^{3 / 4}\right)
$$

where:

$B$ is the spill rate in $\mathrm{m}^{3} \mathrm{~s}^{-1}$

$g$ is the gravitational acceleration.

Combining these expressions for times typical of the time required to empty the release propane tanks by the chosen continuous releases suggests that for the low liquid release rates specified, a conservative but realistic vaporization rate would simply be the liquid release rate. This rate was used in the dispersion calculations.

The simulation models used to provide estimates of the areas of propane flammable gas concentrations from immediate and continuous releases are discussed in Appendix D. The models are Gaussian diffusion models for continuous plumes and instantaneous puffs (representing propane leaks and catastrophic spills).

\subsection{ESTIMATED EXPOSURE FREQUENCY}

The information presented in the previous subsections can be used as conversion factors to modify the release sequence probabilities and release rate categories developed in Section 8. The remainder of this section will show how these factors are applied in the risk calculation. The risk calculation proceeds along two parallel and interrelated paths. One path characterizes 
the consequences of an accidental release, and the other path determines the frequency of occurrence for each event in the consequence analysis.

As discussed in Section 3, risk is expressed by the equation:

$$
R_{i}=\left(Q_{i} \times P_{i}\right) \times \sum_{q}\left(c_{i, q} \times P_{q}\right)
$$

where $q$ represents a number of indices as indicated below.

The terms inside the first set of parentheses represent the product of the amount of material released in the $i^{\text {th }}$ release sequence $\left(Q_{j}\right)$ times the expected frequency of occurrence of the release sequence $\left(P_{j}\right)$. All the information needed to evaluate these terms was developed in Section 8. The two terms in the second set of parentheses represent the consequences of a unit release $\left(C_{i, q}\right)$ and the expected frequency of encountering a given set of environmental conditions $\left(\mathrm{P}_{\mathrm{q}}\right)$. The primary purpose of previous parts of this section has been to determine the factors required to evaluate the consequences of a release. The information required to determine the expected frequency of a given environmental consequence has also been presented; the development of the frequency of occurrence term is shown below.

The analysis presented in this section treated the wind speed, weather stability class and population class as distributed variables. The expected frequency of encountering a given set of environmental conditions can be expressed as:

$$
P_{j, k, l, m}=P_{j / k} P_{k} P_{\ell / m} P_{m}
$$

where:

$j$ is the atmospheric stability classification index

$k$ is the wind speed index

$\ell$ is the population density index in zone $m$ of the U.S.

$m$ is the zone index for the shipping routes 
The notation $j / k$ indicates that the expected frequency of encountering the $j^{\text {th }}$ stability $c l$ ass is a function of the wind speed existing at the time of release. Similarly, the expected frequency of encountering the $e^{\text {th }}$ population density is dependent on the expected frequency that a shipment will pass through zone $\mathrm{m}$.

The values for the "P" in Equation (9-18) are obtained from the following tables:

$$
\begin{aligned}
& P_{k} \text { - Table } 9.9, \text { column } 3 \\
& P_{j / k} \text { - Table } 9.9 \text {, columns } 4-7 \\
& P_{\ell / m} \text { - Table } 9.8 \\
& P_{m} \text { - Table } 4.2
\end{aligned}
$$

By specifying a value for $j, k, l$, and $m$, one can obtain the expected frequency that an environmental condition will be experienced during a shipment. Associated with that frequency is a corresponding value for the release environmental consequences. The relationship is best summarized by the following equation for the environmental term in the risk equation:

$$
\sum_{q} C_{j, q} \times P_{q}=\sum_{j, k, \ell, m, n} A_{n, j, k}(\overline{E / Q})_{n, j, k} N_{\ell / m} P_{j / k} P_{k} P_{\ell / m} P_{m}
$$

where:

$A_{n, j, k}$ is the area within the isopleth of flammable concentration limits $(E / Q)_{n, j, k}$

$(\bar{E} / Q)_{n, j, k}$ is the time integrated air concentration received in $A_{n, j, k}$ per kilogram released.

$\mathrm{N}_{\ell / \mathrm{m}}$ is the population density in the release plume (Table 9.9). The subscripts and the values for $P$ in Equation 9-19 have been defined following Equation 9-18. The product $\left(C_{i, q} \times P_{q}\right)$ has units of population fatalities. 
Equation 9-19 summarizes the information presented in this section. In Section 10, these results will be used in conjunction with the release sequences developed in Section 8 to obtain the risk of shipping propane in the United States for the year 1985. 


\section{REFERENCES}

1. Roger A. Strehlow et a1., The Characterization and Evaluation of Accidental Explosions. N75-32191, University of I1linois, Urbana, I11inois, June 1975.

2. W. A. Bullerdick et a1., A Study to Reduce the Hazards of Tank Car Transportation. PB-199-154, Cornel1 Aeronautical Laboratory, Inc., for the Dept. of Transportation, November 1970.

3. John A. Simmons, Risk Assessment of Storage and Transport of Liquefied Natural Gas and LP-Gas. EPA-520/3-75-015, Science Applications, Inc., for the U.S. Environmental Protection Agency, November 1974.

4. W. D. Brasie and D. W. Simpson, "Guidelines for Estimating Damage Explosions, CEP Technical Manual." Loss Prevention. American Institute of Chemical Engineers, New York, New York, 1968.

5. S. B. Sutton and E. W. McCauley, An Assessment of Hazards Resulting from Atmospheric Propane Explosions at LLL. UCID-16720, Lawrence Livermore Laboratory, February 1975.

6. Nuclear Handbook for Medical Service Personnel. Department of the Army, TM-8-215, Apri1 1969.

7. William C. Reynolds and Henry C. Perkins, Engineering Thermodynamics. McGraw-Hi11 Book Co., New York, 1970.

8. Mott Souders, The Engineer's Companion. John Wiley and Sons, Inc., Copyright 1966.

9. Arthur N. Takata, Review of Fire Hazard Distances. J6194. ITT Research Institute, for the Armed Services Explosives Safety Board, August 1970.

10. R. E. Rhoads et a1., An Assessment of the Risk of Transporting Gasoline by Truck. PNL-2133, Pacific Northwest Laboratory, Richland, Washington, Apri1 1979.

11. Statistical Abstracts of the U.S. 1975. Bureau of the Census, U.S. Dept. of Commerce, Washington DC, 1975.

12. Three-fourths of U.S. Population on 1.5 Percent of Nations Land, Census Bureau Reports. U.S. Dept. of Commerce News, CB72-100, Bureau of the Census, U.S. Dept. of Commerce, Apri1 21, 1972.

13. Population of Urbanized Areas Established Since the 1970 Census, for the U.S.: 1970. Supplementary Report 1970 Census of Population, PC(S1)-106, Bureau of the Census, U.S. Dept. of Commerce, October 1976. 
14. J. P. Pickard, Appalachian Regional Commission, [Urban National Population Growth and Projection, Summary Outline], for Presentation at Conference on Complexity: A Challenge to the Adaptive Capacity of American Society. Society for General Systems Research, Metropolitan Washington Chapter, at Columbia, Maryland, March 25, 1977.

15. Population and the American Future. Volume V, The Report of the Commis sion on Population Growth and the American Future, 1972.

16. P. Shaw and F. Briscoe. Evaporation from Spills of Hazardous Liquids on Land and Water. Safety and Reliability Directorate. U.K. Atomic Energy Authority, SRD R 100, May 1978.

17. R. C. Reid and K. A. Smith. Confined Boiling Rates of Liquefied Petroleum Gas on Water. National Science Foundation, US DOE Report HCP/P4548-01. May 1978. 


\subsection{THE RISK OF SHIPPING PROPANE BY TRUCK AND TRAIN}

In this section, the risk of shipping propane by truck and train will be discussed. The risk was calculated using the methodology presented in Section 3. The probability of an accidental release occurring during transport was determined in Section 8, and the consequences of each release type were discussed in Section 9. Section 10.1 presents the risk of shipping propane in the reference year, 1985, based on the shipping system model given in Section 4. Major contributors to the overall risk are discussed in Section 10.2 and the results of sensitivity studies will be presented in Section 10.3.

\subsection{RISK EVALUATION OF PROPANE SHIPMENTS}

Because of the complex nature of the shipping system model, the risk analysis was divided into three parts, each part corresponding to one of the three propane tank types. The figures that were used for calculations in the analysis are shown in Table 10.1 for each propane tank (bobtail, tank truck and rail car). The risk involved with shipping propane was determined separately for the bobtail truck, the tank truck and the rail tank car. These risks were then summed to determine the overall transportation system risk.

Based on the information presented in Table 10.1, accidents involving tank truck transport shipments of propane will be expected to occur at a rate of 320 every year; accidents involving bobtail trucks would be expected at a rate of 250 every year. Train accidents involving propane shipments (in the assumed rail tank car) would be expected to occur at a rate of about 60 every year.

TABLE 10.1. Simplified Propane Shipping System Model

\begin{tabular}{|c|c|c|c|c|c|c|}
\hline $\begin{array}{c}\text { Propane } \\
\text { Tank Type } \\
\end{array}$ & $\begin{array}{c}\text { Transport } \\
\text { Mode } \\
\end{array}$ & $\begin{array}{c}\text { Amount/ } \\
\text { Container }\left(\mathrm{m}^{3}\right) \\
\end{array}$ & $\begin{array}{c}\text { Material } \\
\text { Shipped/year } \\
\text { (million } \mathrm{m}^{3} \text { ) } \\
\end{array}$ & $\begin{array}{l}\text { Number of } \\
\text { Shipments/ } \\
\text { year } \\
\end{array}$ & $\begin{array}{c}\text { Average } \\
\text { Shipment } \\
\text { Distance }(\mathrm{km})\end{array}$ & $\begin{array}{c}\text { Accident/ } \\
\mathrm{km}\end{array}$ \\
\hline $\begin{array}{l}\text { MC-331 } \\
\text { Tank Truck }\end{array}$ & Truck & 43.0 & 42 & 980,000 & 210 & $1.55 \times 10^{-6}$ \\
\hline $\begin{array}{l}\text { MC-331 } \\
\text { Bobtail }\end{array}$ & Truck & 10.6 & 21 & $1,980,000$ & 80 & $1.55 \times 10^{-6}$ \\
\hline $\begin{array}{l}\text { DOT-112.J340W } \\
\text { Rail Tank Car }\end{array}$ & Rail & 127.2 & 3 & 25,000 & 400 & $6.21 \times 10^{-6}$ \\
\hline
\end{tabular}


Based on the release sequence probabilities determined in Section 8 , a release of any amount of material from propane trucks, under both normal transportation and transport accident conditions, is to be expected at a rate of about 110 per year. Releases from propane rail tank cars would occur about 40 times a year. However, only those releases that occur during a transportation accident or involve a major tank defect include sufficient propane to present the potential for danger to the public. These significant releases can be expected at the lower rate of about fourteen events per year for truck transport and about one event every two years for rail tank car transport. Not all of these significant releases result in fatalities. For truck transport, an expected rate of accidents resulting in one or more fatalities is about 2.2 accidents per year. For rail transport in the insulated tank car an expected rate of accidents resulting in one or more fatalities is about .1 accidents per year, or one event every ten years. These results are summarized in Table 10.2.

All of the figures presented in Table 10.2 are directly related to the number of shipments expected each year and the average shipping distance. Should the declining supply of petroleum products affect propane shipments, the expected accident rates and overall risk would decrease. The probability values that were used to obtain the shipping system risks in Table 10.2 are presented in Table 10.3. These values were derived in Section 8 of this report.

TABLE 10.2. Summary of Propane Shipping System Risks

\begin{tabular}{|c|c|c|c|c|c|}
\hline $\begin{array}{l}\text { Shipping } \\
\text { Container }\end{array}$ & $\begin{array}{c}\text { Transport } \\
\text { Mode } \\
\end{array}$ & $\begin{array}{c}\text { Accidents } \\
\text { (events/year) } \\
\end{array}$ & $\begin{array}{c}\text { Releases of Propane } \\
\text { (events/year) }\end{array}$ & $\begin{array}{c}\text { Significant } \\
\text { Release of Propane } \\
\text { (events/year) }\end{array}$ & $\begin{array}{l}\text { Events per Year } \\
\text { Resulting in } \\
\geq 1 \text { Death } \\
\end{array}$ \\
\hline $\begin{array}{l}\text { MC-331 } \\
\text { Tank Truck }\end{array}$ & Truck & 320 & 40 & 8.9 & 1.6 \\
\hline $\begin{array}{l}\text { MC-331 } \\
\text { Bobtai1 }\end{array}$ & Truck & 250 & 70 & 5.4 & 0.6 \\
\hline $\begin{array}{l}\text { DOT-112J340W } \\
\text { Rail Tank Car }\end{array}$ & Rail & 60 & 40 & 0.4 & 0.1 \\
\hline
\end{tabular}


TABLE 10.3. Probability Values Used to Obtain Risk

\begin{tabular}{|c|c|c|c|c|}
\hline $\begin{array}{l}\text { Shipping } \\
\text { Container }\end{array}$ & $\begin{array}{l}\text { Transport } \\
\text { Mode }\end{array}$ & $\begin{array}{l}\text { Probability of } \\
\text { an Accident } \\
\text { (acc. rate } / \mathrm{km} \text { ) }\end{array}$ & $\begin{array}{l}\text { Probability of } \\
\text { Release } \\
\text { (per shipment) }\end{array}$ & $\begin{array}{l}\text { Probability of } \\
\text { Significant Release } \\
\text { (per shipment) }\end{array}$ \\
\hline $\begin{array}{l}\text { MC-331 } \\
\text { Tank Truck }\end{array}$ & Truck & $1.55 \times 10^{-6}$ & $3.7 \times 10^{-5}$ & $9.1 \times 10^{-6}$ \\
\hline $\begin{array}{l}\text { MC-331 } \\
\text { Bobtai1 }\end{array}$ & Truck & $1.55 \times 10^{-6}$ & $3.4 \times 10^{-5}$ & $2.7 \times 10^{-6}$ \\
\hline $\begin{array}{l}\text { DOT-112J340W } \\
\text { Rail Tank Car }\end{array}$ & Rail & $6.21 \times 10^{-6}$ & $1.61 \times 10^{-3}$ & $1.68 \times 10^{-5}$ \\
\hline
\end{tabular}

Risk spectrum curves for the three propane tank types are shown in Figure 10.1, along with the risk spectrum for the entire shipping system for the reference year. These risk curves portray total risk to the public from all release types. The shipment of propane in tank trucks contributes the greatest portion to the total system risk. The large contribution to the total risk from tank truck transport stems partly from the large number of shipments made each year by this tank type. On a per shipment basis, however, rail tank cars are found to have the highest risk, about three times that of tank trucks. The local delivery units are found to have the lowest risk on a per shipment basis.

As discussed in Section 3, the risk spectrum differentiates between an event that occurs once a year and results in one fatality and the event that occurs once in a thousand years but results in 1000 fatalities. The total risk number, on the other hand, is the sum of the frequencies of occurrence and the consequences of all accidents that can be experienced in the postulated shipping system. The total risk to the public of propane shipments in 1985 is estimated at about 15 fatalities per year. About 11 fatalities per year are the result of tank truck operation, 3 fatalities per year result from bobtail transport of propane, and less than half a death per year stems from the movement of propane by rail.

The total public risk from propane shipment accidents is compared to the risk from other kinds of accidents and natural disasters in Table 10.4. These risks refer to the specific shipping system model used in this report. Changes in the assumed system require a recalculation of risk. 


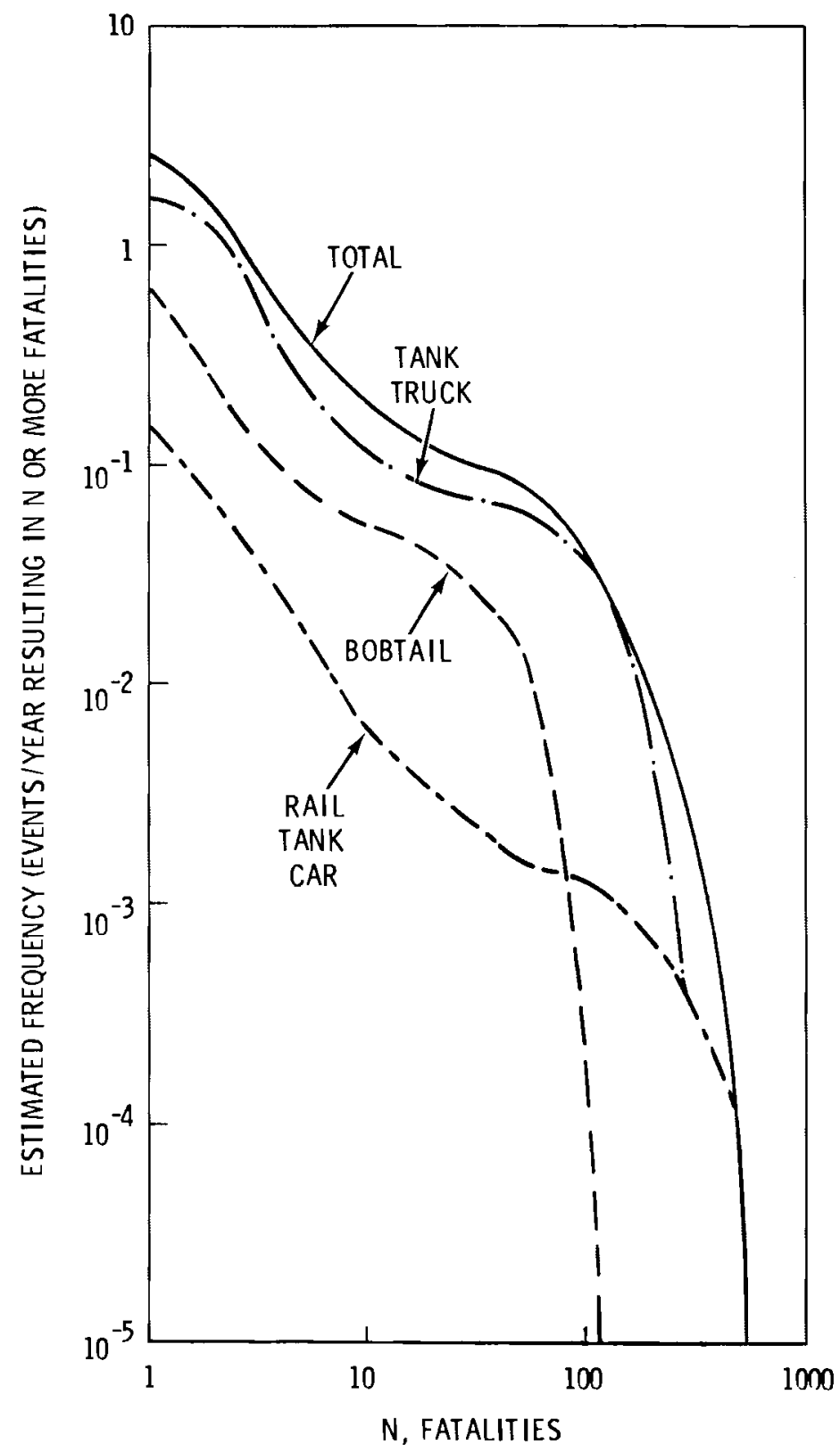

FIGURE 10.1. Risk Spectra for Propane Shipments in 1985 
TABLE 10.4. Average Total and Individual Risk from Various Accidents and Natural Disasters

\begin{tabular}{|c|c|c|}
\hline Event & $\begin{array}{c}\text { Total Risk } \\
\text { (fatalities/year) } \\
\end{array}$ & $\begin{array}{c}\text { Individual } \\
\quad \text { Risk(a) } \\
\end{array}$ \\
\hline A11 Accidents & $103,030^{(b)}$ & 1 in 2,000 \\
\hline $\begin{array}{l}\text { Motor Vehicle } \\
\text { Accidents }\end{array}$ & $46,700^{(b)}$ & 1 in 5,000 \\
\hline Air Crashes & $1,552^{(b)}$ & 1 in 140,000 \\
\hline Dam Failures & $35^{(c)}$ & 1 in $6,300,000$ \\
\hline Gasoline & $28^{(d)}$ & 1 in $7,900,000$ \\
\hline Propane Shipments & 15 & 1 in $15,000,000$ \\
\hline $\begin{array}{l}\text { Air Crashes } \\
\text { (persons on ground) }\end{array}$ & $6^{(e)}$ & 1 in $33,000,000^{(f)}$ \\
\hline Meteorites & $1.0 \times 10^{-3}$ & 1 in $2 \times 10^{11}$ \\
\hline
\end{tabular}

(a) Based on total U.S. population $(220,000,000)$.

(b) Based on 1975 statistics.

(c) Average for dam failures 1889-1972.

(d) From Reference 2.

(e) Average for years 1960-1973.

(f) Based on population at risk.

(g)From Reference 1.

The results of this study indicate that the risk to the public of shipping propane is higher than the risks involved with shipping nuclear materials, but is generally lower than the risk spectrum presented for man-caused and natural disaster events.

Further perspective on the total risk to the public from transporting propane may be gained by examining some of the benefits provided by this energy material. Propane and other liquefied petroleum gases are a significant source of fuel in the United States, supplying about 3 percent of total U.S. energy demand in 1976. Propane may be directly substituted for natural gas, and is a clean-burning fuel.

Propane is also a staple on farms, where it is used for crop drying, flame weeding, tobacco curing, stock tank heating, and frost protection. It also powers trucks, pumps, standby generators, and other farm equipment. Commercial 
establishments, such as hotels, motels, and restaurants, use propane much like the homeowner. Industry relies on it for soldering, heat-treating, annealing, vulcanizing, and many other uses. As an engine fuel, its minimal emissions allow propane to be used indoors. This same feature makes it a desirable fuel in congested areas.

The LPG industry serves about thirteen million customers, including homes, farms, individuals, businesses, and government groups. LP-gas is essentially a rural fuel, and roughly 1-1/2 million farms depend on the fuel for a variety of uses. Industry market calculations show approximately 60 million people dependent on LP-gas for one use or another.

\subsection{MAJOR CONTRIBUTORS TO OVERALL RISK}

During the analysis of the three propane tank types, the release sequences determined in Section 8 were grouped into six categories, corresponding to the six release fractions and rates described in Section 8.4. The hazards from transporting propane stem from the flammable nature of the cargo and resulting effects. In evaluating the consequences of each release category, four effects of the released propane were addressed: explosion, including over-pressure effects; direct flame exposure; radiant heat effects, including damage from secondary fires; and missile damage.

For both truck and rail transport, it was found that the release sequences that involved dispersion of the propane had the greatest potential for producing fatalities.

These release sequences primarily include failure of the tank itself by impact or puncture mechanisms. The failure of the tank in an impact or puncture accident situation was assumed to result in a release of the entire tank contents to the atmosphere, forming a large vapor cloud. The flammable area of the resultant cloud was large enough to affect many of the general public, and this resulted in the most severe consequences when ignited. It was found that in an accident where the propane is immediately ignited, or a fire is involved in the accident, consequences were more localized, and less likely to result in fatalities to the general public. However, these explosion and immediate fire sequences could result in fatalities to the population immediately 
surrounding the ruptured tank truck. This population would include truck drivers, emergency response teams (most commonly firefighters), and people in other vehicles involved in the accident.

Statistics on traffic accidents of hazardous material carriers in $1975^{(5)}$ show that out of about 1,150 accidents, about 40 drivers or rellef drivers were killed. This leads to an estimated driver fatality rate of three percent, given that a hazardous material carrier accident has occurred. To obtain a conservative estimate of the number of drivers killed in propane accidents, it is assumed that all of the recorded driver deaths occurred in propane accidents, and that all were as a result of fire or explosion caused by the propane. Using the accident rates shown in Table 10.2 for significant releases, this leads to a driver fatality rate of about one every 2 years for tank truck and bobtail transport. The way in which a train is put together is assumed to preclude driver deaths. That is, the propane tank car will most likely be placed somewhere near the middle of the train to avoid potential catastrophic effects from the hazardous material should an accident occur.

An estimate of the number of people involved in a truck accident is given in Reference 2 and portrayed in Figure 10.2. Bureau of Motor Carrier statistics were also analyzed in Reference 2 to determine the probability that an occupant of a vehicle involved in a tank truck accident would be killed if a fire resulted. This value was determined to be $0.4 .^{(2)}$ Coupling these values with the 14 truck accidents per year resulting in a significant release gives an approximate value for the expected number of fatalities in a propane truck accident in addition to the drivers and the general public. These values are shown in Table 10.5. The total expected fatalities per year to vehicle occupants is about five. In addition to the general public, about five or six deaths per year from propane truck accidents may thus be expected to account for drivers and other people in the immediate vicinity of the accident.

Transport of propane by rail tank car will affect, in addition to the general public, emergency response teams or firefighters. As explained previously, the train operator is assumed to be far enough away from the accident itself to allow escape. Also, unlike the highway environment, there is no significant additional traffic to consider. This leaves only the accident 


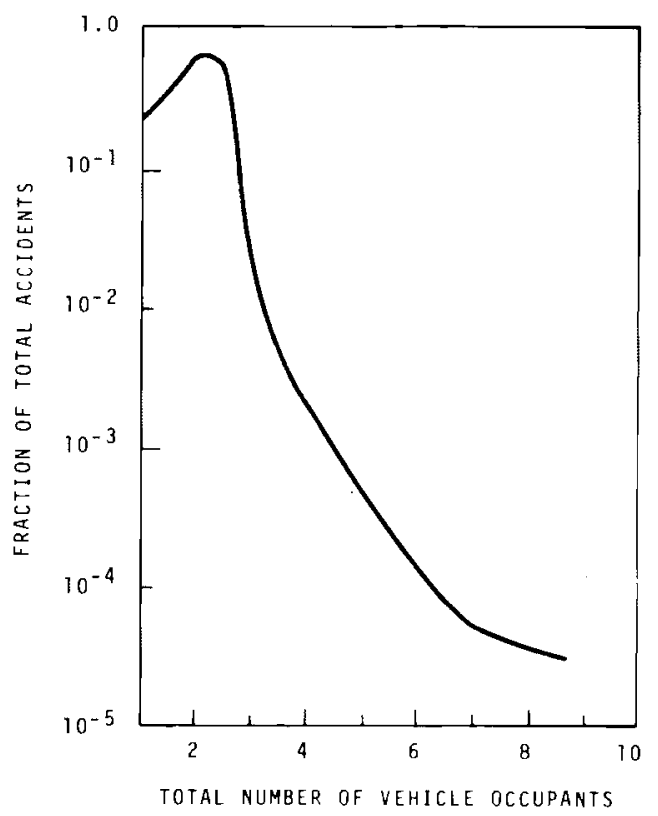

FIGURE 10.2. Estimated Total Number of Vehicle Occupants Involved in Heavy Truck Accidents Plotted as a Function of Accident Frequency

TABLE 10.5. Estimated Fatalities of Vehicle 0ccupants in an Accident with a Significant Release

\begin{tabular}{cccccc}
$\begin{array}{c}\text { Average Number } \\
\text { of People }\end{array}$ & $\begin{array}{c}\text { Fraction of } \\
\text { Total Accidents }\end{array}$ & $\begin{array}{c}\text { Accidents per Year } \\
\text { with Significant Release }\end{array}$ & $\begin{array}{c}\text { Average Fatality } \\
\text { Rate in Fire Accidents }\end{array}$ & $\begin{array}{c}\text { Expected } \\
\text { Fatalities } \\
\text { per Year }\end{array}$ \\
\cline { 1 - 3 } 1 & 0.20 & 14 & 0.4 & 1.12 \\
2 & 0.65 & 14 & 0.4 & 3.64 \\
3 & 0.04 & 14 & 0.4 & 0.22 \\
4 & 0.003 & 14 & 0.4 & 0.02 \\
5 & 0.007 & 14 & 0.4 & 0.0039 \\
6 & 0.0002 & 14 & 0.4 & 0.0011 \\
7 & 0.00008 & 14 & 0.4 & 0.0004 \\
8 & 0.00006 & 14 & 0.4 & 0.0003
\end{tabular}

response teams. Assuming that a group of from ten to fifteen firefighters will respond to an accident, and that, as in the highway environment, a fatality rate in a fire accident is forty percent, an estimate of the number of firefighters killed per year in propane train accidents may be derived. For the significant release event every 2 years from propane train transport, an expected 1 to 2 firefighters may be killed in addition to members of the general public. 
The actual fatality-causing mechanisms experienced varied with population distributions, largely because of shielding effects. Shielding factors were based on the density of structures within a particular population area. In urban areas, direct flame contact and explosion effects caused the majority of deaths. Radiant heat effects played a minor role in causing public fatalities. In "other urban" areas, explosion effects and radiant heat caused most of the fatalities. Direct flame contact was not a major danger in these areas. Rural areas followed the same general pattern of "other urban" regions. These results are shown in Table 10.6.

TABLE 10.6. Approximate Percentage Contributions to Total Risk to the General Public of Various Fatality Mechanisms(a)

\begin{tabular}{clcc}
$\begin{array}{c}\text { Total } \\
\text { Destruction } \\
\text { (explosion/ }\end{array}$ Dlame & $\begin{array}{c}\text { Severe, } \\
\text { flame) }\end{array}$ & $\begin{array}{c}\text { Damage } \\
\text { (overpressure } \\
\text { effects) }\end{array}$ & $\begin{array}{c}\text { Radiant } \\
\text { Heat } \\
\text { (including }\end{array}$ \\
\hline
\end{tabular}

Urban Areas

$\begin{array}{llllll}\text { Tank } & 32 & 21 & 34 & 7 & 4 \\ \quad \text { Truck } & & & & & \\ \text { Bobtail } & 34 & 16 & 36 & 7 & 4 \\ \text { Rail } & 32 & 23 & 33 & 7 & 4 \\ \quad \text { Tank Car } & & & & & \end{array}$

Other Urban Areas

$\begin{array}{llllll}\begin{array}{c}\text { Tank } \\ \text { Truck }\end{array} & 22 & 3 & 23 & 5 & 46 \\ \text { Bobtai1 } & 22 & 3 & 24 & 5 & 46 \\ \begin{array}{l}\text { Rail } \\ \text { Tank Car }\end{array} & 23 & 4 & 24 & 5 & 44\end{array}$

Rural Areas

$\begin{array}{llllll}\text { Tank } & 31 & 2 & 32 & 7 & 28 \\ \text { Truck } & & & & & \\ \text { Bobtail } & 33 & 0.1 & 37 & 8 & 21 \\ \text { Rail } & 26 & 4 & 26 & 6 & 38 \\ \text { Tank Car } & & & & & \end{array}$

(a) Percentages may not add to 100 because of rounding error. 
being able to shield themselves from the flames by hiding in buildings or running away. To ascertain the importance of this parameter to the final risk number, two sensitivity studies were performed. The first study set the value of this parameter at zero, where none of those exposed to the area of direct flame would die. Although risk did decrease slightly, the change was not significant. The second study set this parameter at 100 percent; that is, a11 those within the flammable region would die. In this case, the total risk number was increased by about thirty percent over the base case. A direct relationship between this parameter and total risk was not evident because it was not a major mechanism of fatality in suburban and rural areas, and because other fatality mechanisms are involved in the calculation of total risk.

Other uncertainties in this report stem from the calculation of probability values used in Section 8 . The area presenting perhaps the greatest uncertainty here is the amount of package defects present for any propane shipment. Leaks through valves and piping systems represented a large source of propane release. Eliminating these releases (that is, assuming that no package defects exist) eliminates all releases of propane during normal transportation. This essentially reduces the risk of transporting propane to releases occurring during transportation accidents only. However, because normal releases do not have severe consequences, adjustments to this parameter did not substantially affect the total system risk.

It was assumed in this analysis that all propane tanks when exposed to a fire fail from metal overheating when the tank is half full. To test the effects of this assumption on risk, a sensitivity analysis was performed assuming the tanks failed at $3 / 4$ full and $1 / 4$ full. The results of these studies showed the total risk to be insensitive to this assumption, although the risk from that particular release sequence was altered. This is primarily because the release sequence involving failure of a tank by fire was of a very low probability and had localized consequences. This release sequence thus did not contribute substantially to public risk. 
Total risk values were increased by about 18 percent by the absence of head shields on rail tank cars. Although head shields did reduce the normal incidence of puncture accidents by about 40 percent, they had little effect on impact accidents, which were also included in the release sequence involving a mechanical failure of the tank. Since at higher accident velocities the impact failure mechanism governs, there was not found to be a direct correspondence between the amount of reduction of puncture incidence and total risk reduction.

A tank truck with insulation and a rail tank car without insulation were also analyzed in sensitivity studies. The addition of insulation to the tank truck decreased the risk of the release sequence of tank failure by fire by almost 70 percent. However, there was no change in the other release sequences. Similarly, the analysis of an uninsulated rail tank car resulted in an increased tank fire failure risk of over fifteen times the base case. Again, however, the risk from other release sequences was not changed. The lack of insulation increased the total risk of shipping propane by rail by only 6 percent. This is explained by the fact that initial failure of the tank by fire accounts for less than 1 percent of the system risk in rail transport. Almost 80 percent of the risk stems from failure of the tank by impact or puncture.

Because the release of propane from a tank failed by overpressure or by metal overheat results in localized consequence, and is a fairly low probability event, large changes in risk for this sequence did not have much of an impact on total system risk.

Several states are attempting to institute regulations that outlaw the transport of hazardous materials within a heavily populated region. To gain an understanding of how such a regulation might impact the risks of shipping propane, a sensitivity study on the amount of travel within an urban region was performed. Since it is believed unrealistic to totally outlaw hazardous material shipments through cities, an approximate figure of 20 percent of the base case travel through urban areas was assumed. This assumption resulted in a substantial public risk reduction. Consequences of dispersed releases were drastically reduced, primarily because of the decrease in available population for experience of the effects of released propane. The results of this analysis and other sensitivity studies are shown in Table 10.7. 
TABLE 10.7. Total Public Risk Sensitivity Cases for Propane Shipments

\begin{tabular}{|c|c|c|}
\hline Description of Sensittvity Case & $\begin{array}{c}\text { Estimated Annual Frequency of } \\
\text { Occurrence of One or More Fatalities } \\
\text { Relative to Base Case } \\
\end{array}$ & $\begin{array}{l}\text { Total Public Risk Level } \\
\text { Relative to Base Case }\end{array}$ \\
\hline Base Case - Total System & $1.00(2.35)$ & $1.00(15.04)$ \\
\hline Base Case - Bobtail & $1.00(0.62)$ & $1.00(2.92)$ \\
\hline Base Case - Tank Truck & $1.00(1.59)$ & $1.00(11.43)$ \\
\hline Base Case - Rail Tank Car & $1.00(0.17)$ & $1.00(0.81)$ \\
\hline No Secondary Fires & 1.00 & 1.00 \\
\hline TNT Yield $-1.0^{(a)}$ & 2.81 & 4.81 \\
\hline Direct Flame $-\% k+11-0.0^{(b)}$ & 0.93 & 0.97 \\
\hline Direct Flame $-\%$ kill $-1.0^{(b)}$ & 1.36 & 1.28 \\
\hline No Package Defects ${ }^{(b)}$ & 0.97 & 0.99 \\
\hline Ten Times Package Defects ${ }^{(b)}$ & 1.04 & 1.09 \\
\hline Tank Falls at $3 / 4$ Full & 1.00 & 1.00 \\
\hline No Head Shields (c) & 1.18 & 1.18 \\
\hline Insulated Tank Trucks ${ }^{(b)}$ & 0.99 & 0.99 \\
\hline Uninsulated Rail Cars $(c)$ & 1.07 & 1.06 \\
\hline $20 \%$ Travel in Urban Regions & 0.83 & 0.59 \\
\hline
\end{tabular}

A comparison of the results of this analysis to previous risk assessment work is of interest. Although only transport of propane by truck was included in these previous studies, they can serve as a basis of comparison. The risk assessment by simmons ${ }^{(6)}$ determined a fatality rate of about one or two a year as a result of propane truck shipments. This agrees fairly well with our value of 2.3 events per year that will result in at least one fatality. A risk assessment by Arthur D. Little $\mathrm{P}^{(7)}$ found a range of 0.24 to 3.5 events per year that will result in at least one fatality (after being adjusted for the difference in number of shipments assumed). Differences in basic assumptions and methodologies between these studies explain variations among the analyses. 


\section{REFERENCES}

1. Reactor Safety Study - An Assessment of the Accident Risks in U.S. Commercial Nuclear Power Plants. Wash-1400 (NUREG - 75/014), U.S. Nuclear Regulatory Commission, Washington, D.C., October 1975.

2. R. E. Rhoads, An Assessment of the Risk of Transporting Gasoline by Truck. PNL-2133, Pacific Northwest Laboratory, Richland, Washington, Apri1 1979.

3. J. W. Jimison ed., National Energy Transportation. Volume III - Issues and Problems, Congressional Research Service, Publication No. 95-15, March 1978.

4. 1976 LP-Gas Market Facts. National LP-Gas Association, Oak Brook, Illinois, 1978.

5. 1975 Accidents of Motor Carriers of Property. Bureau of Motor Carrier Safety, DOT, Washington, D.C.

6. J. A. Simmons, Risk Assessment of Storage and Transport of Liquefied Natural Gas and LP-Gas. Science Applications, Inc., McLean, Virginia, November 25, 1974 .

7. Arthur D. Little, Inc., Assessment of Risks and Risk Control Options Associated with Liquefied Natural Gas Trucking Operations From the Distrigas Termina7, Everett, Massachusetts. Cambridge, Massachusetts, December 1978. 
APPENDIX A

PROPERTIES OF PROPANE 
APPENDIX A

\section{PROPERTIES OF PROPANE}

Propane exists as a colorless flammable gas at atmospheric pressure and normal ambient temperatures. It is a member of a group of petroleum products called liquefied petroleum gases (LPG). These gases comprise a spectrum of products, including commercial propane, propane HD-5, commercial butane and butane-propane mixtures. Ethane, a related material, is also a major LP-gas product. About $70 \%$ of LPG products are derived from natural gas processing and 30 percent from refinery operations. Because many of the LP-gases vary in chemical composition, the physical properties of the products also vary within a limited range. (1) Physical properties of propane are summarized in Table A.1. Vapor pressures of typical LP-gas mixtures are shown in Figure A.1.

Propane is most widely used as a fuel for rural and suburban home heating systems and gas appliances. It is also used as a fuel for intraplant trucking and other transportation operations. Propane has been used extensively as a refrigerant in chemical, petroleum refining and gas processing operations, and as a selective solvent for removing asphaltic components from the higherboiling fractions of crude oils. (2)

Propane is soluble in ether, alcohol, and other LP-gases and is slightly soluble in water. (2) It has a slight natural gas odor and usually has added odorants to facilitate detection in case of a leak. Propane vapor is heavier than air. It is not irritating to eyes, nose and throat areas, but will cause dizziness or difficulty in breathing if inhaled. Concentrations in air of greater than ten percent cause dizziness in a few minutes; a one percent gas concentration will cause the same symptoms after a ten minute exposure. Exposure to very high concentrations of propane vapor can cause asphyxiation. However, propane is not considered to be a toxic gas. The 1968 American Conference of Governmental Industrial Hygienists has recommended a threshold limit value of $1000 \mathrm{ppm}$ for propane. This value represents a concentration in air to which nearly all workers may be exposed, day after day, without adverse effects. (1) 
TABLE A.1. Approximate Properties of Propane

Vapor Pressure in MPa at

$21 C$
$38 C$
$41 C$
$54 C$

Specific Gravity of Liquid at $16 \mathrm{C}$

Molecular Weight ${ }^{(a)}$

Initial Boiling Point at $0.10 \mathrm{MPa}$, degrees $\mathrm{C}$

Weight per Cubic Meter of Liquid at $16 \mathrm{C}, \mathrm{kg}$

Specific Gravity of Vapor (air = 1) at $16 \mathrm{C}$

Ignition Temperature in Air, degrees $C$

Maximum Flame Temperature in Air, degrees $C$

Specific Heat Ratio, gas a $16 \mathrm{C}, 0.10 \mathrm{MPa}$, $\mathrm{Cp} / \mathrm{Cv}_{\mathrm{V}}(\mathrm{b})$

Specific Heat of Liquid, Joules/kg-K, at $16 \mathrm{C}$

Limits of Flammability in Air, percent of vapor in air-gas mixture:

a) lower

b) upper
Commercial Propane

0.91

1.41

1.49

2.07

0.509

44.096

$-46$

507.21

1.52

493-604

1980

1.065

2461.84

2.15

9.60

Source: Reference 4.

(a)From Reference 2 .

(b) From Reference 5.

The Gas Processors Association has published a list of specifications for LP-gases to ensure a certain level of quality control for this spectrum of products. (6) These specifications are reproduced in Table A.2.

The primary hazard in transporting propane stems from its flammable nature. Some of the more important properties of the material for assessing the safety of current systems and means of hazard control are enumerated below. The values for these properties may be found in Table A.1 and Figure A. 1 . 


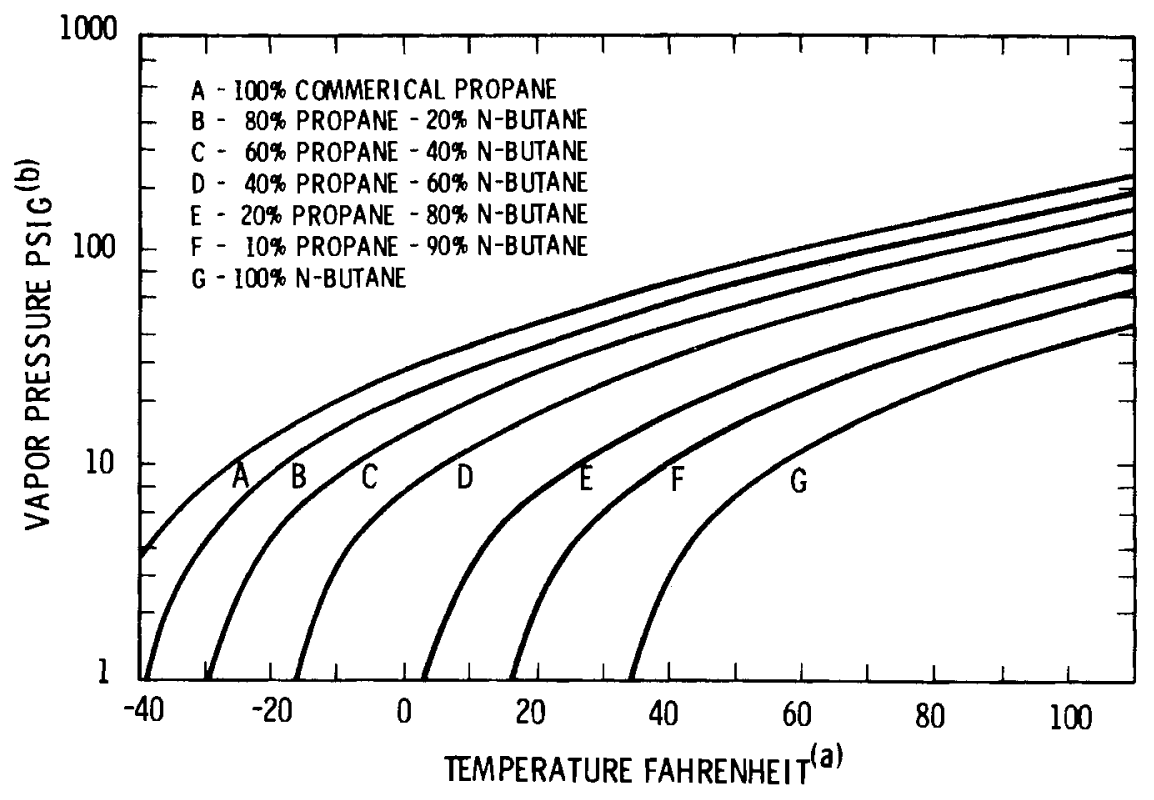

(a) ${ }^{0} \mathrm{C}=\left({ }^{0} \mathrm{~F}-32\right) \times 5 / 9$

(b) $\mathrm{Pa}=\left(6.895 \times 10^{3}\right)(\mathrm{psi})$

FIGURE A.1. Vapor Pressures of Typical Butane-Propane Mixtures $(7)$

- Vapor pressure of a product is important for container design and release consequence analysis. The vapor pressure is directly related to the stresses that a container undergoes during transport of the material.

The vapor pressure is also a factor in determining the rate of vaporization of a propane spill, and can indicate the extent of the vapor cloud that may be formed.

- The specific gravity of propane is greater than air. This means that released propane vapors will tend to gather in low elevation areas, such as valleys, and will resist dispersion by wind to a certain degree.

- Flame temperature is a factor in the fire hazard of propane. It is directly related to the amount of radiative heat that affects nearby objects.

- Limits of flammability specify the range of concentration of propane required to support a flame. Liquid propane, for instance, will not burn, being too rich a concentration to support a fire. 


\section{TABLE A.2. GPA Liquefied Petroleum Gas Specifications}

\begin{tabular}{|c|c|c|c|c|}
\hline \multirow[b]{2}{*}{ Product Characteristics } & \multicolumn{4}{|c|}{ Product Designation } \\
\hline & $\begin{array}{c}\text { Commercial } \\
\text { Propane } \\
\end{array}$ & $\begin{array}{c}\text { Commercial } \\
\text { Butane } \\
\end{array}$ & $\begin{array}{c}\text { Commercial } \\
\text { B-P } \\
\text { Mixtures } \\
\end{array}$ & $\begin{array}{c}\text { Propane } \\
\text { HD-5 }\end{array}$ \\
\hline Composition & $\begin{array}{l}\text { Predominantly } \\
\text { propane and/ } \\
\text { or propylene }\end{array}$ & $\begin{array}{l}\text { Predominantly } \\
\text { butanes and/ } \\
\text { or butylenes }\end{array}$ & $\begin{array}{l}\text { Predominantly } \\
\text { mixtures of } \\
\text { butanes and/ } \\
\text { or butylenes } \\
\text { with propane } \\
\text { and/or } \\
\text { propylene }\end{array}$ & $\begin{array}{l}\text { Not less than } 90 \\
1 \text { iquid volume } \\
\text { percent propane; } \\
\text { not more than } 5 \\
\text { liquid volume per- } \\
\text { cent propylene }\end{array}$ \\
\hline $\begin{array}{l}\text { Vapor Pressure at } 37.8 \mathrm{C} \text {, } \\
\mathrm{kPa} \text {, max. }\end{array}$ & 1434 & 483 & 1434 & 1434 \\
\hline Volatile Residue: & & & & \\
\hline $\begin{array}{l}\text { Temperature at 95\% Evapo- } \\
\text { ration, deg. C max. }\end{array}$ & -38.3 & 2.2 & 2.2 .2 & -38.3 \\
\hline $\begin{array}{l}\text { Butane and Heavier, liquid } \\
\text { volume percent max. }\end{array}$ & 2.5 & $\cdots$ & -- & 2.5 \\
\hline $\begin{array}{l}\text { Pentane and Heavier, liquid } \\
\text { volume percent max. }\end{array}$ & -- & 2.0 & 2.0 & -- \\
\hline Residual Matter: & & & & \\
\hline $\begin{array}{l}\text { Residue on Evaporation of } \\
100 \mathrm{ml} \text {, max. }\end{array}$ & $0.05 \mathrm{mk}$ & --- & -- & $0.05 \mathrm{ml}$ \\
\hline 0il Stain Observation & pass (1) & -- & --- & pass (1) \\
\hline $\begin{array}{l}\text { Volatile Sulfur, grains per } \\
100 \mathrm{cu} \mathrm{ft,} \mathrm{max.}\end{array}$ & 15 & 15 & 15 & 10 \\
\hline
\end{tabular}

(a) As acceptable product shall not yield a persistent oil ring when $0.3 \mathrm{ml}$ of solvent residue mixture is added to a filter paper in 0.1 increments and examined in daylight after 2 minutes as described in ASTM D-2158, a testing procedure.

Source: Reference 4. 


\section{REFERENCES}

1. Encyclopedia of Chemical Technology. Kirk-Othmer, Volume 12, 2nd edition, John WiTey and Sons, Inc., 1967.

2. W. Braker and A. L. Mossman, Matheson Gas Data Book. Fifth edition. 1971.

3. CHRIS: Hazardous Chemical Data. CG-446-Z, Department of Transportation, U.S. Coast Guard, Washington, D.C.

4. Storage and Handling of Liquefied Petroleum Gases. National Fire Protection Association, NFPA-58, Boston, Massachusetts, 1972.

5. W. A. Bullerdick et a1., A Study to Reduce the Hazards of Tank Car Transportation. Prepared for Federal Railroad Administration. Final Report, PB 199 154, Washington, D.C., November 1970.

6. GPA Liquefied Petroleum Gas Specifications and Test Methods. Gas Processors Association, GPA Publication 2140-77. Revised 1977. Tulsa, Oklahoma.

7. "LP-Gas Characteristics and Properties." Marketing Department Bulletin No. 348 (Rev-73), Phillips Petroleum Co. 
APPENDIX B

PROPANE TANK TRUCK, BOBTAIL TRUCK AND RAIL TANK CAR DESCRIPTIONS 
APPENDIX B

PROPANE TANK TRUCK, BOBTAIL TRUCK AND RAIL

TANK CAR DESCRIPTIONS

Propane is classified as a hazardous substance by the Department of Transportation (DOT) and must be transported in containers meeting DOT specifications. The following sections describe the containers assumed for this study, and the reasons these specific systems were chosen.

\section{B.1 TANK TRUCK}

Federal regulations require that liquefied petroleum gases be transported either in MC-330 or MC-331 specification tank trucks. (1) However, the MC-330 specification has been obsolete for over fifteen years. Although existing MC-330 trucks may be used to transport propane, all new construction must follow the MC-331 specification.

The only real difference between the MC-330 and the MC-331 is that the older style truck has a less effective release prevention valve system. DOT now requires, however, that the $M C-330$ trucks must have the newer internal valve system (to be described later in this section) installed in all liquid discharge lines at their next regular inspection. These inspections are required at five year intervals. (2)

Because the MC-330 tank truck is being revised to fit the MC-331 specifications more closely, and al1 new construction (since September 1, 1965) is required to conform to $M C-331$ design, it was assumed that all propane transported by truck was moved in an MC-331 tank truck. An illustration of the specific MC-331 tank truck system chosen for this study is shown in Figure B.1. This particular specification tank truck may also be used to haul anhydrous ammonia.

MC-331 tanks are constructed in accordance with the ASME code. Tanks must be seamless or welded steel construction and are uninsulated. Typical tank dimensions and material properties (and those used in this analysis) are shown in Table B.1. 


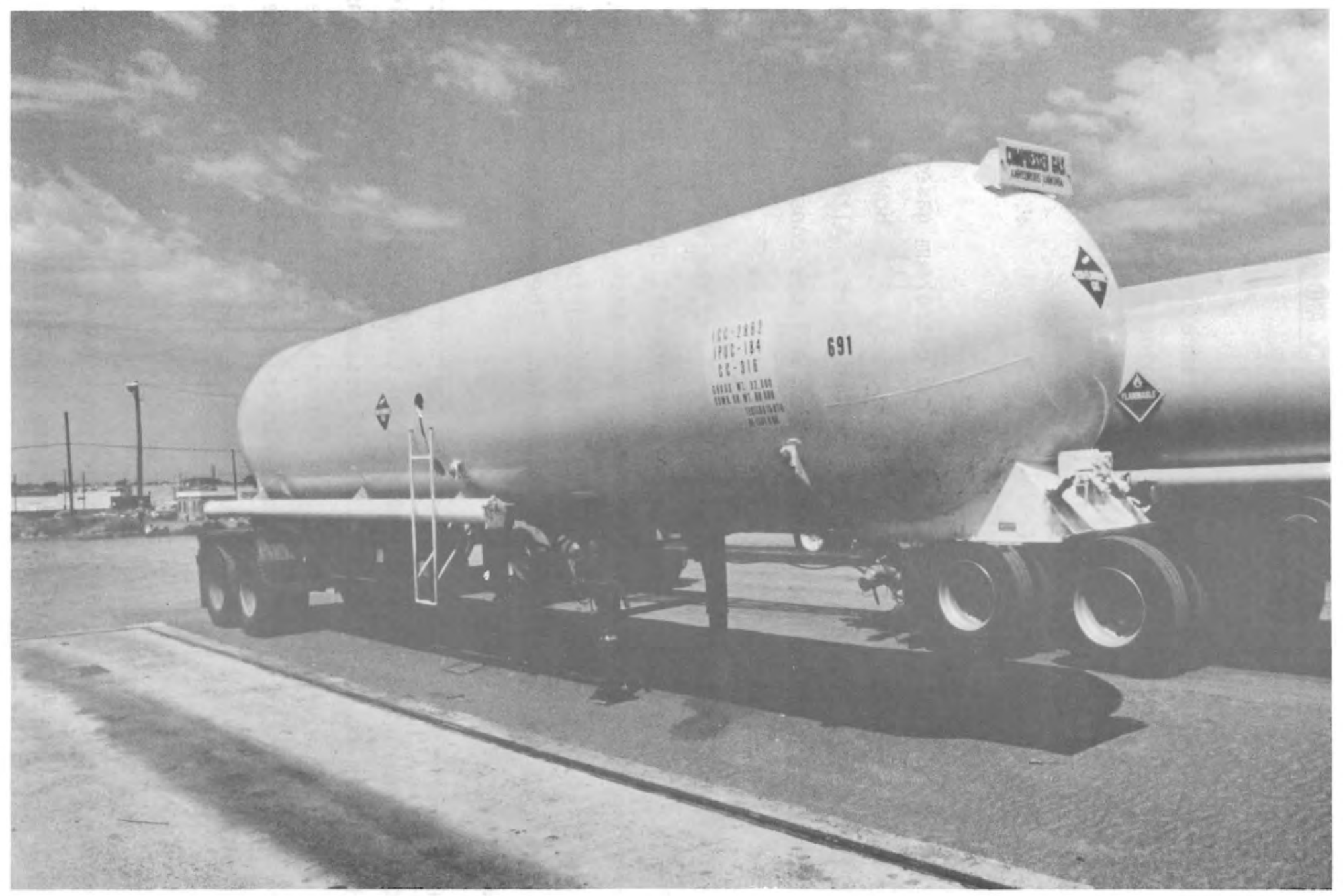

FIGURE B.1. Propane Tank Truck

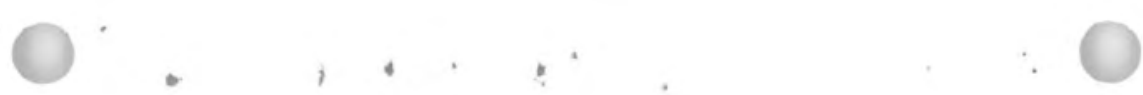


TABLE B. 1. Tank Truck Dimensions and Material Properties

$\begin{array}{lc}\text { Container Diameter } & 2.18 \mathrm{~m} \\ \text { Container Length } & 10.30 \mathrm{~m} \\ \text { Container Wa1l Thickness } & .01 \mathrm{~m} \\ \text { Surface Area } & 86 \mathrm{~m}^{2} \\ \text { Container Material }(3) & \text { SA } 517 \mathrm{Gr} . \mathrm{E} \\ \text { Yield Stress }\left(\sigma_{\mathrm{y}}\right) & 690 \mathrm{MPa} \\ \text { Ultimate Stress }\left(\sigma_{\text {uts }}\right) & 793 \mathrm{MPa} \\ \text { Elastic Modulus } & 2.07 \times 10^{5} \mathrm{MPa} \\ \text { Water Weight Capacity } & 43.91 \mathrm{~m}^{3} \\ \text { Maximum Permitted } & (1) \\ \quad \text { Filling Density } & 45 \% \mathrm{Water}^{2} \text { Weight Capacity } \\ \text { Propane Weight } & \\ \quad \text { at Maximum Fill } & 1.89 \times 10^{5} \mathrm{~N} \\ \text { Tank Working Pressure } & 1.72 \mathrm{MPa} \\ \text { Tank Test Pressure } & 3.45 \mathrm{MPa}\end{array}$

The water weight capacity of MC-331 tank trucks can vary. In this report, a tank truck is defined as any MC-331 vehicle with greater than $13.25 \mathrm{~m}^{3}$ water weight capacity. Any tank of this size or larger is required to have a manhole, ${ }^{(4)}$ which is usually located in the rear head of the tank. The manway opening is about $39 \mathrm{~cm}$ in diameter and is reinforced with a $51-\mathrm{cm}$ diameter, $4-\mathrm{cm}$ thick steel ring welded to the tank material. This ring is drilled to receive the studs that secure the $51-\mathrm{cm}$ diameter, $3-\mathrm{cm}$ thick manway cover and seal to the cargo tank. ${ }^{(5)}$

The tank truck has two other outlets at the top of the tank. These are the safety relief valves, with an 8-cm diameter. The valves are spring-loaded and are required to be set to discharge within a particular pressure range. The Fisher $H 730$ valve was assumed as a typical safety relief valve. The start-to-discharge setting of these valves is approximately $1.86 \mathrm{MPa}$. ${ }^{(6)} \mathrm{A}$ schematic of a spring-loaded safety relief valve (which is used in all propane tanks) is shown in Figure B.2. The area of the valve that limits propane flow through the valve is labeled as $A 2$. The valve itself fits inside the 


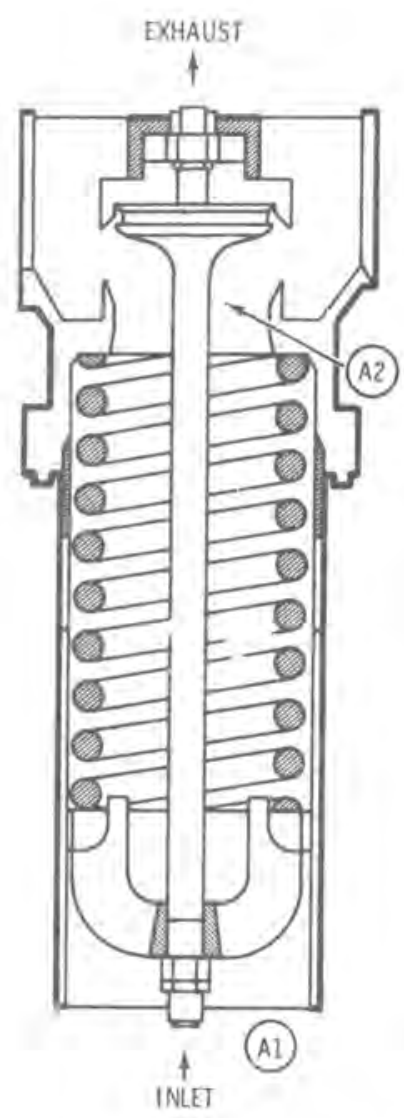

FIGURE B.2. Schematic of Safety Relief Valve

tank, communicating directly with the vapor space. Each valve is required to have a protective cap that prevents the entrance of dirt or water into the valve, but does not impede the flow of propane through the valve. (4)

The MC-331 cargo tank is also provided with liquid level vent valves. These valves are used to give a positive visual indication of the liquid reaching the maximum allowable fill level within the tank. Liquid level vent valves are bleed valves, used to ensure that propane tanks are not overfilled. An 0 -ring seal prevents leakage from around the top of the valves. These valves are set within the side walls of the MC-331 tank, at the level of the maximum legal propane fi11. (6)

The only other outlets communicating directly with the tank contents are the openings that lead to loading and unloading lines. It is required 
that each liquid or vapor discharge opening of a size over 1-1/4-inch diameter in the MC-331 cargo tank be equipped with a remotely-controlled internal shutoff valve. The critical shut-off parts of the valve must be located within the tank. The parts of the valve are arranged so that if, in an accident, the internal valve is sheared off below the flange, or the container pipe coupling, the shutoff assembly will remain intact. The valve assembly system has a section exterior to the tank that is designed to break under undue strain. ${ }^{(4)}$

The internal valves at the liquid opening of the tank have an $8-\mathrm{cm}$ diameter; those at vapor openings have a $5-\mathrm{cm}$ diameter in the assumed system. The internal valves have three functions: they serve as primary shut-off valves, excess flow valves and as back pressure valves. The valves are normally in a closed position. A lever must be pulled to open the valve during loading and unloading operations. The internal valve can also be actuated by remote control. The internal valves contain a built-in excess flow valve. If the flow of propane through the valve exceeds the rating of the excess flow spring, the valve closes to reduce the chance of uncontrolled vapor or liquid discharge. The valve's mechanism is self-closing, allowing quick closure whenever the operating lever is released.

Internal shut-off valves that can be remotely operated are required on any liquid or vapor discharge opening with greater than a $3-\mathrm{cm}$ opening. The release prevention systems included in this valve result in releases from the valve only if it is defective or damaged.

There are several basic piping systems in the MC-331 cargo tank. The sprayfill pipe enters the tank vertically, near the bottom of the tank. Within the tank, it extends to the top, where it bends forward. Propane is loaded through this pipe and is sprayed forward at very low temperature. The excess vapor is condensed back to liquid, eliminating the need for a vapor 7 ine to take off excess vapor. The vapor line is intended to withdraw vapor from the top of the tank and return it to a storage tank, if necessary. The unloading, or liquid withdrawal line connects at the bottom of the tank. Each of these lines is connected to the tank by an internal valve. An internal valve also connects to the pumping system used on the cargo tank. ${ }^{(7)}$ 
The exterior piping and valve system consists of a series of angle valves and globe valves connected by pipe and sealed off with an end cap. Each portion of liquid piping that can be closed off at both ends by valves or end caps must be provided with a hydrostatic relief valve. ${ }^{(4)}$ These valves are typically $1 \mathrm{~cm}$ in diameter and have a start-to-discharge pressure of about $2.75 \mathrm{MPa}$. (6)

The packing for the internal valve is made of tetrafluoroethylene (TFE). Seals are made of synthetic rubber, as are the seat discs. (8) It is assumed that these materials are also used in the other valves.

MC-331 cargo tanks are tested at least once every five years. The tank is given a hydrostatic pressure test to one and one half times the design pressure. The tank is also inspected for corrosion, bad dents and other weaknesses. ${ }^{(9)}$

\section{B.2 BOBTAIL TRANSPORT}

The bobtail cargo tanks are also MC-331 specification tanks. However, they are typically less than $13.25 \mathrm{~m}^{3}$ in water weight capacity, and are not required to have the manhole and manway cover with which the tank truck is equipped. Bobtail cargo tanks are used primarily for local deliveries of propane. Because these tanks are structured somewhat differently from the larger tank trucks, they were analyzed separately.

Bobtail cargo tanks come in a variety of styles and sizes. Some are single-barreled tanks, while others are built with a twin barrel configuration, having two tanks side by side. The designs vary because the tanks are often built according to state and local codes. However, all tanks must still conform to the MC-331 codes, described in more detail in the preceding section. An illustration of the bobtail truck transport is shown in Figure B.3. Typical tank dimensions and material properties are outlined in Table B.2.

There are three major differences between the bobtail tank truck and the larger tank truck. First of all, the bobtail has no manhole. Secondly, it is much smaller than the large tank truck and is used primarily for local 


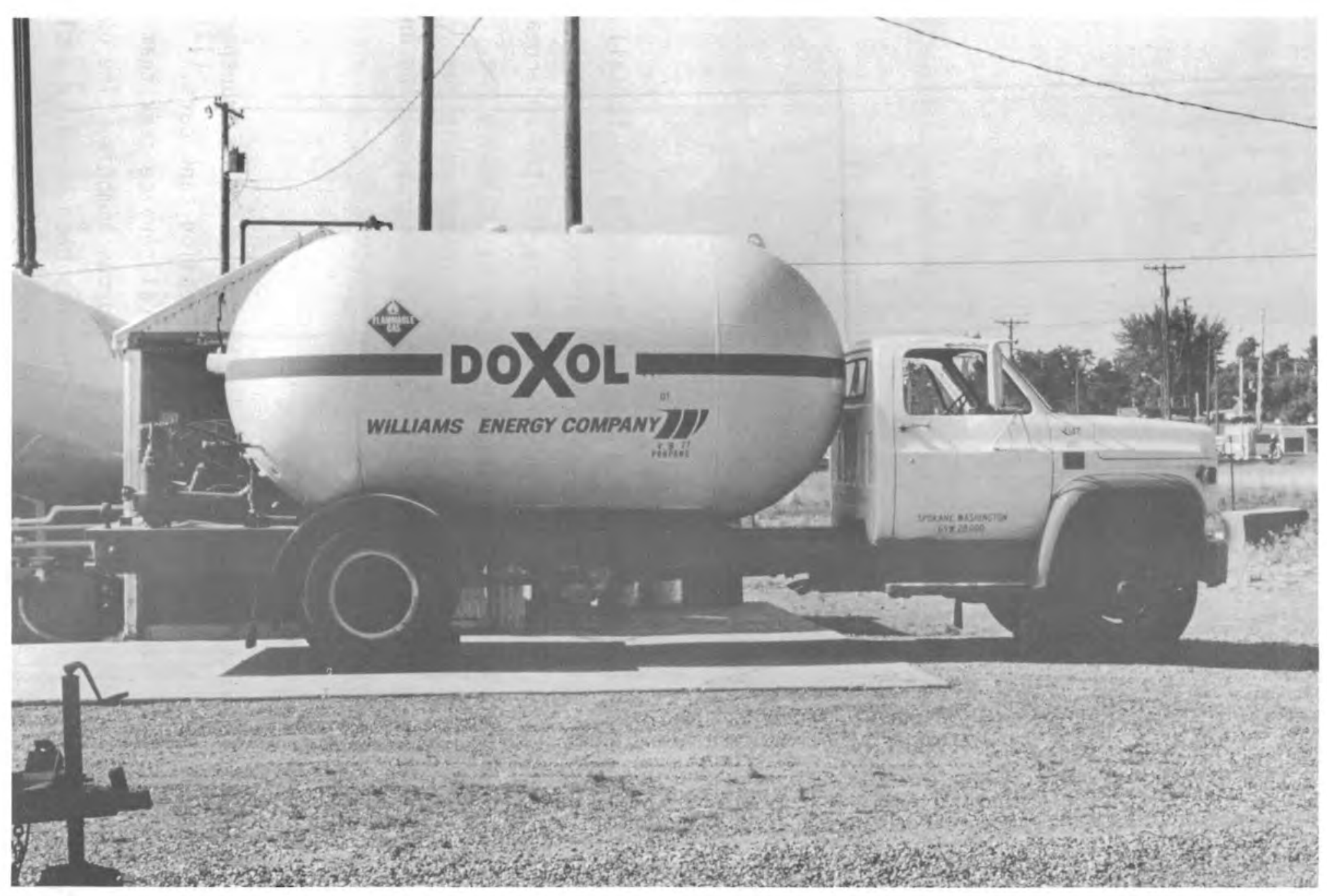

FIGURE B.3. Propane Bobtail 
TABLE B.2. Bobtail Truck Dimensions and Material Properties

$\begin{array}{lc}\text { Container Diameter } & 1.83 \mathrm{~m} \\ \text { Container Length } & 4.70 \mathrm{~m} \\ \text { Container Wall Thickness } & .01 \mathrm{~m} \\ \text { Surface Area } & 29.73 \mathrm{~m}^{2} \\ \text { Container Material }(3) & \text { SA } 202 \mathrm{Gr} . \mathrm{B} \\ \text { Yield Stress }\left(\sigma_{y}\right)(10) & 324 \mathrm{MPa} \\ \text { Ultimate Stress }\left(\sigma_{\text {uts }}\right)(10) & 586 \mathrm{MPa} \\ \text { Elastic Modulus } & 2.07 \times 10^{5} \mathrm{MPa} \\ \text { Water Weight Capacity } & 10.60 \mathrm{~m}^{3} \\ \text { Maximum Permitted }(1) & \\ \quad \text { Filling Density } & 45 \% \text { Water Weight Capacity } \\ \text { Propane Weight at } & \\ \quad \text { Maximum Fill } & 46,706 \mathrm{~N} \\ \text { Tank Working Pressure } & 1.72 \mathrm{MPa} \\ \text { Tank Test Pressure } & 3.45 \mathrm{MPa}\end{array}$

propane deliveries. Finally, most of the piping and valves on the bobtail transport are located at the rear end of the truck, rather than underneath, as on the large tank truck, although the pumping system is located underneath the bobtail tank. The basic valves included are the same, including the internal and safety relief valves. These items are all specified in the MC-331 code, and discussed in the previous section. The exterior piping and valve systems of the bobtail tank truck are shown in Figure B.4.

\section{B.3 RAIL TANK CAR}

Federal regulations require that liquefied petroleum gases be transported in DOT-105A300W, D0T-112A340W, or DOT-114A340W specification tank cars. (11) However, the DOT-114A340W specification car is a general service tank that is allowed to transport materials other than LPG or anhydrous ammonia. The use of DOT-105A300W tank cars for propane transportation has been steadily declining since 1965, while the use of DOT-112A340W tank cars has been increasing. In 1970, the DOT-105A300W, which is a small tank car, comparable in capacity 


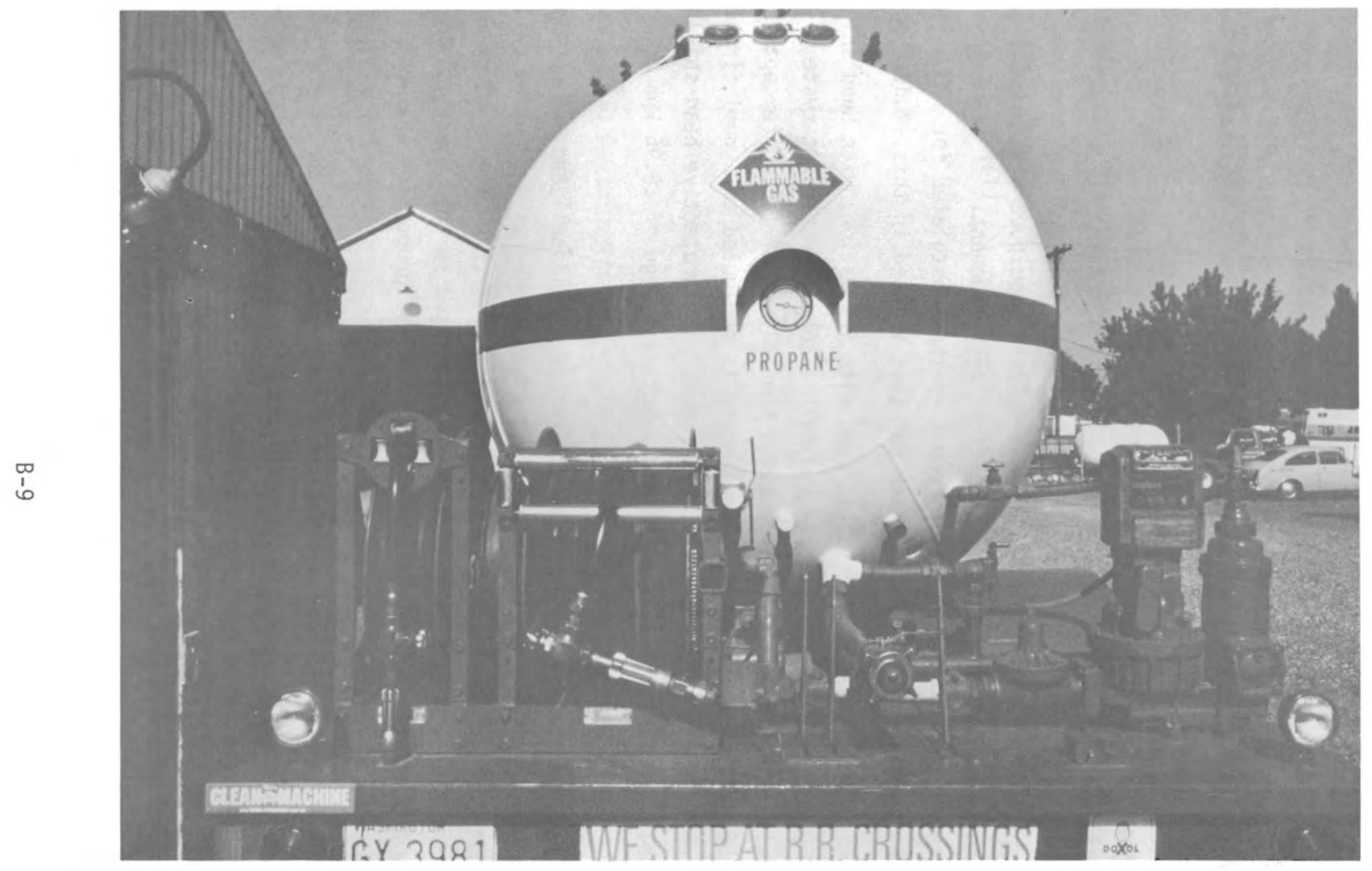

FIGURE B.4. Propane Bobtail Piping Details 
to the tank truck, hauled only $10 \%$ of the carloads of propane moved by this specification tank car and the DOT specification 112A340W tank car. Because of the larger capacity of the 112A340W tank, this corresponds to the 105A300W tank car moving only about 4 percent of the propane moved by these two car types. (12) The declining use of the 105A300W tank car and the multipurpose design of the 114A340W car led to the consideration of only the 112A340W tank car in this analysis.

The current 112A340W tank car is uninsulated. By December 31, 1980, however, all existing and newly built specification 112 and 114 tank cars used to transport flammable LP-gases are required to have both thermal and tank head protection. These tank cars must also be equipped with special couplers that are designed to resist vertical disengagement. (13) Because the shipping system analyzed in this report is that postulated for 1985 , it is this new specification 112J340W tank car that is used in this study.

The 112J340W tank car must be equipped with insulation, with head shields to resist puncture of the tank heads and with a coupler restraint system. The thermal protection system must prevent the release of lading (except through the safety relief valve) when the car is subjected to a pool fire for 100 minutes and/or a torch fire for 30 minutes. The protective head shields must be able to withstand impacts with a velocity change of $28.96 \mathrm{kph}$ or less. (14)

The tank car basically consists of a carbon steel shell and the manway cover outlets. Unlike the tank trucks, all of the tank outlets on the rail car are gathered in one location at the top of the car. An illustration of the specific 112J340W rail tank car system postulated in this study is shown in Figure B.5. Typical tank dimensions and material properties are listed in Table B.3.

A11 the valves and other outlets communicating with the tank car are located at the manway cover. The safety relief valve is about $8 \mathrm{~cm}$ in diameter, and operates like the tank truck safety relief vaive pictured in Figure B.2. The safety relief valve must be mounted on the manway cover. The 


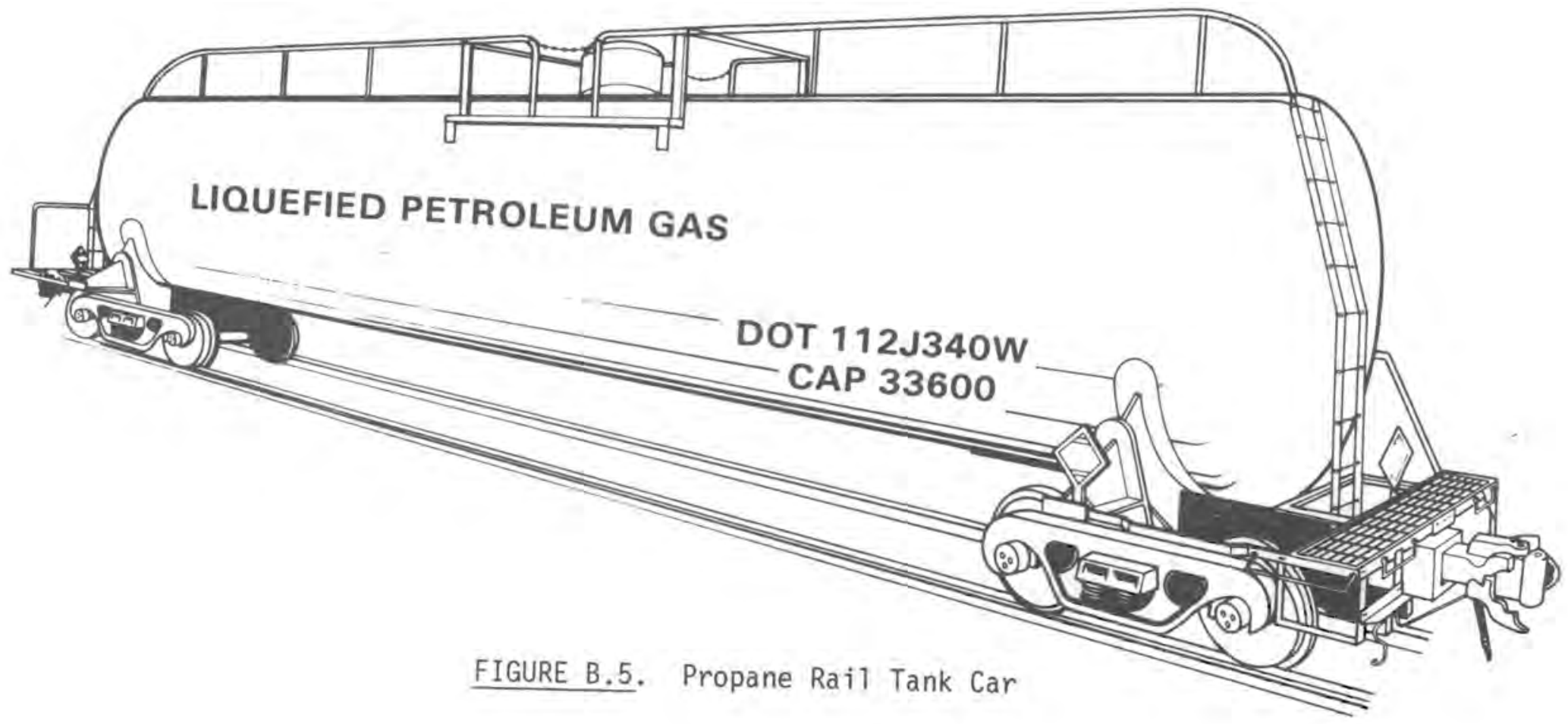


TABLE B.3. Rail Tank Car Dimensions and Material Properties

$\begin{array}{lc}\text { Container Diameter } & 3.02 \mathrm{~m} \\ \text { Container Length } & 18.24 \mathrm{~m} \\ \text { Container Wa11 Thickness } & 1.91 \mathrm{~cm} \\ \text { Surface Area } & 180 \mathrm{~m}^{2} \\ \text { Container Material }(15) & \text { AAR TC-128 Gr. B. } \\ \text { Yield Stress }\left(\sigma_{\mathrm{y}}\right) & 345 \mathrm{MPa} \\ \text { U1timate Stress }\left(\sigma_{u t s}\right) & 558 \mathrm{MPa} \\ \text { Elastic Modulus } & 2.07 \times 10^{5} \mathrm{MPa} \\ \text { Water Weight Capacity } & 126.81 \mathrm{~m}^{3} \\ \text { Maximum Permitted } & (11) \\ \quad \text { Filling Density } & \\ \quad \text { Insulated Cars) } & \\ \text { Apri1-Oct. } & 46.75 \% \\ \text { Nov.-March } & 48.51 \% \\ \text { Propane Weight at } & \\ \quad \text { Maximum Fil1 } & 6.34 \times 10^{5} \mathrm{~N} \\ \text { Container Weight } & 5.36 \times 10^{5} \mathrm{~N} \\ \text { Total Loaded Weight } & \\ \quad \text { of Container } & 1.17 \times 10^{6} \mathrm{~N} \\ \text { Tank Test Pressure } & 2.3 \mathrm{MPa} \\ \text { Tank Rupture or } & \\ \text { Burst Pressure } & 5.9 \mathrm{MPa}\end{array}$

total valve discharge capacity must be sufficient to prevent a pressure buildup in excess of $82.5 \%$ of tank test pressure, or $68.9 \mathrm{KPa}$ above start-to-discharge pressure, whichever is higher. The safety valve is set to begin relieving pressure when the internal tank pressure reaches about $1.93 \mathrm{MPa}$. (11)

All other piping and valve systems are also located within the manway cover dome, or bonnet, that covers the manhole. The manway opening is normally at least $46 \mathrm{~cm}$ in diameter. The manway cover gasket is made of asbestos. The tank car valves are mounted on the manway cover. The manway cover itself is $6 \mathrm{~cm}$ thick. A view of the 112J340W tank manway bonnet is shown in Figure B.6. A schematic of the manway bonnet and valves is shown in Figure B.7. 


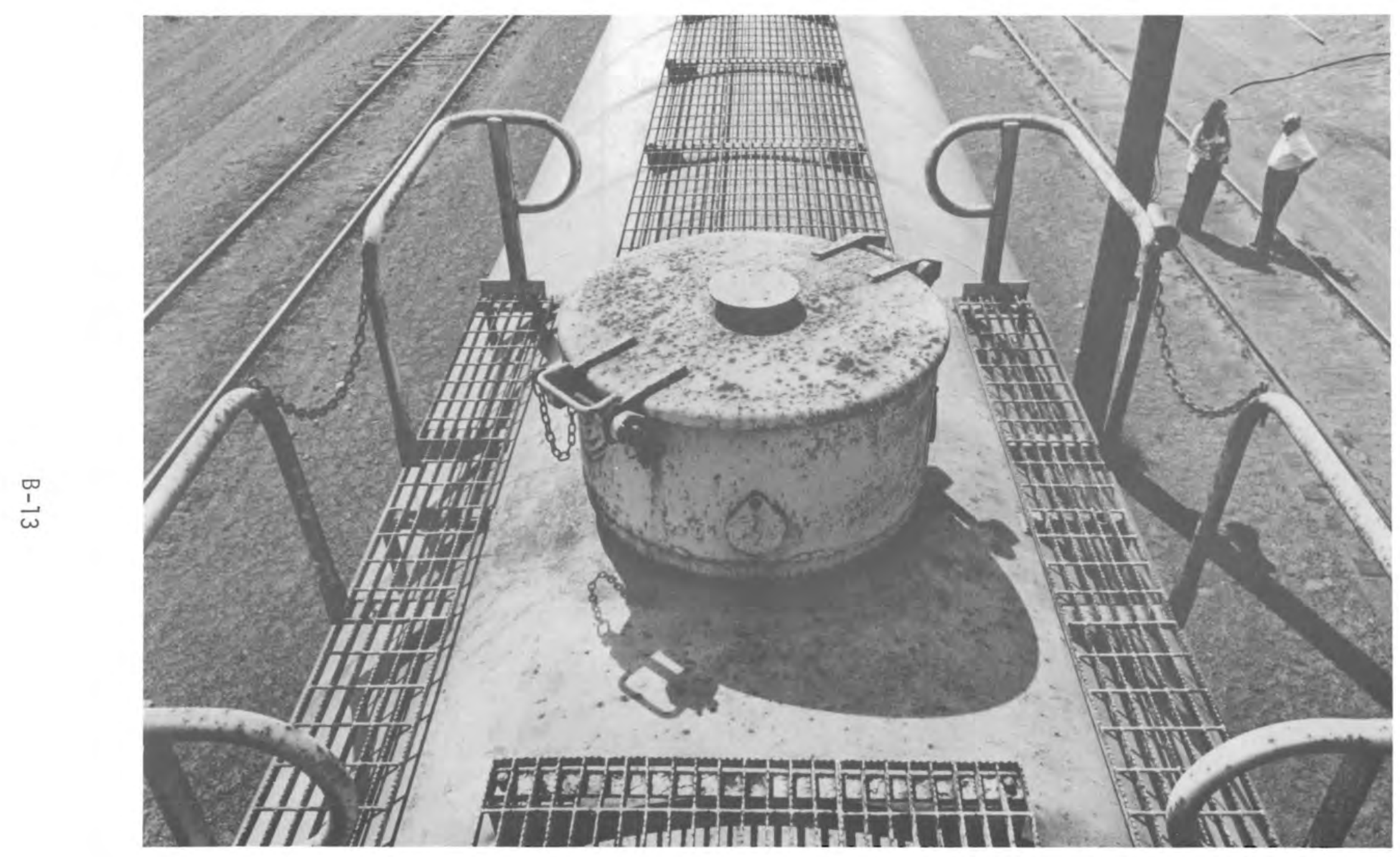

FIGURE B.6. Propane Rai1 Tank Car Manway Bonnet 


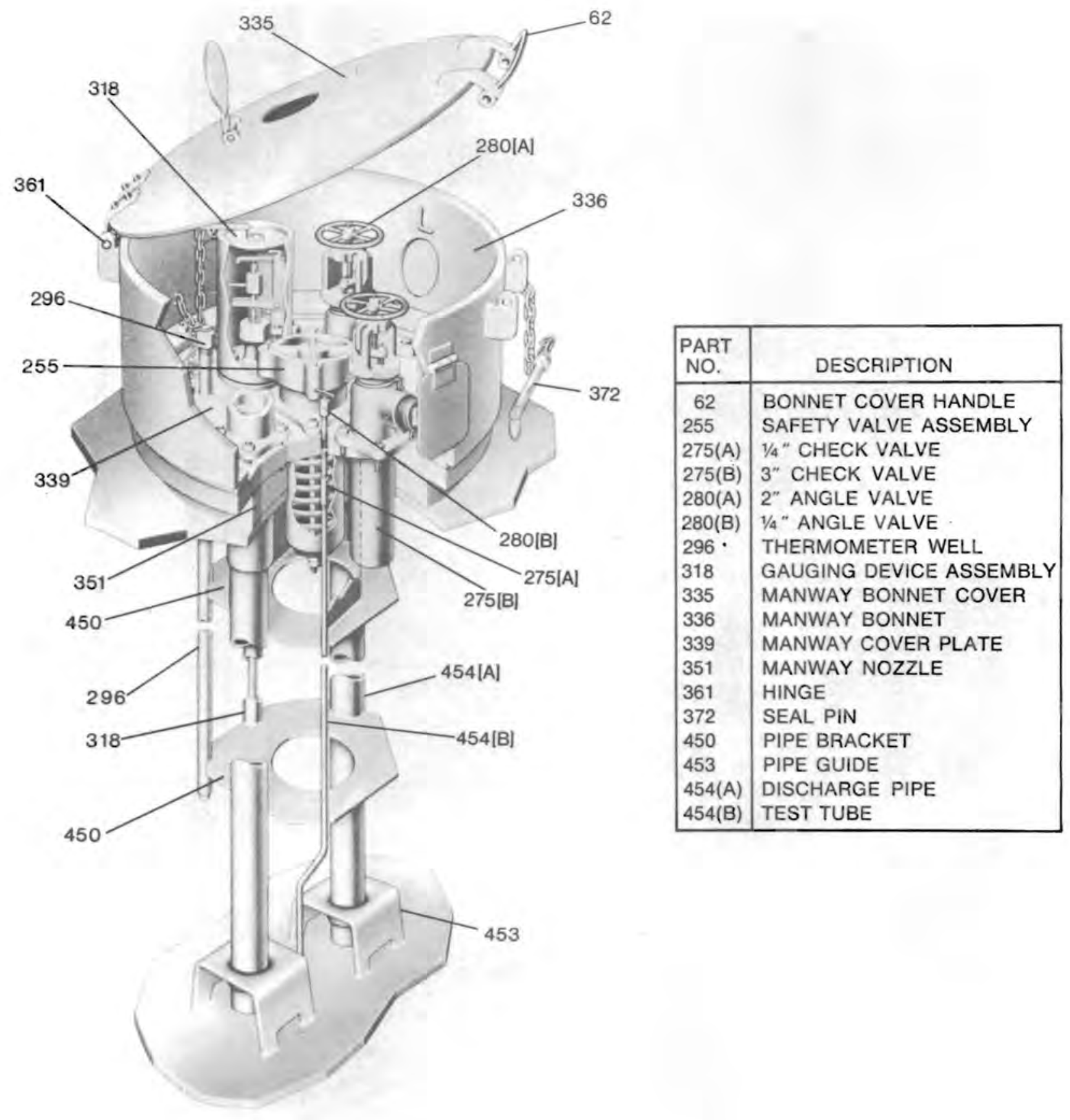

FIGURE B.7. Loading and Unloading Arrangement for Liquefied Petroleum Gases and Anhydrous Ammonia Cars 
Tank car valves are not like the internal vaives described for the tank trucks. They operate as excess flow valves only, and are located in the loading and unloading pipes that communicate with the interior of the car. These valves automatically close against an outward flow of propane when an external valve is broken off. However, they are not effective for stopping leaks, since a certain minimum flowrate is required to activate the valves. The valves have gaskets made of asbestos or stainless steel. More detailed specifications on the piping and construction of the 112J340W tank car are outlined in Reference 16. 


\section{REFERENCES}

1. 49 CFR 173.315.

2. C. Garrad, "LP-Gas Transport Truck Fire." Fire Journal. September 1965.

3. ASME Boiler and Pressure Vessel Code. Sec. II, "Specification for High Strength Alloy Steel Plates, Quenched and Tempered, for Pressure Vessels," Part A, Ferrous Materials, Materials Specifications 1974 Edition.

4. 49 CFR 178.337 "Specification MC-331."

5. Highway Accident Report - Propane Tractor - Semitrailer Overturn and Fire. U.S. Route 501, Lynchburg, VA, March 9, 1972. National Transportation Safety Board, NTSB-HAR-73-3, Washington, D.C. 20591, May 24, 1973.

6. "LP-Gas Equipment Buyer's Guide." Fisher Controls Company, Bulletin LP-21. McKinney, Texas.

7. Highway Accident Report - Multiple-Vehicle Collision Followed by PropyTene Cargo-Tank Explosion, New Jersey Turnpikes, Exit 8, September 21, 1972. National Transportation Safety Board, NTSB-HAR-73-4, Washington, D.C., October 17, 1973.

8. "Internal Valves." Fisher Controls Company, Bulletin LP-200. McKinney, Texas.

9. 49 CFR 173.33.

10. F. F. Lyle, Jr., A Study of Stress Corrosion Phenomena Resulting from Transportation of Anhydrous Ammonia in Quenched-and-Tempered Steel Cargo Tanks. Prepared for DOT, DOT-FH-11-8568, Washington, D.C. February 1976.

11. 49 CFR 173.314.

12. "Final Phase 02 Report on Accident Review." RPI-AAR Cooperative Program, RA-02-2-18, August 14, 1972.

13. Chemical and Engineering News. p. 5. May 15, 1978.

14. Federal Register. $42(179)$, September 15, 1977.

15. "Final Phase 05 Report on Tank Car Head Study." RPI-AAR Cooperative Program, RA-05-1-17, July 14, 1972.

16. 49 CFR 179. 
APPENDIX C

FAILURE THRESHOLD DETERMINATION FOR PROPANE TANKS 
APPENDIX C

\section{FAILURE THRESHOLD DETERMINATION FOR PROPANE TANKS}

This appendix describes the methods used to estimate the propane tank truck and rail tank car failure thresholds presented in Section 6 of this report. Three transport systems were analyzed:

- $44 \mathrm{~m}^{3}$ capacity MC-331 tank truck

- $10.6 \mathrm{~m}^{3}$ capacity MC-331 bobtai1 transport

- $129 \mathrm{~m}^{3}$ capacity DOT $112 \mathrm{~J} 340 \mathrm{~W}$ rail tank car.

A complete description of these transport systems is presented in Appendix $B$. Values for the physical properties of propane used in this appendix were taken from Appendix A.

As explained in Section 6 of this report, only four accident forces were found to be severe enough to significantly threaten the propane tanks: impact, puncture, crush and fire. This appendix will show how the tank failure thresholds for each of these forces were determined. The results of these calculations represent approximate values of failure thresholds obtained using elastic and energy absorption theories of structure behavior. The failure estimates obtained using these methods are believed to be less than the actual strength of the container if tests to failure had been performed. Localized failures, such as pipe failures, and the behavior of the metal at the point of local weakening, were not addressed in this report. Failure threshold values should thus not be used for purposes other than those for which they are used in this analysis.

\section{1 IMPACT}

Impact, in this analysis, is defined as a collision between an LPG-carrying tank and a rigid, unyielding, flat surface. The collision with an unyielding surface results in the energy of impact being absorbed by the tank structure. Failure thresholds are calculated for both side and end impact. In this analysis, damage to the undercarriage is neglected. 
It has been established that tank rupture is governed by interaction of the LPG with its containment. (1) An energy solution is required to define the inelastic behavior of the tank as it approaches failure. A five percent diametrical expansion is assumed as the rupture failure criteria. Five percent expansion is an approximate observed value noticed in pressure vessel burst tests. It is also assumed that the pressure decreases linearly from the impact end of the car, which corresponds to a deceleration over an extended time period.

The pressure for tank rupture is given by

$$
P_{\text {rupture }}=\sigma_{\text {uts }}\left(\frac{2 t}{d}\right)
$$

where

$$
\begin{aligned}
\sigma_{u t s} & =\text { material ultimate stress } \\
t & =\text { tank wall thickness } \\
d & =\text { tank diameter }
\end{aligned}
$$

Substituting the appropriate values from Appendix B,

$$
\text { Prupture }
$$

$\begin{array}{ccr}\text { Tank Truck } & \text { Bobtail } & \text { Rail Car } \\ 6.9 \mathrm{MPa} & 7.0 \mathrm{MPa} & 5.9 \mathrm{MPa}\end{array}$

The pressure for tank yield is given by

$$
P_{y i e 1 d}=\sigma_{y}\left(\frac{2 t}{d}\right)
$$

where

$$
\sigma_{y}=\text { material yield stress }
$$

Substituting the appropriate values from Appendix B,

$$
P_{\text {yield }}
$$

$\begin{array}{ccr}\text { Tank Truck } & \text { Bobtail } & \text { Rail Car } \\ 6.0 \mathrm{MPa} & 3.9 \mathrm{MPa} & 3.6 \mathrm{MPa}\end{array}$


The equivalent length $(H)$ of the LPG column is given by

$$
H=\frac{W_{L P G}}{\rho_{L P G}{ }^{A} C S}
$$

where

$$
\begin{aligned}
W_{L P G} & =\text { weight of the } L P G \\
P_{L P G} & =\text { density of the } L P G \\
A_{C S} & =\text { cross-sectional area of the carrier }
\end{aligned}
$$

Substituting appropriate values from Appendices A and B,

$$
\text { H }
$$

$\begin{array}{clc}\text { Tank Truck } & \text { Bobtail } & \text { Rail Car } \\ 10.1 \mathrm{~m} & 3.5 \mathrm{~m} & 17.7 \mathrm{~m}\end{array}$

The location height ( $h$ ) for the plastic expansion region (Figure C.l) is given by

$$
h=-H \frac{P_{\text {yield }}}{P_{\text {rupture }}}+H
$$

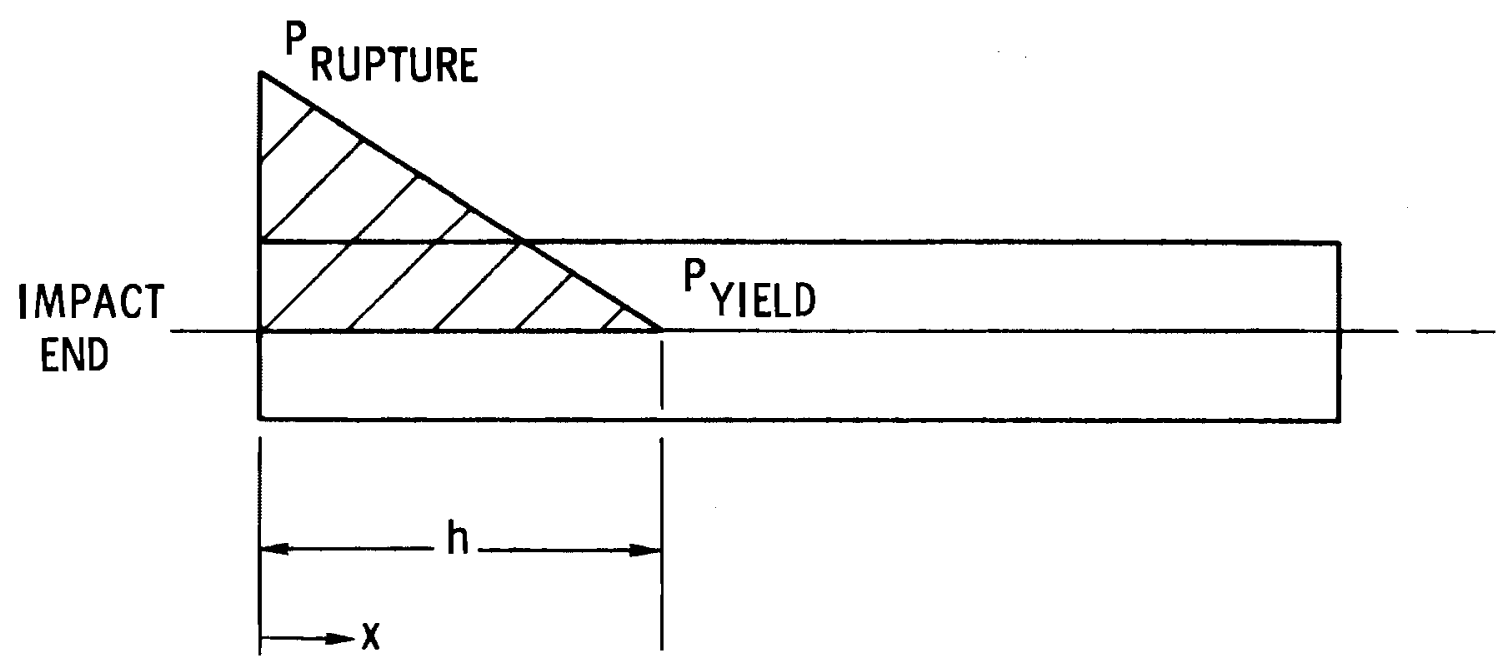

FIGURE C.1. Graphical Location of Equivalent Static Head Required to Produce a Localized 5\% Diametrical Change 
Substituting the appropriate values,

$\begin{array}{clc} & \mathrm{h} \\ \text { Tank Truck } & \text { Bobtail } & \text { Rail Car } \\ 1.33 \mathrm{~m} & 158 \mathrm{~m} & 6.76 \mathrm{~m}\end{array}$

The work done by the LPG on the tank, per unit length of tank, is given by

$$
w=\left(P(x)-P_{0}\right)(\pi d)\left(\frac{.05 d}{2}\right)\left(\frac{h-x}{h}\right)
$$

where

$P(x)$ represents the following time-averaged approximation of the pressure:

$$
\begin{aligned}
& P(x)=\left\{\frac{1}{2} P_{\text {yield }}+\left[P_{\text {yield }}+\left(P_{\text {rupture }}-P_{\text {yield }}\right)\left(\frac{h-x}{h}\right)\right]\right\} \\
& P_{0}=\text { preaccident internal gage pressure (assume } 1.55 \mathrm{MPa} \text { ) }
\end{aligned}
$$

Combining Equations (4a) and (4b) and substituting the appropriate terms,

$$
\begin{aligned}
& \text { Tank Truck } w=.282(4.93-.342 x)(1.33-x) \quad(x \text { in } m, w \text { in } N-m) \\
& \text { Bobtail } w=.166(3.88-.990 x)(1.58-x) \quad(x \text { in } m, w \text { in } N-m) \\
& \text { Rail Car } w=.106(3.19-.166 x)(6.76-x) \quad(x \text { in } m, w \text { in } N-m) \\
& \text { Tank Truck } w_{t}=w d x=\int_{0}^{h=1.33} .282(4.93-3.42 x)(1.33-x) d x \\
& \text { Bobtail } w_{t}=w d x=\int_{0}^{h=1.58} .166(3.88-.990 x)(1.58-x) d x
\end{aligned}
$$




$$
\begin{gathered}
\text { Rail Car } \quad w_{t}=\int w d x=\int_{0}^{h=6.76} .106(3.19-.166 x)(6.76-x) d x \\
w_{t}
\end{gathered}
$$

$\begin{array}{llr}\text { Tank Truck } & \text { Bobtail } & \text { Rail Car } \\ 1.19 \times 10^{6} \mathrm{~N}-\mathrm{m} & 7.00 \times 10^{5} \mathrm{~N}-\mathrm{m} & 6.85 \times 10^{6} \mathrm{~N}-\mathrm{m}\end{array}$

Equating the work term (Equation $\mathrm{C}-6$ ) with the tank kinetic energy (KE) yields

$$
\frac{1}{2} \frac{W_{L P G}}{g} V_{0}^{2}=K E=W_{t}
$$

Solving Equation (C-7) yields the following accident velocities for end impact failure of a propane tank:

$$
\begin{array}{ccc}
V_{0} \text { - Average Preaccident Velocity } & \text { (End Impact) } \\
\text { Tank Truck } & \text { Bobtail } & \text { Rail Car } \\
40 \mathrm{kph} & 61 \mathrm{kph} & 51 \mathrm{kph}
\end{array}
$$

A defective tank is assumed to fail at $3 / 4$ of this velocity.

Side impact is also analyzed by using energy techniques. The work necessary to compress the LPG from the allowable fill pressure $\left(P_{0}\right)$ to the critical pressure $\left(P_{y i e l d}\right)$ is equated to the change in tank kinetic energy. The accident velocities are determined assuming a nearly full LPG tank and neglecting the static head of the liquid.

The work per unit length to compress the $L P G$ from $P_{0}$ to $P_{y i e l d}$ is given by

$$
W=\frac{1}{2}\left(P_{\text {yield }}+P_{0}\right) \frac{\Delta P}{k} A_{c S}
$$


where

$$
\begin{aligned}
W & =\text { work per unit length } \\
P_{\text {yield }} & =\text { gage pressure required to yield tank } \\
P_{0} & =\text { preaccident internal gage pressure } \\
\Delta P & =P_{\text {yield }}-P_{0} \\
k & =L P G \text { bulk modulus }(270 \mathrm{MPa}) \\
A_{c S} & =\text { cross-sectional area of the carrier }
\end{aligned}
$$

Equating the work (Equation $\mathrm{C}-8$ ) with the tank kinetic energy (KE) yields

$$
\frac{1}{2} \frac{W_{L P G}}{g} V_{0}^{2}=K E=W
$$

Substituting the appropriate values, Equation (C-9) yields the following velocities for tank yield in a side impact environment:

$$
\begin{array}{ccc}
V_{0} \text { - Average Preaccident Velocity } & \text { (Side Impact) } \\
\text { Tank Truck } & \text { Bobtail } & \text { Rail Car } \\
56 \mathrm{kph} & 40 \mathrm{kph} & 32 \mathrm{kph}
\end{array}
$$

Again, a defective tank is assumed to fail at $3 / 4$ of this velocity.

\section{C.2 PUNCTURE}

The probability of a puncture failure in an accident environment can be determined from the information presented in Section 5 of this report, if data on tank wall thicknesses are available. The values used for the two tank trucks are those given in Appendix B. However, the rail tank car has head shields placed on the ends of the tank that are intended to act as energy absorbers in case of an accident where the cars decouple. An "equivalent thickness" of the shield and tank wall could be used with the probability data in Section 5 relating puncture and car wall thickness. This "equivalent thickness" of the car would replace the existing tank and shield, yet offer the same impact resistance.

The puncture energy required for a ductile shel1 ${ }^{(3)}$ is given by 


$$
\text { Puncture Energy }=A t^{n}
$$

where

$A$ and $n$ are dependent on the material and car mounting technique used $t=$ thickness

From the AAR report No. RA-05-1-17, ${ }^{(4)} \mathrm{n}$ is found to be 1.333 . Therefore,

$$
\begin{gathered}
t_{\text {eq }}^{1.333}=t_{\text {shield }}^{1.333}+t_{\text {car }}^{1.333} \\
t_{\text {shield }}=1.27 \mathrm{~cm} \\
t_{\text {car }}=1.91 \mathrm{~cm} \\
t_{\text {eq }} \simeq 3.64 \mathrm{~cm}
\end{gathered}
$$

This value is used for the thickness of the tank ends. The wall thickness used for the rail tank car is that given in Appendix B.

\section{C.3 $\underline{\text { CRUSH }}$}

The loading configuration assumed for the crush environment is shown in Figure C.2. The crush load is assumed to be uniformly distributed along the entire length of the tank and is assumed to result from the weight of a heavy, relatively flat object; e.g., a flat car. The point considered for stress calculations was the top of the tank directly beneath the crush load. The tank bottom will most likely be supported in a relatively compliant fashion, such as by soil or gravel forces. Such support will tend to prevent excessive flexure strains due to hydrostatic and crush loading. Since hydrostatic loading has little influence on stress levels at the top of the tank, it was neglected in this analysis. 

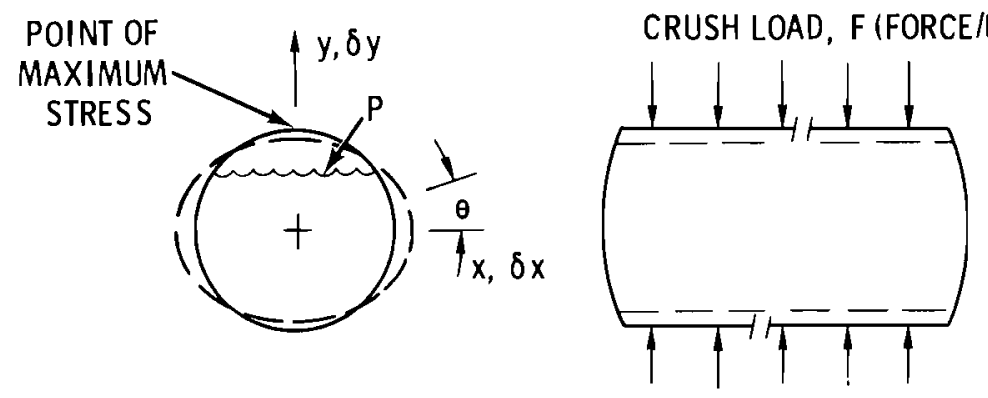

FIGURE C.2. Crush Loading Configuration

The stiffening of the elliptical tank heads was also neglected in this analysis. This assumption is probably conservative, since end stiffness will most likely tend to "shelter" mid-tank regions for most crush loading environments.

LPG shipments are made with relatively full tank cars. Some void space is left in order to allow for thermal expansion of the liquid. In a crush environment, the tank deflection will tend to reduce this void, and an increased gas pressure will result. The degree of pressure increase will depend on the volumetric stiffness of the gas with respect to pressure and the volumetric stiffness of the tank with respect to pressure and crush loading.

For a given pressure and crush loading, the circumferential tensile stress at the inside surface of the tank is: ${ }^{(5)}$

$$
\sigma=\frac{P R}{t}+\frac{1.908 F R}{t^{2}}
$$

where

$$
\begin{aligned}
& \mathrm{R}=\text { tank radius } \\
& \mathrm{t}=\text { tank thickness } \\
& \mathrm{P}=\text { internal pressure (gage) } \\
& \mathrm{F}=\text { crush loading (force/length) }
\end{aligned}
$$


The crush load was assumed to be applied quickly enough to preclude pressure relief due to pressure relief valve actuation. In addition, gas behavior was assumed to be adiabatic and the LPG was assumed to be incompressible. Pressure-volume relations in this case take the following form:

$$
\frac{(P+1 \text { atmos })}{\left(P_{0}+1 \text { atmos }\right)}=\left[\frac{1}{1+\frac{\Delta V_{P}}{V_{i}}+\frac{\Delta V_{F}}{V_{i}}}\right]^{C_{p} / C_{V}}
$$

where

$$
\begin{aligned}
V_{i} & =\text { initial gas volume } \\
C_{P} / C_{V} & =\text { specific heat ratio for } L P G(1.131) \\
\Delta V_{P} & =\text { volume change due to pressure increase } \\
\Delta V_{F} & =\text { volume change due to crush loading } \\
P_{0} & =\text { initial gas pressure (gage) }
\end{aligned}
$$

It can be shown that the term relating volumetric increase and pressure takes the form:

$$
\frac{\Delta V_{P}}{V_{i}}=\frac{P R}{t E}(2.5-2 v)
$$

where

$$
\begin{aligned}
& E=\text { Young's modulus of tank material, } 2.07 \times 10^{5} \mathrm{MPa} \\
& \nu=\text { Poisson's ratio (.3 assumed) }
\end{aligned}
$$

The term relating volumetric change resulting from crush loading is somewhat more complex. Using techniques similar to those found in Reference 5, it can be shown that the transverse tank motion in the first quadrant of Figure C.2 takes the form: 


$$
\begin{aligned}
& \delta_{x}=\frac{F R^{3}}{D_{E}}\left[\frac{\theta \sin \theta}{\pi}+\frac{1}{\pi} \cos \theta-\frac{\sin ^{2} \theta}{2}-\frac{\cos ^{2} \theta}{4}\right] \\
& \delta_{y}=\frac{F R^{3}}{D_{E}}\left[-\frac{\theta}{4}-\frac{\sin 2 \theta}{8}+\frac{\sin \theta}{\pi}+\frac{\sin \theta \cos \theta}{2}-\frac{\theta \cos \theta}{\pi}\right]
\end{aligned}
$$

where

$$
D_{E}=\text { shel1 stiffness }=\frac{E t^{3}}{12\left(1-v^{2}\right)}
$$

It should be emphasized that equations $15 \mathrm{a}$ and $15 \mathrm{~b}$ apply only for $0 \leq \theta \leq \pi / 2$. Deflections for other ranges of $\theta$ may be determined from symmetry.

By use of Equations (C-13) through $(C-15)$, tank pressures were determined in an iterative fashion for various initial pressure conditions and crush load values. With these pressure values, stress values were computed by use of Equation $(C-12)$.

The results of these calculations are shown in Figure C.3 for the tank trucks and Figure C.4 for the rail tank car. Various percentages of void volume were considered. These percentages correspond to gas volumes at various temperatures (indicated in Figures C.3 and C.4) when the tank is filled to its authorized limit, as specified in the code of federal regulations. (6) The failure threshold used for both tank trucks is $690 \mathrm{MPa}$, while that used for the rail tank car is $345 \mathrm{MPa}$.

\section{C.4 FIRE}

There are two basic fire failure modes considered in this report for an LPG tank engulfed in a fire. First, the tank car can fail because of overheating of the unwetted shell, which is the part of the tnak in contact with vapor space. In this failure sequence, safety valves operate normally, opening once internal tank pressure reaches the relief valve setpoint. The valves are sufficient, in this case, to vent the tank, preventing excessive pressure buildup. 


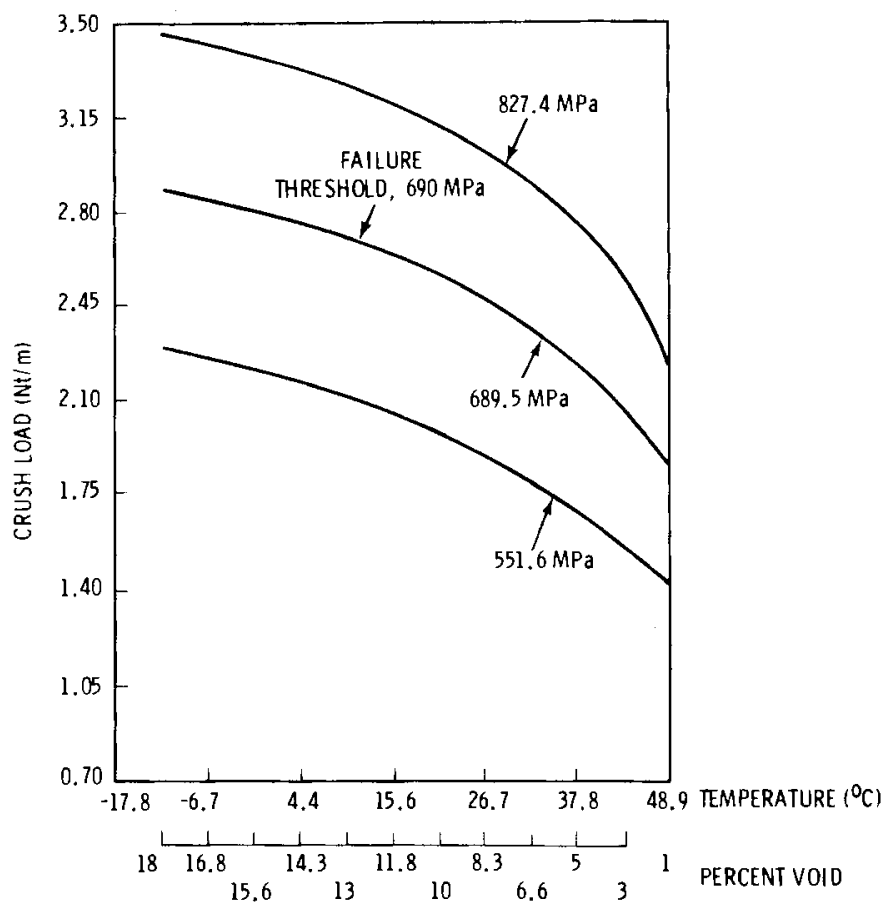

FIGURE C.3. Crush Load versus Percent Void (tank trucks)

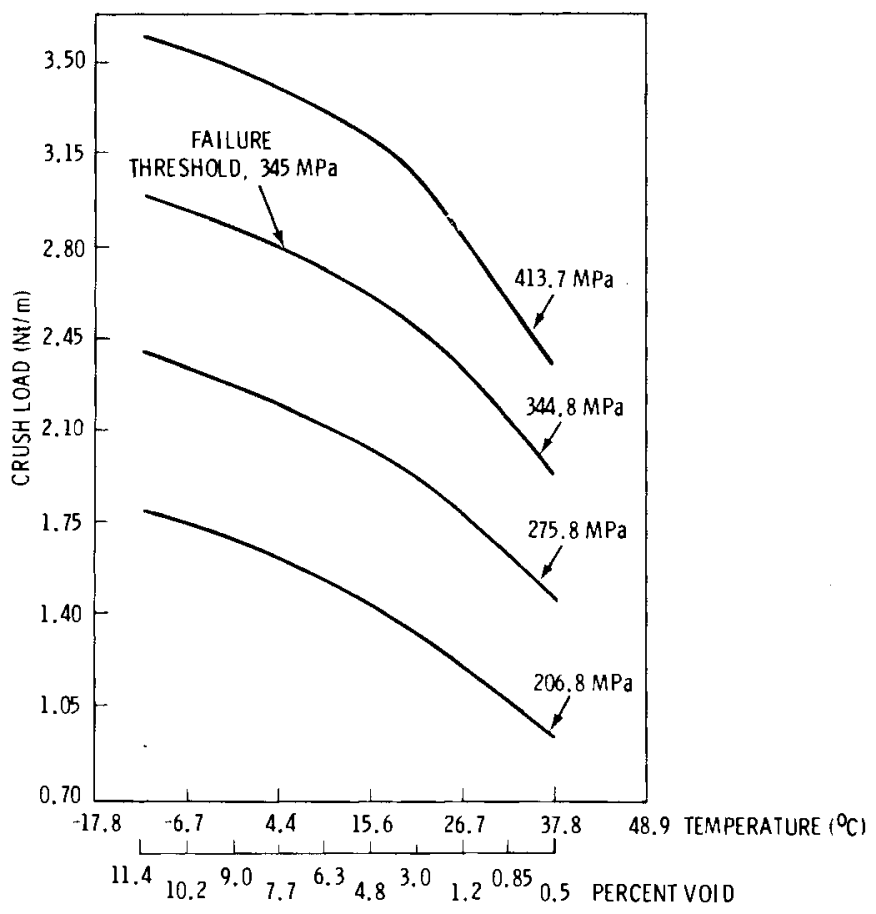

FIGURE C.4. Crush Load versus Percent Void (rail car) 
The second failure mode considered is that of overpressurization of the tank. When engulfed in a fire, the temperature of the liquid inside the tank begins to rise, increasing internal pressure. If the safety relief valves are blocked from venting the tank, are defective in a way that prevents release of lading, or are insufficiently sized to handle the required discharge of propane, the internal pressure will continue to increase until the tank fails.

Several values are required to determine the fire duration necessary to fail a tank by either of the above failure sequences. First, the heat flux from an accident fire must be determined to find the rate of temperature increase of the propane inside the tank. This calculation is performed in Section C.4.1. It is also necessary to know the amount of propane that flows through the safety relief valves once the setpoint pressure is reached. These values are calculated in Section C.4.2. Finally, the times to failure for each tank are calculated in Sections C.4.3 and C.4.4 for the fajlure sequences described above.

\section{C.4.1 Heat Flux Calculations}

Heat flux calculations were performed for insulated and uninsulated LPGcarrying rail and truck containers exposed to a $1010^{\circ} \mathrm{C}$ fire. The cars were assumed to be filled to their authorized limits and be of the dimensions listed in Appendix B. The tanks were also assumed to be totally engulfed by the fire, resulting in conservative failure estimates.

By examining the portion of the heat flux due to conduction through the insulation and assuming that the outer wall is at the fire temperature and neglecting the thermal resistance due to radiation, a conservative estimate of the heat flux is given by

$$
\mathrm{q}_{\mathrm{C}}=\frac{1010^{\circ} \mathrm{C}-\mathrm{T}_{\mathrm{LPG}}}{\mathrm{t}} \mathrm{k}
$$


where

$$
\begin{aligned}
{ }^{q_{C}} & =\text { heat per unit area - transmitted by conduction } \\
T_{L P G} & =\text { temperature of the } L P G \text { (assume } 38^{\circ} \mathrm{C} \text { ) } \\
k & =\text { thermal conductivity of the insulating material } \\
t & =\text { insulation thickness (assume } .0254 \mathrm{~m} \text { ) }
\end{aligned}
$$

Several insulators (Deltaboard insulation and Thermolag, Chartek 59 and De Soto thermal coatings) were proposed as being effective thermal shield systems. (7) However, only thermal properties for the Deltaboard were available. The conductivity for Deltaboard (rock wool - bulk density $=240 \mathrm{~kg} / \mathrm{m}^{3}$ ) was extrapolated from data found in Marks Handbook for Mechanical Engineers, and was estimated to be $.08437 \mathrm{w} / \mathrm{m}^{\circ} \mathrm{C}$.

Substituting the appropriate terms, Equation $(C-16)$ reduces to:

$$
q_{c}=\left(\frac{1010^{\circ} \mathrm{C}-38^{\circ} \mathrm{C}}{.0254 \mathrm{~m}}\right)\left(.08437 \frac{\mathrm{w}}{\mathrm{m}^{\circ} \mathrm{C}}\right)=3230 \frac{\mathrm{w}}{\mathrm{m}^{2}}
$$

This value represents the heat flux for a tank insulated with $2.54 \mathrm{~cm}$ thick Deltaboard.

A conservative estimate of the heat flux for a non-insulated region can be made by neglecting the conduction resistance.

$$
q_{r}=\sigma\left(\frac{1}{\varepsilon_{1}}+\frac{1}{\varepsilon_{2}}-1\right)^{-1}\left(T_{1}^{4}-T_{2}^{4}\right)
$$

where

$q_{r}=$ heat per unit area - transmitted by radiation

$\varepsilon_{1}=$ emissivity of the fire (assume .9)

$\varepsilon_{2}=$ emissivity of the tank wall (assume .8)

$\mathrm{T}_{2}=$ temperature of the $L P G$ (assume $38^{\circ} \mathrm{C}$ )

$\sigma=$ Stephen - Boltzman constant $\left(5.669 \times 10^{-8} \frac{\mathrm{W}}{\mathrm{m}^{2}{ }^{\circ} \mathrm{K}^{4}}\right)$

Substituting these values, Equation $(C-18)$ becomes 


$$
q_{r}=5.669\left(\frac{1}{.9}+\frac{1}{.8}-1\right)^{-1}\left[\left(\frac{1010+275}{100}\right)^{4}-\left(\frac{38+275}{100}\right)^{4}\right]=113 \frac{\mathrm{kw}}{\mathrm{m}^{2}}
$$

The average flux can be represented by weighting the percentage of areas that are insulated and uninsulated.

$$
q_{t}=q_{c} \text { (percent area insulated) }+q_{r} \text { (percent area with insulation removed) }
$$

$$
q_{t}=q_{c}\left(\frac{A_{t}-A_{r}}{A_{t}}\right)+q_{r}\left(\frac{A_{r}}{A_{t}}\right)
$$

where

$$
\begin{aligned}
& q_{t}=\text { total heat flux } \\
& q_{c}=3230 \frac{\mathrm{w}}{\mathrm{m}^{2}} \\
& \mathrm{q}_{r}=113 \frac{\mathrm{kw}}{\mathrm{m}^{2}} \\
& A_{t}=\text { total surface area } \\
& A_{r}=\text { area with insulation removed }
\end{aligned}
$$

Substituting these values, Equation $(C-20)$ becomes

$$
q_{t}=3.230\left(\frac{A_{t}-A_{r}}{A_{t}}\right)+113 \frac{A_{r}}{A_{t}}\left(\frac{k w}{m^{2}}\right)
$$

or

$$
q_{t}=3.230\left(1-\frac{A_{r}}{A_{t}}\right)+113 \frac{A_{r}}{A_{t}}\left(\frac{k w}{m^{2}}\right)
$$

Figure C.5 compares the effect of varying conductivites as influenced by the amounts of insulation removed. 


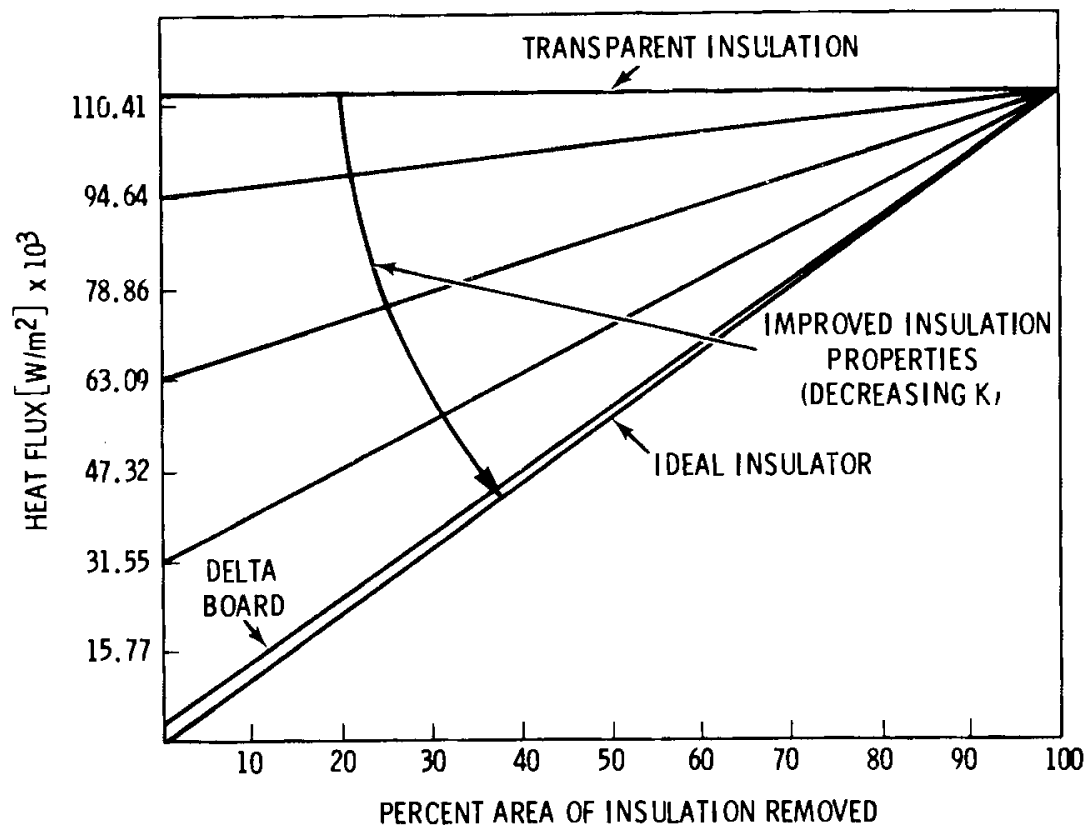

FIGURE C.5. Heat Flux as Influenced by Amount of Insulation Removed at a Fire Temperature of $1010^{\circ} \mathrm{C}$

\section{C.4.2 Flow of Propane Through Safety Relief Valves}

There are two cases of flow through a safety relief valve that must be considered. One is where the tank is overturned as a result of accident forces. In this case, the valve will essentially be venting liquid, since the vapor space will be forming at the top of the tank. The second case is where the valve is discharging propane vapor when the tank is upright.

A method for determining the liquid flow through a safety relief valve is given in Reference 9. The maximum flow relation for liquid propane through an orifice is shown in Figure C.6. The safety relief valves on the trucks have a set pressure of $1.86 \mathrm{MPa}(270 \mathrm{psig})$; the rail tank car valve has a set pressure of $1.93 \mathrm{MPa}(280.5 \mathrm{psig})$. From Figure C.6, a relationship for the maximum flow possible through each valve can be obtained. 


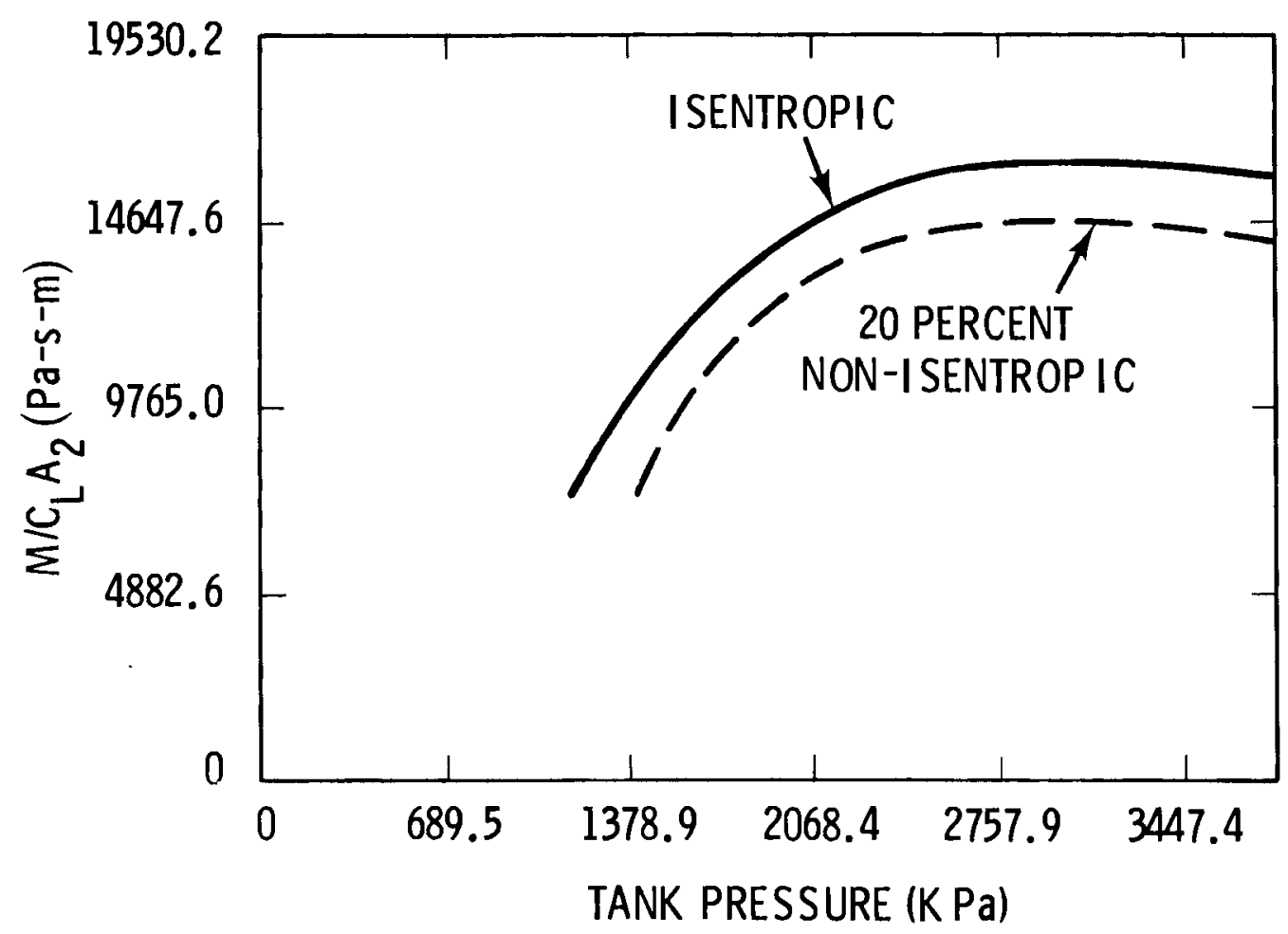

FIGURE C.6. Maximum Flow of Liquid Propane Through an Orifice (Redrawn from Reference 9)

For the truck tanks,

$$
\frac{\dot{M}_{L}}{C_{L} A_{2}}=14,159.4 \text { Pa-s-m }\left(2900 \frac{1 b}{f t^{2}-s e c}\right)
$$

For the rail tank car,

$$
\frac{\dot{M}_{L}}{C_{L} A_{2}}=14,647.6 \mathrm{~Pa}-\mathrm{s}-\mathrm{m}\left(3000 \frac{\mathrm{lb}}{\mathrm{ft}^{2}-\mathrm{sec}}\right)
$$

where

$\dot{M}_{L}=$ maximum flow of liquid propane through the valve

$A_{2}=$ cross section of limiting area of valve (see Figure B.2)

$C_{L}=1$ iquid flow coefficient for the orifice (assume .65) 
Substituting the appropriate values,

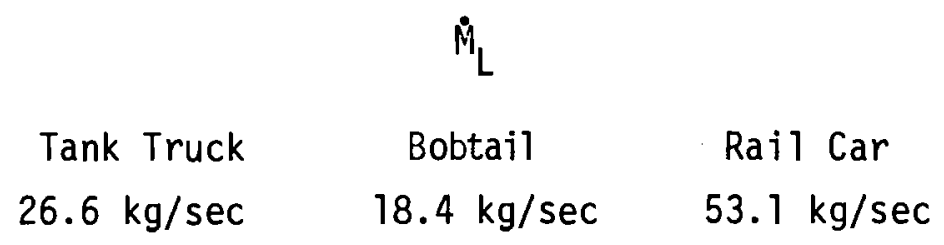

The flow of propane vapor through the safety relief valve is also obtained by methods outlined in Reference 9 . The maximum vapor loss through the safety relief valve is given as

$$
\dot{M}_{v}=\frac{c_{v} A_{2} v_{c}}{v_{c}}
$$

where

$C_{v}=$ vapor flow coefficient for the orifice (assume .80)

$A_{2}=$ cross section of 1 imiting area of valve (see Figure B.2)

$V_{C}=$ acoustic velocity of vapor at temperature $T$

$\nu_{C}=$ specific volume of vapor at pressure $P=.59 P_{0}$ and temperature $T=.97 \mathrm{~T}_{0}$

$$
v_{c}=\sqrt{k g R T}
$$

where

$$
\begin{aligned}
& \mathrm{k}=\text { ratio of specific heats (Appendix A) } \\
& \mathrm{g}=\text { gravitational constant } \\
& \mathrm{R}=\text { gas constant } \\
& \mathrm{T}=.97 \mathrm{~T}_{0} \\
& \text { For the tank truck and the bobtail, } \\
& \quad \mathrm{P}_{0}=1.86 \mathrm{MPa}, \mathrm{T}_{0}=328^{\circ} \mathrm{K}
\end{aligned}
$$

For the rail tank car,

$$
P_{0}=1.93 \mathrm{MPa}, \mathrm{T}_{0}=331^{\circ} \mathrm{K}
$$


Substituting the appropriate values,

$\begin{array}{ccc} & \dot{M}_{v} & \\ \text { Tank Truck } & \text { Bobtail } & \text { Rail Car } \\ 12.9 \mathrm{~kg} / \mathrm{sec} & 8.6 \mathrm{~kg} / \mathrm{sec} & 25.3 \mathrm{~kg} / \mathrm{sec}\end{array}$

We must now determine whether the safety relief valves are sufficiently sized to vent the tank of liquid if it is overturned. The safe condition for the tank, derived in Reference 9, is

$$
\begin{aligned}
& \dot{M}_{L /} q>1.30 \times 10^{-3} \text {, for the tank truck } \\
& \dot{M}_{L /} q>4.48 \times 10^{-4} \text {, for the bobtail } \\
& \dot{M}_{L /} q>7.01 \times 10^{-4} \text {, for the rail car }
\end{aligned}
$$

where $q=$ the input heat flux to the tank.

Substituting the appropriate values from Section C.4.1, and remembering that the rail car is insulated, it is found that the safety relief valves have sufficient capacity to vent the tank of compressed liquid and will prevent excessive pressure increases if functioning properly.

\section{C.4.3 Fire Durations Required to Fail Tanks by Overheating of the Unwetted She 11}

This section considers the fire duration necessary to fail a propane tank by overheating of the unwetted she11. The LPG tank is assumed to be totally engulfed by the fire. LPG tanks have been known to be essentially totally enveloped in some fire accident scenarios. Therefore, the conservative total engulfment assumption will be used in fire failure threshold calculations. Legal filling requirements initially limit the liquid to about 85 to 95 percent of the tank volume, with propane vapor occupying the remaining space. As the temperature of the liquid increases, the liquid volume increases. The rate of expansion is dependent upon the heat flux ( $q A)$ to the tank and the properties of the liquid. The liquid continues to expand, causing the internal pressure to rise. When the start-to-discharge pressure of the safety 
relief valve is reached, the valve begins to release propane. If the flow capacity of the valve is sufficient, the pressure will stabilize at a point within the range of the valve settings and the liquid level will begin to fall.

Propane vapor is a poor conductor of heat. Thus, the part of the tank that is backed by vapor will be uniformly heated by the fire and will eventually reach a weakened state in which it can no longer withstand the relatively low internal pressure at the relief valve setting. At this point, the tank will rupture. Full-scale tests on rail tank cars reveal that the tanks fail from localized weakening of the shell when the tank is about half full of liquid. (10) Thus, it is assumed that the tanks will rupture at half-full. Thermodynamic properties of propane for these calculations were taken from Reference 11.

Fire duration calculations are performed in two steps. First, the time required to reach a shell-full condition and then to raise the internal pressure of the tank to the safety relief valve setpoint must be found. Then, the time to relieve the tank of half its contents is determined, at which point tank rupture is assumed to occur.

To find the time required to reach a venting condition, the following relations are used:

$$
q=C_{p} \Delta T M_{\text {tot }}=\Delta h M_{\text {tot }}
$$

where

$$
\begin{aligned}
q= & \text { heat input required to raise the temperature and pressure of } \\
& \text { the propane to a desired state } \\
\Delta \mathrm{T}= & \text { rate of temperature increase } \\
\Delta \mathrm{h}= & \text { difference in enthalpy between initial and final states } \\
M_{\text {tot }}= & \text { total amount of propane in tank. }
\end{aligned}
$$

and

$$
q / Q=t
$$


where

$$
\begin{aligned}
& Q=\text { heat flux to tank from fire } \\
& t=\text { time (seconds) }
\end{aligned}
$$

Using the thermodynamic properties of propane, lading descriptions from Appendix $B$, and Equations $(C-26)$ and $(C-27)$, the time to venting is found for each tank, and is shown in Table C.1. Note that for the rail tank car, the cases of a partially insulated and an uninsulated car are also analyzed.

The heat flux for a partially insulated rail car can be found if the amount of insulation removed is known. A side-on raking collision is assumed to remove an area of one meter high times the length of the tank, or about $10 \%$ of the tank surface area.

In calculating the time required for the tank to reach half-full, we must differentiate between the overturned and upright tank because of the flow rate differences between liquid and gaseous discharge. However, each calculation wi11 require three steps. First of a11, the rate of venting must be determined. These values may be obtained from Section C.4.2. Secondly, when the valves first open, they are venting liquid. The pressure increase coupled with the limited tank volume has resulted in a subcooled state for the propane. This subcooled liquid must be vented before the propane can again reach a saturated state at the higher temperature and pressure of venting conditions. The time required to vent this subcooled liquid must be determined. Finally, the time required to empty half of the remaining tank contents must be found. This value is related to the rate at which propane is discharged from the valve. The maximum discharge rate is used to keep calculations conservative. However, although the trucks have more than one safety relief valve, it is assumed that only the equivalent of one valve is releasing propane at the maximum rate.

The time required to raise the temperature of the propane lading from the temperature at she 11 full conditions to full venting pressure/temperature conditions is found by using Equations $(C-26)$ and $(C-27)$. The results are tabulated in Table C.1. 
TABLE C.1. Time to Shellfull and to Venting Conditions for Propane Tanks

\begin{tabular}{|c|c|c|c|c|c|}
\hline Shellfull & Tank Truck & Bobtail & $\begin{array}{l}\text { Rafl Car } \\
\text { Insulated }\end{array}$ & $\begin{array}{l}\text { Rail Car } \\
\text { Partially } \\
\text { Insulated } \\
\end{array}$ & $\begin{array}{c}\text { Rail Car } \\
\text { Uninsulated }\end{array}$ \\
\hline$\Delta h\left(\frac{W-h}{k g}\right)$ & 22.9 & 22.9 & 6.7 & 6.7 & 9.1 \\
\hline$M_{\text {tot }}(\mathrm{kg})^{(\mathrm{a})}$ & 19,720 & 4,760 & 61,400 & 61,400 & 60,750 \\
\hline$q(w-h)$ & 452,268 & 109,168 & 412,143 & 412,143 & 553,424 \\
\hline$Q(w)^{(a)}$ & $9,723,060$ & $3,349,170$ & $\underline{580,700}$ & $\underline{2,548,520}$ & $20,258,810$ \\
\hline$t(\min )$ & 2.8 & 2.0 & 42.6 & 9.7 & 1.6 \\
\hline \multicolumn{6}{|l|}{ Venting } \\
\hline$\Delta h\left(\frac{w-h}{k g}\right)$ & 3.4 & 3.4 & 21.8 & 21.8 & 19.4 \\
\hline$q(w-h)$ & 66,250 & 15,990 & $1,336,490$ & $1,336,490$ & $1,176,710$ \\
\hline$M(k g)$ & 318 & 77 & 5,994 & 5,994 & 5,351 \\
\hline$t(\sec )$ & 24.5 & 5.9 & $\begin{array}{r}8,285.4 \\
\left(2.3^{\text {hours }}\right)\end{array}$ & $(31.5 \mathrm{~min})^{1,887}$ & $\begin{array}{r}209.1 \\
\text { (3.5 minutes) }\end{array}$ \\
\hline
\end{tabular}

(a)These values are the same in the venting calculations

The amount of subcooled propane $(M)$ that must be vented before the propane can regain saturated conditions is

where

$$
M=V\left(\frac{1}{v_{1}}-\frac{1}{v_{2}}\right)
$$

$V=$ volume of propane tank

$v_{1}=$ specific volume of saturated propane at shellfull conditions

$v_{2}=$ specific volume of saturated propane at venting temperature and pressure

These amounts are also tabulated in Table C.1. It was found in Section C.4.2 that the valves are sufficiently sized to handle these propane flows, particularly within the given time requirements. It is assumed that the tanks now fail when half of the remaining propane has been discharged. Using the equivalent of one open valve for each tank, the times to half-full 
and total times to failure are tabulated in Table C.2. These are the failure thresholds used for fire failure by weakening of the tank metal.

\section{C.4.4 Fire Durations Required to Fail Tanks by Overpressurization}

This section considers the fire duration necessary to produce an internal tank pressure that fails the propane tanks. This failure sequence is postulated to occur when the safety relief valves are defective or somehow damaged or blocked in an accident situation. If the safety relief valve is prevented from venting propane, the tank will become full of liquid and will remain shellfull. The pressure then rapidly increases until the burst strength of the tank is exceeded. (12) Equation $(c-26)$ is used to calculate the rate of temperature increase of the propane. The final temperature is found by knowing the desired final pressure (of rupture) and using the thermodynamic properties of propane. The following equation is used to calculate the temperature of propane at some chosen pressure:

$$
\log _{10} p=7.33829-\frac{1090}{(t+287.8)}
$$

where

$$
\begin{aligned}
& \mathrm{p} \text { is in } \mathrm{mm} \mathrm{hg} \\
& \mathrm{t} \text { is in }{ }^{\circ} \mathrm{C}
\end{aligned}
$$

TABLE C.2. Time to Failure for Propane Tanks

$\frac{\text { Overturned Tanks }}{\text { Time to Total Time }}$
Half-full to Failure
$\frac{\text { (minutes) }}{}$

Tank Truck

\section{Bobtail}

Rail Car (insulated)

Rail Car (partially insulated)

Rail Car (uninsulated)
6.8

2.4

51.3

17.4

17.4
10.0

$$
4.5
$$

189.4

58.6

22.5

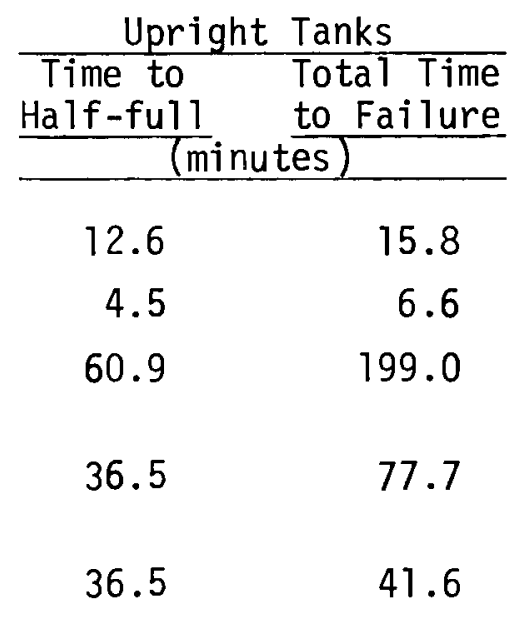


The design pressure for each of the propane tanks, along with assumed pressure failure thresholds and times to failure are shown in Table C.3. These are the failure thresholds used for fire failure by overpressurization of the tank. The test pressure, rather than the design pressure, is used for the rail tank car simply because of the long time-to-failure of an insulated car.

\section{C.4.5 Other Pressure Failure Thresholds}

This section will present calculations used to find pressure failure thresholds for tank pressure buildups during normal transportation as a result of solar insolation.

TABLE C.3. Time to Failure for Propane Tanks by Overpressurization

\begin{tabular}{c}
$\begin{array}{c}\text { Rupture Pressure/ } \\
\text { Test Pressure } \\
\text { (MPa) }\end{array}$ \\
\hline
\end{tabular}

Tank Truck

Normal

Defective

Weakened

Bobtail

Norma 1

Defective

Weakened

Rail Car

Insulated (Norma1)

Insulated (Weak/Def.)

Rail Car

Partially Insulated

(Normal)

$5.9 / 2.3$

Partially Insulated

(Weak/Def.)

$6.9 / 3.4$

6.9

3.4

3.4

$6.9 / 3.4$

6.9

3.4

3.4

$5.9 / 2.3$

5.9

2.3

280.0

130.0
5.9

3.6

3.6

4.1

2.5

2.5
5.9

60.0

Rail Car

Uninsulated (Normal)

$5.9 / 2.3$

Uninsulated (Weak/Def.)

5.9

7.9

2.3

3.7 
There exists the possibility that sunshine heating up a propane tank during normal transportation could result in an internal pressure increase. The maximum solar input to the tank surface is estimated to be about 694 Joules/meter ${ }^{2}$-sec. (13) It is assumed that a rectangular area (the tank diameter multiplied by tank length) will be absorbing this sunlight. The thermal input to each tank, $q$, is thus

q

$\begin{array}{cll}\text { Tank Truck } & \text { Bobtail } & \text { Rail Car } \\ 15,600 \text { watts } & 5,960 \text { watts } & 38,260 \text { watts }\end{array}$

Using Equation ( $C-26)$, the expected rate of temperature rise can be found. The rate of temperature rise from solar insolation, $\Delta T$, for each tank is

$\begin{array}{lll}\text { Tank Truck } & \text { Bobtail } & \text { Rail Car } \\ 1.75^{\circ} \mathrm{C} / \mathrm{hr} & 2.78^{\circ} \mathrm{C} / \mathrm{hr} & 1.38^{\circ} \mathrm{C} / \mathrm{hr}\end{array}$

Since sunlight is expected to affect the tanks for a maximum of only ten to twelve hours, the temperature increase will not be enough to even cause shellfull conditions.

The probability that a truck accident will occur during hours of significant insolation (between 8:30 A.M. and 5:30 P.M.) may be obtained from Bureau of Motor Carrier Safety data as $0.50 .^{(14)}$ It is assumed that cloudy days occur about one-third of the time, dampening heating effects. For the tank trucks, the chances of sunshine causing any increase in tank pressure is thus $(0.50)(2 / 3)$, or .33 . However, as shown above, this pressure increase is not enough to activate the safety relief valves.

There is no data readily available on the time of day occurrence of rail accidents. It was assumed that a 11 rail accidents occur during maximum insolation hours. Thus, the probability of sunshine causing any pressure increase is $(1)(2 / 3)$, or .66 . However, as for the tank trucks, this pressure increase is not sufficient to activate the safety relief valves. 


\section{REFERENCES}

1. F. A. Simonen, "Impact and Puncture of Chlorine Tank Car." Memo, November 23, 1976.

2. Chemical Engineer's Handbook. 4th edition, McGraw Hill.

3. L. B. Shappert, Cask Designers Guide. ORNL-NSIC-68, February 1970.

4. "Final Phase 05 Report on Tank Car Head Study." RPI-AAR Cooperative Program, RA-05-1-17, July 14, 1972.

5. J. P. Den Hartog, Strength of Materials. Dover Publications, Inc., New York, NY, 1961 .

6. Code of Federal Regulations. 49 Transportation, Sections 173.314-315, 1974 .

7. Federal Register. 42(179), "Part 179 - Specifications for Tank Cars," DOT, September 15, 1977.

8. Marks Standard Handbook for Mechanical Engineers. 7th edition, McGraw Hill.

9. W. A. Bullerdick et al., A Study to Reduce the Hazards of Tank Car Transportation. Prepared for the Federal Railroad Administration, PB 199-154, November 1970, Washington, D.C.

10. L. J. Manda, "Phase II Report on Full Scale Fire Tests." RPI-AAR Cooperative Program, RA-11-6-31, December 12, 1975.

11. Matheson Gas Data Book. William Braker and Allen L. Mossman, Fifth Edition, 1971.

12. D. Levine et al., Fire Protection of Railroad Tank Cars Carrying Hazardous Materials - Analytical Calculations and Laboratory Screening of Thermal Insulation Candidates. AD0747 974, Naval Ordinance Laboratory, White Oak, Silver Spring, Maryland, July $21,1972$.

13. R. E. Rhoads et a1., An Assessment of the Risk of Transporting Gasoline by Truck. PNL-2133, Pacific Northwest Laboratory, Richland, Washington, November 1978.

14. 1975 Accidents of Motor Carriers of Property. Bureau of Motor Carrier Safety, DOT. Washington, D.C. 
APPENDIX D

PROPANE DISPERSION MODELS 


\section{PROPANE DISPERSION MODELS}

This appendix describes the simulation models used to provide estimates of propane flammable gas concentrations from immediate and continuous releases. The models presented in Section D.1 are Gaussian diffusion models for continuous plumes and instantaneous puffs (representing leaks and catastrophic spills). Section D.2 discusses the empirical diffusion parameters used in the models, and Section D. 3 details calculations of flammable cloud mass and area. For the purposes of this analysis, it is assumed that the vaporized propane cloud, with a molecular weight of 44 and cooled by a diabatic expansion, remains negatively buoyant with respect to air. The density of the propane vapor is modeled by restraining vertical dispersion similar to that of a trace gas in a stable atmosphere.

\section{1 DISPERSION EQUATIONS}

Two Gaussian dispersion equations are used to describe dispersion downwind of an accident site. Initial conditions and inputs for each case studied consist of propane emissions, fixed meteorological conditions (wind speed and stability), and a spill type. Concentrations for a continuous release of LPG were calculated by specifying a continuous emission rate and using a continuous plume model. Catastrophic spills were simulated by a fixed mass emission in a Gaussian puff model.

In the puff equation, the size of a hemispheric cloud formed from the flash vaporized liquid release was considered as an area source and was modeled as a virtual point source. Virtual point source modifications allow the use of point source equations in evaluating area emission sources. By determining the distance upwind of the area source, a point source could be located that would have a crosswind plume spread equal to the area source width at the area source edge. ${ }^{(1)}$ In other words, since crosswind plume 
standard deviation $\sigma_{y}$ is proportional to distance $x$, at a distance upwind of the area of emission, $x_{0}$, a point could be found such that:

$$
w=4.3 \sigma_{y} \text {. }
$$

where:

$w$ is the source width.

$\sigma_{y}$ is the crosswind dispersion parameter.

Resultant concentrations from an instantaneous tank car failure were calculated using the Gaussian point source puff equation:

$$
C=\frac{Q\left(2 \pi^{3}\right)^{-\frac{1}{-2}}}{\sigma_{x} \sigma_{y} \sigma_{z}} \exp \cdot-\frac{1}{2}\left[\frac{(x-\bar{u} t)^{2}}{\sigma_{x}{ }^{2}}+\frac{y^{2}}{\sigma_{y}{ }^{2}}+\frac{z^{2}}{\sigma_{z}{ }^{2}}\right]
$$

where:

$$
\begin{aligned}
C & =\text { concentration (mass/length }{ }^{2} \text { ) } \\
Q & =\text { total emissions (mass) } \\
x, y, z & =\text { downwind, crosswind, and vertical distance (length) } \\
\bar{u} & =\text { mean wind speed over the period of calculation (length/time) } \\
t & =\text { time after release (time) } \\
\sigma_{x, \sigma_{y}, \sigma_{z}} & =\text { downwind, crosswind and vertical dispersion parameters. }
\end{aligned}
$$

The maximum distance at which the instantaneous cloud is flammable can be determined from Equation (D-2) by determining the distance at which:

$$
C \max =\frac{Q\left(2 \pi^{3}\right)^{-\frac{1}{2}}}{\sigma_{x} \sigma_{y} \sigma_{z}}=C_{L F L}
$$

where:

$C$ max $=$ maximum concentration at puff center

$C_{L F L}=$ flammability limit

$$
\sigma=\text { standard deviation of the puff mass (a function of } x \text { ) }
$$

The flammable cloud area is calculated as described in Section D.3. 
In the continuous leak case, the Gaussian point source diffusion equation is given by:

$$
C=\frac{Q}{\pi \sigma_{y} \sigma_{z} \bar{u}} \exp .-\frac{1}{2}\left[\frac{y^{2}}{\sigma_{y}^{2}}+\frac{z^{2}}{\sigma_{z}^{2}}\right]
$$

Calculational methods for the area within isopleths are provided in the following sections. Equation ( $D-4)$ represents dispersion of a continuous release under steady-state conditions; area calculations for the continuous release are thus not time dependent.

\section{D.2 DISPERSION PARAMETERS}

The calculation of concentrations using instantaneous puff or continuous plume equations requires the use of empirical dispersion parameters determined from experiments of trace gas dispersion in air. This section describes the two collections of dispersion data used in this study along with the modifications used to extend the relations to the dense gas case.

In the instantaneous puff equation used to simulate the effects of dispersion from a catastrophic release of propane, dispersion parameters are given in the crosswind, downwind, and vertical directions and are defined as $\sigma_{y}, \sigma_{x}$ and $\sigma_{z}$. The parameters used are of the form:

$$
\sigma=a x^{b}
$$

where $x$ represents the downwind distance. The coefficients $(a, b)$ vary with atmospheric stability. The downwind and crosswind parameters are related by: ${ }^{(2)}$

$$
\sigma_{x}=4 \sigma_{y}
$$

To correct for the decreased vertical spread of the gas cloud due to the negative buoyancy, the vertical dispersion parameter, $\sigma_{z}$, is assumed to vary 
with distance using coefficients for stable atmospheric conditions. (3) The coefficients used for the simulations ${ }^{(4)}$ are given in Table D.1.

Dispersion of continuous plumes proceeds at a lower rate than that of the puff, due to less axial mixing. The set of dispersion parameters used in the continuous leak case is given in Table D.2. (1) The high cloud density was again treated by assuming that stable mixing occurred in the vertical direction. Parameters given in the table represent plumes of approximately 3 to 10 minutes duration. Plumes lasting for longer periods are on the average more disperse, making this a conservative assumption in the dispersion simulations.

TABLE D.1. Dispersion Equation for an Instantaneous Propane Release

\begin{tabular}{|c|c|c|c|c|}
\hline \multirow[b]{2}{*}{ Stability } & \multicolumn{2}{|c|}{$\sigma_{y}$} & \multicolumn{2}{|c|}{$\sigma_{z}$} \\
\hline & $a$ & $\mathrm{~b}$ & $a$ & $\bar{b}$ \\
\hline$A^{(a)}$ & 0.14 & 0.92 & \multirow{6}{*}{0.05} & \multirow{6}{*}{0.61} \\
\hline B & 0.14 & 0.92 & & \\
\hline C & 0.06 & 0.92 & & \\
\hline D & 0.14 & 0.92 & & \\
\hline$E$ & 0.04 & 0.91 & & \\
\hline $\mathrm{F}$ & 0.92 & 0.89 & & \\
\hline
\end{tabular}

(a) Pasquill stability categories Reference 4 
TABLE D.2. Dispersion Equation for a Continuous Propane Release

\begin{tabular}{|c|c|c|c|c|}
\hline \multirow[b]{2}{*}{ Stability } & \multicolumn{2}{|c|}{$\sigma_{y}$} & $\sigma_{z}$ & \\
\hline & $a$ & b & $a$ & b \\
\hline$A^{(a)}$ & 0.37 & 0.90 & & \\
\hline B & 0.28 & 0.90 & & \\
\hline C & 0.21 & 0.90 & 0.06 & 0.78 for $x \leq 1200 m$ \\
\hline D & 0.15 & 0.90 & 0.44 & 0.51 for $x>1200 m$ \\
\hline$E$ & 0.10 & 0.90 & & \\
\hline $\mathrm{F}$ & 0.07 & 0.90 & & \\
\hline
\end{tabular}

(a) Pasquill stability categories Reference 4

\section{D.3 CLOUD AREAS AND MASS}

Areas of different concentration isopleths are important in predicting the hazard zones for spills of hazardous materials. For propane concentrations of approximately $9 \%$ and $2 \%$ determine the limits of flammability. An approximation for isopleth areas of a continuous steady-state plume were found as a function of spill size and wind size in Reference 4. Areas for the instantaneous clouds were calculated as the area of an ellipse. The semi-major and semi-minor axes are defined by solving the Gaussian puff equation for crosswind cloud extent, $y$, to the flammability level and assuming that the downwind extent of the cloud, $x$, is given by $x=4 y$, consistent with the relationship of $\sigma_{y}$ and $\sigma_{x}$ in Equation (D-6). In this case, area $(A)$ is given by

$$
A=(4 \pi y)^{2}
$$

for clouds centered around the point $x=u t$.

The mass of propane mixed in air between the upper and lower flammability limits is found using the Gaussian assumption that mass is normally distributed around the cloud center of mass. For both continuous and instantaneous clouds, the crosswind distance from plume center to the isopleths representing the 
flammability limits is expressed in units of $\sigma$, the cloud standard deviation. An error function is then used to determine the fractional mass within each flammable limit isopleth.

\section{REFERENCES}

1. D. B. Turner, Workbook of Atmospheric Dispersion Estimates. PB-191 482, NTIS, Springfield, Virginia, 1972.

2. P. Nickola, "Measurements of the Movement, Concentration, and Dimensions of Clouds Resulting from Instantaneous Point Sources." Journal of Applied Meteorology, 16:962-973, October 1971 .

3. D. S. Burgess, J. N. Murphy, M. G. Zabetakis, Hazards of LNG Spillage in Marine Transportation. Bureau of Mines, U.S. Department of the Interior, S-4105, Pittsburgh, Pennsylvania, February 1970.

4. D. H. Slade, (ed.) Meteorology and Atomic Energy. U.S. Energy Commission Oak Ridge, Tennessee, 1968. 


\section{PROPANE REPORT}

\section{DISTRIBUTION}

No. of

Copies

Mr. A. M. Albera

Director, Distribution Development

PPG Industries, Inc.

One Gateway Center

Pittsburgh, PA 15222

Tom Alexander

Department of Energy

Office of Technology Impacts

EV-212, MS-4G085

Forrestal Bldg.

Washington, DC 20585

G. C. Allen, Jr.

Sandia National Laboratories

Division 4552

P.0. Box 5800

Albuquerque, NM 87185
A. L. Babb
Dept. of Nuclear Engineering
Benson $\mathrm{Hall}$
University of Washington
Seattle, WA 98195
Mr. George Bailey
Technical Studies
Washington Public Power
Supply Sys tem
3000 George Washington Way
Richland, WA 99352
Hubert Baker
E. I. DuPont de Nemours \& Co.
Savannah River Laboratory
Aiken, SC 29801
G. D. Bell
United Kingdom Atomic Energy Authority
Safety \& Reliability Directorate
Warrington WA3 4NE
UNITED KINGDOM

No. of

Copies
L. Benner
National Transportation
Safety Board

Department of Transportation

Washington, DC 20594

Dr. K. M. Bertram

Argonne National Laboratory

(EES-17)

9700 S. Cass Avenue

Argonne, IL 60514

W. F. Black

Hazardous Materials Branch

Nassif Building

Federal Railroad Administration

Department of Transportation

Washington, DC 20590

W. A. Brobst

The Transport Environment

SR 285 01d Squaw Drive

Kitty Hawk, NC 27949

Ms. T. Buckingham

1704 Lincoln Ave. (Apt. 2)

San Rafael, CA 94901

T. A. Butler

University of California

Los Alamos Scientific Laboratory

P.O. Box 1663

Los Alamos, NM 87545

M. J. Cardu110, Director

Office of Energy Supply and Transportation

Department of Energy

M/S 3344

Washington, DC 20545

A. Carson

General Electric Company

175 Curtner Avenue

San Jose, CA 95125 
No. of

Copies

Dr. J. M. Cece

DOE/ESED

M/S EV-132, E-201

Washington, DC 20545

R. B. Chitwood

Division of Transportation and Fuel Storage

M/S B-107

Department of Energy

Washington, DC 20545

A. A. Churm

Chicago Patent Group

DOE Chicago Operations Office

9800 South Cass Avenue

Argonne, IL 50439

C. Comar

Electric Power Research Inst.

P.0. 10412

Palo Alto, CA 94304

J. S. Corbett

ChemNuclear Systems, Inc.

P.0. Box 1866

Bellevue, WA 98009

J. Counts

DOE/ESED

M/S EV-132, E-201

Department of Energy

Washington, DC 20545

164 DOE Technical Information Center

J. W. Doty

Mound Laboratories

P.0. Box 32

Miamisburg, OH 45342

Dr. C. W. Draffin

Planning and Evaluation

U.S. Department of Energy

20 Massachusetts Avenue N.W.

Washington, DC 20545
No. of

Copies

F. D. Ducey

Manager, Environmental Services

Holms \& Narver, Inc.

999 Town and Country Road

Orange, CA 92668

D. A. Edling

Mound Laboratories

P.0. Box 32

Miamisburg, $\mathrm{OH} 45342$

R. C. Erdman

Science Applications, Inc.

2680 Hanover Street

Palo Alto, CA 94304

F. P. Falci

Dept. of Energy

M/S B/107

Washington, DC 20545

W. S. Fellows

Southern Interstate Nuclear Board

One Exchange Place, Suite 1230

Atlanta, GA 30341

I. A. Forbes

Energy Research Group, Inc.

1661 Worchester Road

Fromingham, MA 01701

Dr. C. P. Furber

Research and Test Department

Association of American

Railroads

1920 "L" Street N.W.

Washington, DC 20036

R. F. Garrison

DOE/ESED

M/S EV-132, E-201

Washington, DC 20545 
No. of

Copies

T. Glickman

Transportation Systems Center

Kenda $11 \mathrm{Sq}$.

Cambridge, MA 02142

E. P. Goldfinch

Safeguards Branch

Nuclear Health and Safety Dept.

Courtenay House

18 Warwick Lane

London F C4D 4EB

UNITED KINGDOM

M. Gordon

Atomic Industrial Forum

7101 Wiscons in Avenue

Washington, DC 20014

\author{
A. Grella \\ Office of Inspection and \\ Enforcement \\ USNRC \\ Washington, DC 20590 \\ Dr. R. J. Ha 11 \\ Office of Nuclear Waste \\ Isolation \\ Project Management Division \\ Battelle \\ 505 King Avenue \\ Columbus, $\mathrm{OH} 43201$ \\ $\mathrm{Mr} . \mathrm{Cl}$ iff Halverson \\ National Tank Truck Carriers \\ Association \\ 1616 P Street, N.W. \\ Washington, DC 20036 \\ E. C. Hardin, Jr. \\ Doe Albuquerque Operations \\ Office
}

P.0. Box 5400

Albuquerque, NM 87115
No. of

Copies

N. C. Harris

Imperial Chemical Industries, Ltd.

Mond Division

P.0. Box 47 Brunner House

Winnington Northwich

Cheshire CW8 40J

ENGLAND

Mr. W. Harris

Association of American

Railroads

1920 L. Street, N.W.

Washington, D.C. 20036

W. F. Hartman

Sandia National Laboratories

Dept. 1760A

Albuquerque, NM 87185

S. Hartwig

Battelle Institute, e.v.

Am Romerhof 35

600 Frankfurt Main 90

GERMANY

J. A. Hebert

Battelle Seattle Research

Center

P.0. Box 5395

Seattle, WA 98105

Mr. Joe Henderson

Lubbock Manufacturing Company

Lubbock, TX 79408

Brad Holloman

Office of Technology Assessment

U.S. Congress

Washington, DC 20510

Mr. Richard Horn

Office of Systems Research and Analys is

Transportation Systems Center

Department of Transportation

Cambridge, MA 02142 
No. of

Copies

H. Hubner

Bundesanstalt für Materialprufung

Unter den Eichen 87

D-1000 Berlin 45 (West)

GERMANY, FED. REPUBLIC

J. L. Ivie

City of Portland Fire Department

55 S.W. Ash Street

Portland, OR 97204

Dr. J. Jacquemin

Office of Minister für Arbeit,

Gesundheit, und Sociales des

Andes NRW

Landeshaus

4000 Dusseldorf

GERMANY, FED. REPUBLIC

R. M. Jefferson

Sandia National Laboratories

Dept. 4550

Attn: The Library (3)

The Master File (1)

A1buquerque, NM 87185

Mr. Don B. Jenks

Hazardous Materials Control

Santa Fe Railroad

Room 902

80 East Jackson Blvd.

Chicago, IL 60604

John Jimison

Library of Congress

Congressional Research Service

First and Independence S.E.

Washington, DC 20540

Mr. Will Johns

American Trucking Association

1616 P Street, N.W.

Washington, DC 20036

Mr. Walter Johnson

Vice President of Technical

Services

National LP-Gas Association

1301 West 22nd Street

Oak Brook, IL 60521
No. of

Copies

G. P. Jones

University of Southern

California

University Park

Los Angeles, CA 90007

R. H. Jones

P.0. Box 24036

San Jose, CA 95125

B. Jost

Mai1 Stop 18

California Energy Commission

1111 Howe Avenue

Sacramento, CA 95825

Dr. Thomas J. Kabele

The Analytic Sciences

Corporation

6 Jacob Way

Reading, MA 01867

T. K. Keenan

University of California

Los Alamos Scientific Laboratory

P.0. Box 1663

Los Alamos, NM 87545

Franklin King

Savannah River Laboratory

Aiken, SC 29801

Mr. Klyde Klinstiver

Accident Analysis Branch

Materials Transportation Bureau

U.S. Department of Transportation

2100 - 2nd Street, N.W.

Washington, DC 20590

R. A. Koynenburg

University of California

Lawrence Livermore Laboratories

P.0. Box 808

Livermore, CA 94551

W. E. Kreger

Chief Radiological Assessment Branch

Nuclear Regulatory Commission

Washington, DC 20555 
No. of

Copies

M. J. Lawrence
Department of Energy
M/S B/107
Washington, DC 20545

J. R. Ledford

Home Transportation Company

P.0. Box 1169

Burnwe11, SC 29812

R. Y. Lowrey

Department of Energy

M/S B/107

Washington, DC 20545

R. E. Luna

Sandia National Laboratories

Division 4551

Albuquerque, NM 87185

Martin Mal tempo

University of Colorado at Denver

1100 - 14th Street

Denver, CO 80202

W. E. Martinsen

Appl ied Technology Corporation

401 West Main Street

Suite 220

Norman, OK 73070

Dr. D. P. Maxfield

Nonhighway Transport Systems

and Special Projects

Department of Energy

20 Massachusetts Avenue N.W.

Washington, DC 20545

Bob Maxwell

Office of Technology Assessment

U.S. Congress

Washington, DC 20510

C. A. Mayer

Tri-State Motor Transit Co., Inc.

P.0. Box 113

Jopl in, M0 64801
No. of

Copies

D. G. Maxwell

N. L. Industries

Nuclear Division

Foot of West Street

Wilmington, DE 19801

S. A. Mayman

Fuel Recycle Waste Management Program

Whiteshell Nuclear Research Establishment

Pinewa, Manitoba ROE ILO CANADA

J. D. McClure

Sandia National Laboratories

Division 4551

Albuquerque, NM 87185

N. J. McCormack

Department of Nuclear Engineering

Benson Hall

University of Washington

Seattle, WA 98195

C. McDonald Nuclear Regulatory Commission Washington, DC 20555

H. F. McDonald

CEGB

Berkeley Nuclear Labs

Berkeley.

G1 oucestershire GL139PB

UNITED KINGDOM

Mr. C. W. McGuire

Office of Secretary

U.S. Department of Transportation Washington, DC 20590

Susan Metzler

System Communications

N.E. Utilities

P.0. Box 270

Hartford, CT 06101 
No. of

Copies

S. Meyers

Department of Energy

M/S B/107

Washington, DC 20545

R. B. Minogue

Nuclear Regulatory Commission

Washington, DC 20555

R. M. Moser

DOE Chicago Operations Office

9800 South Cass Avenue

Argonne, IL 60439

W. E. Mott, Director

DOE/ESED

M/S EV-132, E-201

Washington, DC 20545

Major General John Murray

Vice President - Assistant to the President

Association of American

Railroads

1929 L Street, N.W.

Washington, DC 20036

$\mathrm{Mr}$. Joe Nalevanko

Materials Transportation Bureau

Department of Transportation

Room 6220

2100 - 2nd Street, S.W.

Washington, DC 20590

D. Okrent

Department of Engineering and Applied Science

University of California

Los Angeles, CA 90024

Al ice Packard

Div. of Environmental Impact Studies

Argonne National Lab.

Argonne, IL 60439
No. of

Copies

Bi11 Pardue

Battelle Memorial Institute

Office of Nuclear Waste Isolation

505 King Avenue

Columbus, $\mathrm{OH} 43201$

R. W. Peterson

Battelle Memorial Institute

Office of Nuclear Waste

Isolation

505 King Avenue

Columbus, $\mathrm{OH} 43201$

Mr. T. A. Phemister

Bureau of Explosives

Associated American Railroads

1920 L. Street, N.W.

Washington, DC 20036

Ms. Marlene Phillips

Maritime Research Board

National Academy of Sciences

2101 Constitution Avenue N.W.

Washington, DC 20418

M. Pollock

Oregon Department of Energy

Salem, OR 97301

R. B. Pope

Sandia National Laboratories Division 4552

ATbuquerque, NM 87185

B. Posik

Chem-Nuclear Systems, Inc.

Burnwel1, SC

Prof. Norman C. Rasmussen

Massachusetts institute of Technology

Cambridge, MA 02139 
No. of

Copies

R. R. Rawl

Materials Transportation Bureau

U.S. Department of Transportation Washington, DC 20545

R. T. Reese

Division 4559

Sandia National Laboratories

Albuquerque, NM 87185

W. R. Rhyne

Science Applications Inc.

P.0. Box 843

Oak Ridge, TN 37830

J. L. Ridihalgh

Ridihalgh, Eggers \& Associates

2112 Iuke Avenue

Columbus, $\mathrm{OH} 43201$

W. M. Rogers

Western Interstate Nuclear Board

1300 Carr

Denver, C0 80226

B. A. Ross

414 Sailfish Ct.

Richland, WA 99352

W. Rowe

Environmental Protection Agency

401 M Street

Washington, DC 20460

Professor G. Russell

Civil Engineering Dept.

Kansas State University

Manhattan, KN 66506

J. L. Russell

Office of Radiation Programs

AW-459, EPA

401 M. Street S. W. Washington, DC 20460
No. of

Copies

L. D. Santman

Materials Transportation Bureau Department of Transportation 2100 Second Street S. W. Washington, DC 20590

A. L. Schmeig

National Transportation

Safety Bureau

Department of Transportation

Washington, DC 20594

Dr. Schmidt-Kuester

Beim Bundesminister fur

Forschung and Technologie

Stresemannstrasse 2

5300 Bonn

GERMANY

B. Schulz-Forberg

Bundesanstalt fur Materialprufung

Unter den Eichen 87

D-1000 Berlin 45 (West)

GERMANY, FED. REPUBLIC

L. Shappert

Union Carbide Corporation

- Oak.Ridge National Laboratories

P.0. Box X

Oak Ridge, TN 37830

H. G. Shealy

Bureau of Radiological Health

South Carolina Department of

Health and Environmental Control

Columbia, SC 29405

E. W. Sheperd

Sandia National Laboratories

Division 4551

Albuquerque, NM 87185 
No. of

Copies

Rober Shober

Burlington Northern

176 East Fifth Street

St. Paul, MN 55101

K. R. Shultz

Atomic Energy Control

Board

P.0. Box 1046

0ttawa KIP 5 S9

CANADA

J. A. Sisler, M/S B/107 (5)

Transportation and Fuel Storage

Department of Energy

Washington, DC 20545

Y. Sousselier

CEA/CEN

B.P. No. 6

F-92260 Fontenay-aux-Roses

FRANCE

M. Stammler

Battelle Institute, e.v.

Am Romerhof 35

600 Frankfurt Main 90

GERMANY

C. Starr

Electrical Power Research Inst.

P.0. Box 10412

Palo Alto, CA 94304

M. J. Steindler

Argonne National Laboratory

9800 South Cass Avenue

Argonne, IL 60439

B. A. Straker

Science Applications, Inc.

P.0. Box 2351

La Jolla, CA 92038

G. R. Swindell

International Atomic Energy Agency

A-1011 Vienna, AUSTRIA
No. of

Copies

D. H. Teeter

Puget Sound

Council of Governments

216 First Ave.

Seattle, WA 98104

L. L. Turner

DOE Savannah River Operations Office

P.0. Box A

Aiken, SC 29801

W. E. Vesely

Nuclear Regulatory Commission

Washington, DC 20555

J. Walker

California Energy Resources Conservation and Development Commission

1111 Howe Avenue

Sacramento, DA 95825

Dr. Henry Walter

DOE/ESED

MS/ EV-132, E-201

Washington, DC 20545

R. Williams

Electrical Power REsearch Inst.

P.0. Box 10412

Polo Alto, CA 94304

E. L. Wilmont

Sandia National Laboratories

Division 4551

Albuquerque, NM 87185

E. J. Wilson

Department of Transport

Dangerous Good Branch

2 Marsham St.

London SW 1

ENGLAND 
No. of

Copies

Joe Wolfson

DOT/TSC 533

Kenda 11 Square

Cambridge, MA 02142

R. Yoshimura

Sandia National Laboratories

Division 4552

A1burquerque, NM 87185

P. H. Zabel

Southwest Research

Institute

6220 Culebra Road

P.0. Box Drawer 28510

San Antonio, TX 78284

\section{ONSITE}

5 DOE Richland Operations Office

M. W. Shupe

J. C. Cummings

J. M. Peterson

H. E. Ransom

J. J. Schreiber

54 Pacific Northwest Laboratory

W. B. Andrews

W. J. Bair

N. M. Burleigh (25)

T. D. Chikalla

J. G. DeSteese

R. M. Fleischman

A. L. Franklin

J. R. Friley

C. A. Geffen (5)

H. Harty

M. R. Kreiter

R. C. Liikala

J. W. Litchfield

D. J. McNaughton

D. W. Murphy

E. S. Murphy

R. E. Rhoads

L. D. Williams

W. K. Winegardner

Technical Information (5)

Publishing Coordination (2)
No. of

Copies

3 Battel le-Human Affairs Research Center

C. Cluett

F. A. Morris

C. R. Schuller 
j 